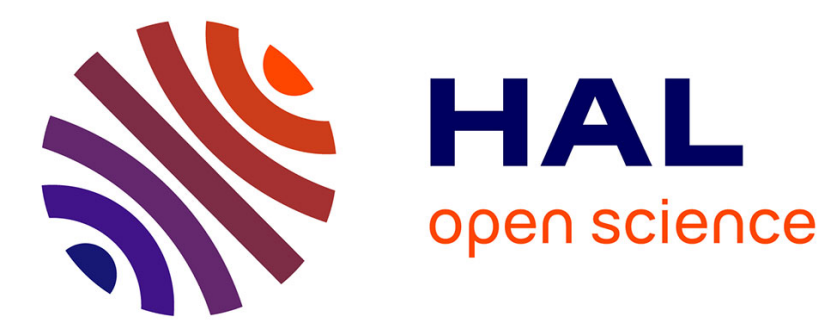

\title{
Recent Developments in Enantioselective Metal-Catalyzed Domino Reactions
}

\author{
Hervé Clavier, Hélène Pellissier
}

\section{To cite this version:}

Hervé Clavier, Hélène Pellissier. Recent Developments in Enantioselective Metal-Catalyzed Domino Reactions. Advanced Synthesis and Catalysis, 2012, 354 (18), pp.3347-3403. 10.1002/adsc.201200254 . hal-01409279

\section{HAL Id: hal-01409279 \\ https://hal.science/hal-01409279}

Submitted on 5 Dec 2016

HAL is a multi-disciplinary open access archive for the deposit and dissemination of scientific research documents, whether they are published or not. The documents may come from teaching and research institutions in France or abroad, or from public or private research centers.
L'archive ouverte pluridisciplinaire HAL, est destinée au dépôt et à la diffusion de documents scientifiques de niveau recherche, publiés ou non, émanant des établissements d'enseignement et de recherche français ou étrangers, des laboratoires publics ou privés.

\section{(ㅇ)(1) $\$$}

Distributed under a Creative Commons Attribution - NonCommercial - NoDerivatives $\mid 4.0$ 


\title{
Recent Developments in Enantioselective Metal-Catalyzed Domino Reactions
}

\author{
Hervé Clavier and Hélène Pellissier*
}

Aix Marseille Université, UMR CNRS n 7313, Equipe Chirosciences, Case 561, Avenue Esc. NormandieNiemen, 13397 Marseille Cedex 20, France

Fax: +33 4912827 65; e-mail: h.pellissier@univ-amu.fr

\begin{abstract}
Since the first definition of domino reactions by Tietze in 1993, an explosive number of these fascinating reactions have been developed, allowing easily building complex chiral molecular architectures from simple materials to be achieved in a single step. Even more interesting, the possibility to join two or more reactions in one asymmetric domino process catalyzed by chiral metal catalysts has rapidly become one challenging goal for chemists, due to economical advantages, such as avoiding costly protecting groups and time-consuming purification procedures after each step. The explosive development of enantioselective metalcatalyzed domino including multicomponent reactions is a consequence of the considerable impact of the advent of asymmetric transition-metal catalysis. This review aims to update the last developments of enantioselective one-, two- and multicomponent domino reactions mediated by chiral metal catalysts, covering the literature since the beginning of 2006 .
\end{abstract}

Keywords: domino reactions; multicomponent reactions; transition metals; asymmetric synthesis

1 Introduction

2 One- and Two-Component Domino Reactions

2.1 Domino Reactions initiated by the Michael Reaction

2.2 Domino Reactions initiated by an Aldol Reaction

2.3 Domino Reductive Aldol Reactions

2.4 Domino Reactions initiated by a $[2+2+2]$ Cycloaddition

2.5 Domino Reactions initiated by an Allylic Alkylation

2.6 Domino Passerini-type Reactions

2.7 Domino Carbonyl Ylide formation-1,3-Dipolar Cycloaddition Reactions

2.8 Domino Reactions initiated by the Heck Reaction

2.9 Domino Reactions initiated by the Wacker Reaction

2.10 Domino Reactions based on Cyclizations

2.11 Domino Radical Reactions

2.12 Miscellaneous Domino Reactions

3 Multicomponent Reactions

3.1 Multicomponent Reactions initiated by the Michael Reaction

3.2 Multicomponent Reactions based on the Mannich Reaction

3.3 Multicomponent Reactions initiated by a Pericyclic Reaction

3.4 Multicomponent Reactions based on the Passerini Reaction

3.5 Multicomponent Reactions initiated by the Friedel-Crafts Reaction

3.6 Multicomponent Reactions of Alkynes, Aldehydes and Amines

3.7 Multicomponent Reactions of 1,3-Dienes, Aldehydes and Reducing Agents

3.8 Multicomponent Reductive Amination Reactions of Ketones

3.9 Multicomponent Kabachnik-Fields Reactions

3.10 Miscellaneous Multicomponent Reactions

4 Conclusions

\section{Introduction}

Metal-catalyzed transformations are of major importance in synthetic organic chemistry. ${ }^{[1]}$ In particular, asymmetric transition-metal catalysis has emerged as a powerful tool to perform reactions in a highly enantioselective fashion over the past few decades. Consequently, an increasing number of enantioselective domino processes including such reactions have been widely developed in the last 6 
years. A domino reaction has been defined by Tietze as a reaction which involves two or more bondforming transformations, taking place under the same reaction conditions, without adding additional reagents and catalysts, and in which the subsequent reactions result as a consequence of the functionality formed by bond formation or fragmentation in the previous step. ${ }^{[2]}$ It must be recognized that a relatively narrow distinction exists between domino and consecutive cascade or tandem reactions. From the point of view of an operator, the only difference between the two lies in the point along the sequence at which one or more catalysts or reagents had to be added to effect either the initiation of a sequence (that is, domino reaction) or propagation to the next step (that is, consecutive reaction). It must be noted that the descriptors domino, cascade, and tandem are often used indistinguishably from one another in the literature, ${ }^{[3]}$ and a variety of opinions exist on how such reactions should be classified. According to Tietze, a domino reaction is strictly defined as a process in which two or more bond-forming transformations occur based on functionalities formed in the previous step and, moreover, no additional reagents, catalysts or additives can be added to the reaction vessel, nor can reaction conditions be changed. ${ }^{[2]}$ Denmark further posited, however, that most domino reactions, as defined by Tietze, fell under the broader category of tandem processes. ${ }^{[4]}$ Other tandem reactions which are not cascades involve the isolation of intermediates, a change in reaction conditions, or the addition of reagents or coupling partners. Furthermore, other authors classified domino reactions with even stricter conditions. ${ }^{[5,6]}$ This review strictly follows the definition according to Tietze, and the reactions have been classified according to the mechanism of the single step(s). The quality and importance of a domino reaction can be correlated to the number of bonds generated in such a process and the increase in molecular complexity. Its goal is the resembling of nature in its highly selective sequential transformations. The domino reactions can be performed as single-, two-, and multicomponent transformations. Multicomponent reactions are defined as domino reactions involving at least three substrates and, consequently, constitute a subgroup of domino reactions ${ }^{[5,7]}$ It must be noted that there are also some confusing ideas among chemists about the definition of a multicomponent reaction. According to Yus, ${ }^{[7 c]}$ this type of reactions should be clearly differentiated from other one-pot processes, such as tandem or cascade reactions, and in general from all processes that involve the reaction between two reagents to yield an intermediate which is captured by the successive addition of a new reagent (sequential component reactions). This review is based on the definition of multicomponent reactions as convergent chemical processes which involve the well defined condensation of more than two reactants to form a product that contains significant portions of all reactants, ideally all atoms. ${ }^{[7 \mathrm{~b}]}$ Moreover, no additional reagents, catalysts or additives can be added to the reaction vessel, nor can reaction conditions be changed as in domino processes according to Tietze. Consequently, a catalytic enantioselective multicomponent reaction can be defined as a one-pot reaction occurring between three or more achiral reagents in the presense of a substoichiometric amount of a chiral catalyst, during which the formation of two or more bonds occurs as well as control over at least one newly formed stereogenic center. The use of one-, two-, and multicomponent domino reactions in organic synthesis is increasing constantly, since they allow the synthesis of a wide range of complex molecules, including natural products and biologically active compounds, in an economically favourable way by using processes that avoid the use of costly and time-consuming protection-deprotection processes, as well as purification procedures of intermediates ${ }^{[8]}$ Indeed, decreasing the number of laboratory operations required and the quantities of chemicals and solvents used have made domino and multicomponent reactions unavoidable processes. ${ }^{[9]}$ The proliferation of these reactions is evidenced by the number of recent reviews covering the literature through 1992. ${ }^{[2,5,7 c, 10]}$ Although asymmetric synthesis is sometimes viewed as a subdiscipline of organic chemistry, actually this topical field transcends any narrow classification and pervades essentially all chemistry. ${ }^{[1]}$ Of the methods available for preparing chiral compounds, catalytic asymmetric synthesis has attracted most attention. The economical interest in combinations of asymmetric catalytic processes with domino reactions is obvious. In spite of the explosive growth of organocatalysis in the last decade,${ }^{[101-0,12,13]}$ and its application in the synthesis of a number of chiral products, ${ }^{[14]}$ the catalysis of organic reactions by metals still constitutes one of the most useful and powerful tools in organic synthesis. ${ }^{[15]}$ The goal of this review is to cover the last efforts of the chemical community in the development of novel enantioselective domino reactions catalyzed by chiral metals published since the beginning of 2006, since this field was most recently reviewed in 2006 by Tietze in a book, and Pellissier in two reviews. ${ }^{[2,10 j-k]}$ Moreover, it must be noted that very recently, Orru reported a review 
on asymmetric multicomponent reactions. ${ }^{[10 t]}$ The review is divided into two parts, which deal with one- and two-component domino reactions for the first part, and multicomponent reactions for the second part. The first part is subdivided into twelve sections, dealing successively with domino reactions initiated by the Michael reaction, domino reactions initiated by an aldol reaction, domino reductive aldol reactions, domino reactions initiated by a $[2+2+2]$ cycloaddition, domino reactions initiated by an allylic alkylation, domino Passerini-type reactions, domino carbonyl ylideformation-1,3-dipolar cycloaddition reactions, domino reactions initiated by the Heck reaction, domino reactions initiated by the Wacker reaction, domino reactions based on cyclizations, domino radical reactions, and finally miscellaneous domino reactions which cannot be included in the other sections, because of their different mechanisms. The second part of the review, which concerns the multicomponent reactions, is subdivided into ten sections, dealing successively with multicomponent reactions initiated by the Michael reaction, multicomponent reactions based on the Mannich reaction, multicomponent reactions initiated by a pericyclic reaction, multicomponent reactions based on the Passerini reaction, multicomponent reactions initiated by the Friedel-Crafts reaction, multicomponent reactions of alkynes, aldehydes and amines, multicomponent reactions of 1,3-dienes, aldehydes and reducing agents, multicomponent reductive amination reactions of ketones, multicomponent Kabachnik-Fields reactions, and finally miscellaneous multicomponent reactions. It must be noted that only reactions catalyzed by chiral metals are considered in this review. Consequently, diastereoselective reactions of chiral auxiliaries catalyzed by achiral metals are not included. Moreover, among recent works dealing with dual catalysis, only representative examples of those involving chiral metal catalysts have been selected, whereas those based on the use of an achiral metal catalyst combined to a chiral organocatalyst have not been included in the review.

\section{Biographical Sketches:}

Hélène Pellissier was born in Gap, France. She carried out her PhD under the supervision of Dr G. Gil in Marseille and then entered the Centre National de la Recherche Scientifique in 1988. After a postdoctoral period in Professor K. P. C. Vollhardt's group at Berkeley, she joined the group of Professor M. Santelli in Marseille in 1992, where she focused on the chemistry of BISTRO and its large application in organic synthesis. Thus, she developed several new very short total syntheses of steroids starting from 1,3-butadiene and benzocyclobutenes.

Hervé Clavier graduated from the Ecole Nationale Supérieure de Chimie de Rennes and received his M.Sc. in organic chemistry from the Universite de Rennes where he completed his Ph.D. in 2005 under the supervision of Drs Jean-Claude Guillemin and Marc Mauduit. He then joined the research group of Prof. Steven Nolan as a post-doctoral fellow and followed him to the ICIQ in Tarragona. In early 2009, he moved to the School of Chemistry at the University of St Andrews to continue work with Prof. Nolan as a senior researcher and in October 2009, he was appointed Chargé de Recherche (CNRS) at Aix-Université Université. His scientific interests include catalysis and new synthetic methodologies.

\section{One- and Two-Component Domino Reactions}

\subsection{Domino Reactions initiated by the Michael Reaction}

The nucleophilic 1,4-addition of stabilized carbon nucleophiles to electron-poor olefins, generally $\alpha, \beta$ unsaturated carbonyl compounds, is known as the Michael addition, although it was first reported by Komnenos in 1883. ${ }^{[16]}$ Michael-type reactions can be considered as one of the most powerful and reliable tools for the stereocontrolled formation of carbon-carbon and carbon-heteroatom bonds, ${ }^{[17]}$ as has been demonstrated by the huge number of examples in which it has been applied as a key strategic transformation in total synthesis. Since the first catalytic domino Michael-aldol reaction reported by Noyori et al. in $1996,{ }^{[18]}$ there have been numerous examples of domino reactions using this methodology. Among them, a number of enantioselective domino reactions initiated by a Michael addition have been promoted by chiral palladium catalysts. It is well known that one of the most 
heavily studied families of transition metal catalysts are those based on palladium. Over the past 40 years, many new reactions have been uncovered, and activity in this area has remained high. Among the increasing number of enantioselective domino processes starting with a transition metal-catalyzed reaction, the enantioselective palladium-catalyzed domino transformations have seen an astounding development over the past few years. ${ }^{[19]}$ Indeed, since palladium has the advantage of being compatible with many functional groups, it constitutes an ideal catalyst for domino reactions. ${ }^{[1 \mathrm{~d}, 20]}$ Among the recent examples of palladium-catalyzed enantioselective domino reactions initiated by a Michael addition, was that reported by Nishikata, which consisted in an asymmetric conjugate addition of arylboronic acids 1a-i to enones $\mathbf{2 a - d}$, bearing a 2-acylaryl group at the $\beta$-carbon, followed by an aldol condensation, which finally afforded the corresponding chiral 1 -aryl-1H-indenes 3a-k. ${ }^{[21]}$ As shown in Scheme 1, the domino Michael-aldol reaction was performed in aqueous isopropanol in the presence of cationic $\mathrm{Pd}(\mathrm{II})-\mathrm{Chiraphos}$ catalyst 4, providing via sequential carbopalladation of $\mathrm{C}-\mathrm{C}$ and $\mathrm{C}-\mathrm{O}-$ double bonds a series of indenes 3a-k in high yields (60-99\%) and excellent enantioselectivities of up to $97 \%$ ee in almost all the cases of substrates tested. It must be noted that there was no clear propensity between the enantioselectivities and functionalities on the aromatic boronic acids or their positions, but the enantioselectivities generally improved with increasing substituent bulk. Furthermore, the para-substituted arylboronic acids $(90-97 \%$ ee) resulted in higher enantioselectivities than those of meta-substituted acids (91-94\% ee), whereas the presence of an ortho-substituent retarded the reaction. As for the substrates, aliphatic and aromatic ketones and aldehydes could be used as trapping functionalities for cyclization with the palladium(II) enolates generated from enones 2a-d and arylboronic acids 1a-i. 
<smiles>[R]C(=O)/C=C/c1ccccc1C([R])=O</smiles>

$1 \mathrm{a}-\mathrm{i}$<smiles>CC[P+]([O+])(F)F</smiles>

4 (1 mol\%) $\mathrm{AgSbF}_{6}(10 \mathrm{~mol} \%)$ i- $\mathrm{PrOH} / \mathrm{H}_{2} \mathrm{O}, 10^{\circ} \mathrm{C}$ $\mathrm{HBF}_{4}, \mathrm{H}_{2} \mathrm{O}$<smiles>[R7]C(=O)C1=C([R7])c2ccccc2C1Br</smiles>

3a-k<smiles>[R]C(=O)C1C(Br)c2ccccc2C1([R])O</smiles>

$\mathrm{H}^{+}$<smiles>C1CCCCCC1</smiles>
aldol condensation

$$
\begin{array}{llll}
\mathrm{R}^{1} & \mathrm{R}^{2} & \mathrm{Ar} & \text { Yield }
\end{array}
$$

\begin{tabular}{|c|c|c|c|c|}
\hline $\mathrm{Me}$ & $\mathrm{Me}$ & $p-\mathrm{ClC}_{6} \mathrm{H}_{4}$ & 91 & 90 \\
\hline Me & $\mathrm{Me}$ & $m-\mathrm{ClC}_{6} \mathrm{H}_{4}$ & 88 & 91 \\
\hline Me & $\mathrm{Me}$ & $p$-Tol & 94 & 93 \\
\hline Me & $\mathrm{Me}$ & $m-\mathrm{MeOC}_{6} \mathrm{H}_{4}$ & 91 & 93 \\
\hline Me & $\mathrm{Me}$ & $p-\mathrm{MeOC}_{6} \mathrm{H}_{4}$ & 90 & 96 \\
\hline Me & Me $p-($ & $-\left(p-\mathrm{MeOC}_{6} \mathrm{H}_{4}\right) \mathrm{C}_{6} \mathrm{H}_{4}$ & 91 & 97 \\
\hline $\mathrm{Me}$ & $\mathrm{Me}$ & $m-\mathrm{BnOC}_{6} \mathrm{H}_{4}$ & 90 & 94 \\
\hline $\mathrm{Ph}$ & $\mathrm{Me}$ & $p-\mathrm{MeOC}_{6} \mathrm{H}_{4}$ & 99 & 92 \\
\hline $\mathrm{Ph}$ & $p-\mathrm{MeOC}_{6} \mathrm{H}_{4}$ & $\mathrm{H}_{4} \quad p-\mathrm{MeOC}_{6} \mathrm{H}_{4}$ & 79 & 90 \\
\hline $\mathrm{Ph}$ & $p-\mathrm{MeOC}_{6} \mathrm{H}_{4}$ & $\mathrm{H}_{4} 3,4-\left(\mathrm{OCH}_{2} \mathrm{O}\right) \mathrm{C}_{6} \mathrm{H}_{3}$ & 81 & 90 \\
\hline $\mathrm{Me}$ & Et & $p-\mathrm{MeOC}_{6} \mathrm{H}_{4}$ & 99 & 93 \\
\hline
\end{tabular}

Scheme 1. Pd-catalyzed domino Michael-aldol reaction of $\beta$-(2-acylaryl)enones and arylboronic acids.

Another cationic palladium complex, in situ prepared from $\mathrm{Pd}(\mathrm{MeCN})_{4}\left(\mathrm{BF}_{4}\right)_{2}$ and axially chiral biphosphine ligands, such as $(R)$-Tol-BINAP, was used as catalyst by $\mathrm{Lu}$ et al. to promote the enantioselective annulation of 2 -formylarylboronic acids with allenoates. ${ }^{[22]}$ In these conditions, the corresponding cis-indenol derivatives were diastereoselectively generated in general excellent yields $(92-100 \%)$ and good enantioselectivities $(77-84 \%$ ee $)$. It must be noted that, however, the scope of this process was limited to electron-deficient allenes. Moreover, the reaction was totally inhibited when the allenoate beared a methyl group at the $\alpha$-position. In the same context, these authors have developed a cationic palladium-catalyzed enantioselective domino annulation of ortho-boronate-substituted cinnamic ketones 5a-d with alkynes $\mathbf{6 a - b}$, affording the corresponding chiral indenes 7a-e in excellent yields and high enantioselectivities of up to $93 \% e e{ }^{[23]}$ The cationic palladium species was prepared in situ by adding the chiral ligand 8 directly to the $\mathrm{Pd}(\mathrm{OTf})_{2} \cdot 2 \mathrm{H}_{2} \mathrm{O}$ without isolation of palladium complexes. The authors have proposed a plausible mechanism for the domino reaction, which is depicted in Scheme 2. First, the monohydroxo cationic palladium species 9 with vacant sites could be 
formed from the in situ reaction of $\mathrm{Pd}(\mathrm{OTf})_{2} \cdot 2 \mathrm{H}_{2} \mathrm{O}$ and the chiral ligand. Intermediate 9 was believed to be the active catalyst and enabled smooth transmetalation with the substrate $\mathbf{5}$ to yield a cationic arylpalladium(II) species 10. Next, $\pi$-coordination of the carbon-carbon triple bond to the cationic palladium center occurred to form 11, followed by the regioselective insertion of the alkyne into the carbon-palladium bond, affording the vinylpalladium intermediate $\mathbf{1 2}$ (carbopalladation). Then, conjugate addition of the vinylpalladium species to the cinnamic ketone occurred to yield the product 7. It was also proposed that the coordinated intermediate $\mathbf{1 2}$ was helpful to the enantioface discrimination of $\alpha, \beta$-unsaturated ketone, resulting in high enantioselectivities. It must be noted that this domino process has provided an efficient way for the construction of optically active, multiply substituted indene derivatives. 


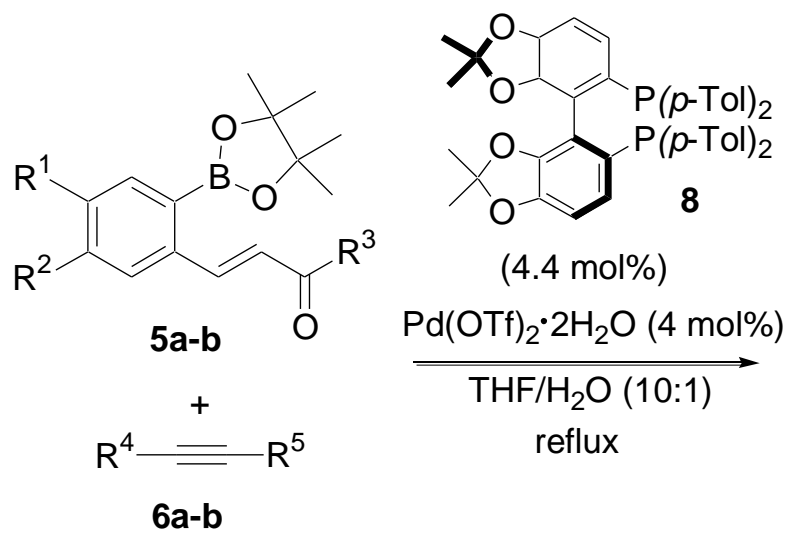<smiles>[R]CCC1C([P])=C([Z7])c2cc([R])c([R7])cc21</smiles>

$$
\mathrm{R}^{1} \quad \mathrm{R}^{2} \quad \mathrm{R}^{3} \quad \mathrm{R}^{4} \quad \mathrm{R}^{5} \quad \text { Yield ee }
$$

$\begin{array}{lcccccc}\mathrm{H} & \mathrm{H} & \mathrm{Me} & \mathrm{Me} & \mathrm{CO}_{2} \mathrm{Me} & >99 & 91 \\ \mathrm{H} & \mathrm{H} & \mathrm{Me} & \mathrm{CH}_{2} \mathrm{OMe} & \mathrm{CH}_{2} \mathrm{OMe} & >99 & 92 \\ \mathrm{H} & \mathrm{H} & \mathrm{Ph} & \mathrm{Me} & \mathrm{CO}_{2} \mathrm{Me} & >99 & 82 \\ \mathrm{H} & \mathrm{OMe} & \mathrm{Me} & \mathrm{Me} & \mathrm{CO}_{2} \mathrm{Me} & 94 & 92 \\ -\mathrm{OCH}_{2} \mathrm{O}- & \mathrm{Me} & \mathrm{Me} & \mathrm{CO}_{2} \mathrm{Me} & 94 & 93\end{array}$

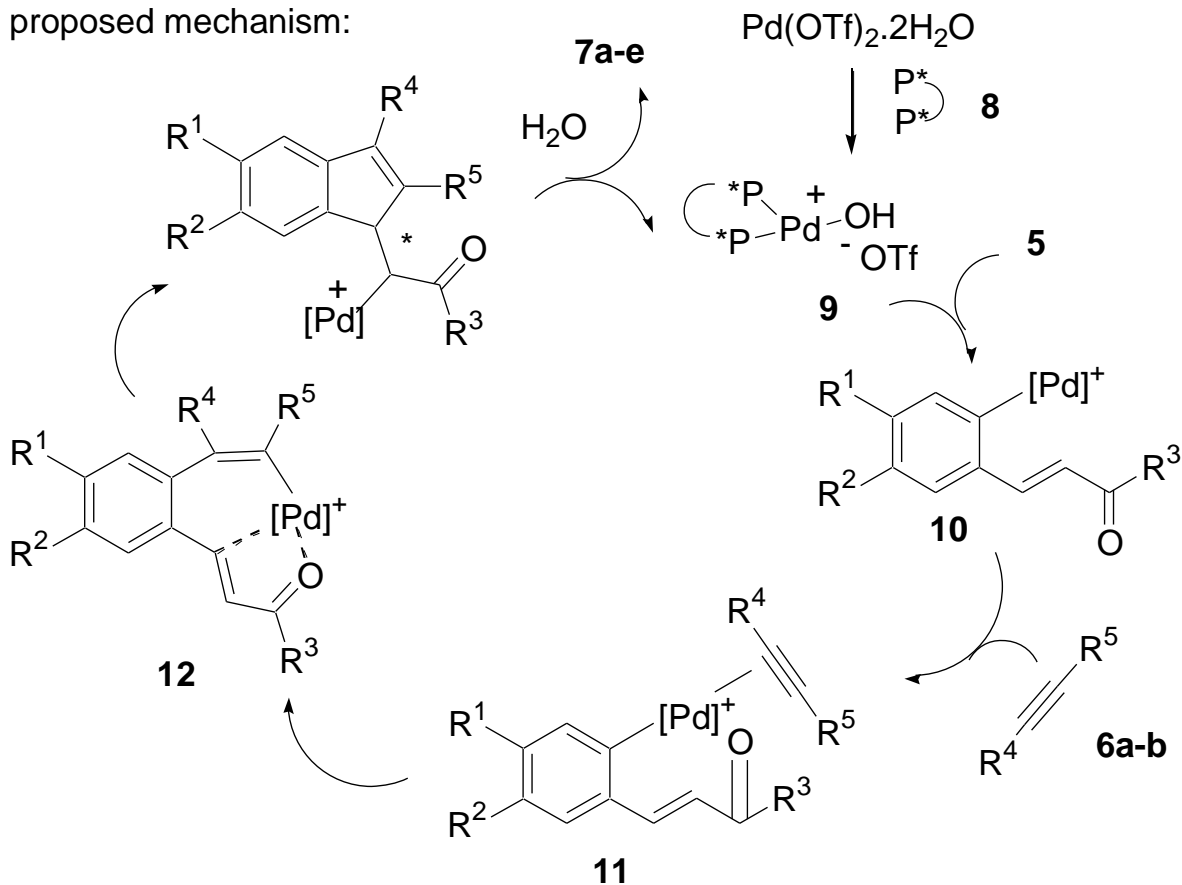

Scheme 2. Pd-catalyzed domino annulation of ortho-boronate-substituted cinnamic ketones with alkynes.

Moreover, the same authors have recently reported the synthesis of chiral aminoindene derivatives 15a-h on the basis of a diastereo- and enantioselective domino annulation reaction of $(S)$-2-(N-tertbutanesulfinylimino)arylboronic acids 13a-d as chiral auxiliaries with a variety of alkynes 14a-e. ${ }^{[2]}$ The reaction was catalyzed by chiral cationic palladium complex, $\left[\mathrm{Pd}[(S, S)-\right.$ bdpp $\left.\left.]\left(\mathrm{H}_{2} \mathrm{O}\right)_{2}\right]\right]^{2+}\left(\mathrm{BF}_{4}{ }^{-}\right)_{2}$, affording through double asymmetric induction the corresponding sulfoxides 15a-h as mixtures of two diastereomers. These sulfoxides were further converted through oxidation by treatment with $m$-CPBA 
into the corresponding more stable sulfones 16a-h with moderate to high yields and excellent enantioselectivities of $>99 \%$ ee, as shown in Scheme 3. It must be noted that the double asymmetric induction was necessary to obtain high enantioselectivities. Indeed, the authors have performed the reaction of the corresponding racemic 2-(N-tert-butanesulfinylimino)arylboronic acid 13a and alkyne 14a under comparable conditions and observed a very low diastereoselectivity $(27 \% d e)$ for the formation of product 15a. Furthermore, the authors have shown that the diastereoselectivity of the reaction was highly dependent on the configuration of the substrate. Thus, under comparable conditions, the reaction of (R)-2-( $N$-tert-butanesulfinylimino)arylboronic acid 13a with alkyne 14a was not diastereoselective. According to these results, it was presumed that the chiral catalyst interfered with the chiral substrates, resulting in different stereocontrol; (S)-2-(N-tertbutanesulfinylimino)arylboronic acid and the cationic palladium complex constituted a matched pair leading to the enhancement of diastereoselectivity. In addition, a moderate enantioselectivity of $50 \%$ $e e$ was reported by the same authors in the domino annulation of racemic 2-aroylmethoxyarylboronic acids with alkynes to give the corresponding 1-benzoxepines upon catalysis with either $[\operatorname{Pd}[(S, S)$ bdpp $\left.\left.]\left(\mathrm{H}_{2} \mathrm{O}\right)_{2}\right]\right]^{2+}(\mathrm{OTf})_{2}$ or $\left.\left[\mathrm{Pd}(R)-\operatorname{BINAP}\left(\mathrm{H}_{2} \mathrm{O}\right)_{2}\right]^{2+} \cdot(\mathrm{OTf})_{2}\right]^{[25]}$ 


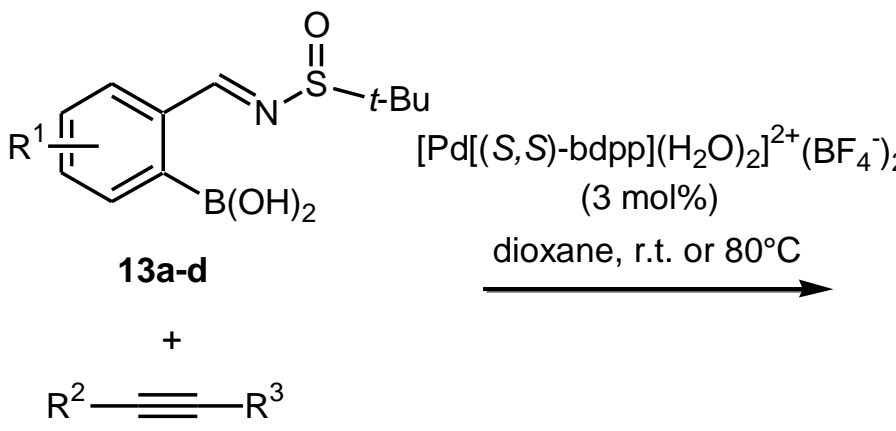

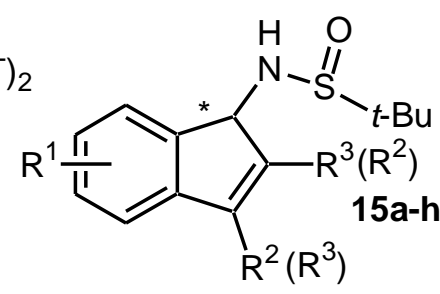

(2 diastereomers)

14a-e

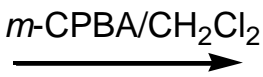

r.t.<smiles>[R7]C1=C([R])[C@H](NS(=O)(=O)[R16](C)(C)C)C2=CC=[R]#CC=C21</smiles>

$R^{1} \quad R^{2} \quad R^{3} \quad$ Yield (15a-h) de (15a-h) Yield (16a-h) ee (16a-h)

$(\%) \quad(\%) \quad(\%)$

\begin{tabular}{ccccccc}
\hline $\mathrm{H}$ & $\mathrm{Me}$ & $\mathrm{CO}_{2} \mathrm{Me}$ & $>99$ & 88 & 85 & $>99$ \\
$m-\mathrm{MeOC}_{6} \mathrm{H}_{4}$ & $\mathrm{Me}$ & $\mathrm{CO}_{2} \mathrm{Me}$ & $>99$ & 98 & 90 & $>99$ \\
$3,4-\mathrm{OCH}_{2} \mathrm{O}$ & $\mathrm{Me}$ & $\mathrm{CO}_{2} \mathrm{Me}$ & 92 & 82 & 68 & $>99$ \\
$m-\mathrm{ClC}_{6} \mathrm{H}_{4}$ & $\mathrm{Me}$ & $\mathrm{CO}_{2} \mathrm{Me}$ & $>99$ & - & 83 & 88 \\
$\mathrm{H}$ & $n-\mathrm{Hex}$ & $\mathrm{CO}_{2} \mathrm{Me}$ & 98 & 90 & 77 & $>99$ \\
$\mathrm{H}$ & $\mathrm{BnCH}_{2}$ & $\mathrm{CO}_{2} \mathrm{Me}$ & 98 & 90 & 97 & $>99$ \\
$\mathrm{H}$ & $\mathrm{CH}_{2} \mathrm{OMe}$ & $\mathrm{CH}_{2} \mathrm{OMe}$ & 99 & - & 31 & 93 \\
$\mathrm{H}$ & $\left(\mathrm{CH}_{2}\right)_{2} \mathrm{OMe}$ & $\left(\mathrm{CH}_{2}\right)_{2} \mathrm{OMe}$ & 94 & 66 & 88 & $>99$
\end{tabular}

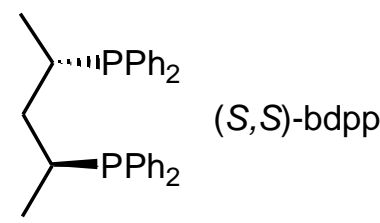

Scheme 3. Pd-catalyzed domino annulation of $(S)$-2-(N-tert-butanesulfinylimino)arylboronic acids with alkynes.

Copper-catalyzed domino reactions have been used for the synthesis of carbocycles, as well as for heterocycles, such as indoles, benzoxazoles, and quinoxalines. Among these reactions, are enantioselective copper-catalyzed domino reactions initiated by conjugate additions. A recent example was reported by Alexakis et al., involving the $\mathrm{Cu}$-catalyzed enantioselective conjugate addition of dialkylzinc to bis- $\alpha, \beta$-unsaturated carbonyl compounds $\mathbf{1 7 a - c}$, followed by the intramolecular trapping of the intermediate zinc enolate through a second intramolecular conjugate addition in the presence of chiral phosphoramidite ligands 19 and 20. ${ }^{[26]}$ This domino Michael-Michael process afforded the corresponding chiral cyclic and heterocyclic products 18a-d having three stereocenters as mixtures of two diastereomers with moderate to high diastereoselectivities of up to $>98 \% d e$, and enantioselectivities of up to $94 \%$ ee, as shown in Scheme 4. The stereochemistry was determined to be trans,trans for the major products and trans, cis for the minor products. 


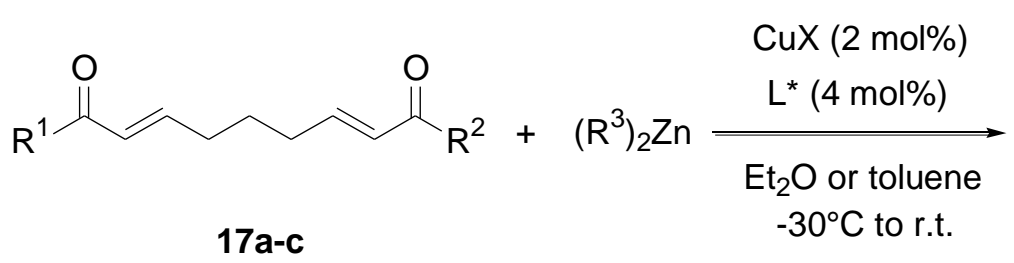<smiles>[R]C(=O)C[C@H]1CCC[C@@H]([13CH3])[C@H]1C([R])=O</smiles>

with $\mathrm{CuX}=\mathrm{Cu}(\mathrm{OTf})_{2}$ and $\mathrm{L}^{*}=19$ :

$\mathrm{R}^{1}=\mathrm{R}^{2}=\mathrm{Me}, \mathrm{R}^{3}=\mathrm{Et}, \mathrm{de}=60 \%$,

ee $($ major $)=79 \%$, ee $($ minor $)=88 \%$

$R^{1}=R^{2}=R^{3}=M e: d e=40 \%$,

ee $($ major $)=88 \%$, ee $($ minor $)=94 \%$

with $\mathrm{CuX}=\mathrm{CuTC}$ and $\mathrm{L}^{*}=\mathbf{2 0}$ :

$\mathrm{R}^{1}=\mathrm{Ph}, \mathrm{R}^{2}=\mathrm{OMe}, \mathrm{R}^{3}=\mathrm{Et}: 43 \%, d e=86 \%$,

ee $($ major $)=92 \%$, ee $($ minor $)=86 \%$

with $\mathrm{CuX}=\mathrm{Cu}(\mathrm{OTf})_{2}$ and $\mathrm{L}^{*}=\mathbf{2 0}$ :

$R^{1}=R^{2}=P h, R^{3}=E t: 97 \%$, de $>98 \%$, ee (major) $=88 \%$

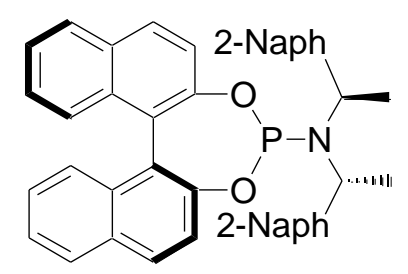

19<smiles>CCC(c1ccccc1)N(C(CC)c1ccccc1)p1oc2c(C)cc(C)cc2c2cc(C)cc(C)c2o1</smiles>

20

Scheme 4. Cu-catalyzed domino intramolecular Michael-Michael reaction.

Another enantioselective domino reaction initiated by a Michael addition was reported by Feringa et al., in 2010. ${ }^{[27]}$ In this work, the authors developed $\mathrm{Cu}$-catalyzed conjugate addition of Grignard reagents to 4-chloro- $\alpha, \beta$-unsaturated esters, thioesters, and ketones 21a-c, which was followed by enolate trapping through intramolecular alkylation reaction to provide the corresponding trans-1-alkyl2-substituted cyclopropane esters, thioesters, and ketones 22a-h, respectively, in good to high yields and enantioselectivities of up to $98 \%$ ee, as shown in Scheme 5. These results were obtained by using $(R)$-Tol-BINAP as chiral ligand. This novel and versatile methodology, employing an extremely simple catalytic system based on a commercial chiral ligand, $\mathrm{CuI}$ and Grignard reagents, was applied to the synthesis of key intermediates for the total syntheses of cascarillic acid and grenadamide. 


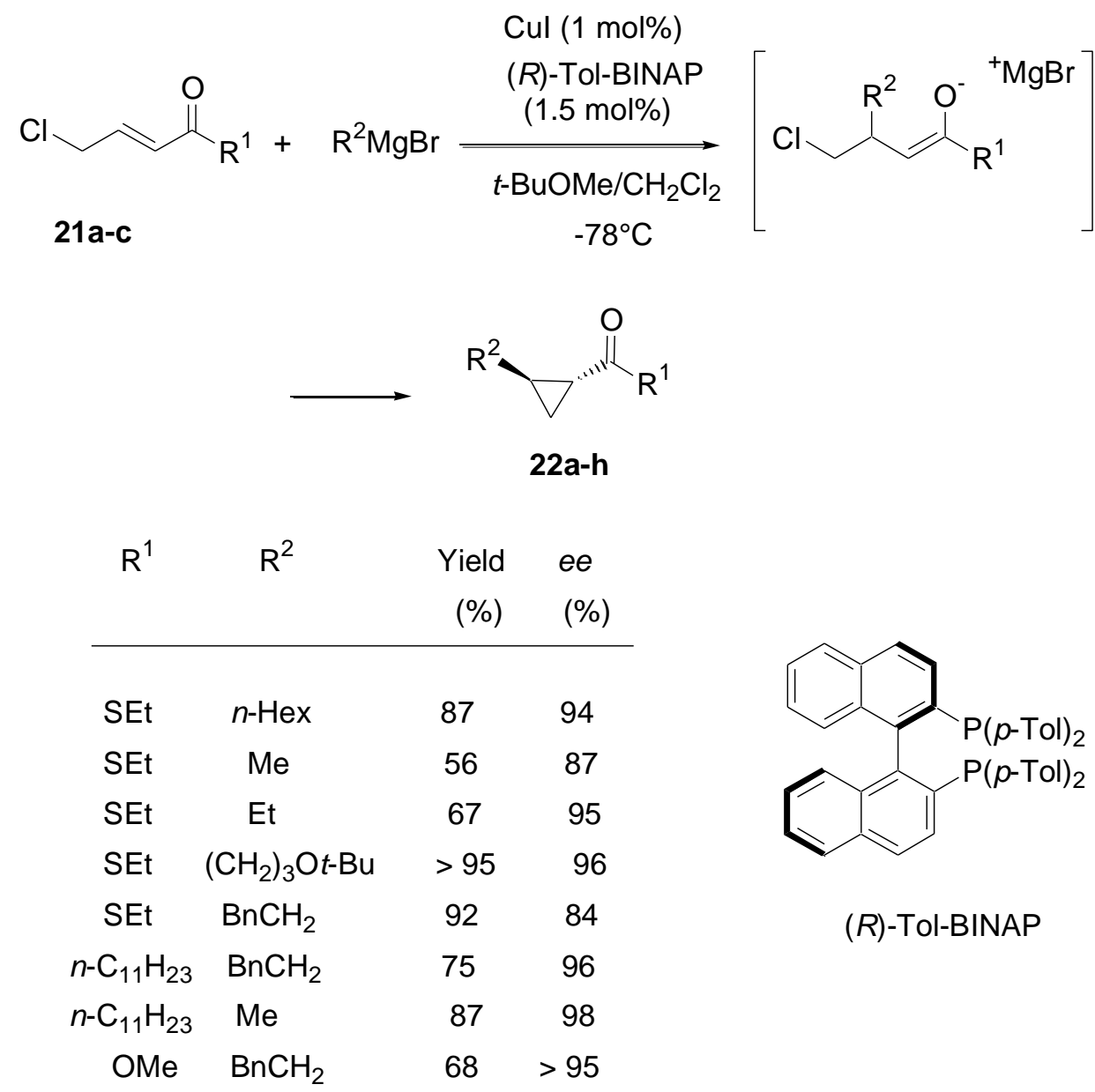

Scheme 5. Cu-catalyzed domino Michael-intramolecular alkylation reaction.

A number of asymmetric domino processes involve 1,3-dicarbonyl compounds as nucleophilic partners in Michael reactions. ${ }^{[28]}$ In this area, Feng et al. have described an efficient asymmetric synthesis of $4 H$-chromene derivatives through a domino Michael addition-cyclization reaction catalyzed by a salen-cobalt(II) complex. ${ }^{[29]}$ Indeed, the asymmetric synthesis of a range of 2-amino-5oxo-4-aryl-5,6,7,8-tetrahydro-4H-chromene-3-carboxylates 23a-k was achieved on the basis of the reaction occurring between easily available cyclohexane-1,3-dione and ethyl 2-cyano-3phenylacrylates 24a-k in the presence of a salen-cobalt(II) complex in situ generated from $\mathrm{Co}(\mathrm{OAc})_{2} \cdot 4 \mathrm{H}_{2} \mathrm{O}$ and chiral salen 25 derived from $(R, R)$-1,2-diphenylenethane-1,2-diamine and 3,5-ditert-butylsalicylaldehyde. The domino process provided moderate to good yields of up to $81 \%$ combined with high enantioselectivities of up to $89 \%$ ee, as summarized in Scheme 6. 


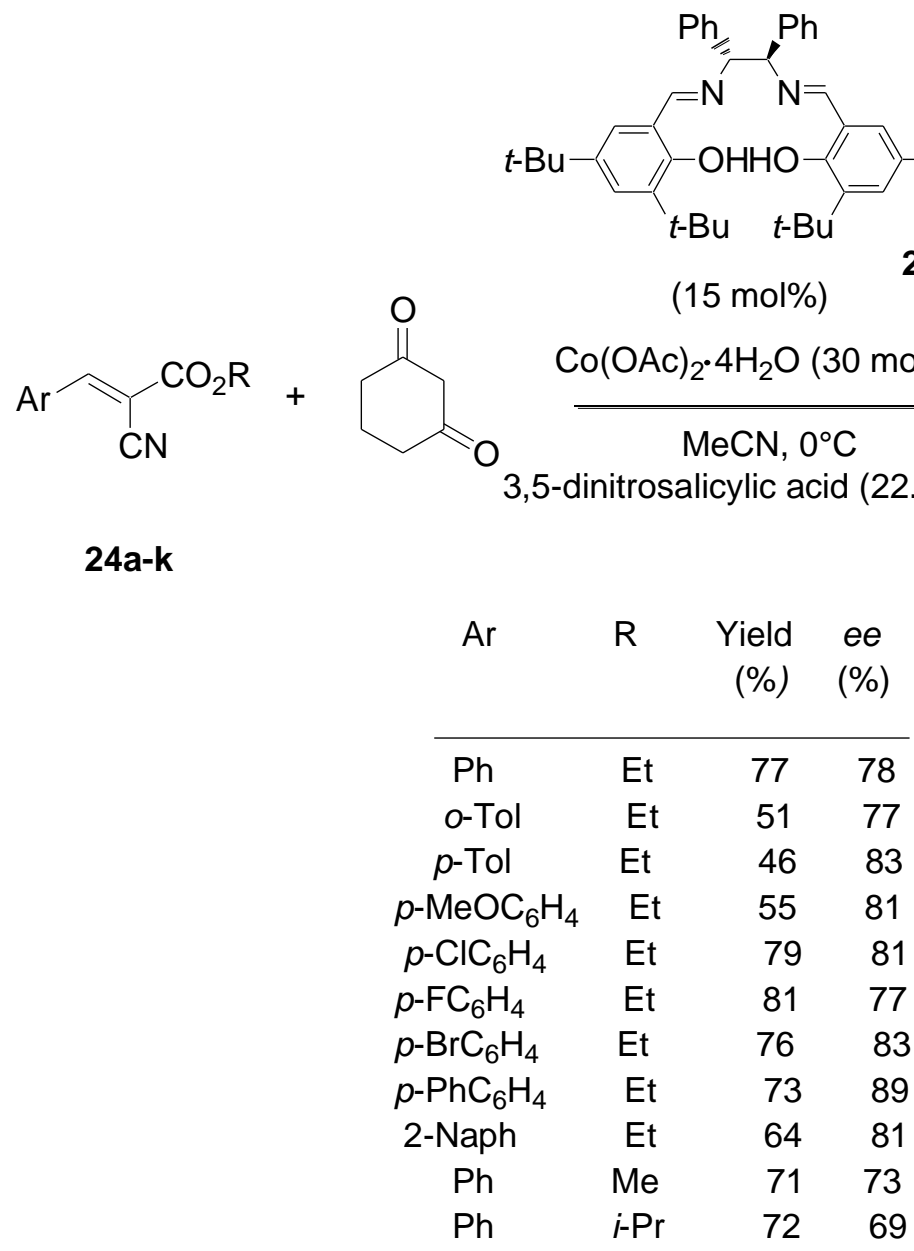

Scheme 6. Co-catalyzed domino Michael-cyclization reaction.

In 2010, Arai et al. investigated a catalytic asymmetric exo'-selective virtual [3+2] cycloaddition of iminoesters 26a-e with trans nitroalkenes 27a-e. ${ }^{[30]}$ Usually, when a trans nitroalkene is used in a [3+2] cycloaddition, the stereoconjunction between the 3- and 4-positions is fixed in a trans conformation, and four diastereomers are possible, classified as endo, exo, endo', and exo' isomers. Screenings of the metal salts to study the exo' adduct ratio have found that nickel salts facilitated the selective production of the exo' products. Thus, these authors have performed the exo'-selective reaction of iminoesters 26a-e and trans nitroalkenes 27a-e by using a combination of $\mathrm{Ni}(\mathrm{OAc})_{2}$ with chiral imidazoline-aminophenol $\mathbf{2 8}$ as catalyst, which provided the corresponding pyrrolidines $\mathbf{2 9 a - i}$ in good yields and diastereoselectivities of up to $84 \%$ de combined with high enantioselectivities of up to 99\% ee for the major isomers, as shown in Scheme 7. This novel methodology represented the first general success in the catalytic asymmetric exo'-selective reaction of iminoesters and nitroalkenes. In order to explain the results, the authors have proposed that the products were generated from a domino Michael addition of the iminoesters onto the trans nitroalkenes, which was then followed by a Mannich reaction, as depicted in Scheme 7. 


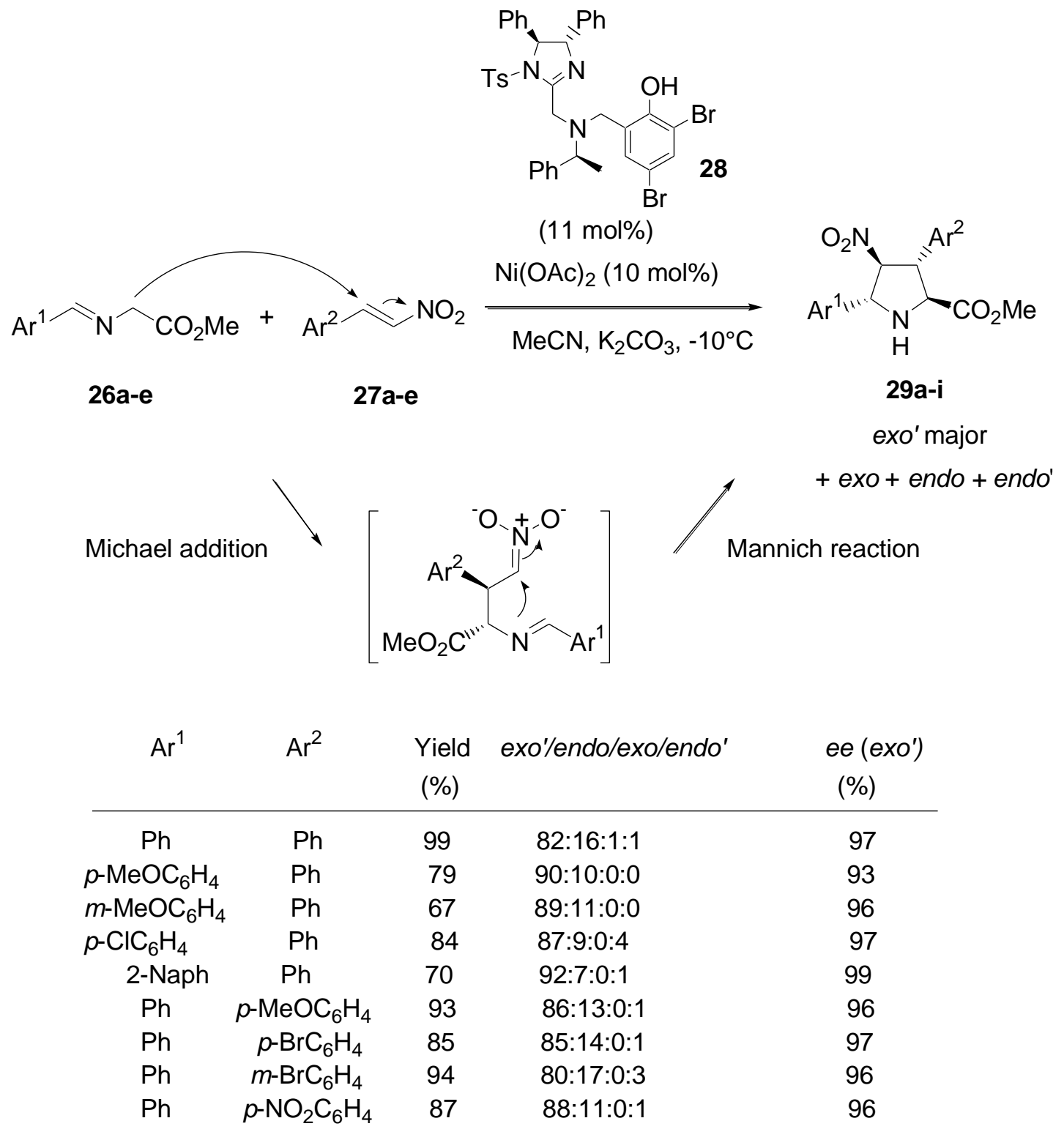

Scheme 7. Ni-catalyzed domino Michael-Mannich reaction.

\subsection{Domino Reactions initiated by an Aldol Reaction}

The direct catalytic asymmetric aldol reaction is a powerful and atom-economical method for synthesizing chiral $\beta$-hydroxy carbonyl compounds. Many metals and organocatalysts for reactions of aldehyde electrophiles have been developed in the past decade. ${ }^{[31]}$ The use of ketone electrophiles in direct aldol reactions for the construction of a tetrasubstituted carbon stereocenter, however, is limited to either activated ketones or intramolecular reactions. Furthermore, catalytic asymmetric construction of two contiguous tetrasubstituted chiral carbon stereocenters in $\mathrm{C}-\mathrm{C}$ bond-forming reactions is rare, probably because of severe steric hindrance. In order to address these issues, Shibasaki et al. have employed a chiral magnesium catalyst to promote the domino aldol condensation-cyclization reaction of $\alpha$-substituted $\alpha$-isothiocyanato esters 31a-b with aryl, heteroaryl, alkyl and alkenyl methyl ketones in addition to a cyclic ketone 30a-i. ${ }^{[32]}$ The process was catalyzed by a combination of $(n-\mathrm{Bu})_{2} \mathrm{Mg}$ with chiral Schiff base 32a or 32 b, affording at room temperature the corresponding protected $\alpha$-amino- $\beta$ hydroxy esters 33a-j bearing two contiguous tetrasubstituted carbon stereocenters in good to excellent yields, diastereoselectivities of up to $96 \% d e$, and enantioselectivities of up to $98 \% e e$, as shown in Scheme 8. 


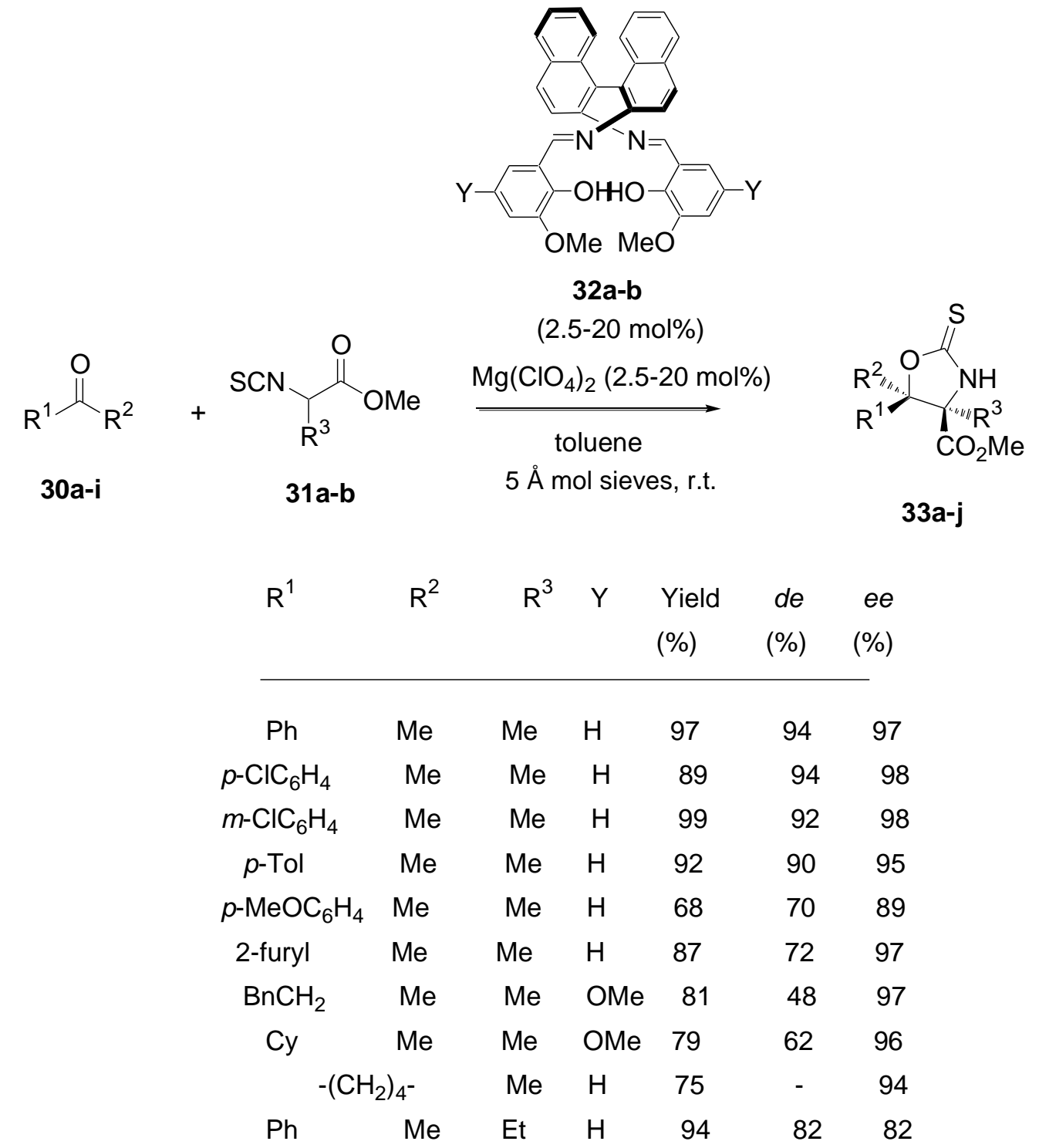

Scheme 8. Mg-catalyzed domino aldol condensation-cyclization reaction.

Chiral tin complex, $[\mathrm{Sn}(R)-\mathrm{Ph}-\mathrm{PyBox}](\mathrm{OTf})_{2}$, has been shown by Zhu et al. to be capable of catalyzing the enantioselective domino condensation-cyclization reaction of $\alpha$-isocyanoacetamides with aldehydes, which afforded the corresponding 5-amino-2-(1-hydroxyalkyl)-oxazoles in low to good yields of up to $72 \%$ and low to good enantioselectivities of up to $80 \% e e$. $^{[33]}$ More recently, Yanagisawa et al. have employed chiral tin dibromide $\mathbf{3 4}$ as a chiral precatalyst and sodium methoxide as a base precatalyst to induce the enantioselective domino aldol condensation-cyclization reaction of $\gamma$-substituted $\beta, \gamma$-didehydro- $\gamma$-lactones 35a-e with aldehydes. ${ }^{[3]}$ The corresponding chiral trans- $\beta, \gamma-$ disubstituted $\gamma$-butyrolactones 36a-g were selectively produced in moderate to high yields and enantioselectivities of up to $99 \%$ ee, as shown in Scheme 9. The authors have proposed the mechanism depicted in Scheme 9, which started with the reaction of chiral tin bromide $\mathbf{3 4}$ with an equimolecular amount of sodium methoxide to give the corresponding chiral tin bromide methoxide, which was the key catalyst of the process. The latter was then added to $\gamma$-substituted $\beta, \gamma$-didehydro- $\gamma$-lactone $\mathbf{3 5}$ to yield a chiral tin enolate 37. Subsequent aldol reaction between chiral tin enolate $\mathbf{3 7}$ and aldehyde provided the corresponding tin alkoxide of $\beta$-hydroxy ketone 38. Finally, tin alkoxide $\mathbf{3 8}$ underwent cyclization via participation of its ester moiety to afford chiral final product $\mathbf{3 6}$ with regeneration of the chiral tin bromide methoxide. The methoxycarbonyl group of intermediates $\mathbf{3 7}$ and $\mathbf{3 8}$ played a crucial role in the catalytic cycle. 

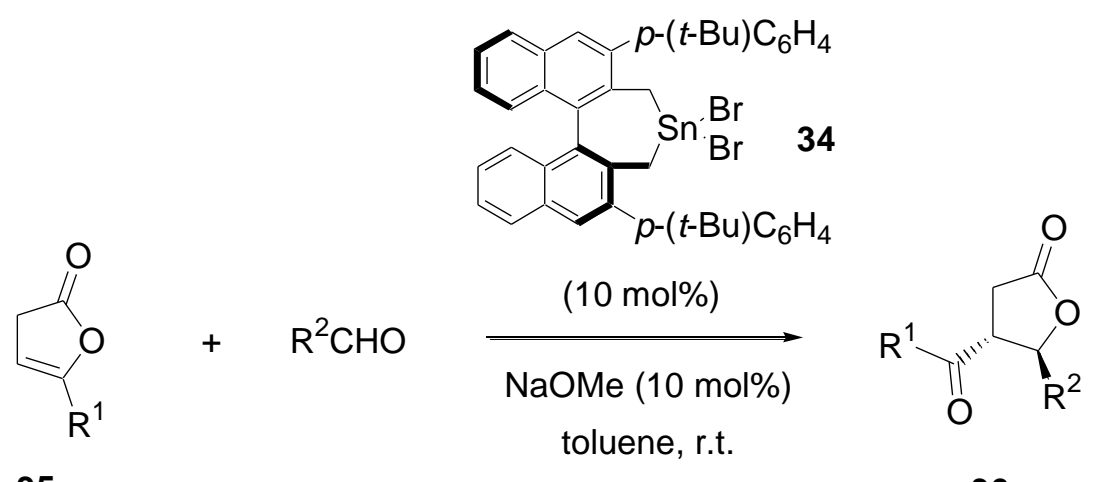

35a-e

$36 \mathrm{a}-\mathrm{g}$

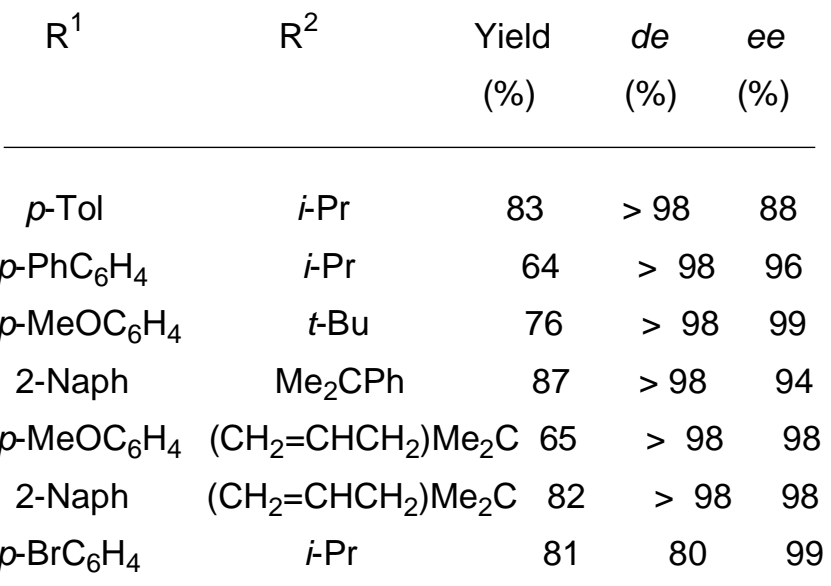

proposed mechanism:

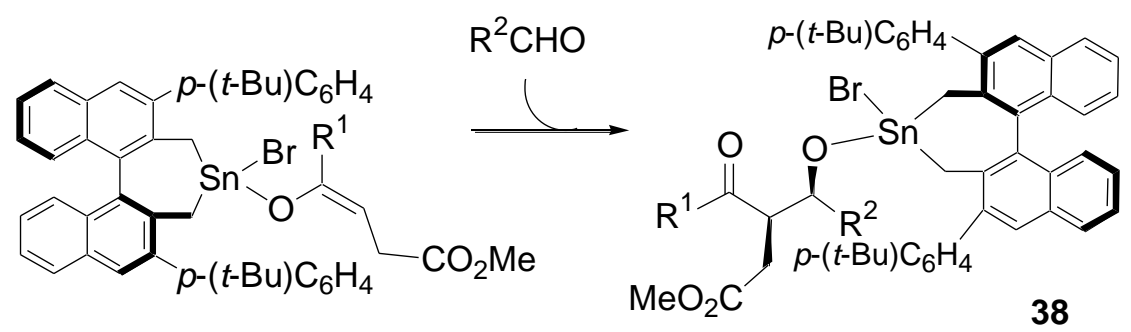

37<smiles>[R]C1=CCC(=O)O1</smiles><smiles>CCCCCC(C)(C)Oc1cc2ccccc2c2c1C[Sn](Br)Cc1c(OC(C)(C)CCCC)cc3ccccc3c1-2</smiles><smiles>[R]C(=O)[C@H]1CC(=O)O[C@@H]1[R7]</smiles>

35

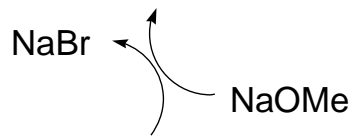

34

Scheme 9. Sn-catalyzed domino aldol condensation-cyclization reaction.

A number of palladium-catalyzed enantioselective domino reactions incorporate an aldol reaction in their sequence of transformations. As a recent example, Klein Gebbink et al. have developed an 
asymmetric domino aldol condensation-cyclization reaction occurring between $\alpha$-methyl isocyanate and various aromatic aldehydes, which afforded the corresponding enantio-enriched oxazolines. ${ }^{[35]}$ The process was catalyzed by chiral five-coordinated NCN-pincer cationic palladium(II) complexes, providing moderate diastereo- and enantioselectivities of $\leq 48 \%$ de and $\leq 42 \%$ ee, respectively. Recently, the combination of organocatalysts and transition metal catalysts has evolved as a new strategy to carry out enantioselective transformations that could not be performed in a traditional way by simply employing one of the two catalysts. ${ }^{[20 c, 36]}$ These transformations not only demonstrate the potential of this merged catalytic approach, but they also show that there are more options to render a reaction highly enantioselective than testing different chiral metal-ligand complexes, organocatalysts, or additives. By using appropriate combinations of a chiral or achiral organocatalyst and an achiral or chiral transition metal catalyst, facile ways for reaction optimization can be realized by simply varying one of the two existing catalysts. Furthermore, such a combination of multiple catalyst systems has opened up new avenues for developing cooperative catalyst systems where the respective catalyst system alone fails to deliver sufficient catalyst reactivity and selectivity. In 2011, Oh et al. developed a cooperative catalyst system for the highly diastereo- and enantioselective catalytic aldol reaction of methyl $\alpha$-isocyanoacetate 39 with aldehydes 40a-g. ${ }^{[37]}$ This domino aldol condensation-cyclization reaction was induced by a combination of achiral thiourea $\mathbf{4 1}$ and a chiral cobalt complex derived from $\mathrm{CoI}_{2}$ and brucine amino diol $\mathbf{4 2}$ as a chiral ligand in the presence of a base, such as DBU. As shown in Scheme 10, the corresponding chiral trans-oxazolines 43a-g were produced in good yields and high diastereo- and enantioselectivities of up to $90 \% d e$ and $98 \% e e$, respectively. The authors assumed that the key to the successful stereocontrol of the domino process lied in the strong anion-binding interaction between isocyanide 39 and thiourea 41, which potentially disturbed the intrinsic metalisocyanide complexation. Indeed, anion-binding interactions between thiourea $\mathbf{4 1}$ and methyl $\alpha$ isocyanoacetate $\mathbf{3 9}$ in $\mathbf{4 4}$ provided a thiourea-assisted enolate, which was capable of coordinating to chiral metal center in a more organized fashion $\mathbf{4 5}$. Then, intermediate $\mathbf{4 5}$ cyclized to give final product 43 . 
<smiles>FC(F)(F)c1cc(NC(=S)Nc2cc(C(F)(F)F)cc(C(F)(F)F)c2)cc(C(F)(F)F)c1</smiles>

(20 mol\%)
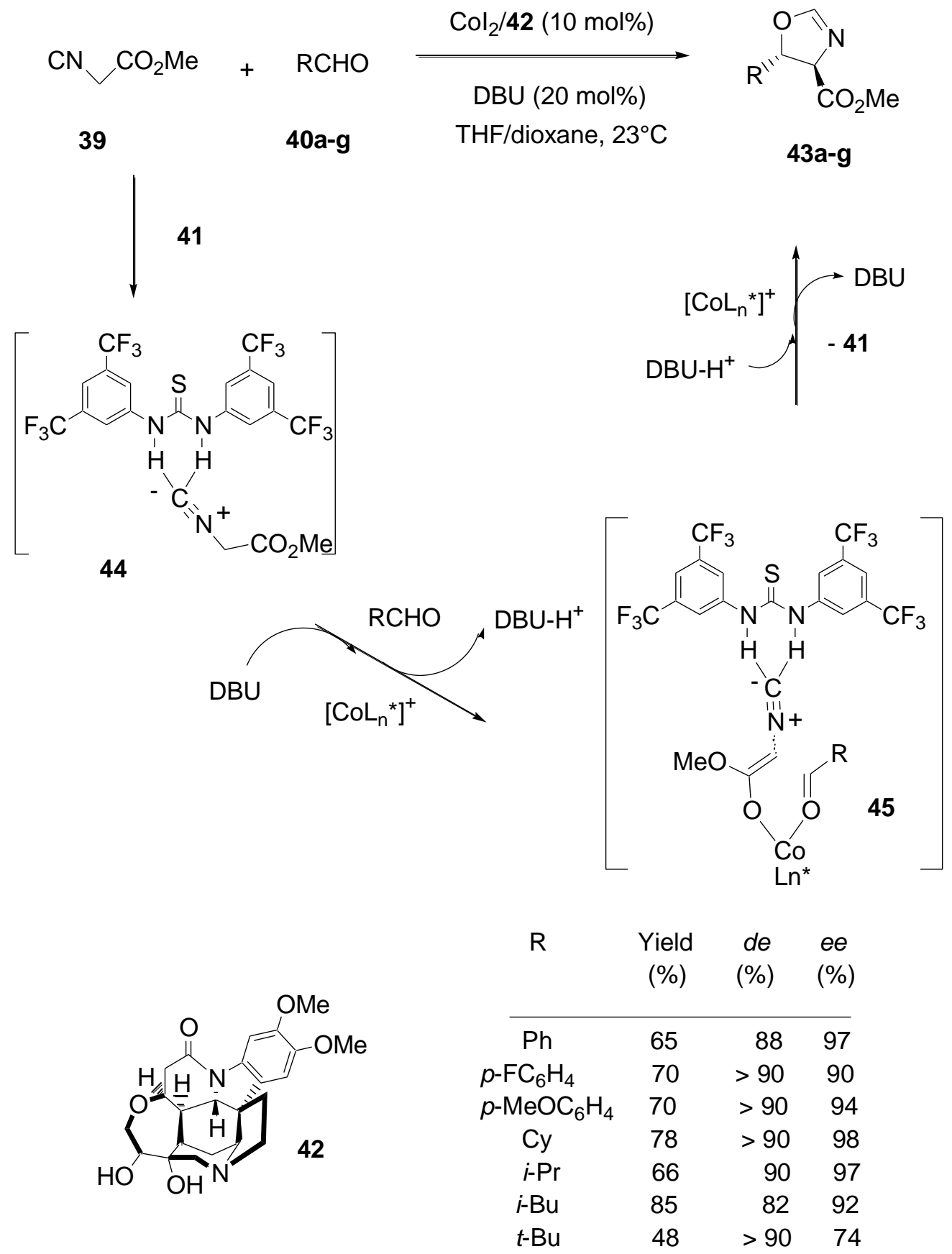

Scheme 10. Co-catalyzed domino aldol condensation-cyclization reaction.

\subsection{Domino Reductive Aldol Reactions}

Recently, excellent progress has been achieved in the area of domino reductive-aldol reactions for the construction of several contiguous stereocenters in one-pot. ${ }^{[38]}$ In 2006, Shibasaki et al. described the first example of a catalytic enantioselective intermolecular reductive aldol reaction. ${ }^{[39]}$ While coppercatalyzed reductive aldol reactions between acetophenone and methyl acrylate, performed in the presence of pinacolborane as the reducing agent, provided the corresponding tertiary alcohol in only 
moderate enantioselectivities $(\leq 30 \% e e)$ in all cases of chiral ligands tested, reductive aldol reactions between symmetric ketones and $\beta$-disubstituted $\alpha, \beta$-unsaturated esters afforded selectively the corresponding $\alpha$-products in moderate to good enantio-induction $(29-80 \% e e)$ when catalyzed by a copper complex of $(R)$-Tol-BINAP. Furthermore, high to excellent enantioselectivities of up to $99 \%$ $e e$ were achieved in the copper-catalyzed reductive aldol reaction of allenic ethyl ester to ketones 46ag. When the reaction was catalyzed by a copper(I) complex of (R)-DTBM-Segphos, it was $\gamma$-cisselective since the corresponding tertiary alcohols 47a-g were formed as single products in both excellent yields and enantioselectivities, as shown in Scheme 11. Surprisingly, the authors have found that the $\alpha$ - or $\gamma$-selectivity of the reaction could be switched depending on the structure of chiral diphosphine ligands used. Thus, when employing a copper(I) complex of chiral ligands Taniaphos 49 and 50, the reaction became $\alpha$-selective and provided the corresponding tertiary alcohols 48a-f in high yields and enantioselectivities of up to $84 \%$ ee, as shown in Scheme 11. 


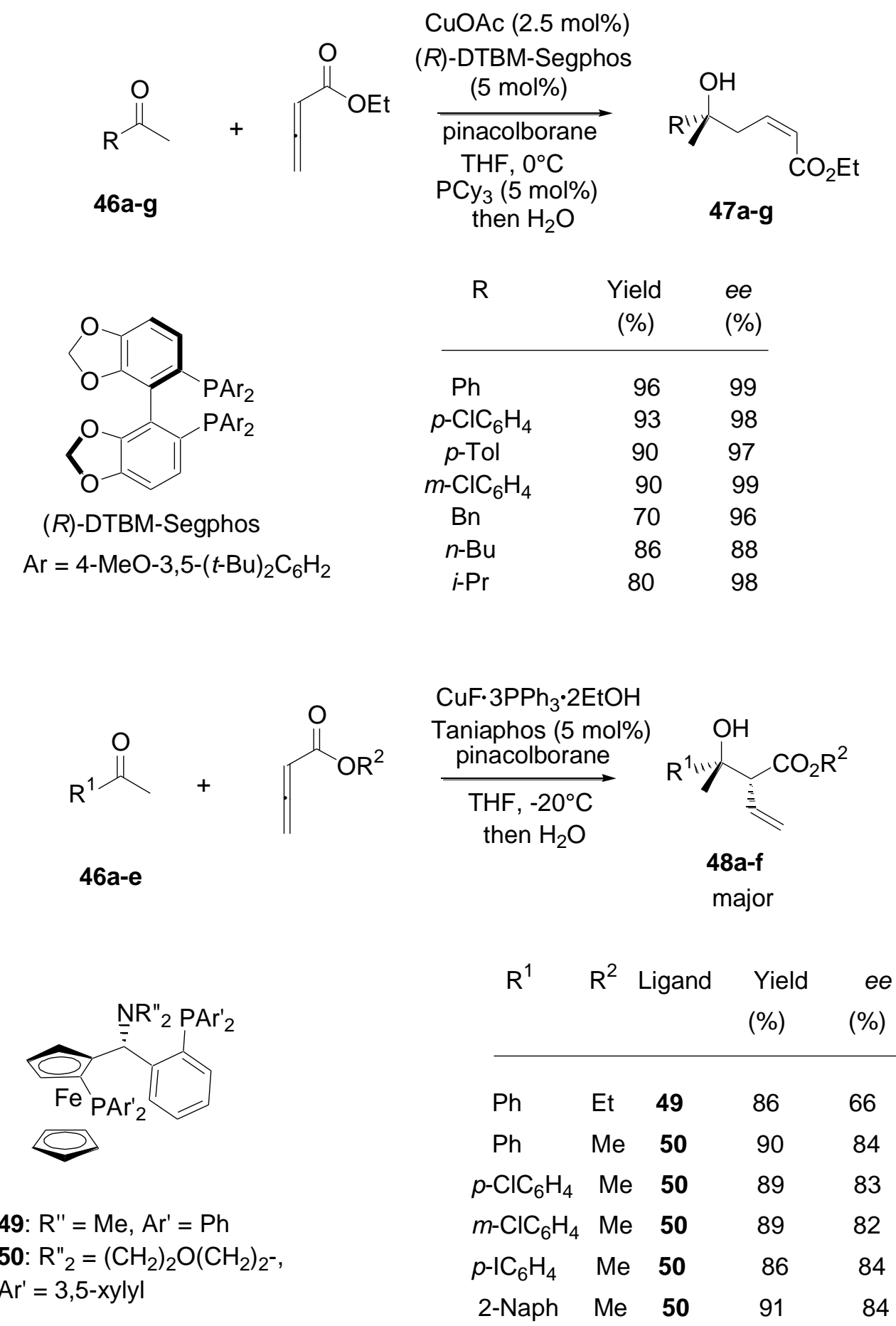

Scheme 11. Cu-catalyzed domino reductive aldol reactions of ketones and allenic esters.

In 2008, Lipshutz et al. described the first hydrometallative intramolecular cycloreduction leading to three new contiguous stereocenters in a one-pot process, based on a chiral ligated catalytic source. ${ }^{[0]}$ Thus, the enantioselective domino conjugate reduction-intramolecular aldol reaction of acyclic $\beta, \beta-$ disubstituted keto enones 51a-f provided the corresponding functionalized cyclohexanols 52a-f as single diastereomers in both high yields and enantioselectivities of up to $97 \%$ ee, as shown in Scheme 12. The generation of the three contiguous stereocenters was achieved by using a combination of $\mathrm{Cu}(\mathrm{OAc})_{2}$ with chiral bis-phosphine $\mathbf{5 3}$ in the presence of diethoxymethylsilane as the reductant. In this process, the initial conjugate hydride addition generated an intermediate chiral (presumably copper) enolate through facial discrimination, which subsequently participated in an intramolecular aldol addition to ketones. Transmetalation of the resulting copper alkoxide with a particular stoichiometric silane regenerated ligated $\mathrm{CuH}$. 


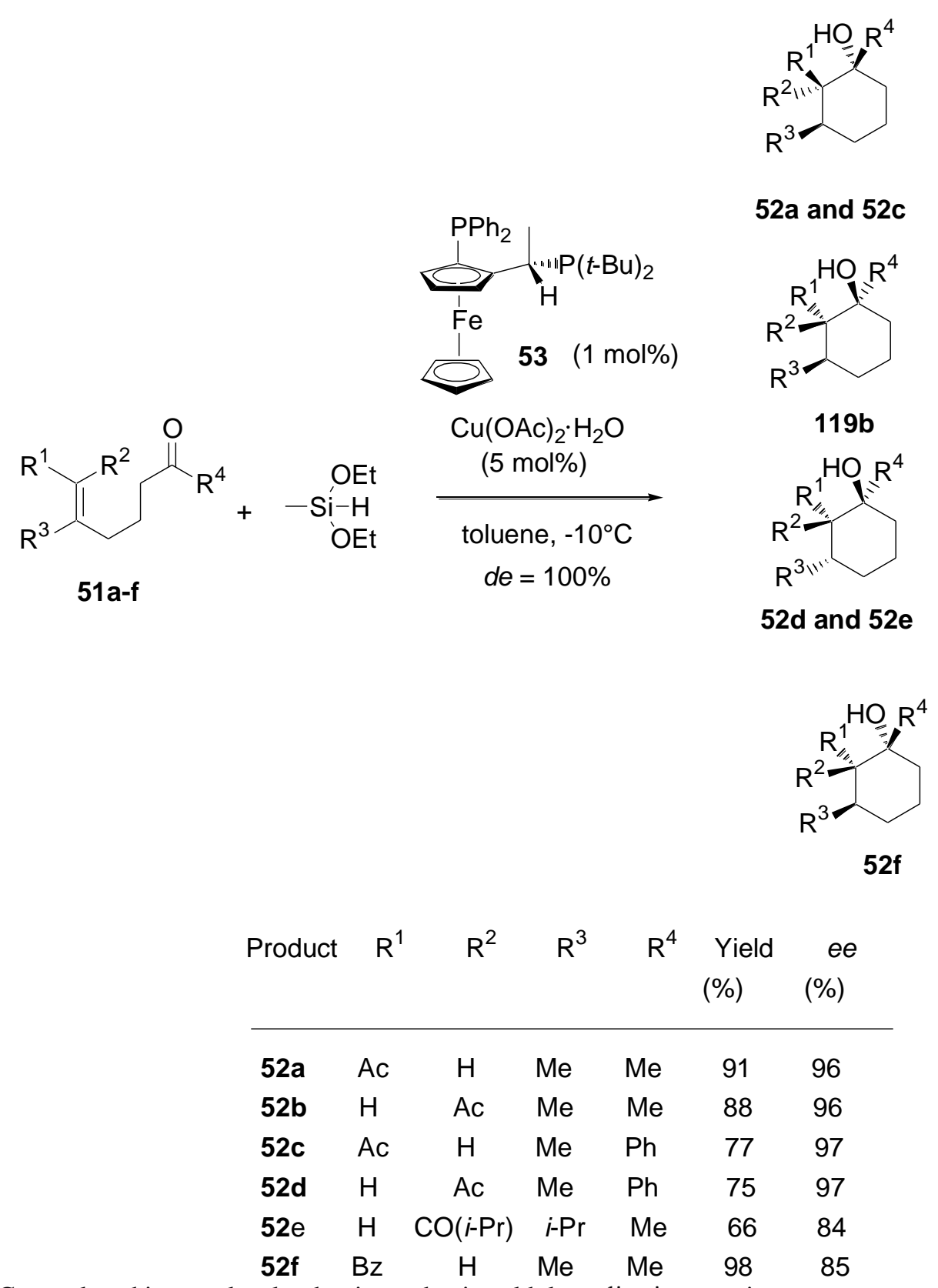

Scheme 12. Cu-catalyzed intramolecular domino reductive aldol-cyclization reaction.

Only few methodologies of domino reductive-aldol reactions have described the synthesis of bi- and tricyclic compounds. One example was recently reported by Riant et al., who developed a versatile methodology for the diastereo- and enantioselective domino reductive-aldol cyclization reaction of functionalized $\alpha, \beta$-unsaturated esters 54a-e into the corresponding bicylic domino products 55a-e in moderate to high yields and enantioselectivities of up to $97 \%$ ee, as shown in Scheme $13{ }^{[41]}$ The reaction was catalyzed by a copper(I) complex of chiral bis-phosphine 56 in the presence of phenylsilane as the reductive agent. The cis product was produced as the major diastereomer with moderate to complete diastereosectivities. In this study, the authors have demonstrated that the stereoselectivity of the process was increased with the steric hindrance of the ester moiety, since the best results were obtained with $t$-butyl esters. Furthermore, it was shown that increasing the steric bulkiness around the phosphorus atoms of the ligand gave further improvement of both cis:trans ratio and enantioselectivity. 


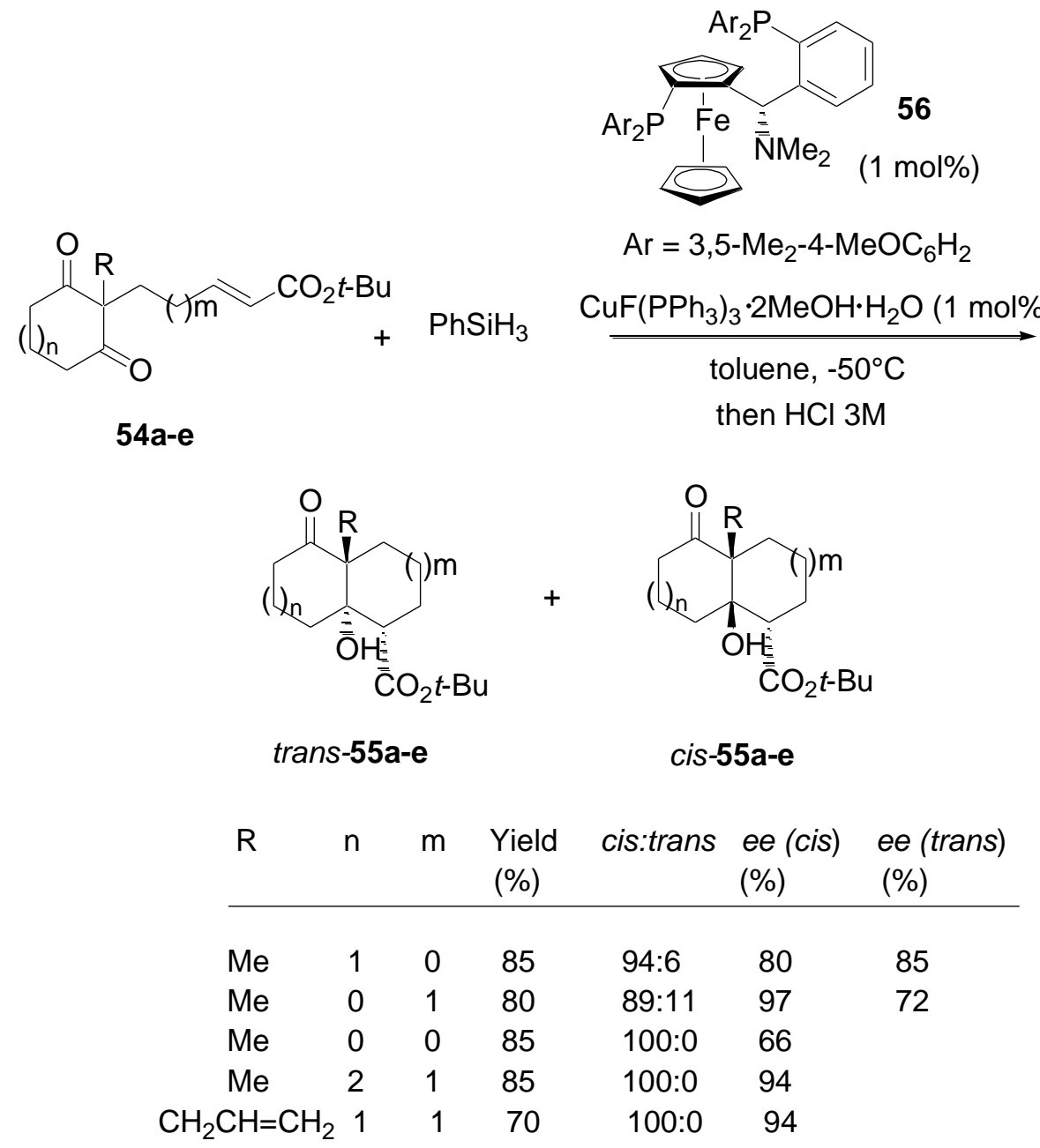

Scheme 13. Cu-catalyzed intramolecular domino reductive aldol-cyclization reaction.

In addition, these authors have employed other chiral Taniaphos-based ligands to induce chirality in copper(I)-catalyzed reductive aldol reactions of methyl acrylate with aldehydes using phenylsilane as the reducing agent. ${ }^{[42]}$ Although the reaction was highly chemoselective, it gave moderate syndiastereoselectivities $(\leq 76 \% d e$ ). However, good to excellent enantioselectivities of up to $97 \%$ ee were obtained for domino products $\mathbf{5 7 a - d}$ arisen from a wide range of cyclic aliphatic, aromatic, and heteroaromatic aldehydes 58a-d when Taniaphos ligand $\mathbf{5 9}$ was employed, as shown in Scheme 14. The scope of this methodology was extended by these authors to the reductive aldol reactions of methyl acrylate with ketones under similar conditions. ${ }^{[43]}$ Thus, the domino reaction of ketones $\mathbf{6 0 a}-\mathbf{e}$ with methyl acrylate and phenylsilane gave rise chemoselectively, by using a closely related chiral Taniaphos ligand 61, to the corresponding tertiary alcohols 62a-e as single products, which were mixtures of erythro- and threo-diastereomers. The major erythro-isomers were produced in moderate diastereoselectivities albeit good to excellent enantioselectivities of up to $97 \%$ ee, as shown in Scheme 14. 


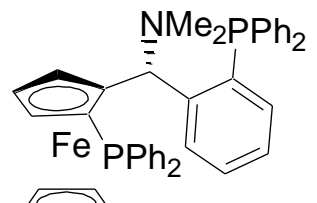

(1 mol\%)

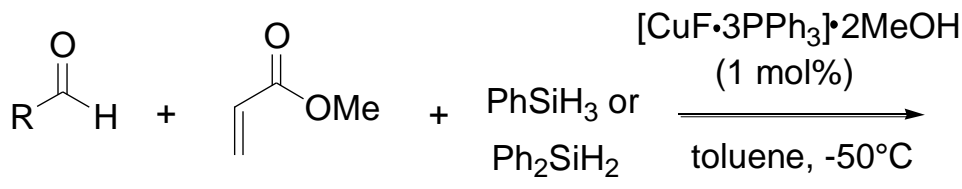

58a-d

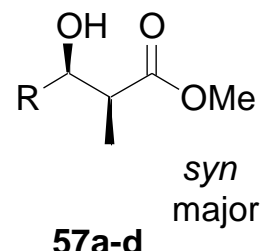

$\mathrm{R}$ reductive agent conversion syn:anti ee (syn)

(\%)

(\%)

\begin{tabular}{ccccc}
\hline $\mathrm{Cy}$ & $\mathrm{Ph}_{2} \mathrm{SiH}_{2}$ & 99 & $88: 12$ & 97 \\
$p-\mathrm{FC}_{6} \mathrm{H}_{4}$ & $\mathrm{PhSiH}_{3}$ & 99 & $44: 56$ & 86 \\
$p-\mathrm{ClC}_{6} \mathrm{H}_{4}$ & $\mathrm{PhSiH}_{3}$ & 99 & $44: 56$ & 85 \\
$p-\mathrm{MeOC}_{6} \mathrm{H}_{4}$ & $\mathrm{PhSiH}_{3}$ & 99 & $60: 40$ & 68
\end{tabular}

${ }_{\mathrm{R}}^{\mathrm{O}}+\stackrel{\mathrm{O}}{\mathrm{O}} \mathrm{OMe}+\mathrm{PhSiH}_{3}$

60a-e<smiles>CCCCc1ccccc1C(C)c1ccccc1[PH](C)(C)C</smiles>

(1 mol\%) $\left[\mathrm{CuF} \cdot 3 \mathrm{PPh}_{3}\right] \cdot 2 \mathrm{MeOH}$ (1 $\mathrm{mol} \%)$

toluene, $-50^{\circ} \mathrm{C}$<smiles>[R]C(C)(O)[C@@H](C)C(=O)OC</smiles>

62a-e erythro

R Yield Chemoselectivity erythro:threo ee (erythro)

(\%)

(\%)

(\%)

$\begin{array}{lcrll}\mathrm{Ph} & 98 & >99 & 92: 8 & 95 \\ p-\mathrm{FC}_{6} \mathrm{H}_{4} & 88 & 94 & 91: 9 & 92 \\ p-\mathrm{MeOC}_{6} \mathrm{H}_{4} & 31 & 97 & 92: 8 & 90 \\ p-\mathrm{ClC}_{6} \mathrm{H}_{4} & 95 & 95 & 86: 14 & 90 \\ m-\mathrm{ClC}_{6} \mathrm{H}_{4} & 70 & 89 & 88: 12 & 82\end{array}$

Scheme 14. Cu-catalyzed domino reductive aldol reactions of aldehydes and ketones.

In 2008, Krische et al. reported the first enantioselective reductive aldol couplings of vinyl ketones 63a-b, which were achieved through the design of a new class of TADDOL-like phosphonite ligands. ${ }^{[44]}$ As shown in Scheme 15, the Rh-catalyzed hydrogenative aldol coupling of methyl vinyl ketone 63a or ethyl vinyl ketone 63b with aldehyde 64, performed in the presence of chiral ligand $\mathbf{6 5}$, allowed the corresponding linear aldol adducts 66a-b to be obtained with high diastereo- and enantioselectivities of up to $96 \%$ de and $96 \% e e$, respectively. More recently, copper(I)ClickFerrophos-complexes were demonstrated by Fukuzawa et al. to catalyze the same reactions. ${ }^{[45]}$ In 
the case of the reductive aldol reaction of ketones, the products were produced in general excellent yields of up to $99 \%$ and moderate to high enantioselectivities $(37-95 \%$ ee) for the major erythro products. While yields and enantioselectivities were comparable, the diastereomeric ratio of erythro:threo was improved of up to $92 \%$ de when compared to that obtained when using Taniaphos ligands.<smiles></smiles>

(12 mol\%)<smiles>[R]C(=O)C=[C+]=CCN1C(=O)c2ccccc2C1=O</smiles>

$\mathrm{R}=\mathrm{Me}: 88 \%, d e=96 \%, e e=96 \%$

$\mathrm{R}=\mathrm{Et}: 94 \%$, de $=96 \%$, ee $=95 \%$

Scheme 15. Rh-catalyzed domino reductive aldol reaction.

\subsection{Domino Reactions initiated by a [2+2+2] Cycloaddition}

Transition metal-catalyzed [2+2+2] cycloaddition of unsaturated motifs, such as alkyne and alkene, constitutes the most atom-economical and facile protocol for the construction of a six-membered ring system. $^{[46]}$ In particular, enantioselective $[2+2+2]$ cycloaddition is a fascinating protocol for the construction of chiral cyclic skeletons. ${ }^{[47]}$ In recent years, this cycloaddition has been included in several enantioselective domino processes promoted by chiral catalysts of transition metals, such as rhodium and iridium. As an example, Tanaka et al. have developed a cationic rhodium $(\mathrm{I}) /(R)-$-Solphos complex-catalyzed enantioselective domino transesterification-[2+2+2] cycloaddition reaction of 1,6diyne esters 67a-c with tertiary propargylic alcohols 68a-e, leading to the corresponding tricyclic 3,3disubstituted phthalides 69a-k. ${ }^{[48]}$ As shown in Scheme 16, the cycloadducts were achieved in both high yields and enantioselectivities of up to $94 \%$ ee. Although the [2+2+2] cycloaddition constitutes the second step of this domino sequence and because this cycloaddition is the key step of the process, it was decided to situate it in this section dealing with domino reactions initiated by a $[2+2+2]$ cycloaddition. 

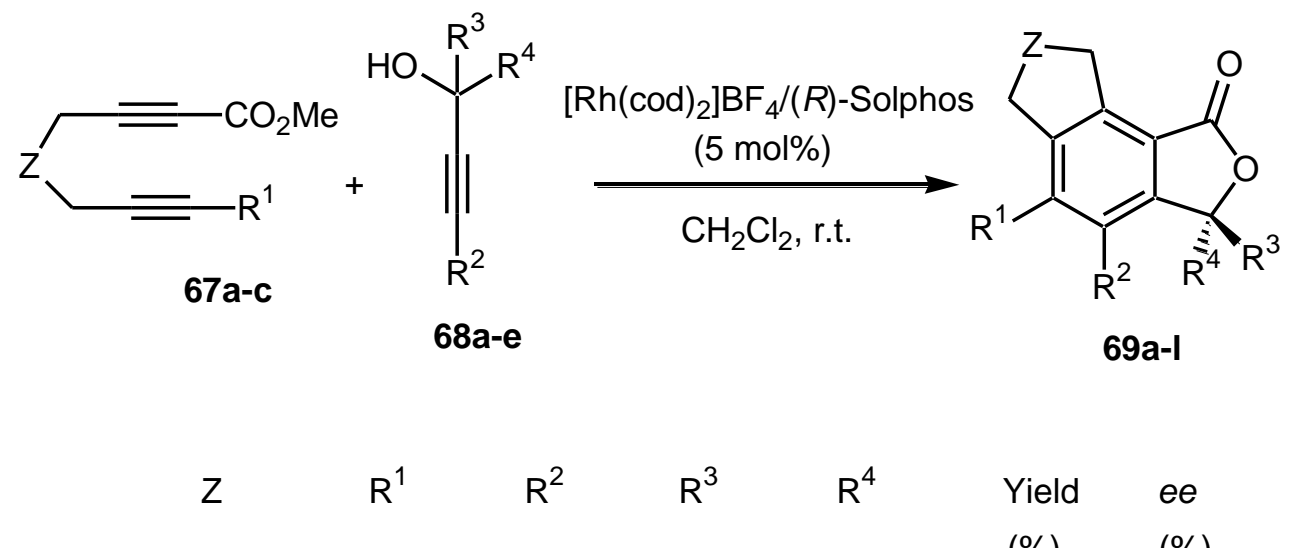

$(\%) \quad(\%)$

\begin{tabular}{lcccccc}
\hline $\mathrm{O}$ & $\mathrm{Me}$ & $\mathrm{Ph}$ & $\mathrm{Me}$ & $\mathrm{CCPh}$ & 82 & 92 \\
$\mathrm{O}$ & $\mathrm{Me}$ & $\mathrm{Me}$ & $\mathrm{Me}$ & $\mathrm{CCMe}$ & 67 & 90 \\
$\mathrm{O}$ & $\mathrm{Me}$ & $\mathrm{CH}_{2} \mathrm{OMe}$ & $\mathrm{Me}$ & $\mathrm{CCCH} \mathrm{OMe}$ & 75 & 92 \\
$\mathrm{O}$ & $\mathrm{Me}$ & $\mathrm{H}$ & $\mathrm{Me}$ & $\mathrm{CCH}$ & 66 & 48 \\
$\mathrm{O}$ & $\mathrm{Me}$ & $\mathrm{Ph}$ & $\mathrm{Et}$ & $\mathrm{CCPh}$ & 66 & 87 \\
$\mathrm{NTs}$ & $\mathrm{Me}$ & $\mathrm{Ph}$ & $\mathrm{Me}$ & $\mathrm{CCPh}$ & 85 & 93 \\
$\mathrm{NTs}$ & $\mathrm{Me}$ & $\mathrm{Me}$ & $\mathrm{Me}$ & $\mathrm{CCMe}$ & 87 & 90 \\
$\mathrm{CH}_{2}$ & $\mathrm{CO}_{2} \mathrm{Me}$ & $\mathrm{Ph}$ & $\mathrm{Me}$ & $\mathrm{CCPh}$ & 61 & 80 \\
$\mathrm{O}$ & $\mathrm{Me}$ & $\mathrm{Ph}$ & $\mathrm{Me}$ & $\mathrm{Ph}$ & 55 & 90 \\
$\mathrm{O}$ & $\mathrm{Me}$ & $\mathrm{Me}$ & $\mathrm{Me}$ & $\mathrm{Ph}$ & 56 & 94 \\
$\mathrm{NTs}$ & $\mathrm{Me}$ & $\mathrm{Ph}$ & $\mathrm{Me}$ & $\mathrm{Ph}$ & 79 & 86 \\
$\mathrm{NTs}$ & $\mathrm{Me}$ & $\mathrm{Me}$ & $\mathrm{Me}$ & $\mathrm{Ph}$ & 89 & 93
\end{tabular}<smiles>CN1CCOc2c1ccc(-c1ccccc1)c2-c1c(-c2ccccc2)ccc2c1OCCN2C</smiles>

(R)-Solphos

Scheme 16. Rh-catalyzed domino transesterification-[2+2+2] cycloaddition reaction.

Enantioselective rhodium-catalyzed domino double $[2+2+2]$ cycloaddition reactions have been independently developed by the groups of Tanaka and Shibata. In 2006, Tanaka et al. established an enantioselective synthesis of tetra-ortho-substituted axially chiral biaryls through rhodium-catalyzed domino double $[2+2+2]$ cycloaddition reaction. ${ }^{[49]}$ By using chiral $\mathrm{Rh}(\mathrm{I})^{+} /$modified- $(S)$-Segphos complex as catalyst, the reaction of electron-deficient malonate-derived 1,6-diynes 70a-b and 1,3diynes 71a-b afforded the corresponding $C_{2}$-symmetric tetra-ortho-substituted biaryls 72a-c in moderate yields and excellent enantioselectivities of up to $>99 \%$ ee, as shown in Scheme 17. Furthermore, comparable reaction conditions were applied to the reaction of bis-diynenitriles, providing through intramolecular enantioselective double $[2+2+2]$ cycloaddition the corresponding $C_{2}$-symmetric spirobipyridines in high yields and moderate enantioselectivities $(\leq 71 \% e e)$. As an extension of this methodology, the same authors have developed the domino double $[2+2+2]$ 
cycloaddition reaction of terminal tetraynes with electron-deficient monoynes to give the corresponding biaryls in moderate yields (24-44\%) and good to excellent enantioselectivities (70-98\% $e e$ ). Later, an intramolecular version of this methodology was also developed by these authors, allowing chiral $C_{2}$-symmetric spirobipyridine ligands to be achieved starting from the corresponding bisdiynenitriles in good to excellent yields (70-99\%) and moderate enantioselectivities of up to $71 \%$ $e e^{[50]}$

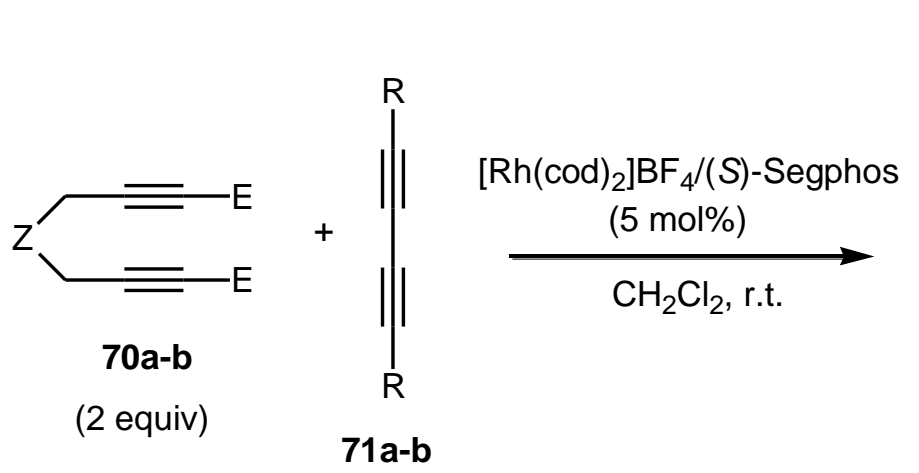<smiles>[Z]CCc1c(F)c2c([R])c(F)c1Cc1c(F)c-2c([R])c(F)c1C[Z]</smiles>

72a-c

\begin{tabular}{ccccc}
$\mathrm{R}$ & $\mathrm{Z}$ & $\mathrm{E}$ & $\begin{array}{r}\text { Yield } \\
(\%)\end{array}$ & $\begin{array}{c}\text { ee } \\
(\%)\end{array}$ \\
\hline $\mathrm{CH}_{2} \mathrm{OAc}$ & $\mathrm{C}\left(\mathrm{CO}_{2} \mathrm{Me}\right)_{2}$ & $\mathrm{CO}_{2} \mathrm{Et}$ & 59 & $>99$ \\
$\mathrm{CH}_{2} \mathrm{OMe}$ & $\mathrm{C}\left(\mathrm{CO}_{2} \mathrm{Me}\right)_{2}$ & $\mathrm{CO}_{2} \mathrm{Et}$ & 48 & 98 \\
$\mathrm{CH}_{2} \mathrm{OAc}$ & $\mathrm{CH}_{2}$ & $\mathrm{CO}_{2} \mathrm{Me}$ & 30 & $>99$
\end{tabular}<smiles>Pc1ccc2c(c1C1=C(c3ccccc3)C=CC3OCOC13)OCO2</smiles>

(S)-Segphos

Scheme 17. Synthesis of chiral biaryls through Rh-catalyzed domino double [2+2+2] cycloaddition reaction.

Later, Shibata et al. described an enantioselective synthesis of chiral tetraphenylenes on the basis of consecutive inter- and intramolecular rhodium-catalyzed [2+2+2] cycloadditions of two triynes. ${ }^{[51]}$ When triynes 73a-f, having a phenylene-bridged 1,5-diyne moiety, were submitted to a cationic rhodium catalyst of $(R)$-Cy-BINAP, they afforded the corresponding dimerized products 74a-f in good yields and high enantioselectivities of up to $>99 \%$ ee, as shown in Scheme 18. The authors assumed that these products were formed through a mechanism, depicted in Scheme 18, involving successively inter- and intramolecular [2+2+2] cycloadditions. In a first time, oxidative coupling of the 1,6-diyne moiety of the first triyne gave metalacyclopentadiene 75. Chemo- and regioselective intermolecular coupling with terminal alkyne moiety of the second triyne gave primary cycloadduct 76. Oxidative coupling of 1,6-diyne moiety of the second triyne and intramolecular coupling with the remaining terminal alkyne moiety of the first triyne gave final tetraphenylenes 74a-f. 


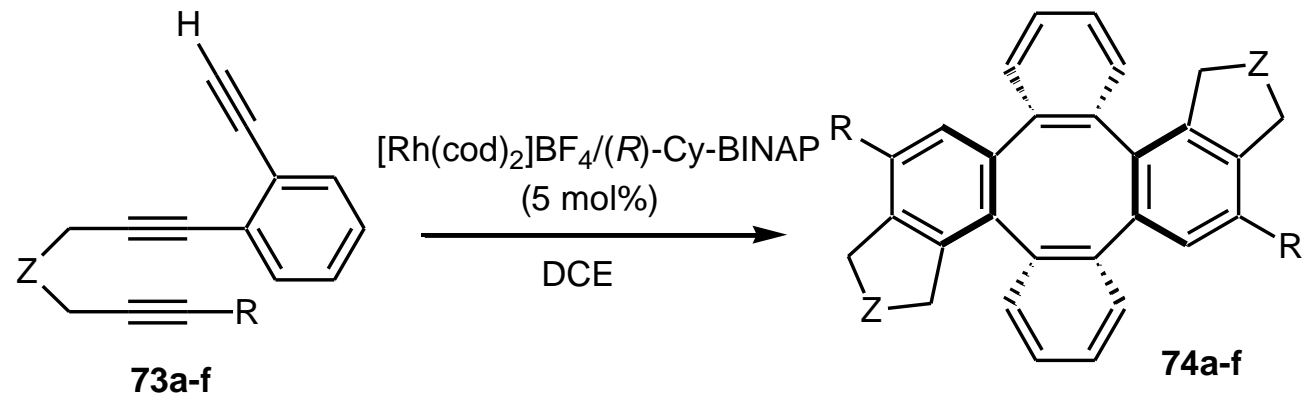

(2 equiv)<smiles>O=[PH](=O)(O)c1ccc2ccccc2c1-c1c(P)ccc2ccccc12</smiles>

$(R)$-Cy-BINAP

\begin{tabular}{lllll}
$\mathrm{R}$ & $\mathrm{Z}$ & Temp. & $\begin{array}{l}\text { Yield } \\
(\%)\end{array}$ & $\begin{array}{r}\text { ee } \\
(\%)\end{array}$ \\
\hline
\end{tabular}

$\begin{array}{ccccc}\mathrm{Ph} & \mathrm{NTs} & \text { reflux } & 62 & 95 \\ \mathrm{Me} & \mathrm{C}\left(\mathrm{CO}_{2} \mathrm{Me}\right)_{2} & 60^{\circ} \mathrm{C} & 86 & 97 \\ \mathrm{Ph} & \mathrm{C}\left(\mathrm{CO}_{2} \mathrm{Me}\right)_{2} & 60^{\circ} \mathrm{C} & 45 & 96 \\ \mathrm{Me} & \mathrm{O} & \text { r.t. }-60^{\circ} \mathrm{C} & 80 & 75 \\ p-\mathrm{BrC}_{6} \mathrm{H}_{4} & \mathrm{O} & 60^{\circ} \mathrm{C} & 56 & >99 \\ \mathrm{Ph} & \mathrm{O} & \text { r.t.-reflux } & 56 & 85\end{array}$

proposed mechanism:<smiles>[Z]CC#Cc1ccccc1C#CCCC(C)C(C)C(C)C</smiles>

75<smiles>[Z]CCC#Cc1ccccc1-c1cc([R])c2c(c1-c1ccccc1C#C)CC2</smiles>

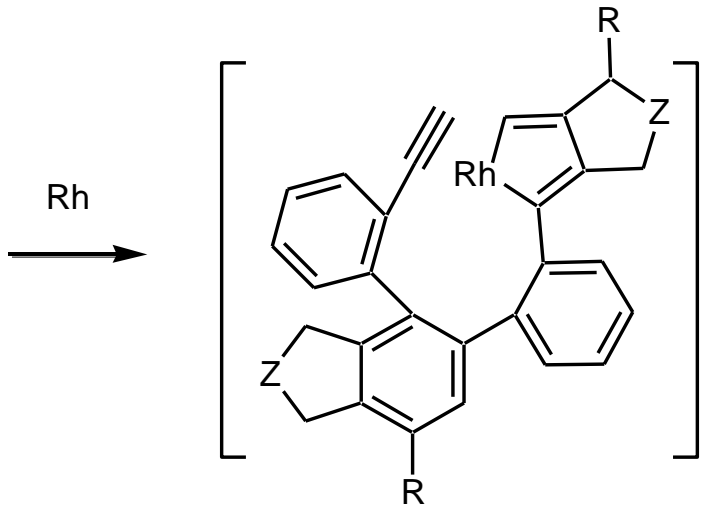

\section{intramolecular cycloaddition}<smiles>[R]c1cc2c(c3c1C[Z]CC3)-c1ccccc1-c1cc([R])c3c(c1-c1ccccc1-2)C([Z])C3</smiles>

Scheme 18. Synthesis of chiral tetraphenylenes through Rh-catalyzed domino double $[2+2+2]$ cycloaddition reaction. 
In addition, these authors have developed iridium-catalyzed consecutive intramolecular and enantioselective [2+2+2] cycloaddition domino reactions of hexaynes 77a-e, possessing 1,3-diyne moiety and oxygen or nitrogen-tether ${ }^{[52]}$ As shown in Scheme 19, the reaction of these substrates in the presence of a combination of $\left[\operatorname{Ir}(\operatorname{cod}) \mathrm{Cl}_{2}\right.$ and $(S)$-Xylyl-BINAP, led to the formation of the corresponding $C_{2}$-symmetrical biaryl products 78a-e in good yields and low to excellent enantioselectivities of up to $98 \%$ ee.

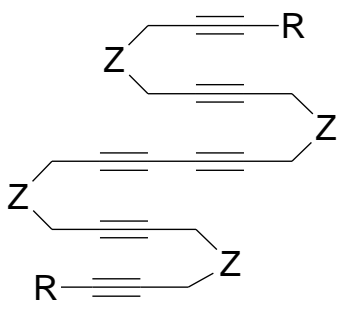

(S)-Xylyl-BINAP (20 mol\%)

$\left[\operatorname{Ir}(\operatorname{cod}) \mathrm{Cl}_{2}(10 \mathrm{~mol} \%)\right.$

xylene, r.t.

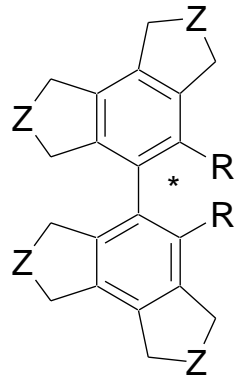

78a-e

77a-e

\begin{tabular}{cccc}
$\mathrm{R}$ & $\mathrm{Z}$ & $\begin{array}{c}\text { Yield } \\
(\%)\end{array}$ & $\begin{array}{c}e e \\
(\%)\end{array}$ \\
\hline$p-\mathrm{BrC}_{6} \mathrm{H}_{4}$ & $\mathrm{O}$ & 66 & 98 \\
$p-\mathrm{MeOC}_{6} \mathrm{H}_{4}$ & $\mathrm{O}$ & 78 & 97 \\
$\mathrm{Ph}$ & $\mathrm{NTs}$ & 52 & 98 \\
$\mathrm{Me}$ & $\mathrm{O}$ & 40 & $<10$ \\
$i-\mathrm{Pr}$ & $\mathrm{O}$ & 69 & 96
\end{tabular}

Scheme 19. Ir-catalyzed domino intramolecular double $[2+2+2]$ cycloaddition reaction.

More recently, the same authors have investigated rhodium-catalyzed enantioselective intramolecular reaction of hexaynes 79a-c bearing a 1,3-diyne moiety. ${ }^{[53]}$ When promoted by a chiral cationic rhodium complex of $(S)$-Tol-BINAP, the domino double [2+2+2] cycloaddition reaction afforded the corresponding axially chiral bis(biphenylenyl) derivatives 80a-c in good yields and good to high enantioselectivities of up to $96 \%$ ee, as shown in Scheme 20. The authors explained the formation of these cycloadducts through two consecutive $[2+2+2]$ cycloadditions. 


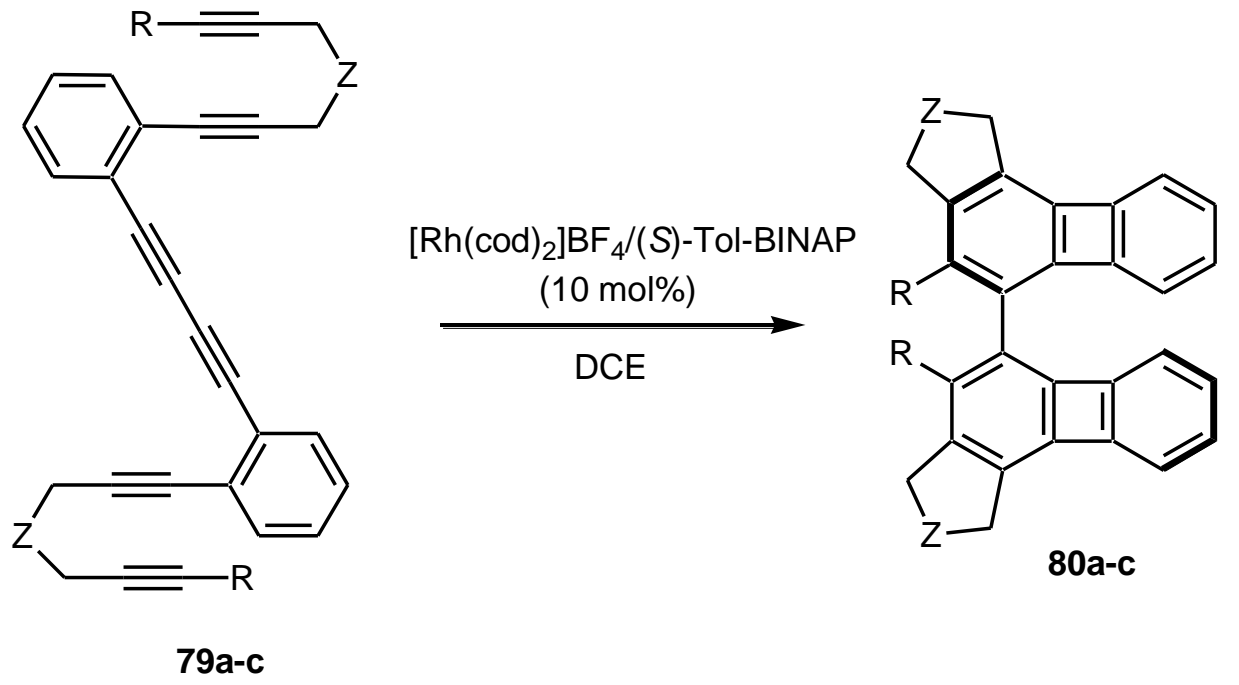

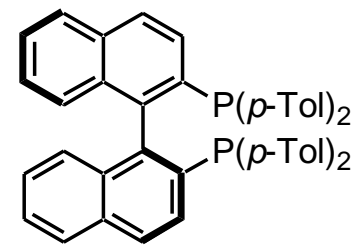

(S)-Tol-BINAP

\begin{tabular}{ccccc}
$\mathrm{R}$ & $\mathrm{Z}$ & Temp. & $\begin{array}{c}\text { Yield } \\
(\%)\end{array}$ & $\begin{array}{c}\text { ee } \\
(\%)\end{array}$ \\
\hline $\mathrm{Ph}$ & $\mathrm{NTs}$ & $60^{\circ} \mathrm{C}$ & 82 & 92 \\
$\mathrm{Ph}$ & $\mathrm{C}\left(\mathrm{CO}_{2} \mathrm{Me}\right)_{2}$ & $60^{\circ} \mathrm{C}$ & 57 & 96 \\
$p-\mathrm{MeOC}_{6} \mathrm{H}_{4}$ & $\mathrm{O}$ & r.t. & 84 & 94
\end{tabular}

Scheme 20. Synthesis of chiral bis(biphenylenyl) derivatives through Rh-catalyzed domino double $[2+2+2]$ cycloaddition reaction.

In addition, the $[2+2+2]$ cycloaddition has been associated to other reaction, such as the Diels-Alder cycloaddition, in enantioselective domino metal-catalyzed reactions. As an example, Tanaka et al. have recently reported an efficient enantioselective domino intermolecular $[2+2+2]$ cycloaddition-intramolecular Diels-Alder cycloaddition reaction occurring between 1,6-diynes 81a-d and amide-linked 1,5-dienes 82a-c bearing two sterically and/or electronically different alkene units. ${ }^{[54]}$ This domino reaction was induced by a cationic rhodium $(\mathrm{I}) /(R)$-Segphos complex and provided the corresponding amides 83a-g in moderate to high yields and excellent enantioselectivities of up to $99 \%$ ee, as shown in Scheme 21. The mechanism of the reaction involved a [2+2+2] cycloaddition between the two substrates, which was induced by the chiral cationic rhodium(I) catalyst, to form the corresponding cyclohexadiene $\mathbf{8 4}$ containing a pendant alkene unit. A subsequent intramolecular Diels-Alder reaction of cyclohexadiene $\mathbf{8 4}$ furnished the final chiral bridged multicyclic product 83, as depicted in Scheme 21. 

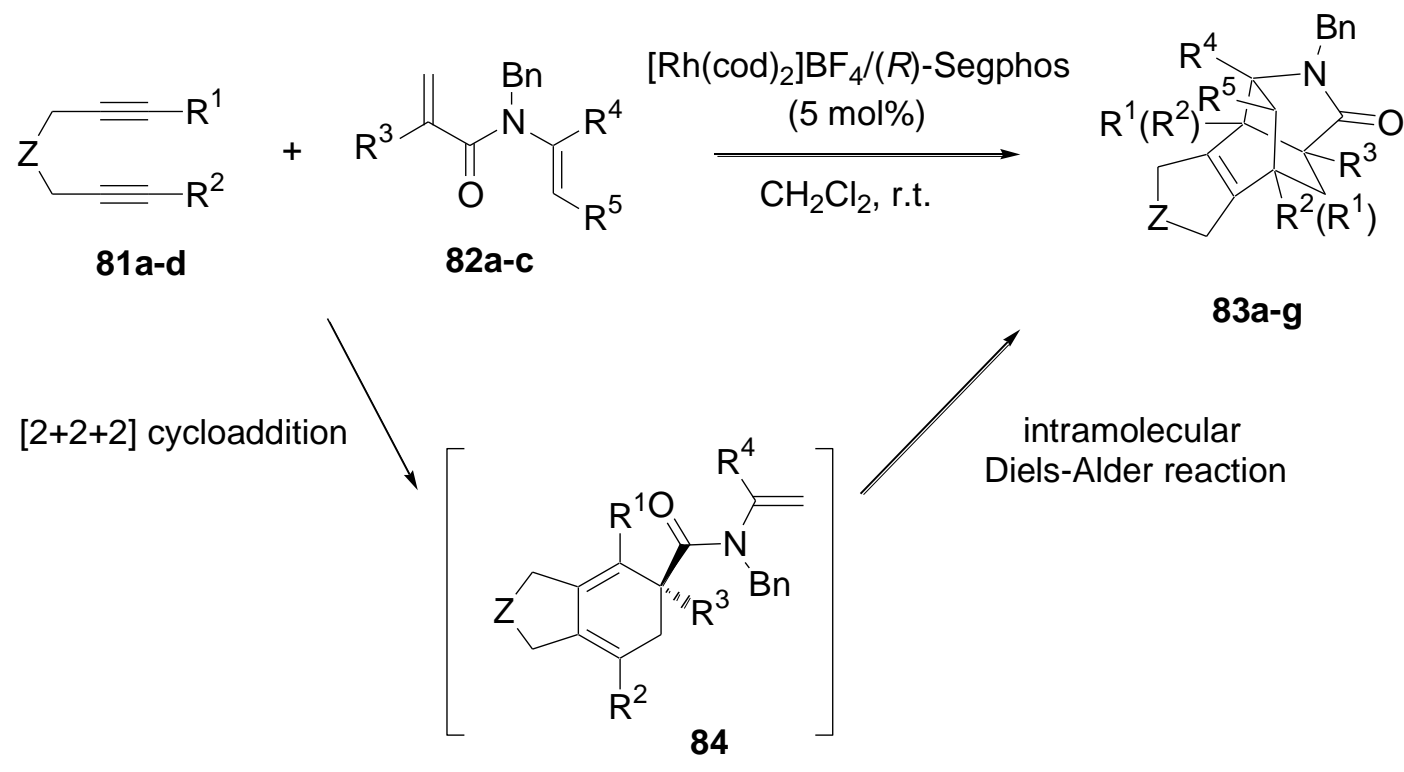

3a-g $\begin{array}{lllllll}R^{1} & R^{2} & R^{3} & R^{4} & R^{5} & Z & \text { Yield }\end{array}$

$(\%)$

(\%)<smiles>PC1=C(c2c(P)ccc3c2OCO3)C2OCOC2C=C1</smiles>

(R)-Segphos

\begin{tabular}{cccccccc}
\hline $\mathrm{Me}$ & $\mathrm{Me}$ & $\mathrm{Me}$ & $\mathrm{Me}$ & $\mathrm{H}$ & $\mathrm{NTs}$ & 96 & 85 \\
$\mathrm{Me}$ & $\mathrm{Me}$ & $\mathrm{Me}$ & $\mathrm{Me}$ & $\mathrm{H}$ & $\mathrm{C}\left(\mathrm{CO}_{2} \mathrm{Bn}\right)_{2}$ & 96 & 90 \\
$\mathrm{Me}$ & $\mathrm{Me}$ & $\mathrm{Me}$ & $\mathrm{Me}$ & $\mathrm{H}$ & $\mathrm{C}(\mathrm{Ac})_{2}$ & 77 & 93 \\
$\mathrm{Me}$ & $\mathrm{Me}$ & $\mathrm{Me}$ & $\mathrm{Me}$ & $\mathrm{H} \mathrm{C}\left(\mathrm{CH}_{2} \mathrm{OMe}\right)_{2}$ & 87 & 94 \\
$\mathrm{Me}$ & $\mathrm{Me}$ & $\mathrm{Me}$ & $\mathrm{Ph}$ & $\mathrm{H}$ & $\mathrm{NTs}$ & 75 & 94 \\
$\mathrm{Me}$ & $\mathrm{Me}$ & $\mathrm{Me}$ & \multicolumn{2}{c}{$-\left(\mathrm{CH}_{2}\right)_{3}-$} & $\mathrm{NTs}$ & 92 & 97 \\
$\mathrm{CO}_{2} \mathrm{Me}$ & $\mathrm{Me}$ & $\mathrm{Me}$ & $\mathrm{Ph}$ & $\mathrm{H}$ & $\mathrm{NTs}$ & 84 & 97
\end{tabular}

Scheme 21. Rh-catalyzed domino intermolecular [2+2+2] cycloaddition-intramolecular Diels-Alder cycloaddition reaction.

\subsection{Domino Reactions initiated by an Allylic Alkylation}

Nitrogen-containing heterocycles, present in a wide number of pharmaceutically interesting compounds, have been usually prepared by palladium-catalyzed asymmetric tandem allylic substitution reaction of allylic acetates, carbonates or halides. Indeed, this reaction also known as the Tsuji-Trost reaction constitutes a powerful procedure for the formation of $\mathrm{C}-\mathrm{C}, \mathrm{C}-\mathrm{O}$, and $\mathrm{C}-\mathrm{N}$ bonds. One of the early impressive examples, where this reaction had been combined with a palladaene reaction, was developed by Oppolzer et al., in 1987. ${ }^{[55]}$ In 1993, Hayashi et al. reported another early work in this area with the palladium-BINAP-catalyzed synthesis of optically active morpholines and piperazines in enantioselectivities of up to $61 \% e e e^{[56]}$ The asymmetric induction of this type of process is controlled during the $\pi$-allyl-palladium intermediate prior to the second nucleophilic attack by the nucleophile. In general, the Tsuji-Trost reaction can be combined with other Pd-catalyzed transformations, such as a Heck reaction or a second Tsuji-Trost reaction. As a recent excellent example, Trost et al. have developed an enantioselective palladium-catalyzed domino double allylic alkylation reaction, which enabled an efficient access to chiral tricyclic pyrrolopiperazinones. ${ }^{[57]}$ As shown in Scheme 22, the reaction of bisallylic carbonate 85 with nucleophile 86, containing both pyrrole and $\mathrm{N}$-methoxyamide, afforded the corresponding piperazinone $\mathbf{8 7}$ in $82 \%$ yield and excellent enantioselectivity of $>97 \%$ ee through a domino double allylic alkylation reaction which was catalyzed by a combination of $\left[\mathrm{Pd}_{2}(\mathrm{dba})_{3}\right] \cdot \mathrm{CHCl}_{3}$ and the standard Trost ligand $(R, R)-\mathrm{L}_{\mathrm{ST}}$ in the presence of acetic acid as an additive. This elegant procedure was applied to a total synthesis of the natural product, (+)-agelastatin $\mathrm{A}$, in five steps starting from piperazinone $\mathbf{8 7}$. 
<smiles>CC(C)(C)O[C@@H]1C=C[C@H](OC(C)(C)C)C1</smiles>

85<smiles>CONC(=O)c1ccc(Br)[nH]1</smiles>

86
$\left[\mathrm{Pd}_{2}(\mathrm{dba})_{3}\right] \cdot \mathrm{CHCl}_{3}$

(5 mol\%)

$(R, R)-\mathrm{L}_{\mathrm{ST}}(15 \mathrm{~mol} \%)$

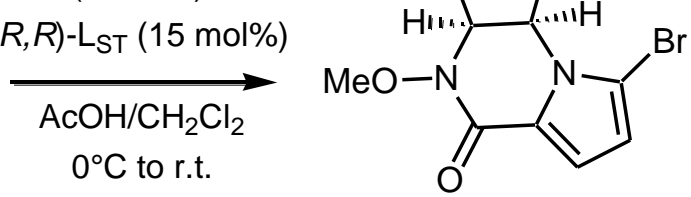

87

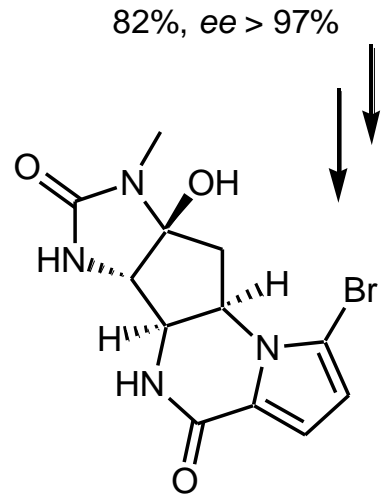

$(+)$-agelastatin $\mathrm{A}$

Scheme 22. Pd-catalyzed domino double allylic alkylation reaction and synthesis of (+)-agelastatin A.

Later, You et al. reported an enantioselective synthesis of 2,3-dihydro- $1 H$-benzo[ $b]$ azepines on the basis of an iridium-catalyzed domino allylic vinylation-amination reaction using chiral phosphoramidite ligand $\mathbf{8 8}{ }^{[58]}$ Indeed, these authors have shown that a combination of this chiral ligand with $[\mathrm{Ir}(\operatorname{cod}) \mathrm{Cl}]_{2}$ could efficiently catalyze the domino allylic vinylation and amination reaction of $(E$ )-but-2-ene-1,4-diyl dimethyl dicarbonate 90 with ortho-amino styrene derivatives 89a-h, affording in the presence of DABCO as a base the corresponding 2,3-dihydro-1- $H$-benzo $[b]$ azepines 91a-h with high yields and enantioselectivities of up to $94 \% e e$, as shown in Scheme 23. In another context, an enantioselective domino reaction including an allylstannylation followed by a Heck reaction was recently reported by Schmalz et al. ${ }^{[59]}$ In this study, these authors have developed an enantioselective access to 3-methylene-1H-indanol through domino allylstannylation-Heck reaction occurring between $o$-iodobenzaldehyde and allyl tributylstannane in the presence of a palladium complex in situ generated from $\left[\mathrm{Pd}_{2} \mathrm{dba}_{3}\right]$ and a Taniaphos chiral ligand. The domino product was produced in $52 \%$ yield and $96 \%$ ee. 


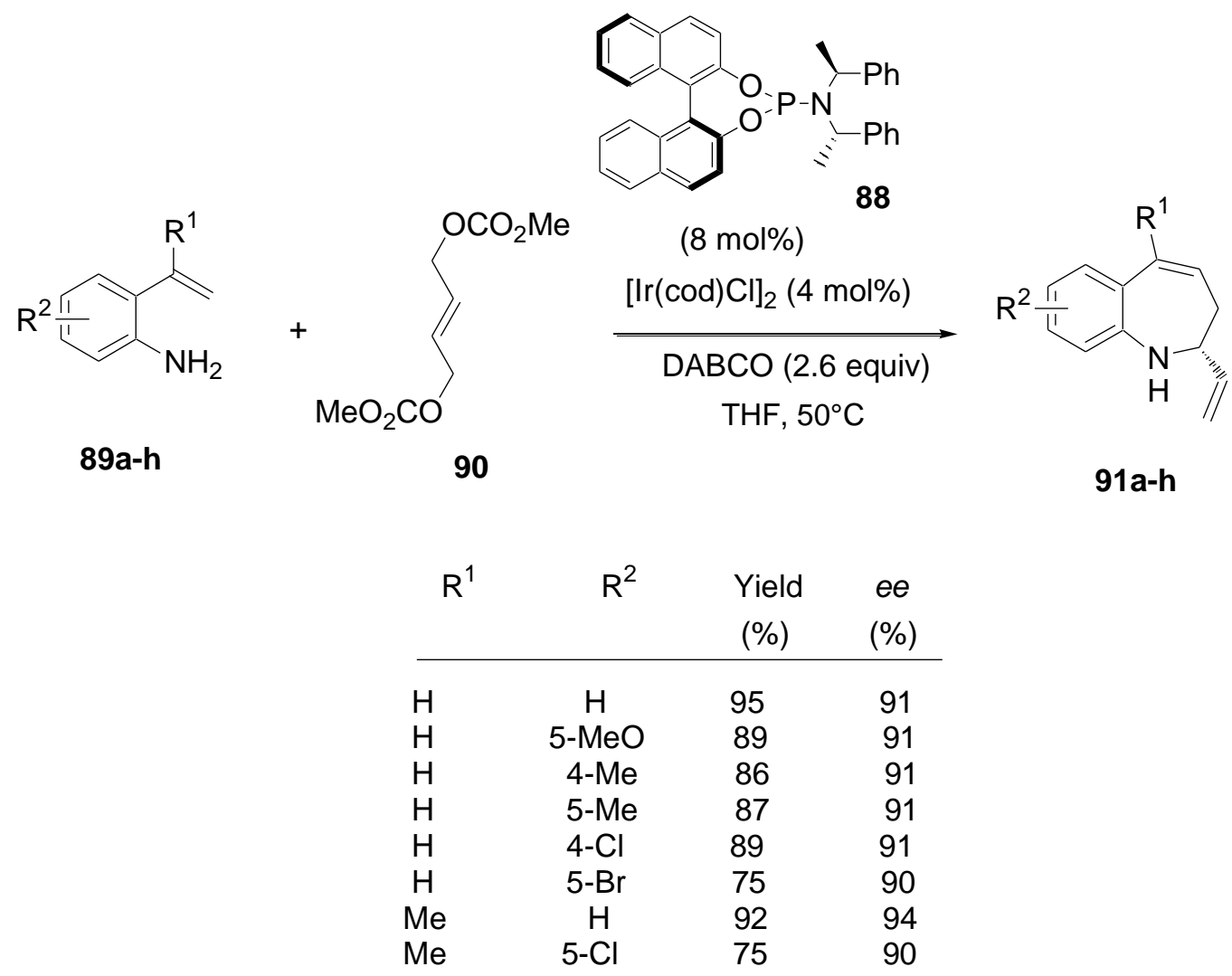

Scheme 23. Ir-catalyzed domino allylic vinylation-amination reaction.

\subsection{Domino Passerini-type Reactions}

The modern concept of domino and multicomponent reactions is intimately related to the reactions developed with isocyanide reagents. ${ }^{[60]}$ The unique ability of isocyanides to serve as $C$-nucleophiles toward imines and aldehydes, resulting in nitrilium ion electrophiles, enables the four-component Ugi reaction and the three-component Passerini reaction, respectively. ${ }^{[61]}$ Despite the strong relationship between domino and multicomponent reactions and isocyanides, there are still few reactions in which the use of isocyanide reagents leads to chiral compounds, and more particularly those which are induced by chiral catalysts. As a recent example, Zhu et al. reported the use of a chiral salen-aluminum(III) complex to induce chirality in a Passerini-type reaction between $\alpha$ isocyanoacetamides and aldehydes to provide the corresponding 2-(1-hydroxyalkyl)-5-aminooxazoles in moderate to good yields $(35-82 \%)$ and enantioselectivities $(54-80 \% e e) .{ }^{[62]}$ The conditions were applicable to both aliphatic and aromatic aldehydes, and in general, the enantioselectivity was higher for aliphatic than for aromatic ones. Two years later, the same authors have developed similar reactions in the presence of a mixture of $\mathrm{Et}_{2} \mathrm{AlCl}$ in combination with a chiral phosphoric acid. A series of 2-(1-hydroxyalkyl)-5-aminooxazoles were produced from the reaction of the corresponding $\alpha$-isocyanoacetamidates and aldehydes in comparable yields and enantioselectivities of up to $91 \%$ $e e{ }^{[63]}$ In addition, Shibasaki et al. have selected the $\alpha$-addition of $\alpha$-isocyanoacetamides 92a-c to aldehydes as a model reaction to investigate the efficiency of bimetallic Schiff base catalysts. ${ }^{[64]}$ When the new heterobimetallic, $\mathrm{Ga}(\mathrm{O} i \text { - } \mathrm{Pr})_{3} / \mathrm{Yb}(\mathrm{OTf})_{3} / o$-vanillin-derived Schiff base 93 complex, was used for catalytic asymmetric addition of $\alpha$-isocyanoacetamides to a range of aryl, heteroaryl, alkenyl, as well as alkyl aldehydes, the corresponding domino products 94a-h were achieved in general high yields and excellent enantioselectivities of up to $98 \%$ ee, as shown in Scheme 24. In this study, the authors have demonstrated that the chiral diamine backbone affected both the reactivity and enantioselectivity of the reaction. For example, Schiff bases bearing a binaphthyl diamine unit gave unsatisfactory results. 


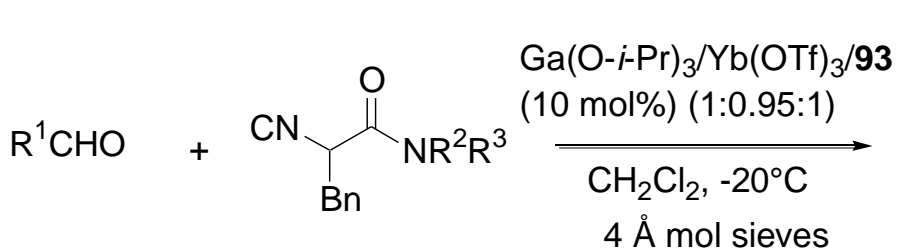

92a-c<smiles>[R]C(O)c1nc(Br)c(N=[Pt])o1</smiles>

94a-h

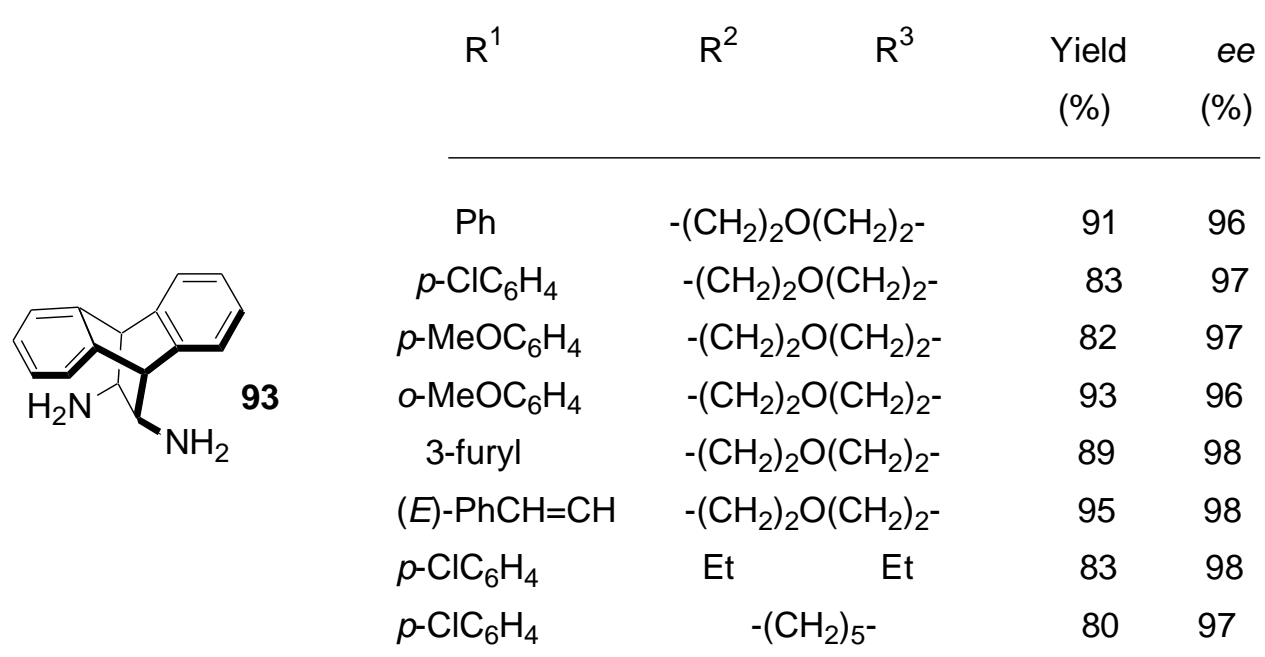

Scheme 24. Ga- and Yb-catalyzed-domino Passerini-type reaction.

\subsection{Domino Carbonyl Ylide formation-1,3-Dipolar Cycloaddition Reactions}

Catalytic methods encompassing metal carbene intermediates constitute a vast array of transformations that offer the synthetic chemist great scope in the synthesis of many complex molecules. ${ }^{[65]}$ Of these processes, the catalytic domino carbonyl ylide formation-1,3-dipolar cycloaddition offers an elegant route to highly substituted oxygen-containing heterocycles. ${ }^{[65 b, 66]}$ This powerful methodology has been extensively advanced by the Padwa group, in particular. ${ }^{[65 c, 67]}$ The development of a catalytic enantioselective version of this domino reaction has become a challenging objective. The primary work in this area was reported by Hodgson et al. in 1997, dealing with intramolecular enantioselective catalytic domino carbonyl-ylide formation-cyclization reactions of $\alpha$-diazo- $\beta$-ketoesters in enantioselectivities of up to $53 \%$ ee by using Davies'prolinate catalyst, $\mathrm{Rh}_{2}((S)-\mathrm{DOSP})_{4}{ }^{[68]}$ Ever since, the formation of keto carbenoids by treatment of diazo keto compounds with rhodium(II) salts has been broadly employed in enantioselective domino processes as the primary step. This is then followed by the generation of a 1,3-dipole through an intramolecular cyclization of the keto carbenoid onto an oxygen atom of a neighboring keto group and an inter- or intramolecular 1,3-dipolar cycloaddition. More recently, Hashimoto et al. have reported the use of chiral dirhodium(II) tetrakis[ $N$-benzene-fused-phthaloyl- $(S)$-valinate, $\mathrm{Rh}_{2}(S \text {-BPTV })_{4}$, to promote the enantioselective domino carbonyl ylide formation-1,3-dipolar cycloaddition reaction of a range of $\alpha$-diazo ketones 95a-i with various aromatic aldehydes 96a-g, affording the corresponding bicyclic cycloadducts 97a-n in good yields and enantioselectivities of up to $92 \%$ ee for the exo-diastereomer which was diastereoselectively generated as a single product in almost all the cases of substrates studied, as shown in Scheme $25 .{ }^{[69]}$ On the other hand, it must be noted that the use of aliphatic aldehydes gave disappointingly complex mixtures of products. This methodology was applied to the construction of the exo-7-aryl-6,8-dioxabicyclo[3.2.1] octane framework $\left(\mathrm{R}^{1}=i\right.$ - $\left.\mathrm{Pr}, \mathrm{R}^{2}=\mathrm{H}, \mathrm{R}^{3}=\mathrm{OH}, \mathrm{n}=1\right)$ of natural products, psoracorylifols $\mathrm{B}$ and $\mathrm{C}$, exhibiting significant inhibitor activity against Helicobacter pylori. 

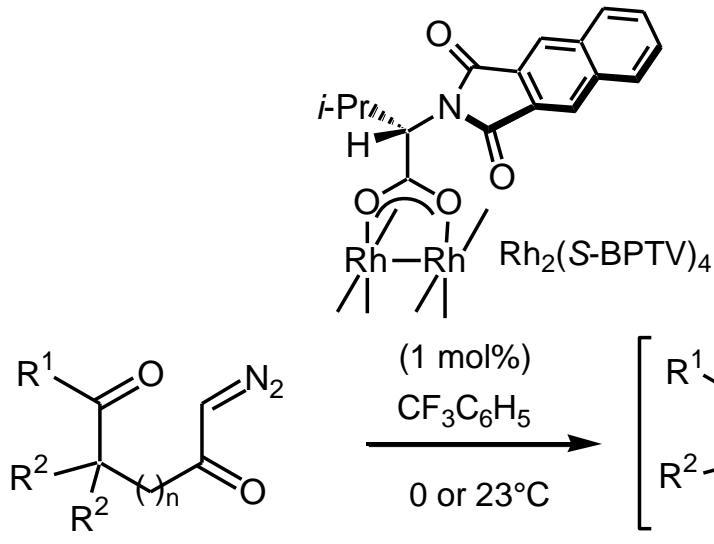

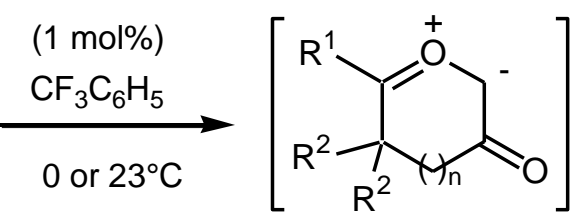

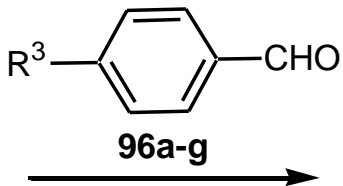

95a-i<smiles>[R]c1ccc([C@@H]2OC3([R])O[C@H]2C(=O)[C@@H]3[R7])cc1</smiles><smiles>[R9]c1ccc([C@@H]2OC3([R])OC2C(=O)[C@H]3[R7])cc1</smiles>

97a-n

\begin{tabular}{rrrrrr}
$R^{1}$ & $R^{2}$ & $n$ & Yield & de & ee \\
& & $(\%)$ & $(\%)$ & $(\%)$ \\
\hline
\end{tabular}

\begin{tabular}{ccccccc}
\hline $\mathrm{Ph}$ & $\mathrm{H}$ & $\mathrm{NO}_{2}$ & 1 & 71 & 100 & 92 \\
$\mathrm{Ph}$ & $\mathrm{H}$ & $\mathrm{CF}_{3}$ & 1 & 69 & 100 & 91 \\
$\mathrm{Ph}$ & $\mathrm{H}$ & $\mathrm{Cl}$ & 1 & 68 & 100 & 88 \\
$p-\mathrm{MeOC}_{6} \mathrm{H}_{4}$ & $\mathrm{H}$ & $\mathrm{NO}_{2}$ & 1 & 74 & 100 & 89 \\
$p-\mathrm{Tol}$ & $\mathrm{H}$ & $\mathrm{NO}_{2}$ & 1 & 60 & 100 & 88 \\
$p-\mathrm{ClC}_{6} \mathrm{H}_{4}$ & $\mathrm{H}$ & $\mathrm{NO}_{2}$ & 1 & 80 & 100 & 89 \\
$p-\mathrm{CF}_{3} \mathrm{C}_{6} \mathrm{H}_{4}$ & $\mathrm{H}$ & $\mathrm{NO}_{2}$ & 1 & 67 & 100 & 88 \\
$\mathrm{Me}$ & $\mathrm{H}$ & $\mathrm{NO}_{2}$ & 1 & 14 & 100 & 19 \\
$\mathrm{Me}$ & $\mathrm{Me}$ & $\mathrm{NO}_{2}$ & 0 & 74 & 100 & 12 \\
$\mathrm{Ph}$ & $\mathrm{H}$ & $\mathrm{NO}_{2}$ & 2 & 60 & 100 & 79 \\
$i-\mathrm{Pr}$ & $\mathrm{H}$ & $\mathrm{OAc}$ & 1 & 63 & 88 & 77 \\
$i-\mathrm{Pr}$ & $\mathrm{H}$ & $\mathrm{OMe}$ & 1 & 57 & 88 & 87 \\
$i-\mathrm{Pr}$ & $\mathrm{H}$ & $\mathrm{OMOM}$ & 1 & 60 & 88 & 87 \\
$i-\mathrm{Pr}$ & $\mathrm{H}$ & $\mathrm{OBn}$ & 1 & 64 & 90 & 86
\end{tabular}

Scheme 25. Rh-catalyzed domino carbonyl-ylide formation-1,3-dipolar cycloaddition reaction of $\alpha$-diazo ketones with aromatic aldehydes.

In addition, these authors have found that dirhodium(II) tetrakis[ $N$-tetrachlorophthaloyl-( $S)$-tertleucinate], $\mathrm{Rh}_{2}(S \text {-TCPTTL })_{4}$, was an exceptionally effective catalyst for the enantioselective domino carbonyl ylide formation-1,3-dipolar cycloaddition reaction of 2-diazo-3,6-diketoesters 98a-d with arylacetylenes and alkoxyacetylenes 99a-e, providing the corresponding cycloadducts 100a-h in good to high yields and enantioselectivities of up to $98 \%$ ee, as shown in Scheme $26{ }^{[70]}$ Furthermore, the scope of this methodology could be extended to other dipolarophiles, such as styrenes 101a-e, which provided by reaction with 2-diazo-3,6-diketoesters 98a-b the corresponding cycloadducts 102a-f with 
a complete exo/endo diastereocontrol combined with high yields and excellent enantioselectivities of up to $99 \%$ ee, as shown in Scheme 26.

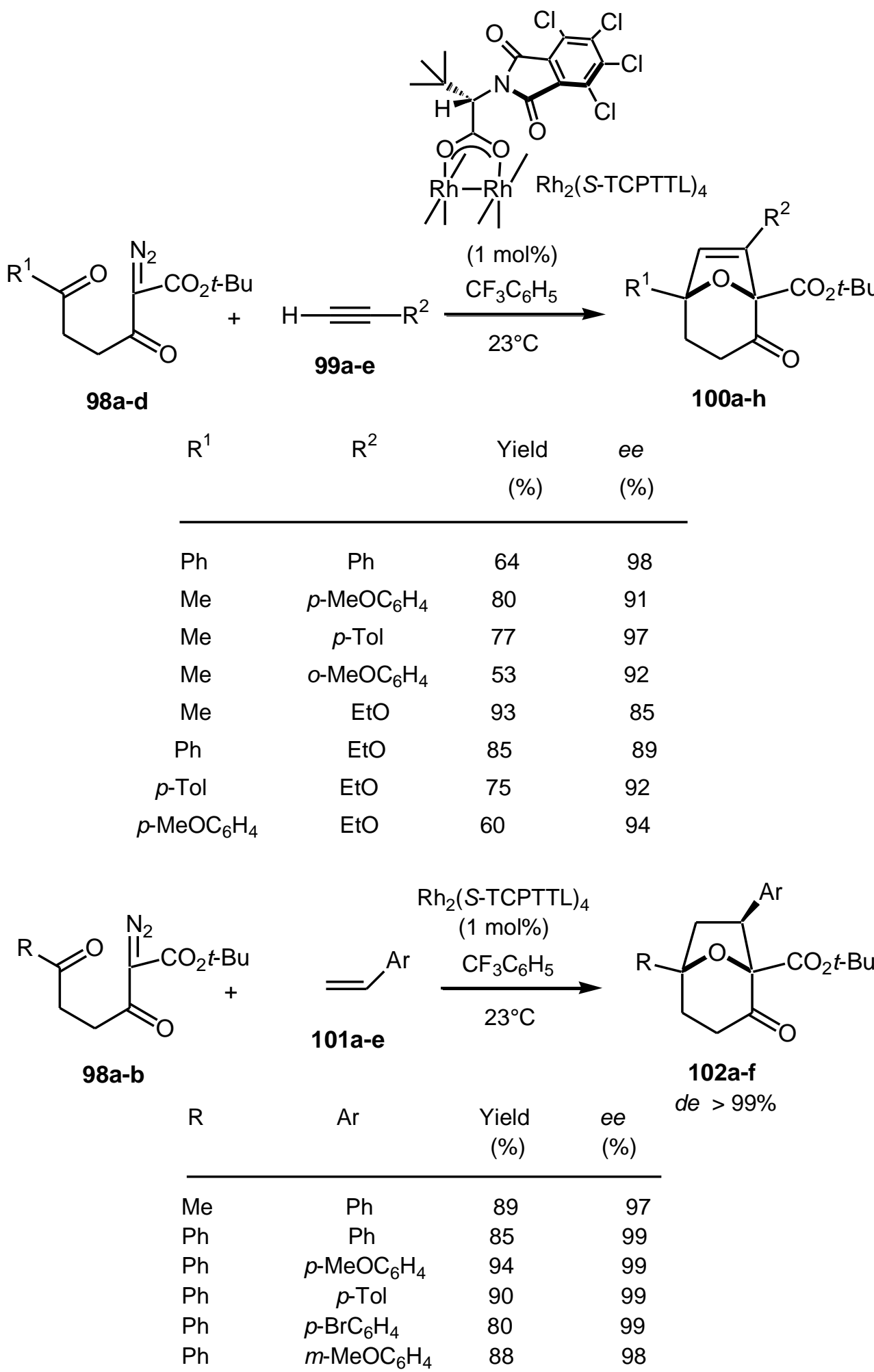

Scheme 26. Rh-catalyzed domino carbonyl-ylide formation-1,3-dipolar cycloaddition reactions of 2-diazo-3,6diketoesters with aryl- and alkoxyacetylenes and styrenes.

Another extension of this methodology was the enantioselective reaction of the formyl-derived carbonyl ylide generated from diazo compound 103 with 4-hydroxy-3-methoxyphenylacetylene 104, which provided upon catalysis with $\mathrm{Rh}_{2}(S \text {-TCPTTL })_{4}$ the corresponding domino cycloadduct $\mathbf{1 0 5}$ in $73 \%$ yield and $95 \% e e .^{[71]}$ This product could be converted into natural product, endo-6-aryl-8- 
oxabicyclo[3.2.1] oct-3-en-2-one, as shown in Scheme 27. In addition, another natural and biologically active product, descurainin, was achieved on the basis of the same domino reaction albeit catalyzed with $\mathrm{Rh}_{2}(R \text {-TCPTTL })_{4} \cdot{ }^{\left[{ }^{[2]}\right.}$ Indeed, by using the $(R)$-enantiomer of the same dirhodium(II) catalyst, the corresponding cycloadduct ent-105 was obtained in 77\% yield and 95\% ee, as shown in Scheme 27. This product was further converted into expected descurainin in 10 steps.<smiles>COc1cc([C@@H]2CC3OC2(CO)C=CC3=O)ccc1O</smiles>

natural product

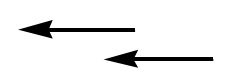

$\mathrm{Rh}_{2}(S-\mathrm{TCPTTL})_{4}$

(1 $\mathrm{mol} \%)$<smiles>COc1cc(C2=C[C@H]3CCC(=O)[C@@]2(C(=O)OC(C)(C)C)O3)ccc1O</smiles>

$73 \%$, ee $=95 \%$<smiles>N#CC(=O)C(=O)CCC=O</smiles>

103<smiles>C#Cc1ccc(O)c(OC)c1</smiles><smiles>COc1cc(C2C[C@@H]3O[C@]2(CO)C=CC3=O)cc(OC)c1O</smiles>

descurainin

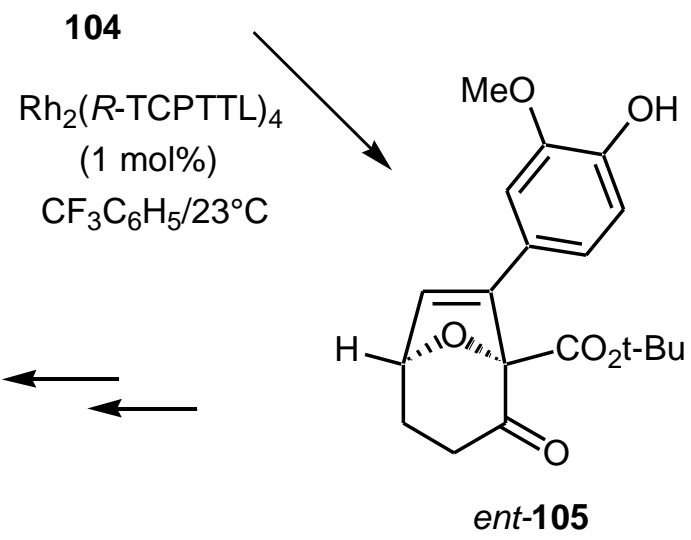

$77 \%$, ee $=95 \%$

Scheme 27. Rh-catalyzed domino carbonyl-ylide formation-1,3-dipolar cycloaddition reaction of 2-diazo-5formyl-3-ketoester with 4-hydroxy-3-methoxyphenylacetylene and synthesis of natural products.

In 2011, catalyst $\mathrm{Rh}_{2}(S \text {-TCPTTL })_{4}$ was also employed by the same authors to induce the first enantioselective intermolecular cycloaddition of carbonyl ylides with another type of dipolarophiles, such as indoles. ${ }^{[73]}$ Thus, the domino reaction of 2-diazo-3,6-diketoesters 108a-b with a series of $N$ methylindoles 106a-f led to the corresponding tetracyclic cycloadducts 107a-f in both high yields and enantioselectivities of up to $99 \% e e$, as well as excellent exo-diastereoselectivity of $>98 \% d e$, as shown in Scheme 28. In the same context, these authors have described the first example of asymmetric induction (up to $66 \% e e$ ) in an intramolecular 1,3-dipolar cycloaddition of carbonyl ylides in situ generated from the diazo decomposition of indolyl-substituted 2-diazo-5-imido-3-ketoesters under the influence of $\mathrm{Rh}_{2}(S \text {-TCPTTL })_{4}$ This reaction constituted an elegant approach to the pentacyclic skeleton of Aspidosperma alkaloids. ${ }^{[74]}$ In addition, Hodgson et al. investigated the enantioselective intramolecular domino carbonyl ylide formation-1,3-dipolar cycloaddition reaction employing sulfonyl functionality as a different type of electron-withdrawing group at the ylidic carbon, specifically using unsaturated $\alpha$-diazo- $\beta, \varepsilon$-diketo sulfones. ${ }^{[75]}$ Among a series of chiral catalysts tested, chiral dirhodium(II) tetrakis[ $N$-benzene-fused-phthaloyl-( $S)$-valinate], $\operatorname{Rh}_{2}(S \text {-BPTV })_{4}$, 
provided the best albeit moderate enantioselectivity of $43 \%$ ee for the cycloadduct derived from phenyl sulfone along with $75 \%$ yield.<smiles>[R16]C(=O)CCC(=O)C(=N)C(=O)OCC</smiles>

106a-f

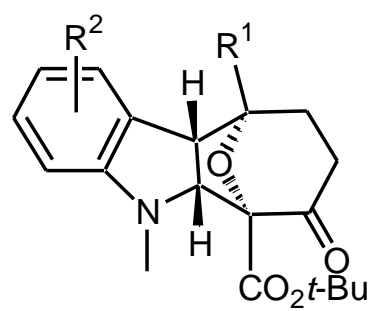

$107 a-f$

de $>98 \%$

\begin{tabular}{cccc}
$\mathrm{R}^{1}$ & $\mathrm{R}^{2}$ & $\begin{array}{c}\text { Yield } \\
(\%)\end{array}$ & $\begin{array}{l}\text { ee } \\
(\%)\end{array}$ \\
\hline $\mathrm{Ph}$ & $\mathrm{H}$ & 83 & 97 \\
$\mathrm{Me}$ & $5-\mathrm{MeO}$ & 86 & 97 \\
$\mathrm{Me}$ & $5-\mathrm{Me}$ & 80 & 97 \\
$\mathrm{Me}$ & $5-\mathrm{Br}$ & 76 & 99 \\
$\mathrm{Me}$ & $4-\mathrm{Me}$ & 85 & 95 \\
$\mathrm{Me}$ & $7-\mathrm{Me}$ & 84 & 94
\end{tabular}

Scheme 28. Rh-catalyzed domino carbonyl-ylide formation-1,3-dipolar cycloaddition reaction of 2-diazo-3,6diketoesters with indoles.

Chiral catalysts of metals other than rhodium, such as nickel and silver, and chiral catalysts of ytterbium have also been employed to induce enantioselective domino carbonyl-ylide formation-1,3dipolar cycloaddition reactions. For example, Suga et al. have reported 1,3-dipolar cycloaddition reactions of carbonyl ylides in situ generated from $o$-( $p$-bromobenzyloxy)carbonyl- $\alpha-$ diazoacetophenones and 3-crotonoyl-2-oxazolidinones by using a combination of a chiral Pybox ligand with $\mathrm{Yb}(\mathrm{OTf})_{3}$ as the chiral Lewis acid catalyst. ${ }^{[76]}$ Indeed, the reaction of $\alpha$-diazoacetophenone derivative wih a 3-crotonoyl-2-oxazolidinone derivative afforded the corresponding endo-cycloadduct as a sole product with a diastereoselectivity $>98 \% d e$ and with extremely high enantioselectivity of $96 \%$ ee. In contrast, $o$-(methylbenzyloxy)carbonyl- $\alpha$-diazoacetophenone reacted more slowly with 3crotonoyl-2-oxazolidinones to give the corresponding domino products with moderate enantioselectivities $(\leq 78 \% e e)$. On the other hand, Suga et al. have developed the first successful example of reverse-electron-demand dipole-LUMO/dipolarophile-HOMO controlled cycloaddition reactions between carbonyl ylides, which were in situ generated from o-methoxycarbonyl- $\alpha$ diazoacetophenone and their acyl derivatives in the presence of $\mathrm{Rh}_{2}(\mathrm{OAc})_{4}$, and vinyl ether derivatives activated by chiral Lewis acids. ${ }^{[77]}$ As shown in Scheme 29, when cyclohexyl vinyl ether was activated by $(R)$-BINIM-4Me-2QN-Ni(II) complex chiral Lewis acids, it reacted with $\alpha, \alpha^{\prime}$-dicarbonyl diazo compounds 108a-h to yield the corresponding endo-cycloadducts 109a-h in high yields, complete diastereoselectivity and high enantioselectivities of up to $97 \%$ ee. 


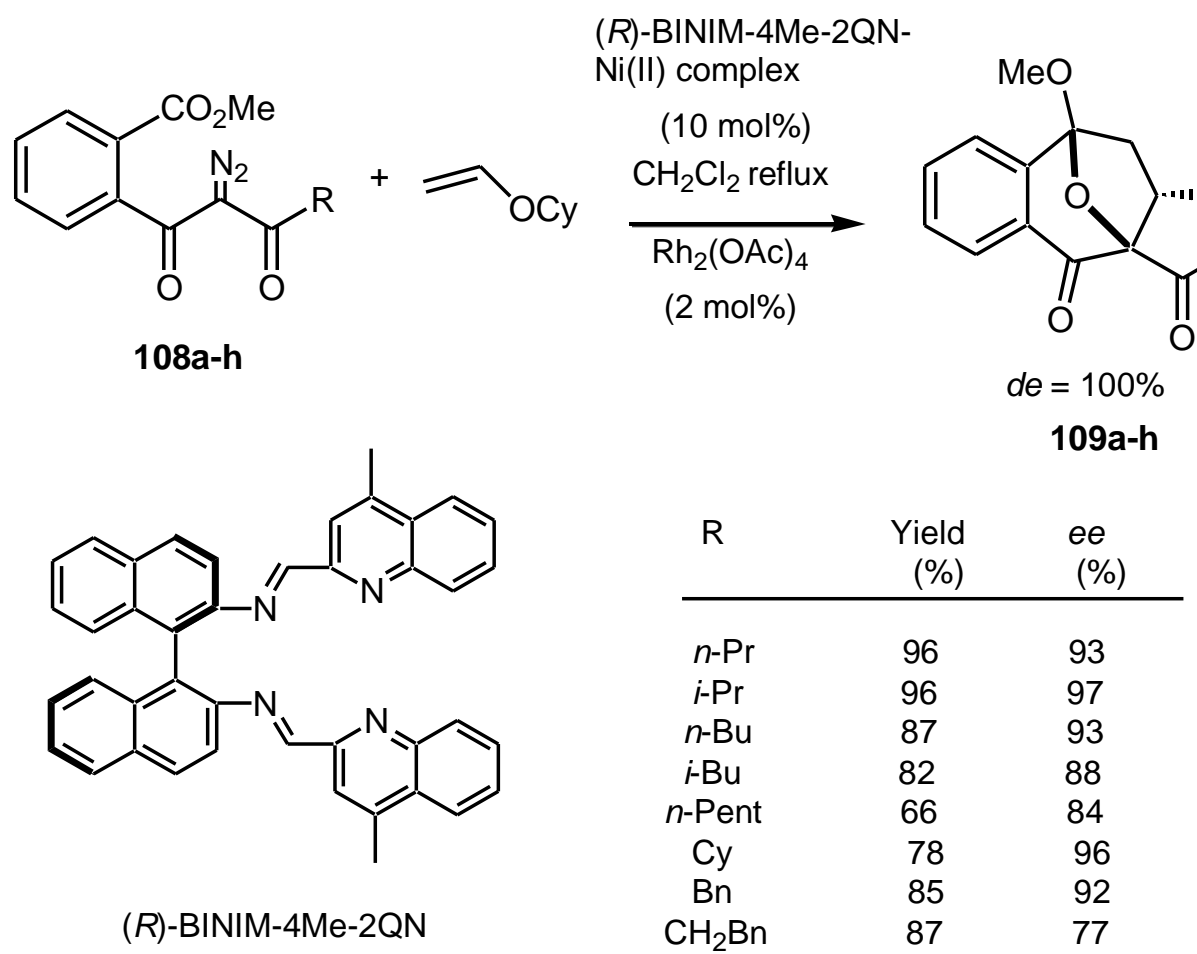

Scheme 29. Ni-catalyzed domino carbonyl-ylide formation-1,3-dipolar cycloaddition reaction of $\alpha, \alpha$ 'dicarbonyl diazo compounds and cyclohexyl vinyl ether.

Finally, Dias et al. have reported a highly efficient silver-catalyzed enantioselective domino carbonylylide formation-1,3-dipolar cycloaddition reaction of arylideneiminoglycinates 110a-e with maleimides 111a-c. ${ }^{[78]}$ The process, performed in toluene in the presence of a catalytic amount of TEA, and employing a $5 \mathrm{~mol} \%$ of an equimolecular mixture of $(S)$-BINAP and $\mathrm{AgSbF}_{6}$, led highly stereoselectively to the corresponding endo cycloadducts 112a-h in high yields, excellent general diastereoselectivity of $>96 \% d e$, and enantioselectivity of $>99 \% e e$ in almost all the cases of substrates studied, as shown in Scheme 30. It must be noted that, however, acrylates, maleates, and fumarates were found to be not suitable dipolarophiles for the process, whereas good results were observed by using (E)-1,2-bis(phenylsulfonyl)ethylene as dipolarophile. Indeed, the corresponding endo cycloadducts were generated under the same conditions in high yields (80-91\%), general diastereoselectivity of $>96 \%$ de, and good to high enantioselectivities $(88-92 \% e e)$. 

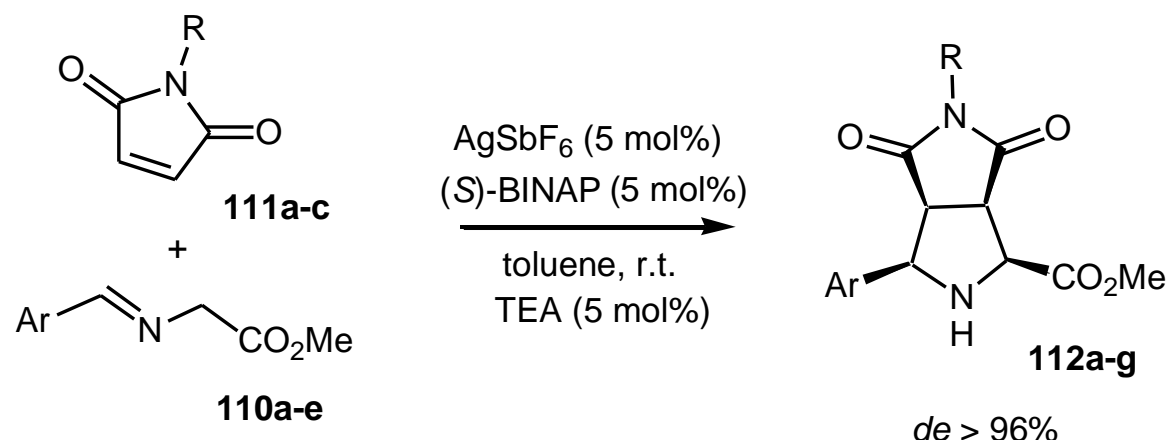

de $>96 \%$

\begin{tabular}{cccc}
$\mathrm{Ar}$ & $\mathrm{R}$ & $\begin{array}{c}\text { Yield } \\
(\%)\end{array}$ & $\begin{array}{c}\text { ee } \\
(\%)\end{array}$ \\
\hline $\mathrm{Ph}$ & $\mathrm{Me}$ & 90 & $>99$ \\
o-Tol & $\mathrm{Me}$ & 85 & $>99$ \\
o- $\mathrm{ClC}_{6} \mathrm{H}_{4}$ & $\mathrm{Me}$ & 82 & $>99$ \\
$p-\mathrm{Tol}^{2}$ & $\mathrm{Me}$ & 85 & 99 \\
$\mathrm{P}-\mathrm{MeOC}{ }_{6} \mathrm{H}_{4}$ & $\mathrm{Me}$ & 85 & 99 \\
$\mathrm{Ph}$ & $\mathrm{Et}$ & 84 & 99 \\
$\mathrm{Ph}$ & $\mathrm{Ph}$ & 86 & 82
\end{tabular}

Scheme 30. Ag-catalyzed domino carbonyl-ylide formation-1,3-dipolar cycloaddition reaction of arylideneiminoglycinates with maleimides.

\subsection{Domino Reactions initiated by the Heck Reaction}

The Heck reaction is an important way to couple aryl and vinyl systems in the presence of palladium, ${ }^{[79]}$ and has been recently exploited as key step of many total syntheses of natural products. ${ }^{[80]}$ Furthermore, it forms the keystone of a number of domino reactions. ${ }^{[81]}$ In 1989, Overman et al. highlighted the feasibility of applying the asymmetric intramolecular Heck reaction to domino cyclization of polyenes as a route to fashion quaternary chiral spirocyclic centers from trienyl triflates. ${ }^{[82]}$ Following this seminal work, there have been many publications dealing with the application of the tandem Heck reaction, and the inclusion of the Heck reaction as a single step in asymmetric palladium-catalyzed domino processes. ${ }^{[2]}$ In 1996 , Keay et al. reported the synthesis of (+)-xestoquinone by the palladium-catalyzed asymmetric domino Heck coupling ${ }^{[83]}$ On the other hand, sequences of intramolecular Heck reaction-anion capture have met with great success in the synthesis of structurally diverse heterocycles and spirocycles. ${ }^{[84]}$ In addition to a variety of nucleophiles employed to trap the stable $\sigma$-alkylpalladium complex, such as organoboronic acids, organotin derivatives, enolates, and $\pi$ nucleophiles, cyanide has rarely been used as a terminating agent in such processes. As a recent example, Zhu et al. have reported an efficient synthesis of enantiomerically enriched 3-substituted-3-cyanomethyl-2-oxindoles 113a-c based on an enantioselective palladium-catalyzed domino intramolecular Heck-cyanation employing potassium ferro(II)cyanide, $\mathrm{K}_{4}\left[\mathrm{Fe}(\mathrm{CN})_{6}\right]$, as a trapping agent for the $\sigma$-alkylpalladium intermediate. ${ }^{[85]}$ As shown in Scheme 31, reaction of ortho-iodoanilidines 114a-c with potassium ferro(II)cyanide as a cyanide donor in DMF in the presence of potassium carbonate as a base, silver phosphate $\left(\mathrm{Ag}_{3} \mathrm{PO}_{4}\right)$ as an additive, and a combination of bis(dibenzylideneacetone)palladium, [Pd( $\left.\mathrm{dba})_{2}\right]$, and $(S)$ DIFLUORPHOS as a chiral catalyst, afforded the corresponding chiral oxindoles 113a-c in moderate to good yields and enantioselectivities of up to $79 \%$ ee. The authors have demonstrated that the enantioselectivity of the domino process was very sensitive to the ligand structure by investigating a series of other chiral ligands, such as $(R)$-BINAP, $(R)$-Tol-BINAP, $(R)$-SYNPHOS, $(R)$-DIOP, $(R, S)$ JOSIPHOS, $(S)$-Cl-MeO-BIPHEP and $(R)$ - $\mathrm{C}_{3}$-TUNEPHOS. Among all the tested ligands, $(S)$ DIFLUORPHOS proved to be the most effective. The authors have proposed a possible reaction path which is depicted in Scheme 31. The oxidative addition of aryl iodide 114 to a Pd(0) species generated in situ led to intermediate 115, which underwent a 5-exo-trig cyclization to afford the $\sigma$ alkylpalladium complex 116. Displacement of the iodide by cyanide afforded palladium complex 117, 
which upon reductive elimination produced the desired oxindole 113 with the concurrent regeneration of the $\mathrm{Pd}^{0}$ species. This novel methodology was applied to a concise total synthesis of esermethole and physostigmine, which are powerful inhibitors of acetyl- and butyryl-cholinesterase.

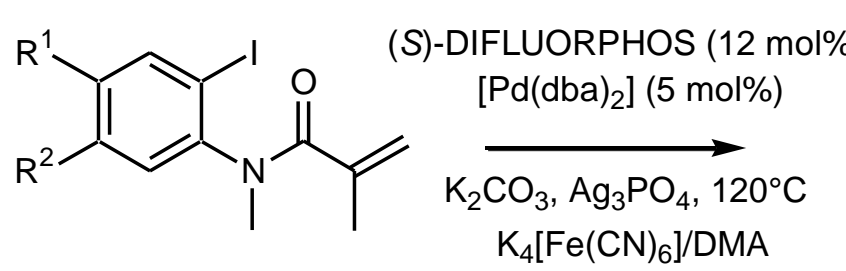

$114 a-c$<smiles>[R]c1cc2c(cc1[R][H])[C@@](C)(CC#N)C(=O)N2C</smiles>

$113 a-c$

$\mathrm{R}^{1}=\mathrm{MeO}, \mathrm{R}^{2}=\mathrm{H}: 78 \%, e e=72 \%$

$R^{1}=R^{2}=H: 54 \%$, ee $=61 \%$

$\mathrm{R}^{1}, \mathrm{R}^{2}=(\mathrm{CH}=\mathrm{CH})_{2}: 55 \%$, ee $=79 \%$<smiles>FC1(F)Oc2ccc(-c3ccccc3)c(-c3c(-c4ccccc4)ccc4c3OC(F)(F)O4)c2O1</smiles>

(S)-DIFLUORPHOS

proposed mechanism:<smiles>[R7]c1cc2c(cc1[R])[C@@](C)(CC#N)C(=O)N2CCC(C)C</smiles>

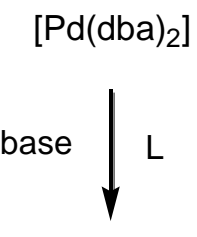

$\mathrm{Pd}^{0} \mathrm{~L}_{\mathrm{n}}$<smiles>CCC(C)CC</smiles><smiles>[R7]c1cc([R17])c(N(C)C(=O)C(=C)C)cc1[R]</smiles>

115

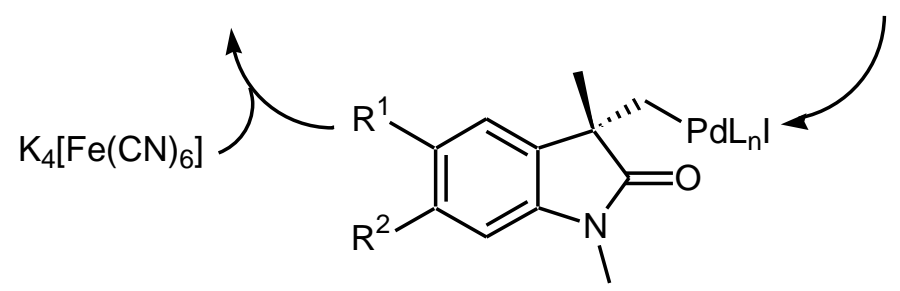

116

Scheme 31. Domino Heck-cyanation reaction. 
In 2006, Keath et al. investigated a series of chiral ligands derived from BINAP to induce chirality in the palladium-catalyzed domino Heck-cyclization reaction of aryl triflate 118, which provided the corresponding tetracyclic product $119 .{ }^{[86]}$ When the reaction was carried out in toluene at $105^{\circ} \mathrm{C}$ upon catalysis with a combination of $\mathrm{Pd}_{2}(\mathrm{dba})_{3}$ and $(S)-3,3^{\prime}$-di-O $i$-Pr-BINAP as a catalyst and in the presence of 1,2,2,6,6-pentamethylpiperidine (PMP) as a base, cyclized product $(R)-\mathbf{1 1 9}$ was generated as major enantiomer with $93 \%$ yield and moderate enantioselectivity of $74 \%$ ee. Surprisingly, the employment of $(S)$-BINAP as a ligand provided approximatively the same enantioselectivity and yield $(e e=72 \%$, yield $=88 \%)$ for product 119 , albeit with the opposite configuration $(S)$. More recently, the same authors have demonstrated that the enantioselectivity of this reaction could be dramatically enhanced by using an electron-deficient ligand, such as $(R)$-DIFLUORPHOS, and by using ethanol rather than toluene as the solvent. ${ }^{[87]}$ As shown in Scheme 32, either the use of oil bath or microwave for the reaction performed in ethanol gave rise to expected product $(R)$-119 with excellent enantioselectivity ranging from 94 to $>99 \% e e$. The authors have proposed possible reasons for the observed results that use of both electron-deficient ligands and ethanol gave higher enantioselectivities due to the ligand and ethanol stabilizing the cationic intermediate $\mathbf{1 2 0}$ formed after oxidative addition thereby slowing the rate of cyclization onto the first olefin to form intermediate 121. Furthermore, it must be noted that the time to completion was reduced significantly using microwave irradiation.<smiles></smiles><smiles>C=Cc1coc(C(=O)c2ccccc2P(C)P2CC[C@H](C)CP2CC)c1C</smiles>

120
(R)-DIFLUORPHOS (20 mol\%) $\mathrm{Pd}_{2}(\mathrm{dba})_{3}(5 \mathrm{~mol} \%)$

PMP (5 equiv), solvent, $110^{\circ} \mathrm{C}$ MWI<smiles>C[C@]12CC=Cc3coc(c31)C(=O)c1ccccc12</smiles>

119

in toluene: $76 \%$ ee $=94 \%$

in $\mathrm{EtOH}: 3 \%$ ee > $99 \%$<smiles>CC=Cc1coc2c1C(C)(C[Pb]P(CC)CC)c1ccccc1C2=O</smiles><smiles>FC1(F)Oc2ccc(-c3ccccc3)c(-c3c(-c4ccccc4)ccc4c3OC(F)(F)O4)c2O1</smiles>

(R)-DIFLUORPHOS

Scheme 32. Domino Heck-cyclization reaction.

\subsection{Domino Reactions initiated by the Wacker Reaction}


The most important reaction based on Pd(II)-catalysis is the Wacker reaction, ${ }^{[88]}$ which is employed industrially for the synthesis of acetaldehyde starting from ethene. In 2005, the Wacker reaction was combined by Tietze et al. with a Heck reaction in an enantioselective domino process. ${ }^{[89]}$ This highly efficient methodology was later used by the same authors as key step in a novel total synthesis of vitamin E ${ }^{[90]}$ Indeed, this process allowed the formation of part of the chiral chroman framework, and the concurrent introduction of part of the side chain of this natural product. The reaction comprised the enantioselective Wacker cyclization of benzyl-protected phenol 122 and methyl vinyl ketone $\mathbf{1 2 3}$ performed in dichloromethane in the presence of catalytic amounts of $\operatorname{Pd}(\mathrm{TFA})_{2}$, the chiral ligand $(S, S)$-Bn-BOXAX, and $p$-benzoquinone as a reoxidant, affording the corresponding chiral chroman 124 in 84\% yield and an excellent enantioselectivity of $97 \%$ ee, as shown in Scheme 33. The authors assumed that the first step of the domino reaction, the chiral catalyst generated from $\mathrm{Pd}(\mathrm{TFA})_{2}$ and the chiral ligand, coordinated enantiofacially to the aliphatic double bond in 122 (Scheme 33). Oxypalladation provided the enantioselective formation of palladated chroman 125 with the correct absolute configuration at $\mathrm{C}-2$ relative to $\alpha$-tocopherol. Because $\beta$-hydride elimination was not possible, an intermolecular reaction with methyl vinyl ketone $\mathbf{1 2 3}$ to form intermediate $\mathbf{1 2 6}$ occurred, which could now undergo $\beta$-hydride elimination to yield final chroman 124. This domino product was further submitted to an aldol condensation with (3R)-3,7-dimethyloctanal, followed successively by 1,2-addition of methyllithium, elimination of water and then hydrogenation to yield desired vitamin $\mathrm{E}$. Furthermore, a similar methodology was applied by the same authors to the enantioselective domino Wacker-Heck reaction of alkenyl phenol $\mathbf{1 2 7}$ and methyl acrylate 128, which provided upon comparable conditions the corresponding chroman $\mathbf{1 2 9}$ in 55\% yield and 88\% ee, albeit after a rather long reaction time of seven days (Scheme 33). ${ }^{[91]}$ Attempts to increase the reaction rate by performing the process at elevated temperature resulted, however, in a significant reduction of the enantioselectivity. In addition, another asymmetric domino reaction including a Heck reaction was recently reported by Schmalz et al. ${ }^{[59]}$ Indeed, these authors have developed an enantioselective access to 3-methylene- $1 \mathrm{H}$-indanol through domino allylstannylation-Heck reaction, occurring between $o$ iodobenzaldehyde and allyl tributylstannane in the presence of a palladium complex in situ generated from $\left[\mathrm{Pd}_{2} \mathrm{dba}_{3}\right]$ and a Taniaphos chiral ligand. The domino product was produced in $52 \%$ yield and $96 \%$ ee. 
<smiles>C=CC(C)=O</smiles>
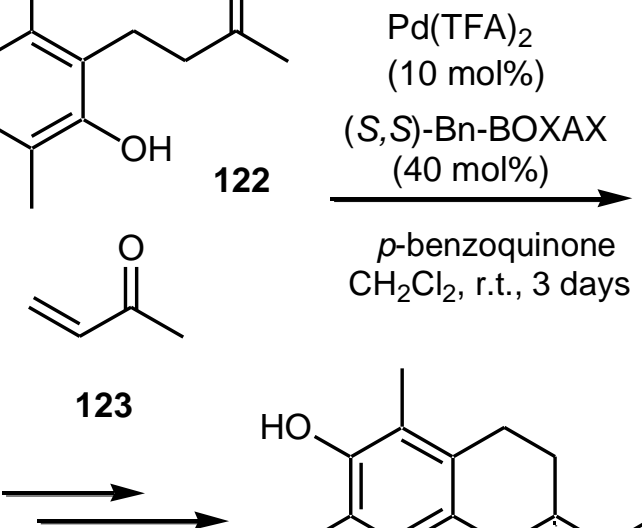<smiles>Cc1c(C)c2c(c(C)c1O)CC[C@@](C)(CCC[C@H](C)CCC[C@H](C)CCCC(C)C)O2</smiles><smiles>CC(=O)/C=C/C[C@]1(C)CCc2c(C)c(OCc3ccccc3)c(C)c(C)c2O1</smiles>

124

$84 \%$, ee $=97 \%$

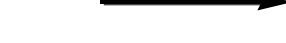

$\alpha$-tocopherol

proposed mechanism:

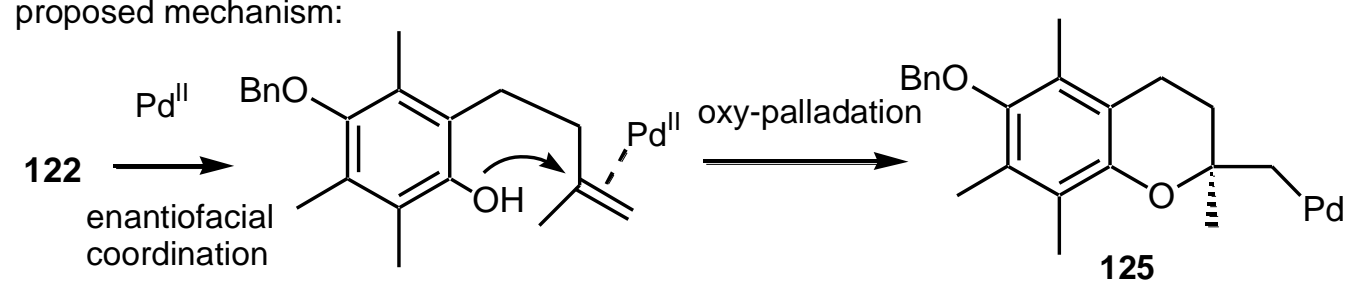<smiles>C=CC(C)=O</smiles><smiles>C=C(C)CCc1c(O)cc(C)cc1OC</smiles>

$\operatorname{Pd}(\text { TFA })_{2}$

(10 mol\%)

(S,S)-Bn-BOXAX

127

$+$<smiles>C=CC(=O)OC</smiles>

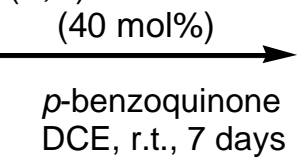

DCE, r.t., 7 days<smiles>COC(=O)/C=C/C[C@]1(C)CCc2c(OC)cc(C)cc2O1</smiles>

$55 \%$, ee $=88 \%$

128<smiles>c1ccc(C[C@H]2COC(c3ccc4ccccc4c3-c3cccc4ccc(C5=N[C@H](Cc6ccccc6)CO5)cc34)=N2)cc1</smiles>

$(S, S)$-Bn-BOXAX

Scheme 33. Domino Wacker-Heck reactions and synthesis of vitamin E. 
In 2009, Sasai et al. focused on the synthesis of novel chiral spiro ligands bearing $\mathrm{N}$-heterocycles to be applied to induce palladium-catalyzed asymmetric reactions, including domino Wacker-type cyclization reactions. ${ }^{[92]}$ Various types of chiral spiro ligands were prepared, such as spiro bis(isoxazole), spiro (isoxazole-isoxazoline), spiro bis(oxazoline), spiro bis(pyrazole) ligands, and further investigated as palladium ligands to promote the enantioselective domino Wacker-type cyclization of dialkenyl alcohol $\mathbf{1 3 0}$ into its corresponding bicyclic product 131. Among these ligands, spiro bis(isoxazoline) ligand, $i$-Pr-SPRIX, and hybrid spiro (isoxazole-isoxazoline) ligand $\mathbf{1 3 2}$ combined with $\mathrm{Pd}(\mathrm{TFA})_{2}$ provided the best results both in terms of yields and enantioselectivities with values of up to $89 \%$ and $97 \%$ ee, respectively. While the domino reaction based on the use of $i$-PrSPRIX ligand was performed in $\mathrm{CH}_{2} \mathrm{Cl}_{2}$ as the solvent, that employed ligand $\mathbf{1 3 2}$ was carried out in a mixed solvent $\mathrm{CH}_{2} \mathrm{Cl}_{2} / \mathrm{MeOH}$ (1:1), as shown in Scheme 34. The authors have proposed the mechanism depicted in Scheme 34 to explain the results. Intramolecular nucleophilic attack of the hydroxyl group at the activated $\mathrm{C}-\mathrm{C}$ double bond produced alkyl $\mathrm{Pd}(\mathrm{II})$ intermediate 133. A subsequent $\mathrm{C}-\mathrm{C}$ bond formation led to domino bicyclic product 131 through the formation of palladacycle $\mathbf{1 3 4}$ by intramolecular carbopalladation or from a direct insertion intermediate $\mathbf{1 3 5}$. 
<smiles>CC(C)=CCC(CC=C(C)C)(COC(=O)OCc1ccccc1)COC(=O)c1ccccc1</smiles>

130

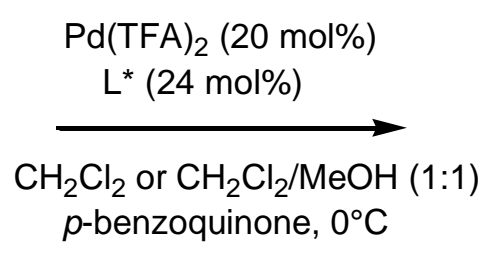

p-benzoquinone, $0^{\circ} \mathrm{C}$

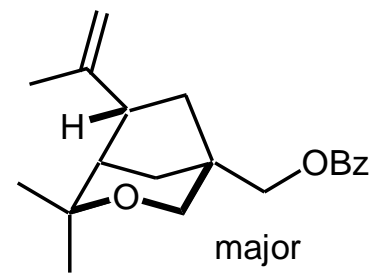

131

with $\mathrm{L}^{*}=i$-Pr-SPRIX: $65 \%$, ee $=95 \%$ with $L^{*}=132: 59 \%$, ee $=97 \%$<smiles>CCCC1(C(C)C)ON=C2[C@H]1CC[C@]21CC[C@@]2(C)C1=NOC2(C(C)C)C(C)C</smiles>

$(M, S, S)-i-\operatorname{Pr}-S P R I X$

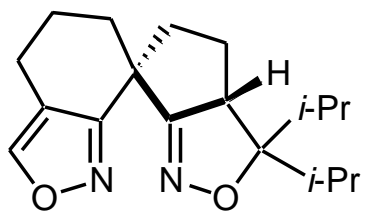

132

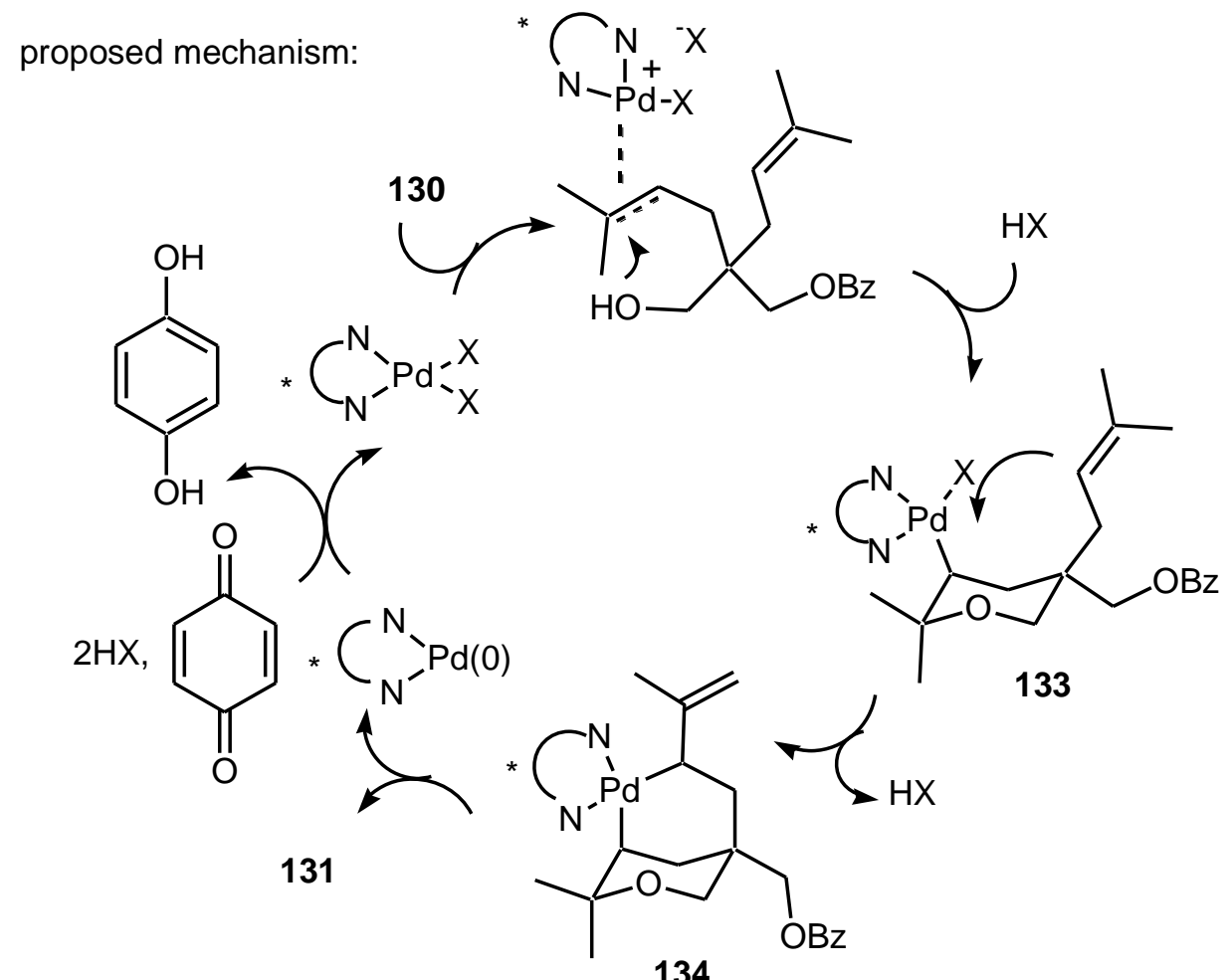

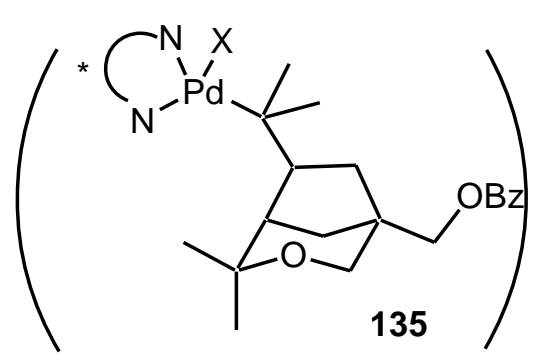

Scheme 34. Domino Wacker-type cyclization reaction of dialkenyl alcohol.<smiles>[R]C1([R])ON=C2C1CCC[C@@]21CC[C@H]2C1=NOC2([R])[R]</smiles>

\subsection{Domino Reactions based on Cyclizations}


In the last few years, a number of novel enantioselective domino processes catalyzed by various chiral metal complexes have been developed on the basis of cyclization reactions. In 2006, Yang et al. developed a $\mathrm{Pd}(\mathrm{II})$-catalyzed enantioselective oxidative domino cyclization reaction using readily available (-)-sparteine as the chiral ligand and molecular oxygen as a green oxidant, providing direct access to enantioenriched and structurally versatile indolines. ${ }^{[93]}$ As shown in Scheme 35, treatment of a series of mono-substituted unsaturated anilides 136a-e by molecular oxygen upon catalysis with a combination of Pd(TFA $)_{2}$ and (-)-sparteine in the presence of $3 \AA$ molecular sieves and tertiary amine diisopropylethylamine (DIPEA) at $80^{\circ} \mathrm{C}$ produced the corresponding tricyclic indolines 137a-e in moderate to good yields and enantioselectivities of up to $91 \%$ ee. The investigation of a series of other chiral ligands, such as (DHQ) ${ }_{2} \mathrm{PHAL},(\mathrm{DHQ})_{2} \mathrm{AQN},(\mathrm{DHQD})_{2} \mathrm{PYR},(-)$-cinchonidine, hydroquinine, and $(S, S)-\mathrm{Ph}-\mathrm{BOX}$, has shown the emergence of (-)-sparteine as the most effective ligand to induce chirality in this process.<smiles>[R7]c1cc(NC(=O)/C=C/[18F])c(CC=C)c([R])c1[2H]</smiles>

136a-e

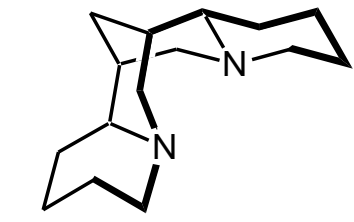

(-)-sparteine (80 mol\%)

$\operatorname{Pd}(\mathrm{TFA})_{2}$

$(10-20 \mathrm{~mol} \%)$

toluene, $\mathrm{O}_{2}(1 \mathrm{~atm}), 80^{\circ} \mathrm{C}$ DIPEA (2 equiv)

$3 \AA$ mol sieves<smiles>[Z7]C=C1C[C@H]2Cc3c(cc([R])c([R7])c3[Y])N2C1=O</smiles>

137a-e

\begin{tabular}{llllll}
$\mathrm{R}^{1}$ & $\mathrm{R}^{2}$ & $\mathrm{R}^{3}$ & $\mathrm{R}^{4}$ & $\begin{array}{c}\text { Yield } \\
(\%)\end{array}$ & ee \\
& & & $(\%)$ \\
\hline
\end{tabular}

$\begin{array}{cccccc}\mathrm{H} & \mathrm{H} & \mathrm{H} & \mathrm{H} & 78 & 86 \\ \mathrm{H} & \mathrm{Cl} & \mathrm{H} & \mathrm{H} & 61 & 75 \\ \mathrm{H} & \mathrm{H} & \mathrm{H} & m-\mathrm{ClC}_{6} \mathrm{H}_{4} & 60 & 80 \\ \mathrm{Me} & \mathrm{H} & \mathrm{Me} & \mathrm{H} & 63 & 91 \\ \mathrm{Me} & \mathrm{H} & \mathrm{Me} & m-\mathrm{ClC}_{6} \mathrm{H}_{4} & 64 & 87\end{array}$

Scheme 35. Pd-catalyzed oxidative domino cyclization reaction of monosubstituted unsaturated anilides.

Later, these authors have developed other new chiral palladium catalyst systems, comprising quinoline and chiral oxazoline units, which had the advantages of being air stable, structurally tunable, and highly diastereo- and enantioselective for a variety of disubstituted olefinic substrates $\mathbf{1 3 6 f}-\mathbf{k}$. While the use of (-)-sparteine as a ligand provided good enantioselectivities in the case of oxidative domino cyclization of monosubstituted olefinic substrates 136a-e, its use for the reaction of disubstituted olefinic substrates 136f-k gave only low enantioselectivities $(\leq 14 \% e e)$. On the other hand, the use of novel catalyst systems, such as the combination of $\mathrm{Pd}(\mathrm{OAc})_{2}$ with $t$-Bu-QUOX as the ligand, allowed the formation of the corresponding tricyclic products 137f-k in good yields and high enantioselectivities of up to $96 \%$ ee, as shown in Scheme 36. ${ }^{[94]}$ Moreover, it was noteworthy that the process of all substrates essentially yielded only one diastereomer. The authors assumed that the olefin geometry of the substrate completely controlled the relative stereochemistry of the product. 
<smiles>[R3]C=CC(=O)Nc1ccccc1CC=C([R7])[R7]</smiles>

136f-k

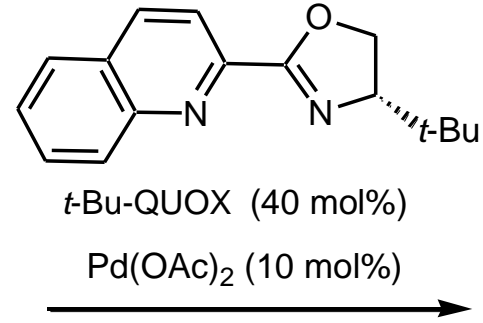

2,6-lutidine, $\mathrm{HNTf}_{2}, 3 \AA$ mol sieves

toluene, $\mathrm{O}_{2}(1 \mathrm{~atm}), 75^{\circ} \mathrm{C}$

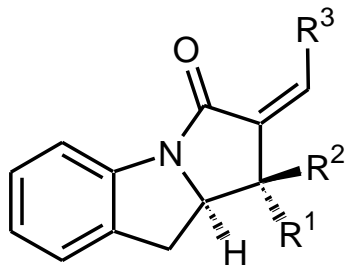

137f-k

$d e=100 \%$

\begin{tabular}{ccccc}
$\mathrm{R}^{1}$ & $\mathrm{R}^{2}$ & $\mathrm{R}^{3}$ & $\begin{array}{c}\text { Yield } \\
(\%)\end{array}$ & $\begin{array}{c}\text { ee } \\
(\%)\end{array}$ \\
\hline $\mathrm{Ph}$ & $\mathrm{H}$ & $\mathrm{H}$ & 75 & 98 \\
$p-\mathrm{FC}_{6} \mathrm{H}_{4}$ & $\mathrm{H}$ & $\mathrm{H}$ & 68 & 92 \\
$p-\mathrm{Tol}$ & $\mathrm{H}$ & $\mathrm{H}$ & 74 & 96 \\
$2-\mathrm{Naph}$ & $\mathrm{H}$ & $\mathrm{H}$ & 65 & 91 \\
$\mathrm{Ph}$ & $\mathrm{H}$ & $\mathrm{Ph}$ & 55 & 90 \\
$\mathrm{H}$ & $\mathrm{Ph}$ & $\mathrm{H}$ & 73 & 80
\end{tabular}

Scheme 36. Pd-catalyzed oxidative domino cyclization reaction of disubstituted unsaturated anilides.

Metal-catalyzed cyclization reactions of $1, n$-enynes have appeared as conceptually and chemically highly attractive processes as they contribute to the highly demanded search for atom economy and allow the discovery of new reactions. ${ }^{[95]}$ In particular, the use of gold catalysts for organic transformations has become increasingly common over the past decade, leading to the development of a number of useful carbon-carbon and carbon-heteroatom bond-forming processes, allowing the synthesis of a wide variety of carbo- and heterocycles presenting a high degree of structural complexity ${ }^{[96]}$ The development of enantioselective variants of these transformations are, however, still rare ${ }^{[97]}$ probably because of a highly substrate-dependency encountered with these systems. Among the numerous 1,n-enynes cyclization reactions, Michelet et al. have recently developed domino processes based on cycloisomerizations performed in the presence of external nucleophiles, such as alcohols, electron-rich aromatic rings, amines, carboxylic acids, and 1,3-dicarbonyl compounds, which led to functionalized cyclic cyclopentenes. ${ }^{[98]}$ In this context, these authors have reported enantioselective gold-catalyzed domino hydroarylation-cyclization reactions of 1,6-enynes 138a-d and various aromatic nucleophiles 139a-f induced by a chiral $\mathrm{Au}(\mathrm{I})$ catalyst, such as $(R)-\mathrm{MeO}-$ dtbm-BIPHEP $(\mathrm{AuCl})_{2}$, associated with AgOTf. As shown in Scheme 37, the corresponding arylated cyclic products 140a-g were produced in high yields as single diastereomers and with good to excellent enantioselectivities of up to $98 \%$ ee by using a variety of aromatic nucleophiles, such as pyrrole, indole derivatives, and di- or trimethoxybenzene derivatives (Scheme 37). In this study, the authors have highlighted a general strong dependency of both the intrinsic hindrance generated by the enyne and the nucleophile. The mechanism of this domino hydroarylation-cyclization reaction has been widely argued and is still under debate (Scheme 37). Based on a combined theoretical and experimental study, the nucleophilic attack-cycloisomerization reaction has been proposed to operate via a transient unstable cyclopropylcarbene $\mathbf{1 4 2}$ by the group of Echavarren. ${ }^{[95 \mathrm{~g}]}$ More recently, Fürstner and Morency proposed an alternative rationale relying on the mesomeric "nonclassical carbocation 143. ${ }^{[99]}$ The present results of asymmetric reactions showed a variation of enantioselectivity observed for a given enyne substrate in the presence of different carbon nucleophiles. In this regard, intermediates 142 and 143 did not adequately account for the formation of cyclic alkene 145. Indeed, considering the anti nucleophilic attack on the cyclopropylcarbene 
intermediate 142 as a stereospecific event, the external carbon nucleophile did not take part in the cyclopropylcarbene formation which represented the enantiodetermining step of the transformation. Considering the variation of enantioselectivity observed for a given enyne substrate and different carbon nucleophiles, the major contribution of intermediate 142, and of its diastereomeric counterpart 142', was bound to the existence of an equilibrium between forms 141 and 142/142'. The intervention of $\mathbf{1 4 3}$ could theoretically lead to a diastereomeric mixture of syn/anti derivatives if bond rotation of the carbocationic intermediates was faster compared to the addition of the carbon nucleophile, which had never been observed by the authors. According to these authors, the addition of the nucleophile could be concerted with the cyclization. In this possible scenario, the intervention of a conformationally favored intermediate 144, as proposed by Fürstner, ${ }^{[99]}$ could better account for the experimental results. It was indeed observed that the $e e$ values increased with the size of the enyne tether. Considering a "chair-like" $\eta^{2}$-complex 144, the addition of the nucleophile could occur in complete analogy with the Stork-Eschenmoser hypothesis ${ }^{[100]}$ introduced to account for the selectivity of polyene cyclization reactions. In 2011, the authors extended the scope of this methodology to oxygen nucleophiles, such as water and methanol, affording the corresponding heterocycles in moderate to excellent yields (46-99\%), complete diastereoselectivity and moderate enantioselectivities of up to $68 \% e e e^{[101]}$ According to these results, it seemed that the nature of the nucleophile had a strong influence on the enantioselectivity of the reaction. 
(R)-MeO-dtbm-BIPHEP $(\mathrm{AuCl})_{2}$<smiles>CC(C)(C)CC#CC=Cc1ccccc1</smiles>

(3 $\mathrm{mol} \%)$

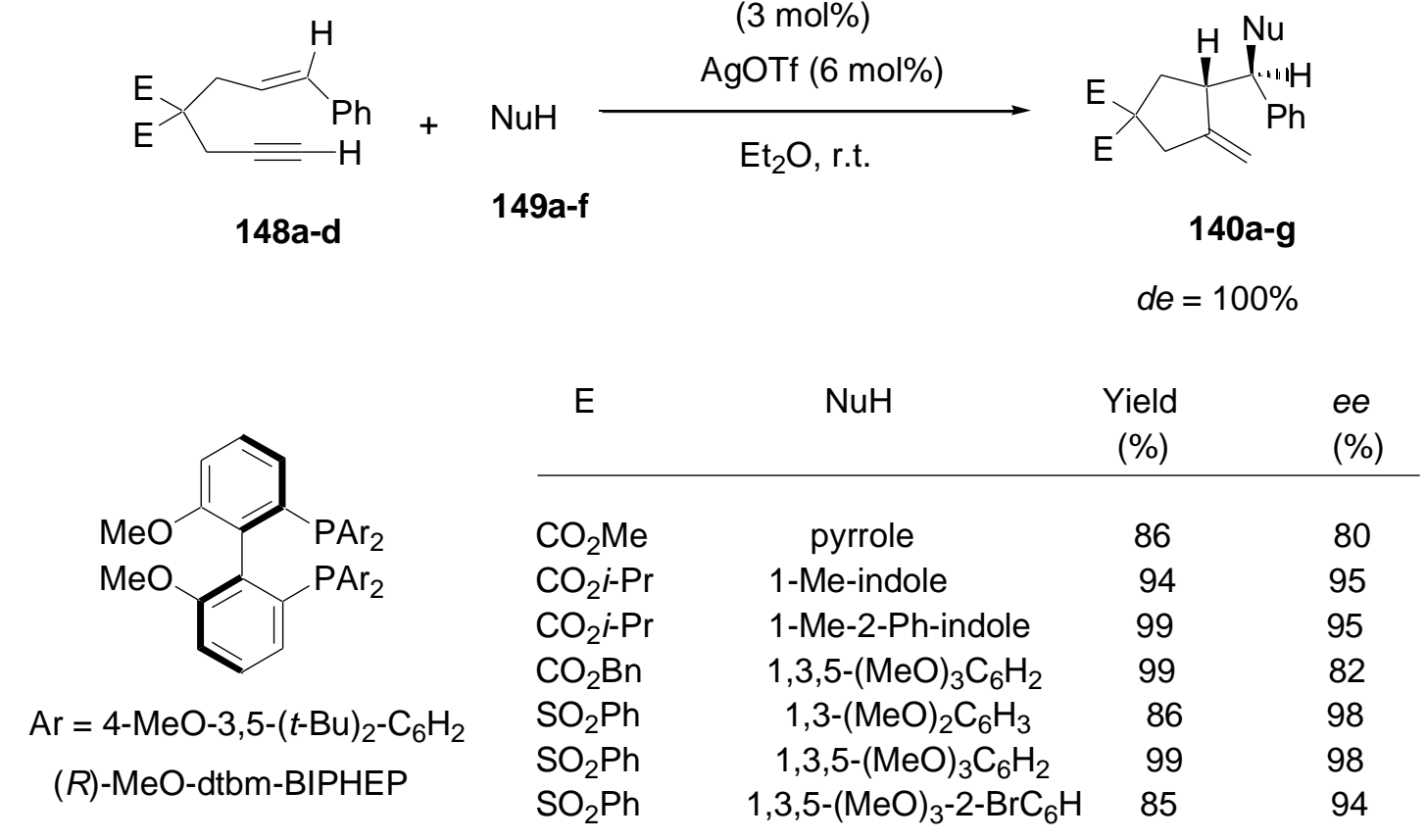

proposed mechanism:

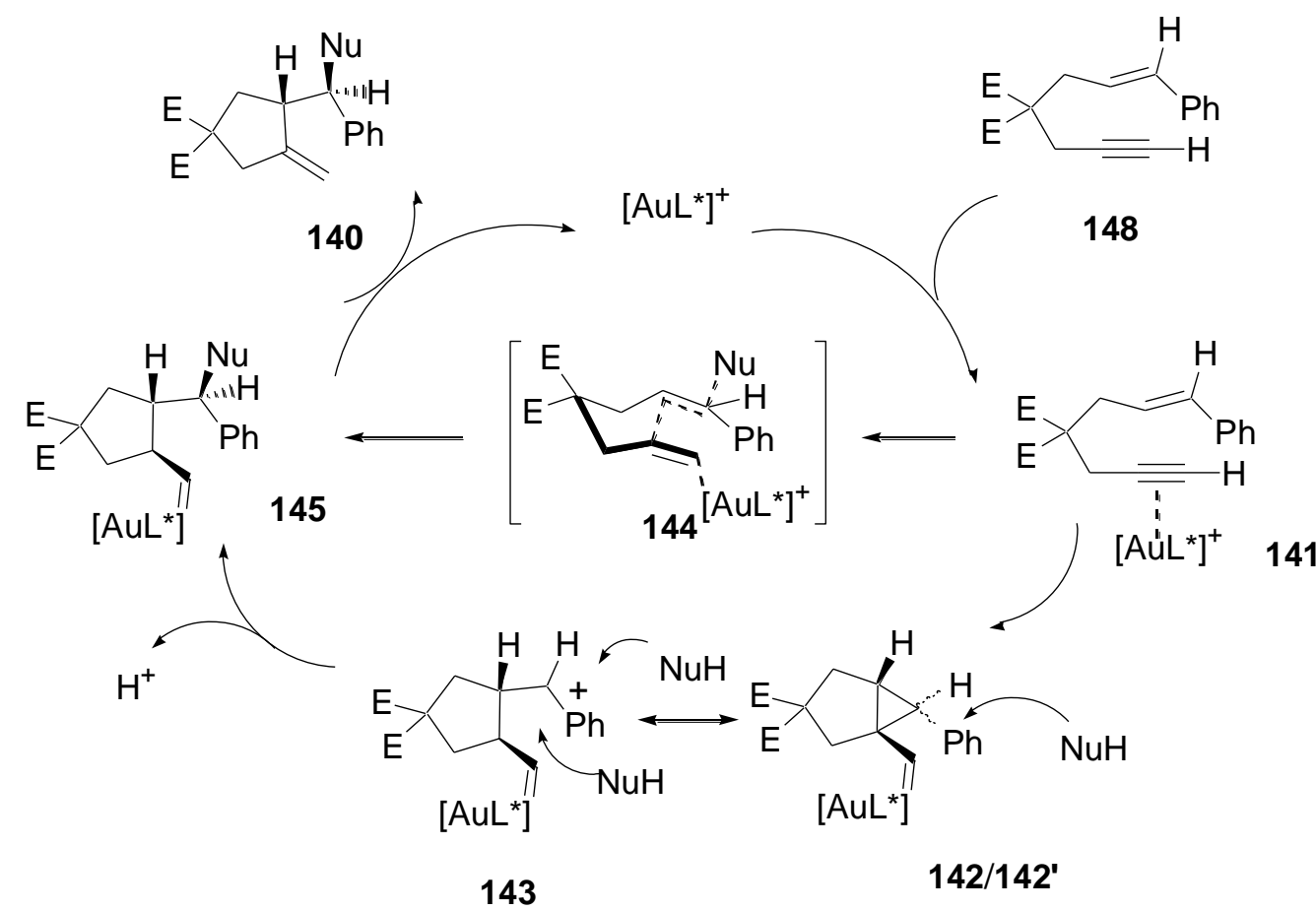

Scheme 37. Au-catalyzed domino hydroarylation-cyclization reaction.

In 2006, Genêt et al. developed enantioselective platinum-catalyzed domino hydroxyl- and alkoxycyclization reactions of 1,6-enynes. ${ }^{[102]}$ As shown in Scheme 38, when the reaction of 1,6enynes 146a-d with water or methanol was catalyzed by a chiral platinum complex of $(R)-\mathrm{Ph}-$ BINEPINE, a monophosphane atropisomeric ligand, in the presence of silver salts as additives, it afforded the corresponding functionalized carbo- and heterocycles 147a-d in moderate to high yields and good enantioselectivities of up to $85 \%$ ee. A reasonable hypothesis for the mechanism of the process based on the Lewis acid character of the Pt catalyst is depicted in Scheme 38. The reaction could be initiated by the formation of $\pi$-alkynyl complex 148 through the complexation of the 
unsaturated triple bond to the metal catalyst. The $\pi$-alkynyl complex 148 could then evolve to give a cyclopropyl metal carbene complex 150, which could be opened by an external nucleophile, such as methanol or water, to give rise to vinylmetallate 149. Further protonolysis of this intermediate formed the final cycloadduct and regenerated the catalyst. It must be noted that the Pt carbene has not been isolated; consequently, the concerted addition of the nucleophile on intermediate $\mathbf{1 4 8}$ and formation of the $\mathrm{C}-\mathrm{C}$ bond is also possible. 


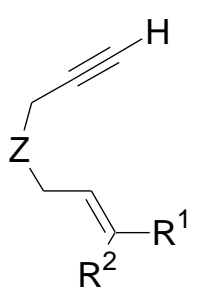

$146 a-d$<smiles>c1ccc(PCc2ccc3ccccc3c2-c2cccc3ccccc23)cc1</smiles>

(R)-Ph-BINEPINE (15 mol\%)

$\mathrm{PtCl}_{2}(5 \mathrm{~mol} \%)$

$\mathrm{AgSbF}_{6}(25 \mathrm{~mol} \%)$

dioxane/ $\mathrm{H}_{2} \mathrm{O}\left(\mathrm{R}^{3}=\mathrm{H}\right)$ or

$\mathrm{MeOH}\left(\mathrm{R}^{3}=\mathrm{Me}\right)$

$60-80^{\circ} \mathrm{C}$

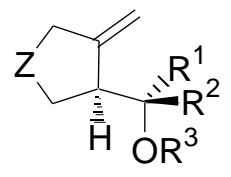

147a-d

\begin{tabular}{cccccc}
$\mathrm{R}^{1}$ & $\mathrm{R}^{2}$ & $\mathrm{Z}$ & $\mathrm{R}^{3}$ & $\begin{array}{c}\text { Yield } \\
(\%)\end{array}$ & $\begin{array}{r}\text { ee } \\
(\%)\end{array}$ \\
\hline $\mathrm{Ph}$ & $\mathrm{H}$ & $\mathrm{C}\left(\mathrm{CO}_{2} \mathrm{Me}\right)_{2}$ & $\mathrm{H}$ & 94 & 85 \\
$\mathrm{Me}$ & $\mathrm{Me}$ & $\mathrm{C}\left(\mathrm{CO}_{2} \mathrm{Me}\right)_{2}$ & $\mathrm{H}$ & 87 & 66 \\
$\mathrm{Me}$ & $\mathrm{Me}$ & $\mathrm{NTs}$ & $\mathrm{H}$ & 57 & 56 \\
$\mathrm{Ph}$ & $\mathrm{H}$ & $\mathrm{NTs}$ & $\mathrm{Me}$ & 49 & 78
\end{tabular}

possible mechanism:

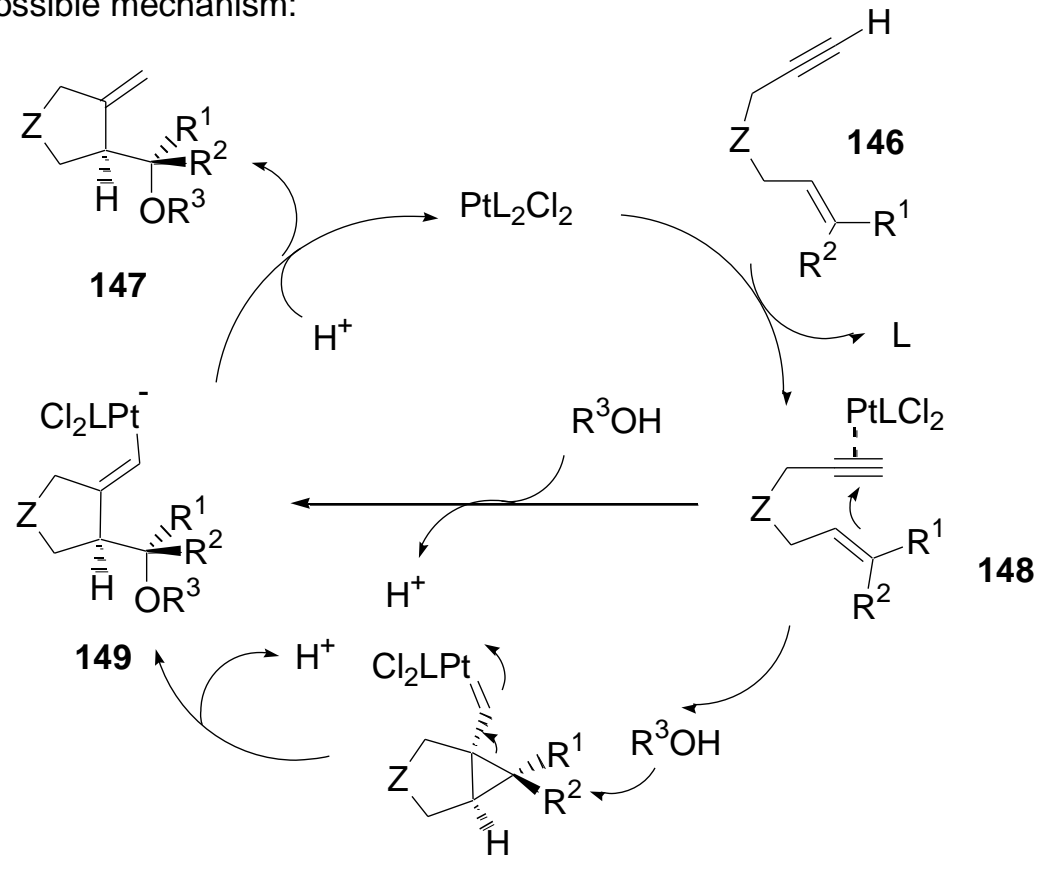

150

Scheme 38. Pt-catalyzed domino alkoxy- and hydroxycyclization reaction.

As an extension of this methodology, these authors have applied similar conditions to the enantioselective domino hydroarylation-cycloisomerization reaction of 1,6-enynes 151c-f with a variety of electron-rich aromatic and heteroaromatic nucleophiles to give a range of functionalized cyclic derivatives 152a-h in good yields and enantioselectivities, as shown in Scheme $39 .{ }^{[103]}$ It must 
be noted that for all the substrates investigated, products 152a-h were formed in > 19:1 syn:anti diastereoselectivity. As depicted in Scheme 39, the reaction could evolve through initial $\eta^{2}$ coordination of the metal to the alkyne to give intermediate 153, which was subsequently submitted to an intramolecular addition of the alkene, leading to cyclopropylcarbene 154. In the presence of the external nucleophile $\mathrm{Ar}^{2} \mathrm{H}$, ring opening of the cyclopropylcarbene and rearrangement to cyclized vinylmetal complex 155 occurred. Then, protodemetalation completed the catalytic cycle, providing the final product $\mathbf{1 5 2}$ and regenerated catalyst. 


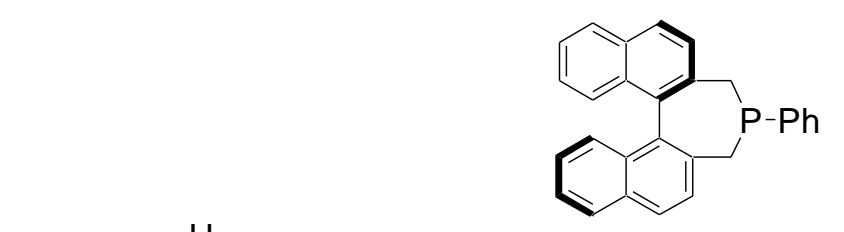

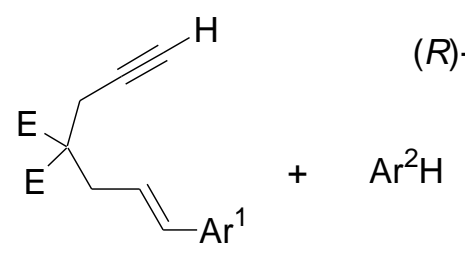

151c-f
$(R)$-Ph-BINEPINE (5 or $16 \mathrm{~mol} \%$ ) $\mathrm{PtCl}_{2}(5 \mathrm{~mol} \%)$

$\mathrm{AgSbF}_{6}(12.5 \mathrm{~mol} \%)$

dioxane, $60^{\circ} \mathrm{C}$

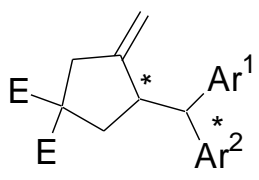

152a-h

syn:anti > 95:5
$\mathrm{Ar}^{1}$
E
$\mathrm{Ar}^{2}$
Yield ee
(\%)
(\%)

\begin{tabular}{clccc}
\hline $\mathrm{Ph}$ & $\mathrm{CO}_{2} \mathrm{Me}$ & 1-methylindole & 62 & 91 \\
$\mathrm{Ph}$ & $\mathrm{CO}_{2} i-\mathrm{Pr}$ & 1-methylindole & 75 & 82 \\
$\mathrm{Ph}$ & $\mathrm{CO}_{2} \mathrm{Bn}$ & 1-methylindole & 77 & 83 \\
$\mathrm{Ph}$ & $\mathrm{CO}_{2} t-\mathrm{Bu}$ & 1-methylindole & 70 & 80 \\
$\mathrm{Ph}$ & $\mathrm{CO}_{2} \mathrm{Me}$ & 1 1,-dimethylindole & 85 & 89 \\
$\mathrm{Ph}$ & $\mathrm{CO}_{2} \mathrm{Me}$ & 1-methyl-5-methoxyindole & 95 & 87 \\
$3,4-\left(\mathrm{OCH}_{2} \mathrm{O}\right) \mathrm{C}_{6} \mathrm{H}_{3}$ & $\mathrm{CO}_{2} \mathrm{Me}$ & 1-methylindole & 78 & 79 \\
$\mathrm{Ph}$ & $\mathrm{CO}_{2} \mathrm{Me}$ & $1,3-(\mathrm{MeO})_{2} \mathrm{C}_{6} \mathrm{H}_{3}$ & 53 & 80
\end{tabular}

proposed mechanism:
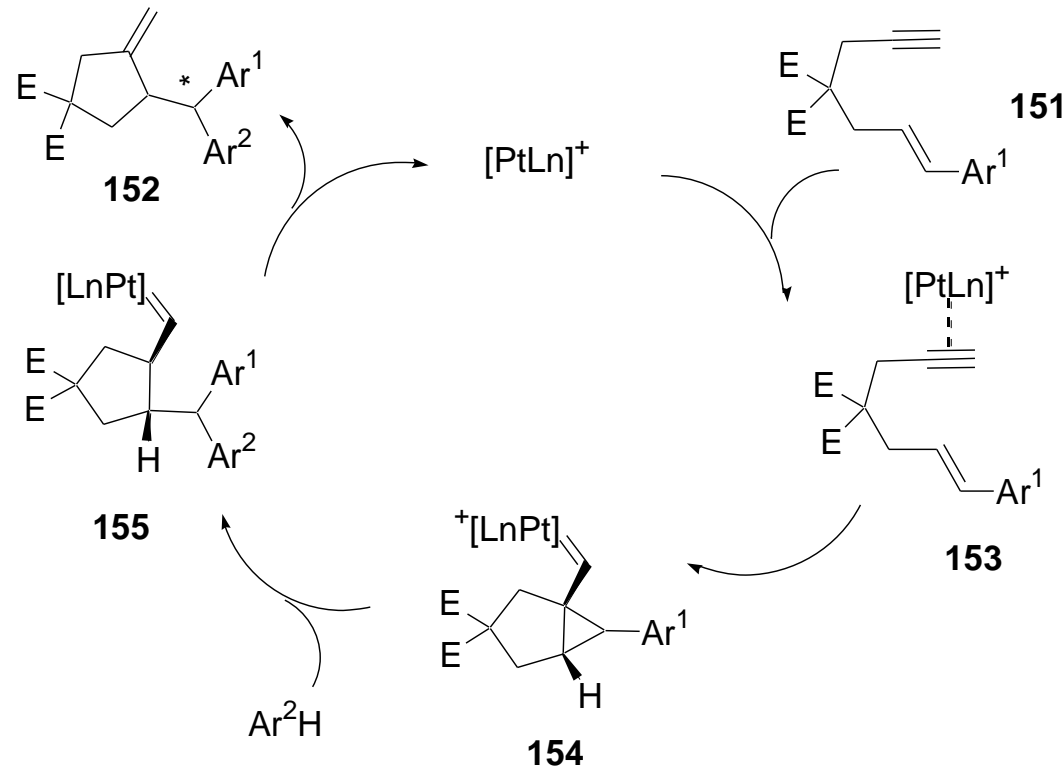

Scheme 39. Pt-catalyzed domino hydroarylation-cycloisomerization reaction.

The utility of $N$-heterocyclic carbenes as catalysts in domino reactions has received growing attention in the past few years. ${ }^{[104]}$ In this area, asymmetric domino methoxycyclizations of 1,6-enynes and 
methanol have also been investigated by Tomioka et al. by using gold(I) complexes of chiral $C_{2^{-}}$ symmetric $N$-heterocyclic carbenes. ${ }^{[105]}$ The corresponding functionalized cyclopentanes were achieved in high yields (93-95\%) albeit low to moderate enantioselectivities (4-56\% ee). On the other hand, Sanz et al. have reported enantioselective gold-catalyzed alkoxy- and hydroxycyclization of $o$ (alkylnyl)styrenes 156a-f and alcohols and water, respectively, by employing a gold complex of $(S)$ 3,5-Xylyl-MeO-BIPHEP in the presence of silver salts. ${ }^{[106]}$ The process provided a range of chiral functionalized $1 H$-indene derivatives 157a-g in high yields and moderate to high enantioselectivities of up to $92 \%$ ee, as shown in Scheme 40. The catalytic cycle depicted in Scheme 40 explained the formation of indenes 157a-g. The reaction was initiated by coordination of the cationic gold complex to the triple bond of the $o$-(alkynyl)styrene 156 to give intermediate 158. Intramolecular addition of the alkene moiety selectively led to the cationic intermediate $\mathbf{1 5 9}$ through a 5-endo-dig-cyclization. In the presence of alcohol $\mathrm{R}^{5} \mathrm{OH}$, trapping of the carbocation 159 led to formation of vinyl gold intermediate 160. A further protodemetalation furnished the final product 157, and regenerated catalyst. 


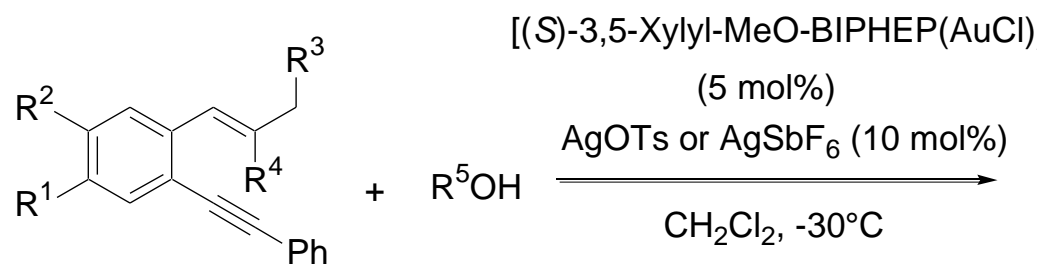

156a-f

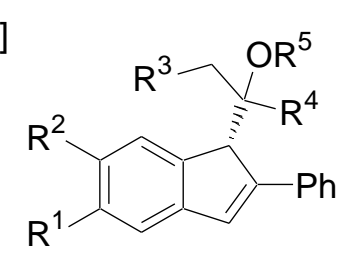

157a-g

\begin{tabular}{ccccccc}
\hline $\mathrm{H}$ & $\mathrm{H}$ & $\mathrm{H}$ & $\mathrm{Me}$ & $\mathrm{Me}$ & 99 & 88 \\
$\mathrm{H}$ & $\mathrm{H}$ & $\mathrm{H}$ & $\mathrm{Me}$ & $\mathrm{H}$ & 93 & 86 \\
$\mathrm{H}$ & $\mathrm{H}$ & $\mathrm{H}$ & $\mathrm{Me}$ & $i-\mathrm{Pr}$ & 72 & 92 \\
$\mathrm{H}$ & $\mathrm{F}$ & $\mathrm{H}$ & $\mathrm{Me}$ & $\mathrm{Me}$ & 93 & 82 \\
\multicolumn{2}{c}{$\mathrm{O}-\mathrm{CH}_{2}-\mathrm{O}$} & $\mathrm{H}$ & $\mathrm{Me}$ & $\mathrm{H}$ & 80 & 88 \\
$\mathrm{H}$ & $\mathrm{H}$ & & $\left(\mathrm{CH}_{2}\right)_{3}$ & $\mathrm{Me}$ & 87 & 80 \\
$\mathrm{H}$ & $\mathrm{H}$ & & $\left(\mathrm{CH}_{2}\right)_{3}$ & $\mathrm{H}$ & 77 & 84
\end{tabular}

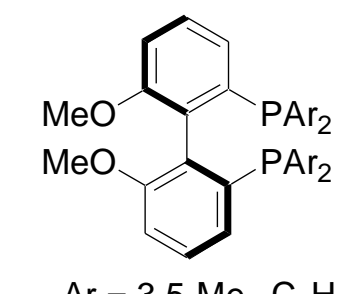

$\mathrm{Ar}=3,5-\mathrm{Me}_{2}-\mathrm{C}_{6} \mathrm{H}_{3}$

(S)-3,5-Xylyl-MeO-BIPHEP

proposed mechanism:
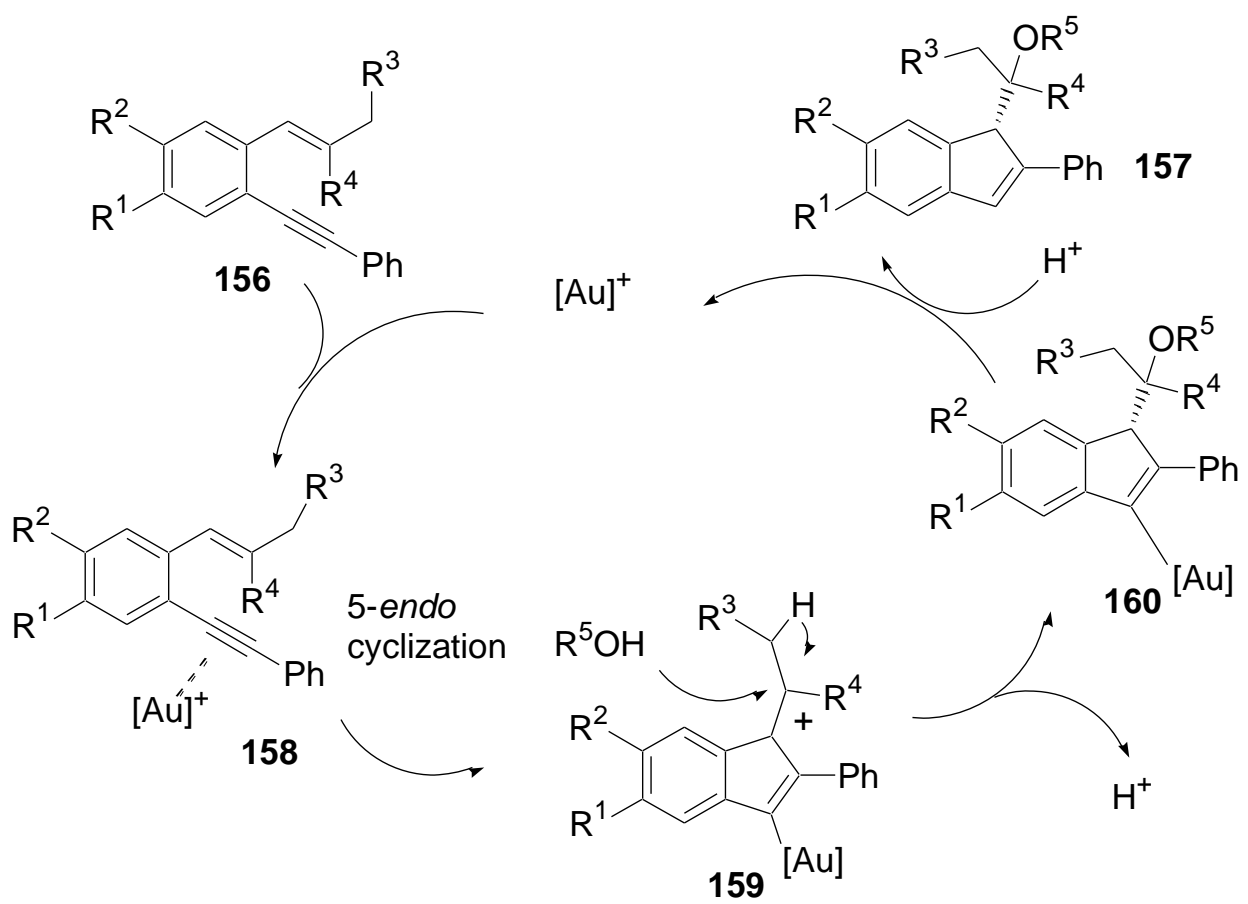

Scheme 40. Au-catalyzed domino alkoxy- and hydroxycyclization reactions. 
Acyclic diaminocarbene ligands, also known as nitrogen acyclic carbenes, are potentially advantageous over the more familiar $\mathrm{N}$-heterocyclic carbenes for enantioselective catalysis, because their wide N-C-N angles $\left(116-121^{\circ}\right)$ can place chiral substituents closer to the metal. In this context, Slaughter et al. have very recently reported the use of this type of ligands to mediate enantioselective domino acetalization-cycloisomerization reaction of alkynylbenzaldehydes 161a-c in the presence of alcohols. ${ }^{[107]}$ As shown in Scheme 41, a series of chiral bicyclic products 162a-k could be achieved in moderate to good yields and enantioselectivities of up to $>99 \%$ ee by employing this new class of chiral gold(I) complexes of nitrogen acyclic carbenes, such as catalysts 163a-b which bear chiral groups near the catalytic site. These complexes were generated through addition of bulky amines to $\mathrm{Au}(\mathrm{I})$ complexes of suitably substituted chiral biaryl isocyanides. In order to explain the results, the authors have proposed that enantioselectivity in alkynylbenzaldehyde cyclization correlated with the presence of $\mathrm{Au}$-arene interactions with an electron-deficient aryl group. The combined structural, catalytic, and DFT results have suggested a dynamic chiral pocket in which reversible Au-aryl association, increased by intra-ligand sterics in the case of $\mathbf{1 6 3 b}$, was sufficiently favourable to influence the enantiodetermining step. The reaction is supposed to evolve through the mechanism depicted in Scheme 41. The metal-activated alkyne formed a $\pi$-complex that was liable to nucleophilic attack directly from the oxygen of the carbonyl to give a highly reactive benzopyrylium intermediate 164 through a 6-endo-dig cyclization reaction. The nucleophile could then attack this benzopyrylium intermediate and led to catalyst recycling by protodemetallation with formation of the final isochromene $\mathbf{1 6 2}$. 


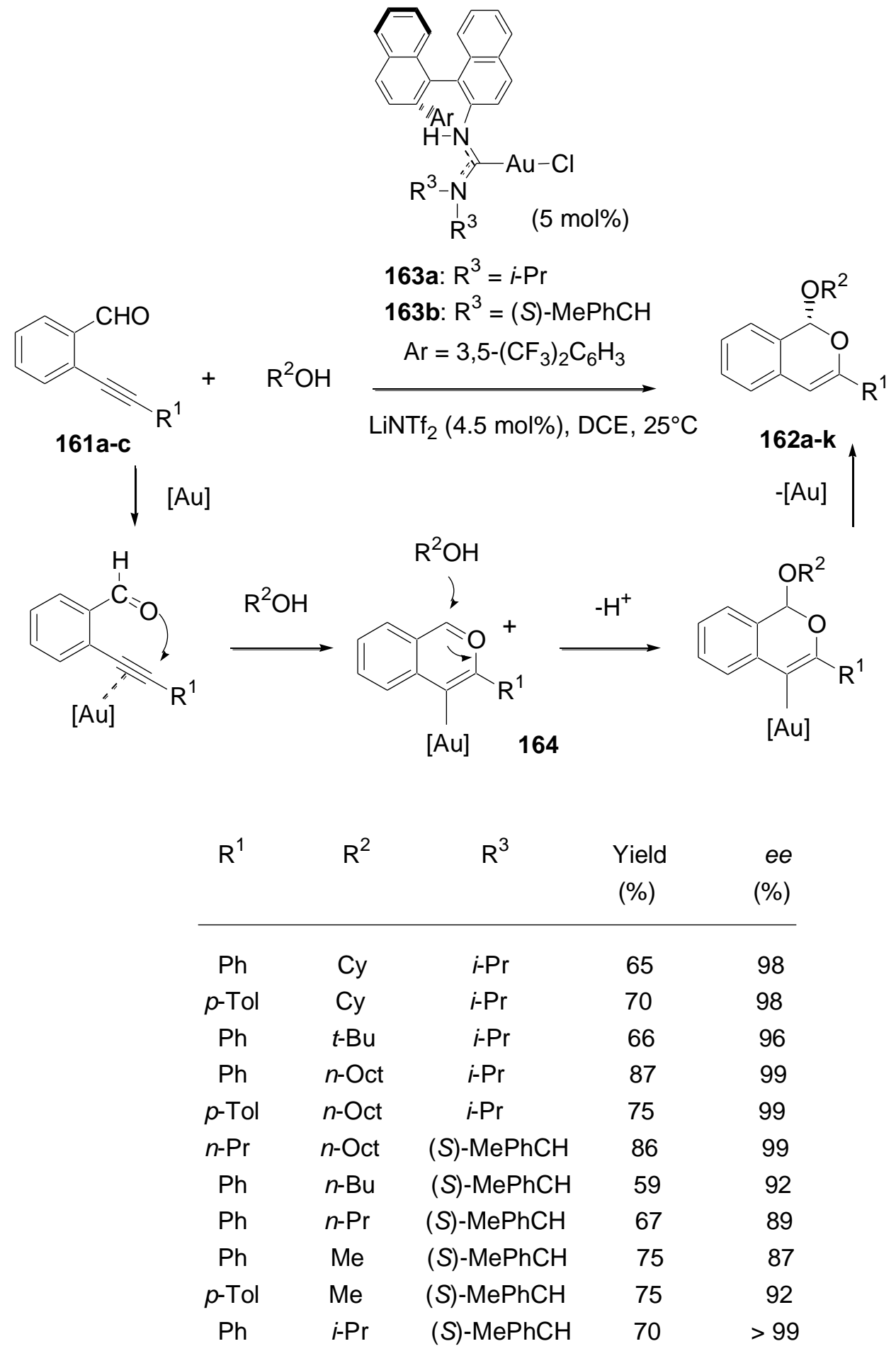

Scheme 41. Au-catalyzed domino acetalization-cycloisomerization reaction.

In 2010, Zhang et al. reported a novel gold(I)-catalyzed diastereo- and enantioselective domino cyclization-[3+3] cycloaddition reaction of 2-(1-alkynyl)-2-alken-1-ones 165a-g with nitrones 166a-e, affording the corresponding chiral heterobicyclic furo[3,4-d][1,2] oxazines $\mathbf{1 6 7 a - k} .^{[108]}$ In this study, several chiral ligands derived from BIPHEP were investigated, such as $(R)-\mathrm{C}_{1}$-TUNEPHOS and $(R)$ MeO-dtbm-BIPHEP bearing bulky substituents onto the phosphine aryl rings. In general, the use of $(R)-\mathrm{MeO}$-dtbm-BIPHEP as the ligand provided higher enantioselectivities of up to $98 \%$ ee than those obtained by using simple $(R)$-MeO-BIPHEP as the ligand. Furthermore, the authors have shown that placing aliphatic substituents on the olefin or the alkyne moiety of the substrates 165a-g resulted in dramatic decreases in enantio- and diastereoselectivity. These results indicated that there was a steric 
demand to obtain excellent enantioselectivity. Moreover, in some cases of substrates, ligand $(R)-C_{1^{-}}$ TUNEPHOS provided better enantioselectivities than ligand $(R)-\mathrm{MeO}-\mathrm{dtbm}-\mathrm{BIPHEP}$, which demonstrated that two strategies of modification of MeO-BIPHEH were effective, with the former being more efficient, owing to the $\mathrm{Au}-\mathrm{Au}$ interaction which could make the structure more rigid. The best results are collected in Scheme 42, in which a plausible mechanism for this reaction is depicted. The cationic gold(I) species first coordinated the furanyl gold complex 168 arisen from cyclization, which was rapidly trapped by the nucleophilic oxygen atom of the nitrone to afford intermediate $\mathbf{1 6 9}$. Subsequent intramolecular [3+3] cycloaddition produced final product as well as regenerated the gold catalyst. 
<smiles>[R]C#CC(=C[R])C([R7])=O</smiles>

165a-g<smiles>[O-]/C=[N+](/[O-])c1ccccc1</smiles>

166a-e
$\left[\mathrm{L}^{*}(\mathrm{AuCl})_{2}\right](2.5 \mathrm{~mol} \%)$

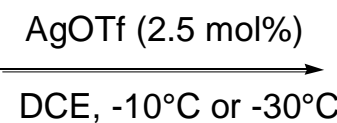

DCE, $-10^{\circ} \mathrm{C}$ or $-30^{\circ} \mathrm{C}$<smiles>[R]c1oc([R])c2c1C([R7])ON(c1ccccc1)C2[PH]</smiles>

167a-k

$$
\begin{array}{llllll}
R^{1} & R^{2} & R^{3} & R^{4} & \text { Yield ee }
\end{array}
$$

\begin{tabular}{|c|c|c|c|c|c|}
\hline Me & $\mathrm{Ph}$ & $\mathrm{Ph}$ & 1-furyl & (R)-MeO-dtbm-BIPHEP & 97 \\
\hline $\mathrm{Me}$ & $\mathrm{Ph}$ & $\mathrm{Ph}$ & $\mathrm{D}-\mathrm{NO}_{2} \mathrm{C}_{6} \mathrm{H}_{4}$ & $(R)$-MeO-dtbm-BIPHEP & 93 \\
\hline Me & $\mathrm{Ph}$ & $\mathrm{Ph}$ & o- $\mathrm{MeOC}_{6} \mathrm{H}_{4}$ & $(R)-C_{1}$-TUNEPHOS & 98 \\
\hline $\mathrm{Me}$ & $\mathrm{Ph}$ & $\mathrm{Ph}$ & $p-\mathrm{BrC}_{6} \mathrm{H}_{4}$ & $(R)$-MeO-dtbm-BIPHEP & 95 \\
\hline Me & $\mathrm{Ph}$ & p-Tol & $\mathrm{Ph}$ & (R)-MeO-dtbm-BIPHEP & 99 \\
\hline Me & $\mathrm{Ph}$ & $p-\mathrm{MeOC}_{6} \mathrm{H}_{4}$ & $\mathrm{f}_{4} \mathrm{Ph}$ & (R)-MeO-dtbm-BIPHEP & 99 \\
\hline Me & $n-\mathrm{Bu}$ & $\mathrm{Ph}$ & $\mathrm{Ph}$ & $(R)-C_{1}$-TUNEPHOS & 92 \\
\hline $\mathrm{Ph}$ & $\mathrm{Ph}$ & $\mathrm{Ph}$ & $\mathrm{Ph}$ & ( $R$ )-MeO-dtbm-BIPHEP & 94 \\
\hline 10 & $\mathrm{Ph}$ & Cy & $\mathrm{Ph}$ & (R)-MeO-dtbm-BIPHEP & 87 \\
\hline \multicolumn{2}{|c|}{$-\left(\mathrm{CH}_{2}\right)_{3}^{-}$} & $\mathrm{Ph}$ & $\mathrm{Ph}$ & $(R)-C_{1}$-TUNEPHOS & 90 \\
\hline \multicolumn{2}{|c|}{$-\left(\mathrm{CH}_{2}\right)_{3-}^{-}$} & $\mathrm{Ph}$ & $-\mathrm{NO}_{2} \mathrm{C}_{6} \mathrm{H}_{4}$ & $(R)-C_{1}$-TUNEPHOS & 84 \\
\hline
\end{tabular}<smiles>COc1cccc(OC)c1-c1c(OC)cccc1P(#N)(=O)c1ccccc1</smiles>

(R)-MeO-dtbm-BIPHEP $\mathrm{Ar}=4-\mathrm{MeO}-3,5-(t-\mathrm{Bu})_{2}-\mathrm{C}_{6} \mathrm{H}_{2}$<smiles>c1ccc(-c2cccc(-c3ccccc3)c2-c2cccc3c2COCO3)cc1</smiles>

(R)- $C_{1}$-TUNEPHOS

proposed mechanism:

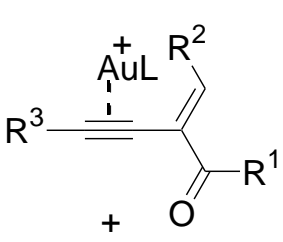

other complexes

165

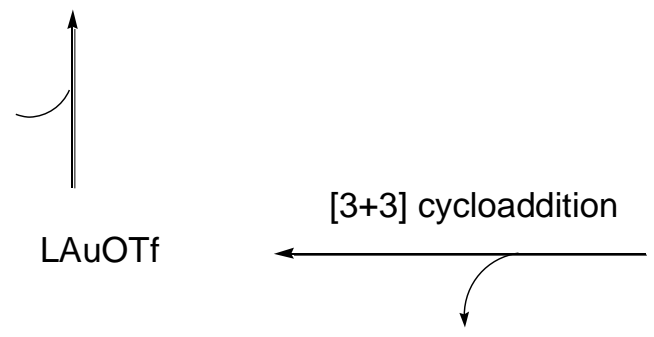

167

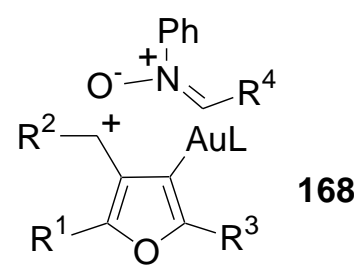

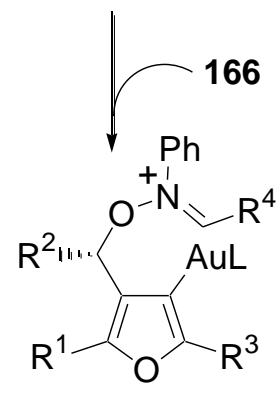

Scheme 42. Au-catalyzed domino cyclization-[3+3]cycloaddition reaction. 
These authors have recently applied ligand $(R)$-MeO-dtbm-BIPHEP to induce another type of goldcatalyzed domino reaction based on an intramolecular cyclization-1,5-hydride transfer-cyclization reaction of 2-(1-alkynyl)-2-alken-1-ones 170a-h. ${ }^{[109]}$ This process allowed a range of chiral furanfused azepine derivatives 171a-h to be achieved in general both high yields and enantioselectivities, as shown in Scheme 43. These results represented the first example of enantioselective redox-neutral domino reaction catalyzed by gold(I) that resulted in the direct functionalization of unreactive $\mathrm{sp}^{3} \mathrm{C}-\mathrm{H}$ bonds. A plausible mechanism for this reaction is depicted in Scheme 43. Activation of the alkyne moiety of substrate $\mathbf{1 7 0}$ by gold catalyst caused a heterocyclization (first cyclization) to give furanyl intermediate 172, possessing a reactive carbocation. After 1,5-hydride shift to produce intermediate 173, followed by subsequent ring closure (second cyclization), final furan-fused azepine derivative 171 was achieved.<smiles>[Y20]CCCN1CC(C([R])=O)=Cc2ccc([R])cc21</smiles>

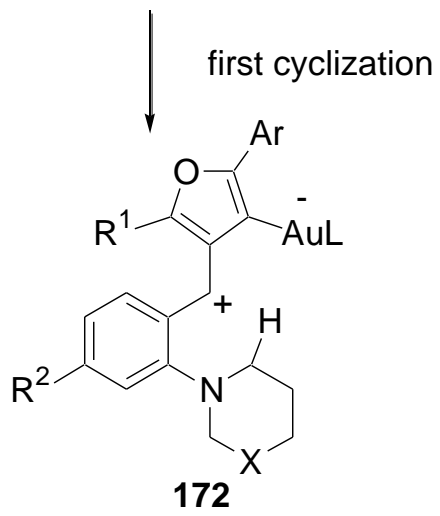

$\left[(R)-\mathrm{MeO}-\mathrm{dtbm}-\mathrm{BIPHEP}(\mathrm{AuCl})_{2}\right]$ (5 mol\%)<smiles>CCOC(=O)[SbH2]OCC(C)C</smiles>

$\mathrm{MeCN}$, r.t.<smiles>[X]CN1c2cc([R])ccc2Cc2c([R])oc([Al])c21</smiles>

171a-h

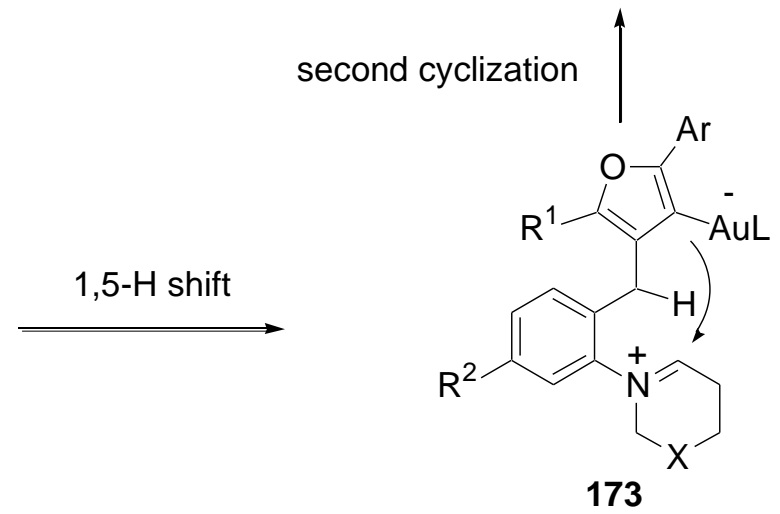

$$
\mathrm{R}^{1} \quad \operatorname{Ar} \quad \mathrm{X} \quad \mathrm{R}^{2} \quad \text { Yield ee }
$$

$\begin{array}{cccccc}\mathrm{Me} & \mathrm{Ph} & \mathrm{O} & \mathrm{Br} & 94 & 97 \\ \mathrm{Me} & o-\mathrm{MeOC}_{6} \mathrm{H}_{4} & \mathrm{O} & \mathrm{H} & 92 & 93 \\ \mathrm{Me} & p-\mathrm{Tol} & \mathrm{O} & \mathrm{H} & 91 & 99 \\ \mathrm{Me} & p-\mathrm{AcC}_{6} \mathrm{H}_{4} & \mathrm{O} & \mathrm{H} & 95 & 95 \\ \mathrm{Me} & p-\mathrm{MeO}_{2} \mathrm{CC}_{6} \mathrm{H}_{4} & \mathrm{O} & \mathrm{H} & 92 & 95 \\ \mathrm{Me} & \mathrm{Naph}_{\mathrm{Et}}^{\mathrm{Ph}} & \mathrm{O} & \mathrm{H} & 87 & 92 \\ \mathrm{Me} & p-\mathrm{MeOC}_{6} \mathrm{H}_{4} & \mathrm{O} & \mathrm{H} & 83 & 90 \\ & \mathrm{CH}_{2} & \mathrm{H} & 92 & 96\end{array}$

Scheme 43. Au-catalyzed domino intramolecular cyclization-1,5-hydride transfer-cyclization reaction.

In another context, Toste et al. have reported the use of the same chiral ligand $(R)$-MeO-dtbm-BIPHEP and its closely related analogue $(R)$-MeO-dtb-BIPHEP to induce chirality in gold(I)-catalyzed 
enantioselective domino polycyclization reactions of a range of functionalized 1,6-enynes. ${ }^{[110]}$ As shown in Scheme 44, the carboxylic acids 174a-b were bicyclized under gold catalysis into the corresponding bicyclic lactones 175a-b in good yields and high enantioselectivities of $92 \%$ ee through a highly enantioselective polyene cyclization reaction in which transition metal-promoted alkyne activation served as the cyclization initiating event. The scope of this methodology was extended to phenoxy-substituted phenyl alkynes 176a-c, which provided the corresponding chiral hexahydroxanthene derivatives $\mathbf{1 7 7 a - c}$ in excellent yields and enantioselectivities of up to $94 \% e e$, as shown in Scheme 44. Additionally, the use of an electron-rich aryl group as a nucleophile on substrate $\mathbf{1 7 8}$ allowed for the enantioselective formation of $\mathbf{1 7 9}$, which contained a benzylic quaternary center in 98\% yield and $94 \%$ ee (Scheme 44). These results have constituted the first example of a highly enantioselective polyene cyclization reaction in which transition metal-promoted alkyne activation served as the cyclization initiating event. In another context, Liu et al. have recently reported the stereoselective synthesis of azacyclic products through a gold-catalyzed domino redox $-[2+2+2]$ cycloaddition reaction of 1-alkynyl-2-nitrobenzenes and a range of alkenes. ${ }^{[111]}$ The authors have developed an enantioselective version of this methodology by employing a gold complex of $(R)$-DM-Segphos. When this ligand was used to induce the domino reaction between 1-ethynyl-2nitrobenzene and 2,3-dihydrofuran, the corresponding azacyclic product was obtained as a single diastereomer with a moderate enantioselectivity of $73 \%$ ee. 
<smiles>[X][M]CC=C(C)CC(CC(=O)OCC)(CC(=O)OCC)C(=O)OCC</smiles>

$174 a-b$

$$
\begin{gathered}
{\left[\mathrm{L}^{*}(\mathrm{AuCl})_{2}\right](3-5 \mathrm{~mol} \%)} \\
\mathrm{AgSbF}_{6}(3-5 \mathrm{~mol} \%)
\end{gathered}
$$

$m$-xylene, r.t.

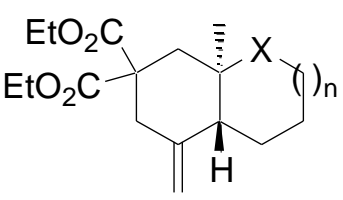

$175 a-b$

with $\mathrm{L}^{*}=(R)$-MeO-dtb-BIPHEP, $\mathrm{X}=\mathrm{OCO}, \mathrm{n}=0: 86 \%$, ee $=92 \%$

with $\mathrm{L}^{*}=(R)$-MeO-dtbm-BIPHEP, $\mathrm{X}=\mathrm{NTs}, \mathrm{n}=1: 75 \%$, ee $=92 \%$<smiles>[R]C#CCC(CC(C)=CCc1cc([X])ccc1O)(C(=O)OCC)C(=O)OCC</smiles>

$\left[(R)-\mathrm{MeO}-\mathrm{dtbm}-\mathrm{BIPHEP}(\mathrm{AuCl})_{2}\right]$

(5 mol\%)

$$
\frac{\mathrm{AgSbF}_{6}(5 \mathrm{~mol} \%)}{m \text {-xylene, r.t. }}
$$<smiles>[R]C=C1C[C@](C)(COCC)C[C@]2(C)Oc3ccc([X])cc3C[C@H]12</smiles>

$\mathrm{R}=\mathrm{X}=\mathrm{H}: 96 \%, e e=93 \%$

$177 a-c$

$\mathrm{R}=\mathrm{H}, \mathrm{X}=\mathrm{OMe}: 98 \%$, ee $=94 \%$

$\mathrm{R}=\mathrm{Me}, \mathrm{X}=\mathrm{H}: 93 \%, e e=93 \%$

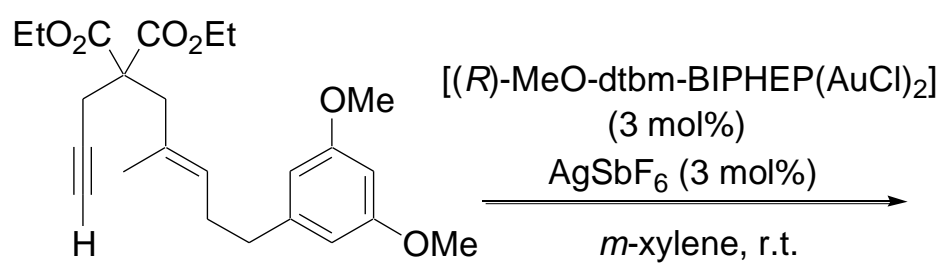

178<smiles>C=C1CC(C)(C(=O)OCC)CC2c3c(cc(OC)cc3OC)CC[C@H]12</smiles>

179

$98 \%, e e=94 \%$<smiles>COc1cccc(OC)c1-c1c(OC)cccc1P(#N)(=O)c1ccccc1</smiles>

(R)-MeO-dtb-BIPHEP<smiles>COc1cccc(OC)c1-c1c(OC)cccc1P(#N)(=O)c1ccccc1</smiles>

(R)-MeO-dtbm-BIPHEP

$\mathrm{Ar}=4-\mathrm{MeO}-3,5-(t-\mathrm{Bu})_{2}-\mathrm{C}_{6} \mathrm{H}_{2}$

Scheme 44. Au-catalyzed domino polycyclization reactions.

In 2008, Glueck et al. showed that enantioselective domino alkylation-arylation reacton of primary phosphines with 1-bromo-8-chloromethylnaphthalene could be catalyzed by $\mathrm{Pt}(\mathrm{DuPhos})$ complexes to provide the corresponding P-stereogenic 1-phosphaacenaphthenes in moderate enantioselectivities of up to $74 \% e e .^{[112]}$ In the same year, Gagné et al. reported the enantioselective platinum-catalyzed cascade cyclization of 3,7-dienol substrates to give the corresponding bicyclic products. ${ }^{[113]}$ Among a wide variety of chiral readily available diphosphine ligands investigated in this process, platinum complex of $(S)$-Xylylphanephos was shown to be the most effective, providing low to good enantioselectivities of up to $87 \%$ ee. The reaction was compatible with monosubstitution and 1,2disubstitution at the terminal alkene, however, $Z$ alkenes were better behaved than the $E$ alkenes. In each case of substrates investigated, a single stereo- and regioisomer of the product was obtained. Although perfect sterospecificity was observed in the $E$ and $Z$ substrates, they markedly differed in their enantioselectivities. Indeed, the terminal $Z$ alkene cyclized with the highest enantioselectivities 
( $87 \%$ ee), whereas non-substituted terminal alkenes provided moderate to good enantioselectivities (79\% ee), and terminal $E$ alkenes poor enantioselectivities (10-12\% ee). On the other hand, a coppercatalyzed enantioselective domino reaction based on an aziridination reaction followed by a Friedel-Crafts cyclization was recently developed by Hajra et al. ${ }^{[114]}$ As shown in Scheme 45, styrene 180 was reacted with $\mathrm{PhINNs}$ in the presence of $\mathrm{Cu}(\mathrm{OTf})_{2}$ and $(R)$-phenyl glycinol-derived $(R)$-Box ligand 182, to give the corresponding chiral bicyclic domino product $\mathbf{1 8 1}$ in $82 \%$ yield, almost complete trans-diastereoselectivity and enantioselectivity of $95 \%$ ee. As depicted in Scheme 45, styrene 180 was converted in a first step into the corresponding chiral aziridine 183 (nouveau) by reaction with PhINNs. Then, aziridine $\mathbf{1 8 3}$ was submitted to ring-opening through a Friedel-Crafts reaction type cyclization to lead to the final product $\mathbf{1 8 1}$. The utility of this methodology was illustrated in a total synthesis a dopamine D1 agonist, A-86929.
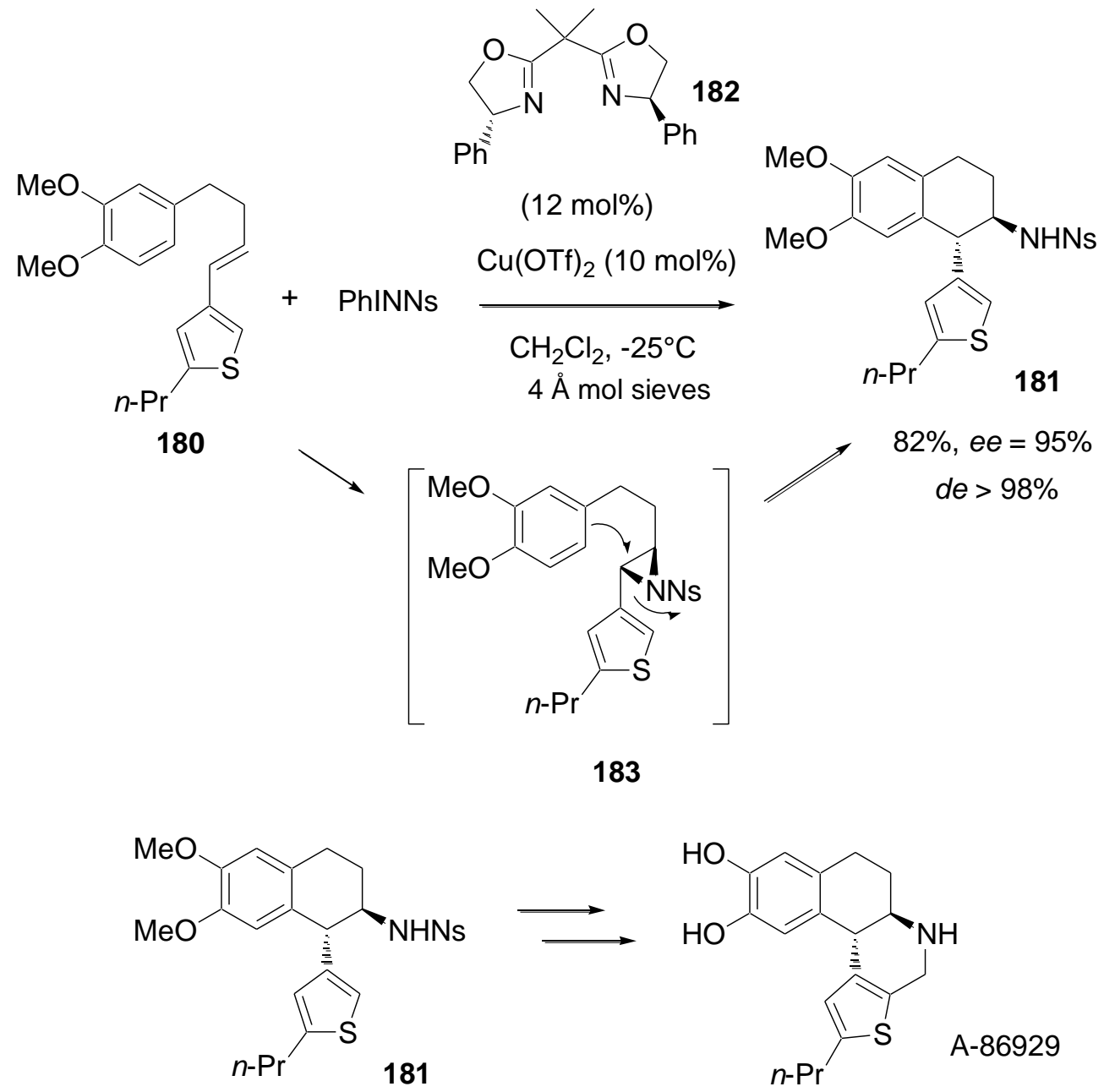

Scheme 45. Cu-catalyzed domino aziridination-Friedel-Crafts cyclization reaction and synthesis of dopamine D1 agonist, A-86929.

In a recent work, Toste et al. have reported the enantioselective synthesis of highly substituted furans on the basis of a copper(II)-catalyzed domino cycloisomerization-indole addition reaction. ${ }^{[15]}$ As shown in Scheme 46, copper(II) catalyst of chiral phosphine $\mathbf{1 8 6}$ promoted the intramolecular heterocyclization of a range of 2-(1-alkynyl)-2-alkene-1-ones 184a-f and facilitated high levels of enantioselectivity in the subsequent nucleophilic attack of indoles 185a-d, providing the corresponding tetracyclic products $\mathbf{1 8 7 a - i}$. The reaction showed a wide substrate scope since both aromatic and aliphatic alkynes gave high yields and enantioselectivities of up to $94 \%$ ee. Similarly, electronic variations in the aryl ring of the indole scaffold were also tolerated, as both electro donating and withdrawing substituents gave the desired products in high yields and enantioselectivities. However, 2-methyl indole proved to be a difficult substrate for the reaction as only $16 \%$ yield was 
reached in this case of substrate. The authors have demonstrated that formation of a copper(II)-indole species was important for the catalysis of the process.<smiles>[3H]C#CC1=CCCCC1=O</smiles>

184a-f<smiles>[R]c1ccc2cc([R])[nH]c2c1</smiles>

$185 a-d$

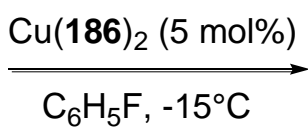

$4 \AA$ mol sieves<smiles>[R]c1ccc2[nH]c([R9])c([C@@H]3CCCc4oc([R])cc43)c2c1</smiles>

$187 a-i$

$$
\mathrm{R}^{1} \quad \mathrm{R}^{2} \quad \mathrm{R}^{3} \quad \text { Yield ee }
$$

(\%) (\%)

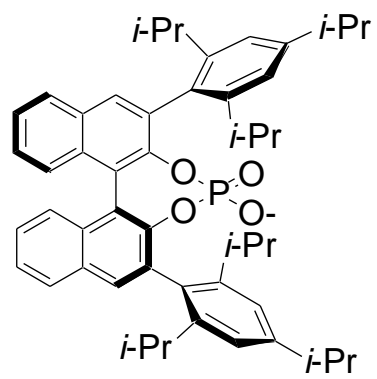

\begin{tabular}{ccccc}
\hline $\mathrm{Ph}$ & $\mathrm{H}$ & $\mathrm{H}$ & 92 & 91 \\
$p-\mathrm{MeOC}_{6} \mathrm{H}_{4}$ & $\mathrm{H}$ & $\mathrm{H}$ & 82 & 92 \\
$p$-Tol & $\mathrm{H}$ & $\mathrm{H}$ & 85 & 90 \\
$p-t-\mathrm{BuC}_{6} \mathrm{H}_{4}$ & $\mathrm{H}$ & $\mathrm{H}$ & 85 & 90 \\
$\mathrm{Bn}$ & $\mathrm{H}$ & $\mathrm{H}$ & 84 & 73 \\
$\mathrm{Cy}$ & $\mathrm{H}$ & $\mathrm{H}$ & 85 & 94 \\
$\mathrm{Ph}$ & $5-\mathrm{Br}$ & $\mathrm{H}$ & 90 & 93 \\
$\mathrm{Ph}$ & $5-\mathrm{Cl}$ & $\mathrm{H}$ & 81 & 90 \\
$\mathrm{Ph}$ & $\mathrm{H}$ & $\mathrm{Me}$ & 16 & 85
\end{tabular}

Scheme 46. Cu-catalyzed domino cycloisomerization-nucleophile addition reaction.

\subsection{Domino Radical Reactions}

In recent years, studies on enantioselective radical reactions have achieved some remarkable success, particularly in intermolecular reactions. ${ }^{[116]}$ In contrast, only few reports have described enantioselective radical cyclizations. As a recent example, Takemoto et al. have developed enantioselective domino radical addition-cyclization reactions of hydroxamate esters 188a-b with alkyl iodides. ${ }^{[117]}$ These reactions were induced by one equivalent of a combination of $\mathrm{Zn}(\mathrm{OTf})_{2}$ with chiral ligand 189 in the presence of one equivalent of triethylborane which played the role of radical initiator. The process afforded diastereoselectively the corresponding cis-lactams 190a-c in moderate yields and enantioselectivities of up to $88 \%$ ee. As shown in Scheme 47, the domino reaction began with the addition of radical arising from alkyl iodide to hydroxamate esters $\mathbf{1 8 8 a}-\mathbf{b}$, which generated radical intermediates $\mathbf{1 9 1}$. The later subsequently cyclized to give intermediates $\mathbf{1 9 2}$. Then, an iodide atom-transfer process from secondary or tertiary alkyl iodide $\left(\mathrm{R}^{2} \mathrm{I}\right)$ to unstable primary intermediate radicals occurred, providing the final lactams 190a-c. It must be noted that the reaction of 193 with alkyl iodides led to the formation of the corresponding trans-lactams 194a-c in higher enantioselectivities of up to $92 \%$ ee, albeit lower yields and diastereoselectivities (Scheme 47). In spite of good results obtained by using this methodology, it suffered from the disadvantageous of requiring one equivalent of catalyst. 

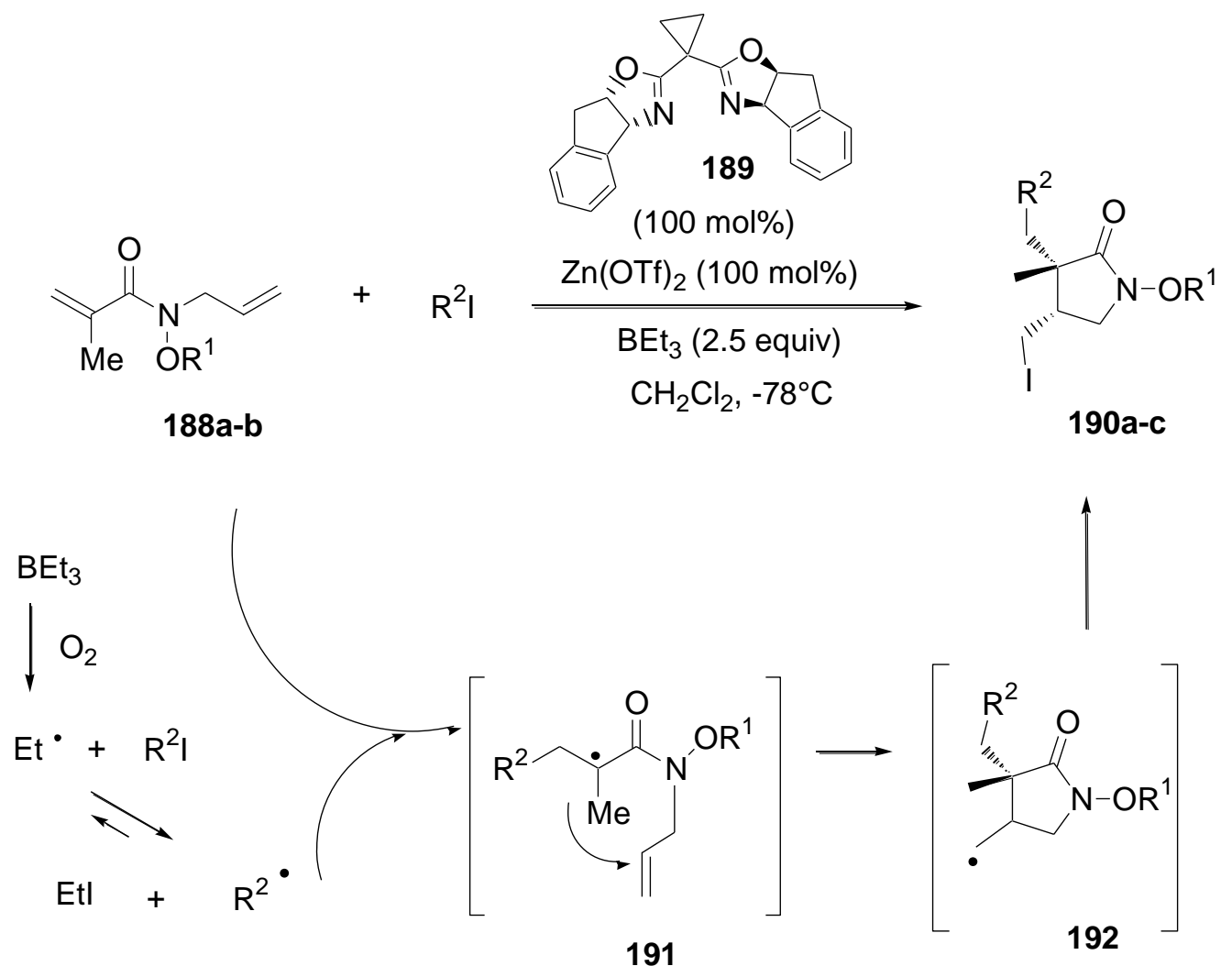

$$
\begin{aligned}
& \mathrm{R}^{1} \quad \mathrm{R}^{2} \quad \text { Yield de ee } \\
& \text { (\%) } \quad(\%) \quad(\%) \\
& \text { Me } \quad i-\operatorname{Pr} \quad 75>96 \quad 82 \\
& t-\mathrm{Bu} \quad i-\operatorname{Pr} \quad 71>96 \quad 75 \\
& \begin{array}{llll}
\mathrm{Me} & t-\mathrm{Bu} & 78 & >96 \quad 88
\end{array}
\end{aligned}
$$
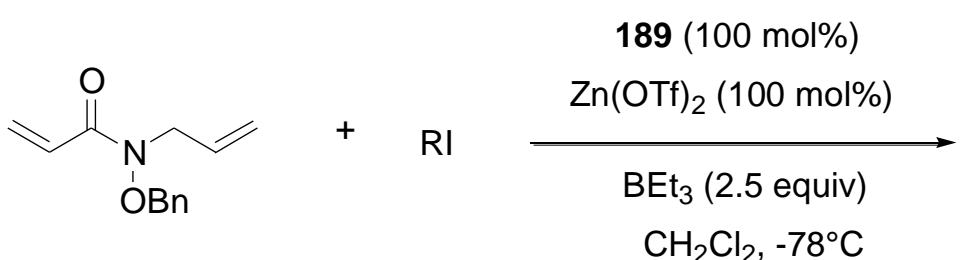

\begin{tabular}{cccc}
\hline$i-\operatorname{Pr}$ & 52 & 84 & 92 \\
Cy & 57 & 88 & 92 \\
$c$-Pent & 35 & 88 & 91
\end{tabular}

Scheme 47. Zn-catalyzed domino radical addition-cyclization reactions of hydroxamate esters with alkyl iodides.

The scope of this methodology was extended to the domino radical addition-cyclization reaction of closely related hydroxamate esters bearing an alkyne moiety instead of the alkene moiety in 183, which afforded the corresponding domino products in both high yields and diastereoselectivities, combined with good enantioselectivities of up to $92 \% e e e^{[117]}$ The authors have shown that reduction of 
the catalyst loading to $10 \mathrm{~mol} \%$ resulted in a decrease of the chemical yield and enantioselectivity. Furthermore, these conditions were also applied to the enantioselective zinc-catalyzed domino radical addition-cyclization reaction of oxime ethers, which produced the corresponding trans-lactams in moderate yields, diastereo- and enantioselectivities of up to $86 \%$ de, and $86 \%$ ee, respectively. ${ }^{[18]}$ Finally, Yang et al. reported the first enantioselective catalytic domino group-transfer-radical cyclization reaction, in 2006. ${ }^{[119]}$ This work delt with the enantioselective PhSe-group-transfer radical cyclization reaction of $\alpha$ (phenylseleno)- $\beta$-ketoesters 196a-b which was catalyzed by a complex generated from $\mathrm{Mg}\left(\mathrm{ClO}_{4}\right)_{2}$ and chiral bisoxazoline 195 to give the corresponding bicyclic products 197a-b. Substrate 196a $(\mathrm{n}=1)$ led to cis-6,5-fused ring product $197 \mathbf{a}$ in $70 \%$ yield and $67 \%$ ee, whereas substrate 196b $(\mathrm{n}=2)$ underwent 6-endo/6-exo cyclization to give the corresponding 6,6trans-fused ring product 197b in 33\% yield and 87\% ee, as shown in Scheme 48.

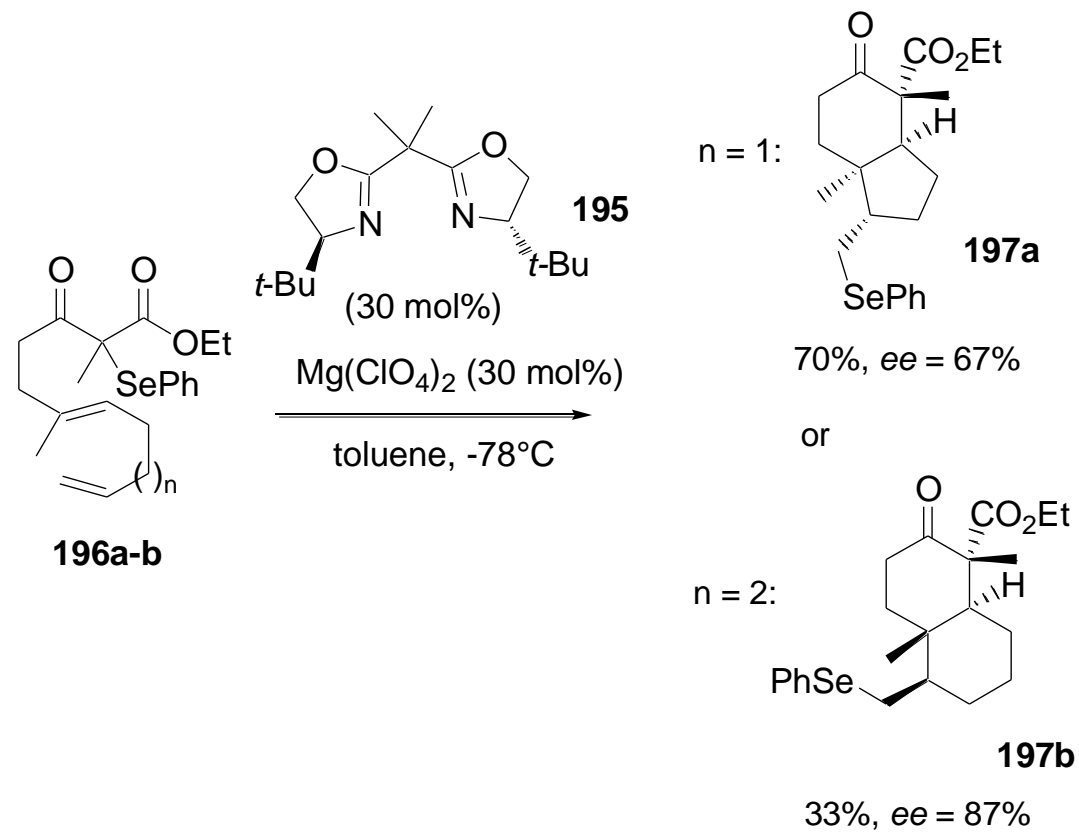

Scheme 48. Mg-catalyzed domino group-transfer-radical cyclization reaction.

\subsection{Miscellaneous Domino Reactions}

In 2007, Willis et al. have described enantioselective addition of imide 198 to $N$-tosylimines 199a-l, providing the corresponding cyclized Mannich adducts 200a-l in both general excellent yields and enantioselectivities of up to $99 \%$ ee, albeit moderate to good anti diastereoselectivities, as shown in Scheme 49. ${ }^{[120]}$ The reaction was catalyzed by a chiral magnesium complex in situ generated from $\mathrm{Mg}\left(\mathrm{ClO}_{4}\right)_{2}$ and a chiral bisoxazoline ligand 201, which was selected among a series of chiral ligands tested, including other bisoxazoline ligands such as PyBox ligands. As shown in Scheme 49, a variety of aryl-, alkenyl-, and alkyl-derived imines could be employed, allowing a novel enantioselective route to anti configured protected $\alpha, \beta$-diamino acids 200a-l on the basis of a direct enantioselective Mannich reaction. 


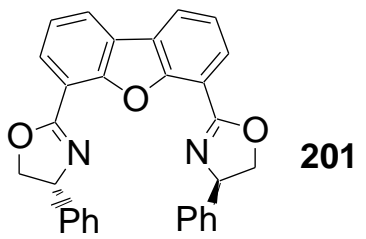

(11 $\mathrm{mol} \%)$

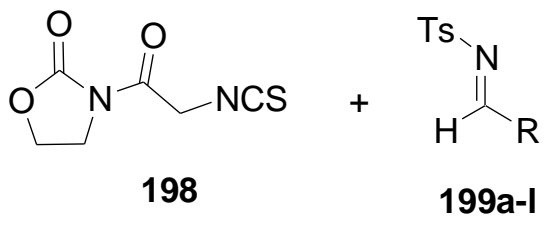

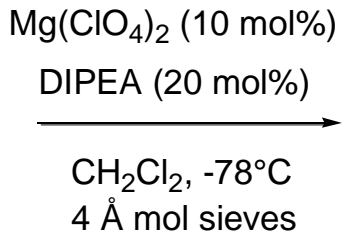

$4 \AA \mathrm{mol}$ sieves<smiles>[R]C1C(C(=O)N2CCOC2=O)NC(=S)[N+]1[S-]</smiles>

200a-I

\begin{tabular}{cccc}
$\mathrm{R}$ & $\begin{array}{l}\text { Yield } \\
(\%)\end{array}$ & syn:anti & $\begin{array}{c}\text { ee (anti) } \\
(\%)\end{array}$ \\
\hline$p$-Tol & 96 & $12: 88$ & 99 \\
$m$-Tol & 91 & $14: 86$ & 99 \\
$o-$ Tol & 94 & $14: 86$ & 99 \\
$p-(t-\mathrm{Bu}) \mathrm{C}_{6} \mathrm{H}_{4}$ & 96 & $18: 82$ & 99 \\
$p-\mathrm{MeOC}_{6} \mathrm{H}_{4}$ & 86 & $24: 76$ & 97 \\
$p-\mathrm{ClC}_{6} \mathrm{H}_{4}$ & 98 & $20: 80$ & 95 \\
$p-\mathrm{CNC}_{6} \mathrm{H}_{4}$ & 85 & $32: 68$ & 99 \\
$3-$ furyl & 94 & $14: 86$ & 91 \\
$2-N-\mathrm{Ts}$-indolyl & 99 & $10: 90$ & 99 \\
$(E)-$ cinnamyl & 97 & $22: 78$ & 97 \\
Cy & 98 & $32: 68$ & 99 \\
$c-\mathrm{Pr}$ & 96 & $28: 72$ & 85
\end{tabular}

Scheme 49. Mg-catalyzed Mannich reaction.

In another context, Fu et al. have established that, through the use of a planar chiral bipyridine ligand, enantioselective copper-catalyzed [4+1] cycloadditions of $\alpha, \beta$-unsaturated ketones with diazoacetates could produce highly substituted 2,3-dihydrofurans in good yields, and both high diastereo- and enantioselectivities of up to $>90 \%$ de and $92 \%$ ee, respectively. ${ }^{[121]}$ The best results were reached with enones having unsaturated substituents. The transition metal-mediated conversion of alkynes, alkenes and carbon monoxide in a formal $[2+2+1]$ cycloaddition manner, commonly known as the Pauson-Khand reaction is an elegant protocol for the construction of cyclopentenones. ${ }^{[122]}$ Asymmetric versions of this reaction have been included in various domino reactions. In this context, Kwong et al. have reported tandem rhodium-catalyzed cooperative decarbonylation and asymmetric Pauson-Khand-type cyclization reactions of 1,6-enynes in which a formate or an aldehyde was a CO surrogate. ${ }^{[123]}$ In the presence of a chiral rhodium complex, generated from $[\mathrm{Rh}(\operatorname{cod}) \mathrm{Cl}]_{2}$ and $(S)$ BisbenzodioxanPhos as chiral ligand, a series of oxygen-, amine-, and carbon-tethered 1,6-enynes reacted under microwave with cinnamaldehyde as a source of $\mathrm{CO}$ to give the corresponding cyclopentenones in moderate to good yields (40-73\%), and moderate to good enantioselectivities (49$90 \%$ ee). In another context, Nishibayashi et al. have reported the ruthenium-catalyzed enantioselective formal [3+3] cycloaddition of propargylic alcohols 202a-d with 2-naphthols 203a-b, which afforded the corresponding naphthopyran derivatives 204a-g in moderate to good yields and high enantioselectivities of up to $99 \% e e$, as shown in Scheme $50 .{ }^{[124]}$ The process was induced by chiral thiolate-bridged diruthenium complex 205 in combination with $\mathrm{NaBH}_{4} \mathrm{BF}_{4}$. The authors assumed that the process proceeded via stepwise reactions of propargylation and intramolecular 
cyclization, in which ruthenium-allenylidene and vinylidene complexes worked as key reactive intermediates, respectively.

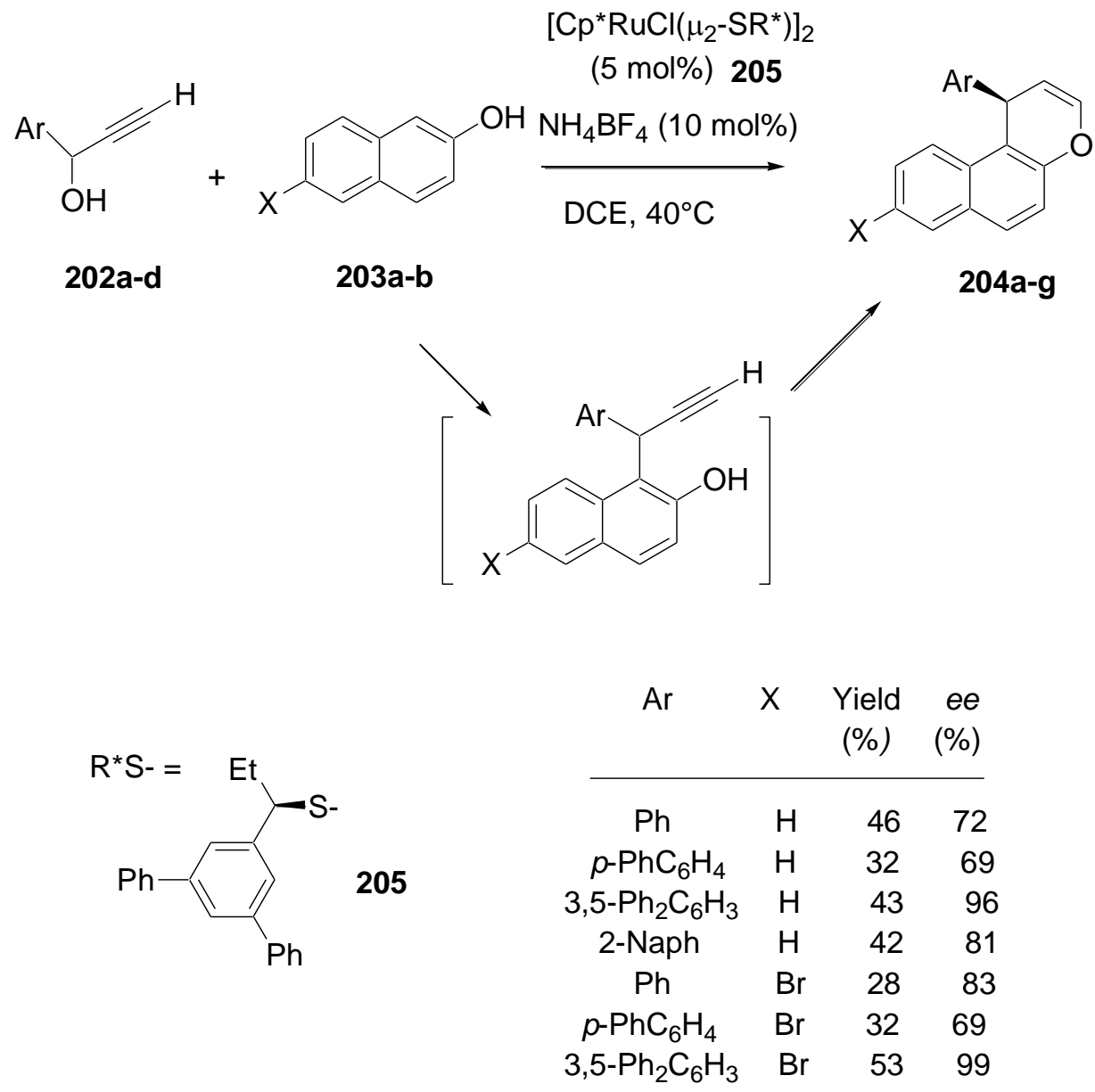

Scheme 50. Ru-catalyzed domino propargylation-intramolecular cyclization reaction.

The enantioselective reductive amination of ketones in a one-pot reaction without isolation of the intermediates by using multifunctional catalysts remains a challenge of high importance. In this context, Bruneau et al. have developed an enantioselective domino reductive amination of 2-tetralone into the corresponding chiral amine ${ }^{[125]}$ By parallel screening of a small library of ligands incorporated with three different metals, such as ruthenium, rhodium, and iridium, the catalytic system, $\left\{\mathrm{Ru}(\mathrm{cod})\left(\mathrm{O}_{2} \mathrm{CCF}_{3}\right)_{2}+(S)-\mathrm{MeOBIPHEP}\right\}$, was found to be superior. When this system was used in the presence of hydrogen, it allowed the chiral amine to be produced with enantioselectivity of up to $47 \%$ $e e$. On the other hand, Londregan et al. have developed an enantioselective synthesis of $(R)$-3-amino3,4-dihydro-1 $H$-[1,8]naphthyridin-2-one $\mathbf{2 0 6}$ based on a novel asymmetric domino reduction-lactamization reaction of the corresponding enone 207. ${ }^{[126]}$ Upon hydrogenation in the presence of $\mathrm{Ru}((R)-\mathrm{BINAP}) \mathrm{OAc}_{2}$ as catalyst, the bicyclic product $(R)-\mathbf{2 0 6}$ was achieved in both excellent yield and enantioselectivity of $97 \%$ and $98 \%$ ee, respectively, as shown in Scheme 51. Furthermore, the authors have demonstrated that by simply switching the chirality of the ruthenium catalyst to $\mathrm{Ru}\left((S)\right.$-BINAP)OAc $\mathrm{OAn}_{2}$ under identical reaction conditions, the corresponding enantiomeric product, $(S)$-206, was obtained in $97 \%$ yield and $97 \%$ ee . 


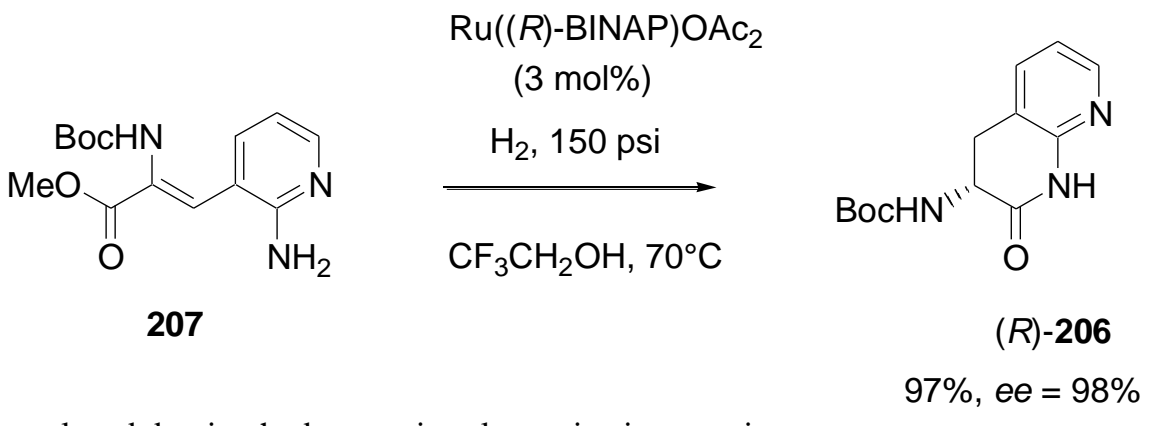

Scheme 51. Ru-catalyzed domino hydrogenation-lactamization reaction.

In 2010, Peters et al. applied the cooperative activation by a soft bimetallic catalyst, a hard Brønsted acid, and a hard Brønsted base to the formation of highly enantioenriched, diastereomerically pure masked $\alpha$-amino acids 208a-j bearing adjacent quaternary and tertiary stereocenters on the basis of a domino azlactone formation-Michael addition reaction starting from $N$-benzoylated amino acids 209a-c and $\alpha, \beta$-unsaturated ketones 210a-h. ${ }^{[127]}$ As shown in Scheme 52, the best results for the domino reaction were achieved when bispalladacycle FBIP-Cl was activated by AgOTf in the presence of catalytic amounts of NaOAc. Since the activated catalyst was stable toward acetic anhydride, the in situ formation of azlactones 212a-c could be achieved through $O$-acylation with acetic anhydride of $N$-benzoylated amino acids 209a-c, generating mixed anhydrides 211a-c. In a second time, the azlactones 212a-c added to $\alpha, \beta$-unsaturated ketones 210a-h through a Michael addition to give the final products 208a-j in high yields combined with excellent diastereo- and enantioselectivities of up to $>96 \%$ de and $99 \%$ ee, respectively. The formed chiral products could be applied to prepare bicyclic dipeptides. 
<smiles>[R]C(NC(=O)c1ccccc1)C(=O)OC(C)=O</smiles>

$\mathrm{Ac}_{2} \mathrm{O} \|$ in situ azlactone formation<smiles>[R]C(NC(=O)c1ccccc1)C(=O)O</smiles>

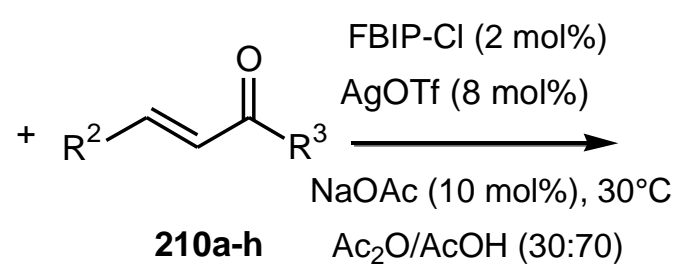

209a-c 210a-h $\quad \mathrm{Ac}_{2} \mathrm{O} / \mathrm{AcOH}(30: 70)$<smiles>[R]C(=O)CC([R7])[C@]1([2H])N=C(c2ccccc2)OC1=O</smiles>

\begin{tabular}{|c|c|c|c|}
\hline $\mathrm{R}^{1}$ & $\mathrm{R}^{2}$ & $\mathrm{R}^{3}$ & $\begin{array}{c}\text { Yield } \\
(\%)\end{array}$ \\
\hline
\end{tabular}

$\begin{array}{lcccc}\mathrm{Me} & \mathrm{Ph} & \mathrm{Me} & 95 & 76 \\ \mathrm{Et} & \mathrm{Ph} & \mathrm{Me} & 92 & 93 \\ \mathrm{Et} & \mathrm{Me} & \mathrm{Et} & 92 & 87 \\ n-\mathrm{Pr} & \mathrm{Ph} & \mathrm{Me} & 89 & 98 \\ n-\mathrm{Pr} & p-\mathrm{ClC}_{6} \mathrm{H}_{4} & \mathrm{Me} & 85 & 98 \\ n-\mathrm{Pr} & o-\mathrm{ClC}_{6} \mathrm{H}_{4} & \mathrm{Me} & 82 & 99 \\ n-\mathrm{Pr} & p-\mathrm{NO}_{2} \mathrm{C}_{6} \mathrm{H}_{4} & \mathrm{Me} & 76 & 98 \\ n-\operatorname{Pr} & 2-\text { furyl } & \mathrm{Me} & 88 & 96 \\ n-\operatorname{Pr} & \mathrm{Ph} & \mathrm{Ph} & 87 & 90 \\ n-\operatorname{Pr} & i-\mathrm{Pr} & \mathrm{Me} & 64 & >97\end{array}$

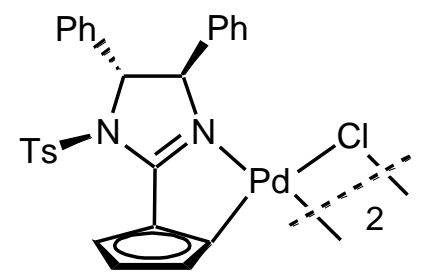

$\mathrm{Fe}$

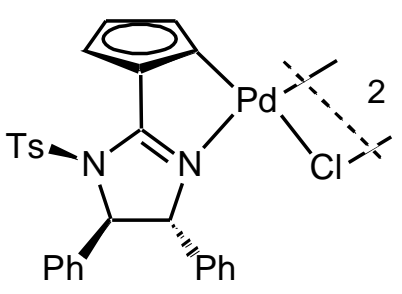

FBIP-Cl

Scheme 52. Ag-catalyzed domino azlactone formation-Michael addition reaction. 
In 2011, chiral 2-substituted-1,5-benzodiazepine derivatives were synthesized for the first time from an enantioselective domino reaction involving o-phenylenediamine 213 and 2'-hydroxychalcones 214a-i. ${ }^{[128]}$ The process was induced by a titanium complex formed from chiral ligand $\mathbf{2 1 5}$ derived from $(S)$-BINOL and L-prolineamide and $\mathrm{Ti}(\mathrm{O} i \text {-Pr })_{4}$. It led to the formation of a range of 2-aryl-1,5benzodiazepine derivatives 216a-i in good yields and enantioselectivities of up to $82 \%$ ee, as shown in Scheme 53. The 2'-hydroxy group of the $\alpha, \beta$-unsaturated ketones was demonstrated to be critical for both the reactivity and stereoinduction of the process. In order to explain these results, the authors have proposed that the $\alpha, \beta$-unsaturated ketimine intermediate $\mathbf{2 1 7}$ formed in a first time might be stabilized by an intramolecular hydrogen bond of the hydroxyl group. In the presence of the chiral titanium complex, intermediate 217 could coordinate to the metal with the oxygen atom of the hydroxyl group and the nitrogen atom of the imine moiety to generate intermediate 218 . In intermediate 218, the amino group preferred to attack the $\beta$-Si face of the $\mathrm{C}=\mathrm{C}$ bond due to the fact that there was less steric hindrance between the aniline moiety of the ligand. Thus, $(S)$-216a-i were afforded through a final aza-Michael addition and the chiral titanium complex was released.<smiles>O=C(/C=C/[18F])c1ccccc1O</smiles>

214a-i<smiles>Nc1ccccc1N1Oc2ccccc2C1/C=C/[Al]</smiles><smiles>Nc1ccccc1N</smiles>

213

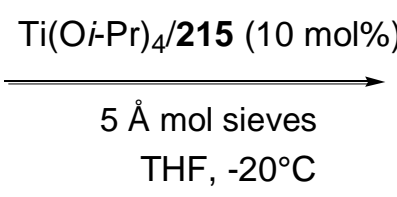

THF, $-20^{\circ} \mathrm{C}$<smiles>Oc1ccccc1C1=Nc2ccccc2NC(Br)=C1</smiles>

216a-i

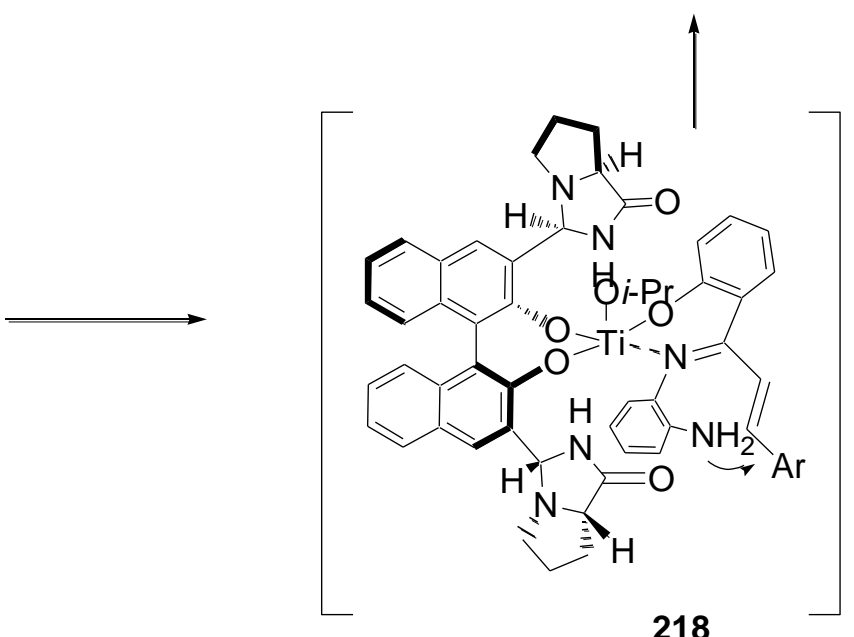

\section{8}

Ar Yield ee

$(\%) \quad(\%)$

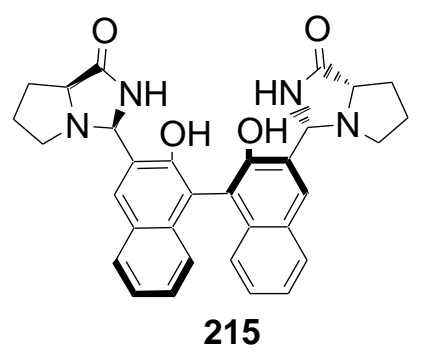

\begin{tabular}{ccc}
\hline \multicolumn{1}{c}{$\mathrm{Ph}$} & 71 & 73 \\
$o-\mathrm{Tol}$ & 62 & 71 \\
$m-\mathrm{Tol}$ & 73 & 73 \\
$o-\mathrm{MeOC}_{6} \mathrm{H}_{4}$ & 23 & 69 \\
$p-\mathrm{ClC}_{6} \mathrm{H}_{4}$ & 83 & 79 \\
$p-\mathrm{BrC}_{6} \mathrm{H}_{4}$ & 93 & 78 \\
$o-\mathrm{ClC}_{6} \mathrm{H}_{4}$ & 93 & 82 \\
$m-\mathrm{BrC}_{6} \mathrm{H}_{4}$ & 74 & 65 \\
$m-\mathrm{CF}_{3} \mathrm{C}_{6} \mathrm{H}_{4}$ & 94 & 67
\end{tabular}

Scheme 53. Ti-catalyzed domino imine formation-aza-Michael addition reaction.

The forerunner in the cobalt-catalyzed domino processes was that developed by Vollhardt et al. with their excellent synthesis of steroids initiated by a $[2+2+2]$ cycloaddition. ${ }^{[129]}$ Ever since, a number of 
other cobalt-catalyzed domino reactions have been developed. Among them, Feng et al. have reported a highly enantioselective synthesis of tetrahydroquinolines via cobalt(II)-catalyzed domino 1,5hydride transfer-cyclization reaction. ${ }^{[130]}$ As shown in Scheme 54, a chiral catalyst generated from Lproline-derived $N, N^{\prime}$-dioxide 221 and $\mathrm{Co}\left(\mathrm{BF}_{4}\right)_{2} \cdot 6 \mathrm{H}_{2} \mathrm{O}$ was applied to the asymmetric intramolecular hydride transfer initiated cyclization reaction of a series of $o$-dialkylamino-substituted alkylidene malonate derivatives 219a-i to provide the corresponding biologically interesting tetrahydroquinolines 220a-i in high to excellent yields and high enantioselectivities of up to $90 \% e e$. The mechanism of the process involved the formation of zwitterionic intermediate $\mathbf{2 2 2}$ through intramolecular hydride transfer, which subsequently cyclized to give the final product $\mathbf{2 2 0}$ (Scheme 54).

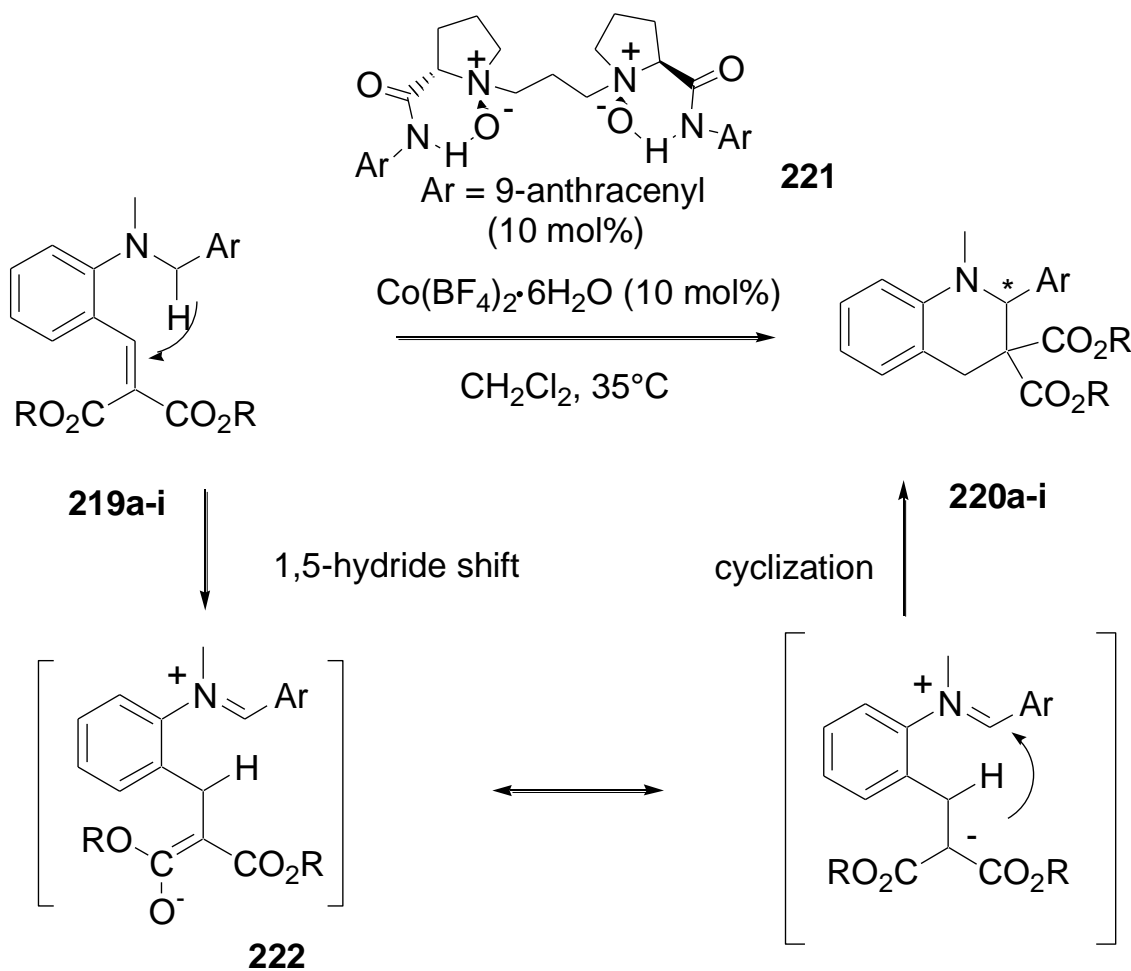

222

Scheme 54. Co-catalyzed domino 1,5-hydride transfer-cyclization reaction.

In another context, Davies et al. have recently developed a novel domino reaction initiated by the formation of an oxygen ylide and which involved vinyldiazoacetates and allylic alcohols as the substrates. The enantioselective domino reaction generated highly functionalized chiral cyclopentanes 223a-d bearing four stereogenic centers as almost single diastereomers ( $d e>90 \%)$ and moderate to high enantioselectivities of up to $92 \%$ ee, as shown in Scheme $55 .{ }^{[131]}$ The process was catalyzed by a combination of $\mathrm{Rh}_{2}(S \text {-DOSP })_{4}$ and $\mathrm{Sc}(\mathrm{OTf})_{3}$ and was supposed to evolve through five distinct steps. The authors assumed that the first step of the sequence was a rhodium-catalyzed oxygen ylide 
formation, which was followed by a [2,3]-sigmatropic rearrangement, an oxy-Cope rearrangement, a keto/enol tautomerization, and then finally a carbonyl ene reaction, as summarized in Scheme 55.

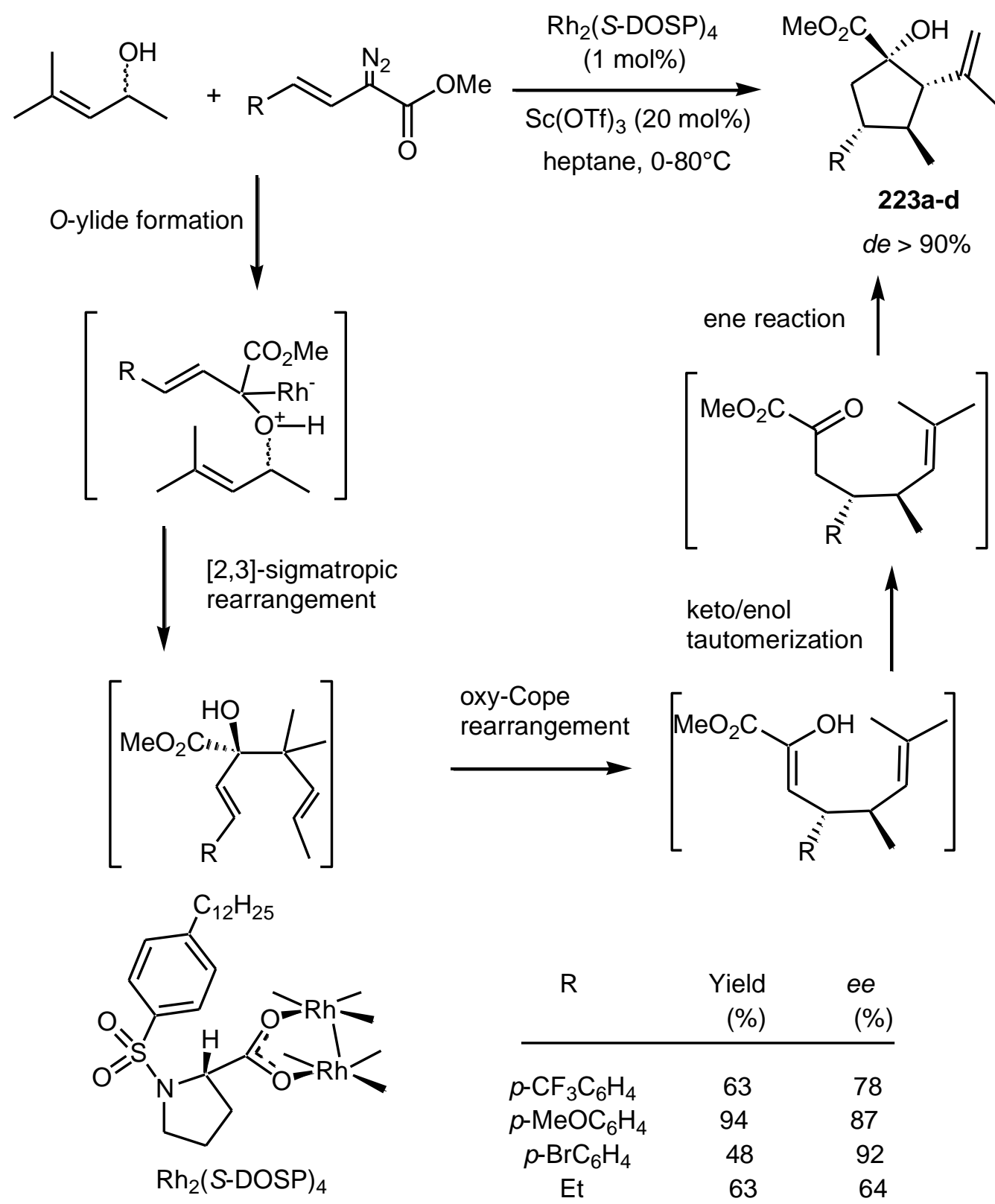

Scheme 55. Rh- and Sc-catalyzed domino oxygen ylide formation-[2,3]-sigmatropic rearrangement-oxy-Cope rearrangement-keto/enol tautomerization-carbonyl ene reaction of vinyldiazoacetates and allylic alcohol.

Finally, Lautens et al. have reported a novel enantioselective domino process in which rhodium was demonstrated to successively promote four reactions, such as asymmetric ring-opening reaction, allylic alcohol isomerization, acetalization, and oxidation. ${ }^{[132]}$ In this work, a series of chiral bicyclo[2.2.2]lactone products 224a-g were achieved in good yields and excellent enantioselectivities of up to $>98 \%$ ee by reaction occurring between the corresponding doubly bridgehead substituted oxabicyclic alkene 225 with a range of dialkyl amines 226a-g, as shown in Scheme 56. The asymmetric induction of the domino process was provided by using cationic $\mathrm{RhOTf} /(R, S \mathrm{p})-\mathrm{Josiphos}$ system as chiral catalyst. This result constituted the first intermolecular rhodium-catalyzed asymmetric ring-opening reaction of this type of substrates. In order to explain the results, the authors have proposed the mechanism depicted in Scheme 56. It was reasoned that the asymmetric ring-opening reaction was the first step of the process leading to intermediate $\mathbf{2 2 7}$ which contained an alkene function which could isomerize in a second step to the corresponding intermediate aldehyde $\mathbf{2 2 8}$. The later thus formed in close proximity to the tertiary alcohol function led to the formation of 
intermediate hemiacetal 229, which was finally oxidized under the reaction conditions to give the observed product 224.
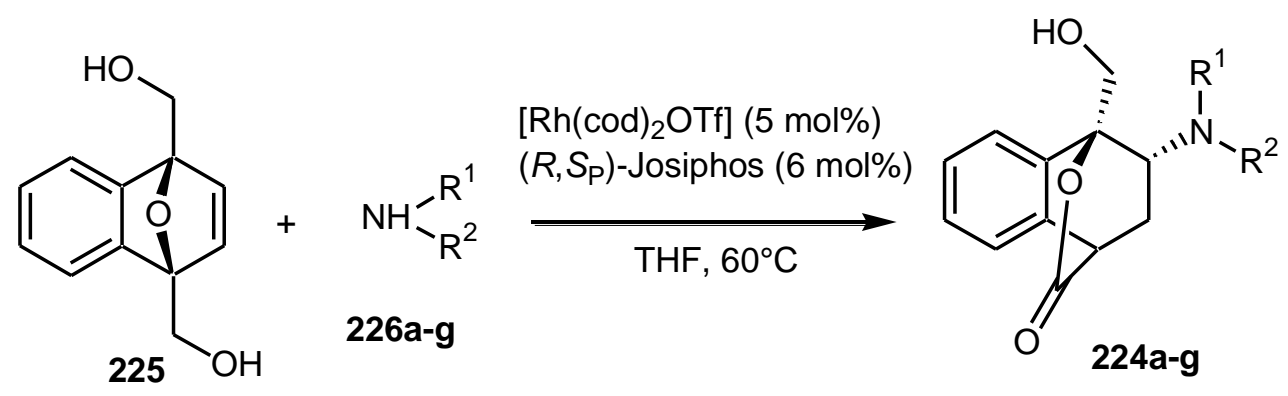

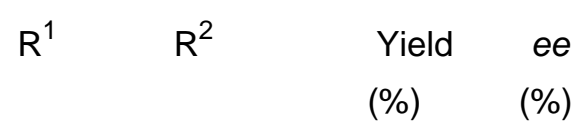

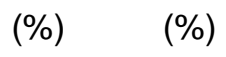

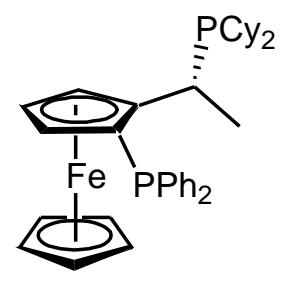

$\left(R, S_{\mathrm{P}}\right)$-Josiphos

proposed mechanism:<smiles>OCC12C=CC(CO)(O1)c1ccccc12</smiles>

\begin{tabular}{llcc}
$\mathrm{Me}$ & $\mathrm{Bn}$ & 65 & 98 \\
$\mathrm{Bn}$ & $\mathrm{Bn}$ & 58 & $>98$ \\
$n-\mathrm{Pr}$ & $n-\mathrm{Pr}$ & 64 & $>98$ \\
$\mathrm{Et}$ & $\mathrm{Et}$ & 64 & $>98$ \\
\multicolumn{2}{c}{$-\left(\mathrm{CH}_{2}\right)_{5}-$} & 62 & 97 \\
\multicolumn{2}{r}{$-\left(\mathrm{CH}_{2}\right)_{4}{ }^{-}$} & 65 & $>98$ \\
$\mathrm{Me} \quad\left(\mathrm{CH}_{2}\right)_{2} \mathrm{CO}_{2} \mathrm{Et}$ & 60 & $>98$
\end{tabular}<smiles>[R4]C1CC2O[C@]1(CO)c1ccccc1C2=O</smiles><smiles>CCOCCOCCO</smiles><smiles>CCC(CC)CCCOCCO</smiles>

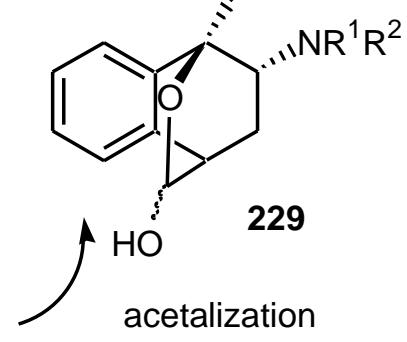<smiles>[R7]N[C@H]1C=C(CO)c2ccccc2[C@@]1(O)CO</smiles>
227 isomerization<smiles></smiles>

Scheme 56. Rh-catalyzed domino ring-opening-isomerization-acetalization-oxidation reaction.

\section{Multicomponent Reactions}

In spite of the recent emergence of organocatalysis, enantioselective metal-catalyzed multicomponent reactions represent the majority of catalytic enantioselective multicomponent reactions. Asymmetric 
organometallic catalysis has considerably contributed to the development of novel enantioselective metal-catalyzed multicomponent reactions. A range of various metal catalysts, such as copper, rhodium, gold, platinum, palladium, cobalt, ruthenium, scandium, magnesium, titanium, zinc, aluminum, nickel, silver, iridium, as well as tin have been demonstrated to induce a wide number of types of these powerful one-pot reactions, which allow reaching easily high molecular complexity in an economically favourable way with advantages of savings in solvent, time, energy, and costs by avoiding costly protecting groups and time-consuming purification procedures after each step. Even though the history of multicomponent reactions dates back to the second half of $19^{\text {th }}$ century with the reactions of Strecker, Hantzsch, and Biginelli, it was only in the last decades with the work of Ugi that the concept of multicomponent reaction has emerged as a powerful tool in synthetic chemistry. ${ }^{[133]}$

\subsection{Multicomponent Reactions initiated by the Michael Reaction}

Reactions which evolved through nucleophilic 1,4-addition of stabilized carbon nucleophiles to electron-poor olefins, generally $\alpha, \beta$-unsaturated carbonyl compounds, are considered as Michael additions. Michael-type reactions can be considered as one of the most powerful and reliable tools for the stereocontrolled formation of carbon-carbon and carbon-heteroatom bonds, as has been demonstrated by the huge number of examples in which it has been applied as a key strategic transformation in total synthesis. Since the first catalytic domino Michael-aldol reaction reported by Noyori et al. in 1996, ${ }^{[18]}$ there have been numerous examples of domino and multicomponent domino reactions initiated by the Michael reaction. Among them, a number of enantioselective metal-catalyzed Michael-initiated multicomponent reactions have been successfully developed. As a recent example, Yus et al. have reported a convenient access to enantiopure $\beta$-amino ketones 231a-h on the basis of a multicomponent reaction of dialkyl zinc reagents, cyclic enones, and chiral $N$-tert-butanesulfinimines 230a-d catalyzed by a copper complex of chiral phosphoramidite ligand 232. ${ }^{[134]}$ Three contiguous stereocenters and two carbon-carbon bonds could be generated with excellent stereocontrol through a double asymmetric induction, arising from the chiral ligand and the chiral $N$-tert-butanesulfinimine used, as shown in Scheme 57. The authors assumed that whereas the enantioselection at the cycle stereocenters was governed by the phosphoramidite auxiliary, in the case of the aminic $\alpha-C-$ stereocenter the asymmetric induction came from the tert-butylsulfinyl moiety. 


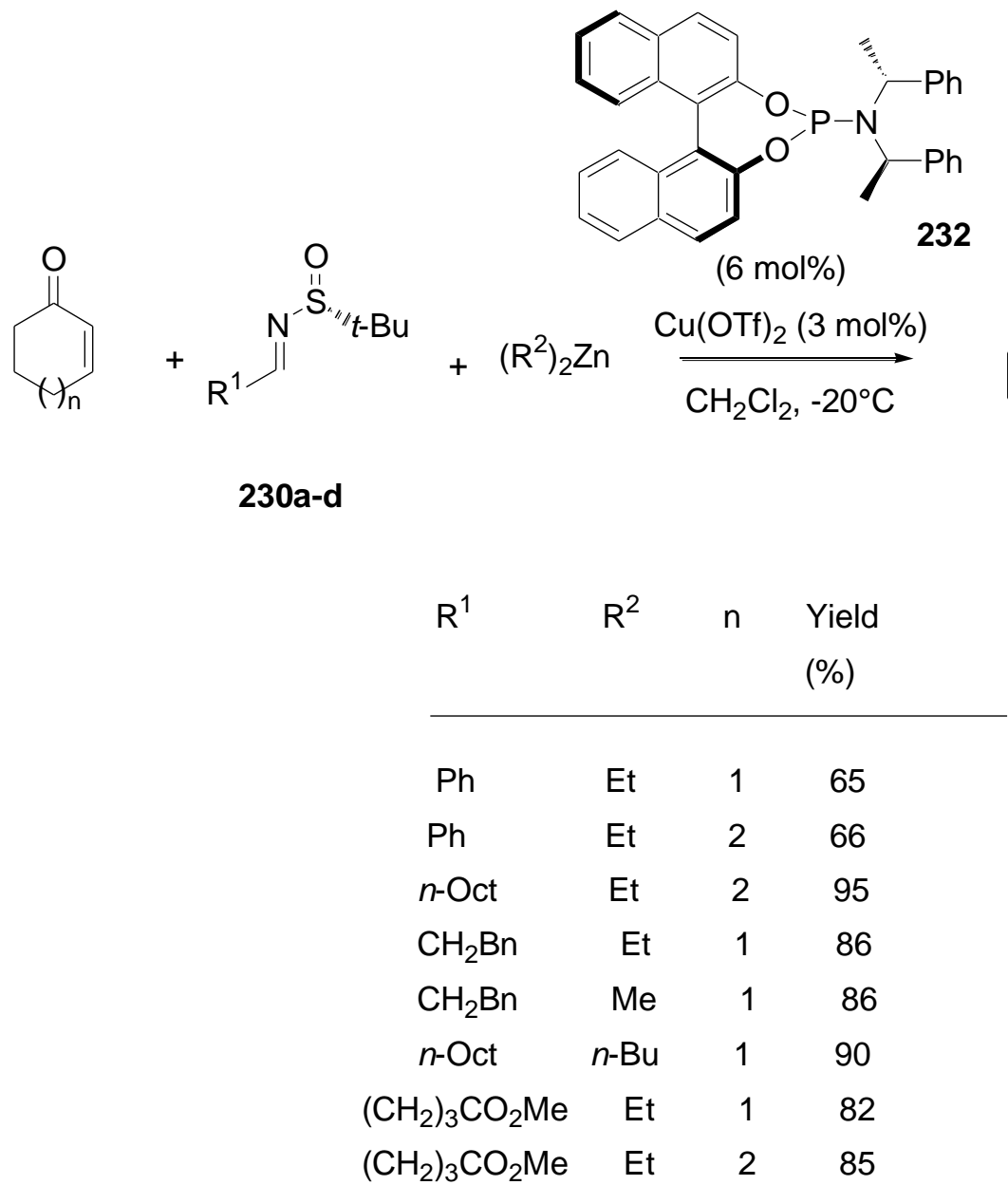

Scheme 57. Cu-catalyzed three-component domino Michael-Mannich reaction.

In the same area, Huang et al. have reported a highly diastereo- and enantioselective construction of three contiguous acyclic stereogenic centers through a copper-catalyzed multicomponent domino Michael-Mannich reaction of organozinc reagents, such as $\mathrm{ZnEt}_{2}$, and acyclic $\alpha, \beta$-unsaturated ketones in the presence of imines to afford the corresponding $\beta$-aminocarbonyl derivatives. ${ }^{[135]}$ High yields and enantioselectivities of up to $95 \%$ ee were reached along with moderate to good diastereoselectivities of up to $86 \%$ de, when a combination of $\mathrm{CuBr}$ and a chiral phosphite was employed as catalyst. The scope of the process was broad since both aromatic and aliphatic imines provided high enantioselectivities. Since the first catalytic domino Michael-aldol reaction reported by Noyori in 1996, there have been numerous examples of domino and multicomponent reactions of this type, including enantioselective versions, based on this powerful methodology. ${ }^{[18]}$ In 2009 , Shibasaki et al. reported an enantioselective multicomponent domino Michael-aldol reaction occurring between 3phenyl-2-cyclohexen-1-one, benzaldehyde and pinacolborane. ${ }^{[136]}$ In the presence of a copper complex of a chiral diphosphine, conjugate boration of the enone, followed by aldol condensation onto benzaldehyde led to the corresponding chiral tertiary organoboric ester, which was directly oxidized into the corresponding diol in $71 \%$ yield, good diastereoselectivity of $74 \% \mathrm{de}$, and enantioselectivity of $91 \%$ ee. More recently, Huang et al. have developed highly diastereo- and enantioselective multicomponent double Michael reactions, allowing a range of chiral functionalized pyrrolidines 233a-n bearing multiple stereocenters to be achieved. ${ }^{[137]}$ The process involved diethylzinc, $\alpha, \beta-$ unsaturated ketones, and nitroalkenes 234a-j as the three components, and was catalyzed by a combination of $\mathrm{CuCl}$ and chiral ligand 235. As shown in Scheme 58, the double Michael adducts possessing three contiguous stereocenters were generally obtained in high yields, and both remarkable diastereo- and enantioselectivities of up to $>98 \% d e$, and $97 \%$ ee, respectively. The dramatic effect of neutral copper in the domino reaction was disclosed, which provided evidence that the electrophilic of catalyst precursor played a crucial role in the control of the stereoselectivity. This exceptional 
methodology cumulates several advantages, such as the employment of a low catalyst loading of 1 mol\%, a broad scope, and general excellent levels of diastereo- and enantioselectivities reached in the control of three contiguous stereocenters.

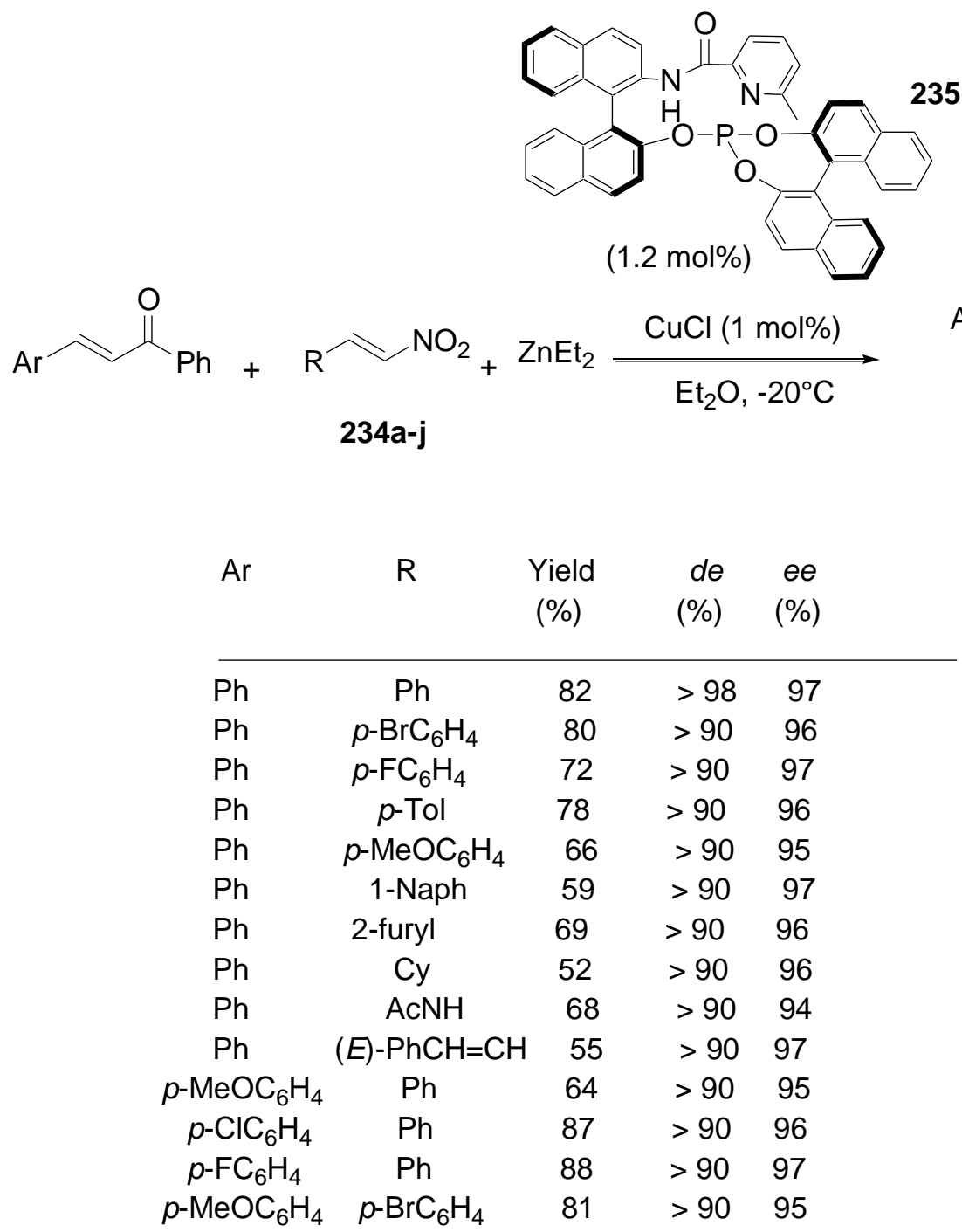

Scheme 58. Cu-catalyzed three-component domino Michael-Michael reaction.

The Henry reaction has been often associated to the Michael reaction in successful asymmetric domino sequences. ${ }^{[138]}$ In this context, a novel highly enantio- and diastereoselective copper-catalyzed domino Michael-Michael-Henry reaction was reported by Huang et al., in 2012. ${ }^{[139]}$ This remarkable three-component reaction involved two equivalents of nitroalkenes 236a-i and $\alpha$-ketoesters 237a-b, which produced the corresponding highly functionalized cyclohexane carboxylates $\mathbf{2 3 8} \mathbf{3}-\mathbf{j}$, having six stereogenic centers including one quaternary, in excellent yields, diastereo-, and enantioselectivities of up to $>90 \% d e$, and $98 \% e e$, respectively (Scheme 59). This highly efficient formal $[2+2+2]$ annulation provided the best results when catalyzed by a combination of $\mathrm{Cu}(\mathrm{OAc})_{2} \cdot \mathrm{H}_{2} \mathrm{O}$ and chiral ligand 239. The performance of this exceptional process is situated in the excellent general levels of diastereo- and enantioselectivities obtained to control six contiguous stereocenters under mild conditions. 


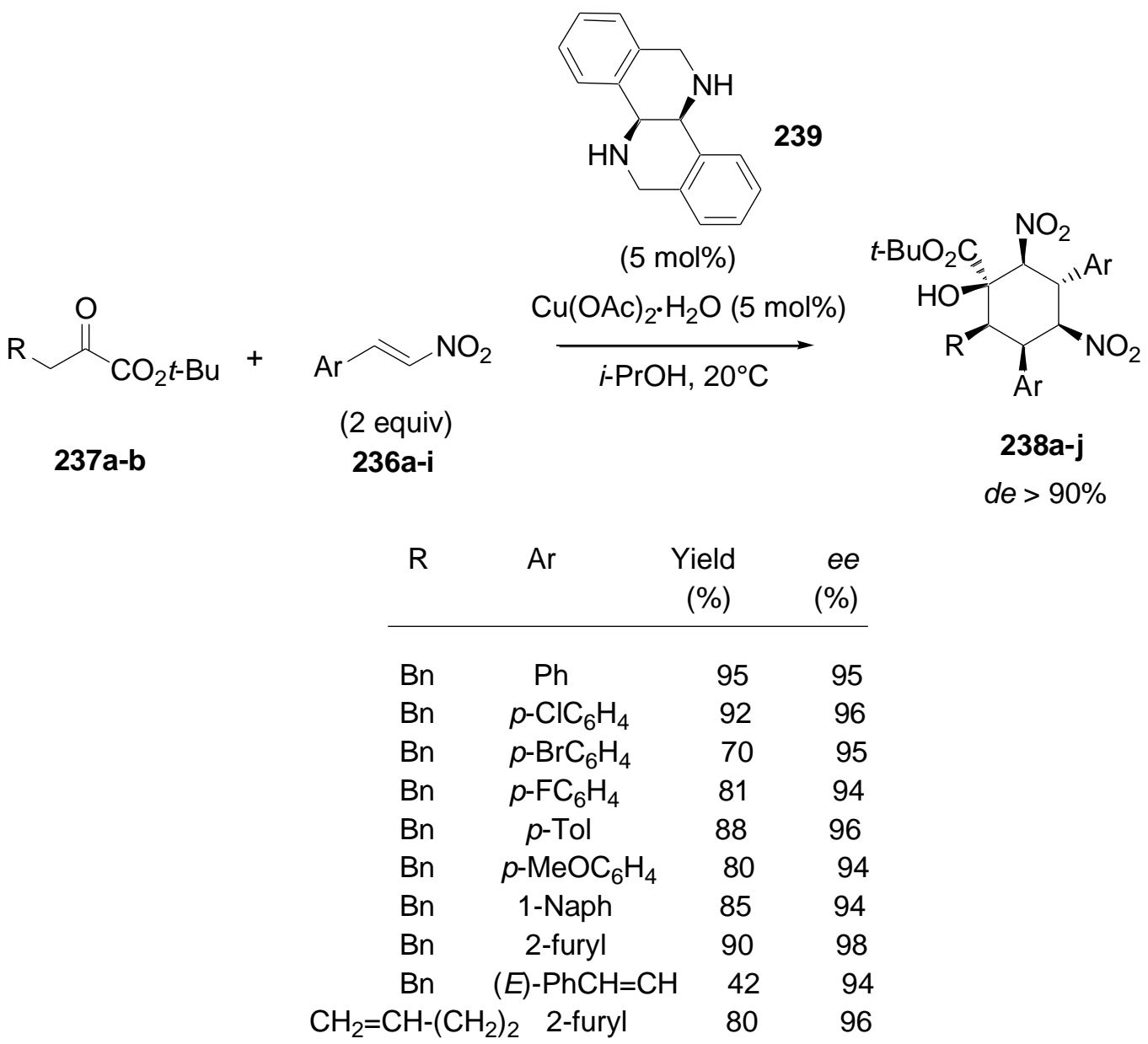

Scheme 59. Cu-catalyzed three-component domino Michael-Michael-Henry reaction.

\subsection{Multicomponent Reactions based on the Mannich Reaction}

The classic direct Mannich reaction discovered in $1912,{ }^{[140]}$ is an aminoalkylation of carbonylic compounds involving ammonia (or a primary or secondary amine derivative), a non-enolizable aldehyde (usually formaldehyde) or a ketone, and an enolizable carbonyl compound, leading to $\beta$ aminocarbonyl derivatives. ${ }^{[141]}$ In the last few years, several groups have developed efficient enantioselective Mannich-type reactions by using chiral catalysts of various metals, such as scandium, silver, tin, zirconium, and copper. For example, Feng et al. have applied a scandium complex of chiral ligand 240 to promote a three-component Mannich-type reaction occurring between aldehydes, $O$ anisidine and a ketene silyl acetal, as shown in Scheme $60 .{ }^{[142]}$ Indeed, a series of chiral $\beta$-amino esters 241a-i were achieved through the reaction of in situ generated aldimines and ketene silyl acetal in the presence of a combination of ligand $\mathbf{2 4 0}$ with $\mathrm{Sc}(\mathrm{OTf})_{3}$ and 1-adamantol. As shown in Scheme 60, a number of products were produced in moderate to good yields and high enantioselectivities of up to 97\% ee. Later, these authors applied the same complex derived from chiral ligand $\mathbf{2 4 0}$ and $\mathrm{Sc}(\mathrm{OTf})_{3}$ to the enantioselective catalysis of a three-component vinylogous Mannich reaction of various aldehydes, $o$-anisidine and acyclic silyl dienol ester $242 .{ }^{[143]}$ The process afforded the corresponding highly functionalized $\delta$-amino- $\alpha, \beta$-unsaturated esters 243a-g in excellent yields, complete regioselectivity and enantioselectivities of up to $>99 \%$ ee, as shown in Scheme 60. 


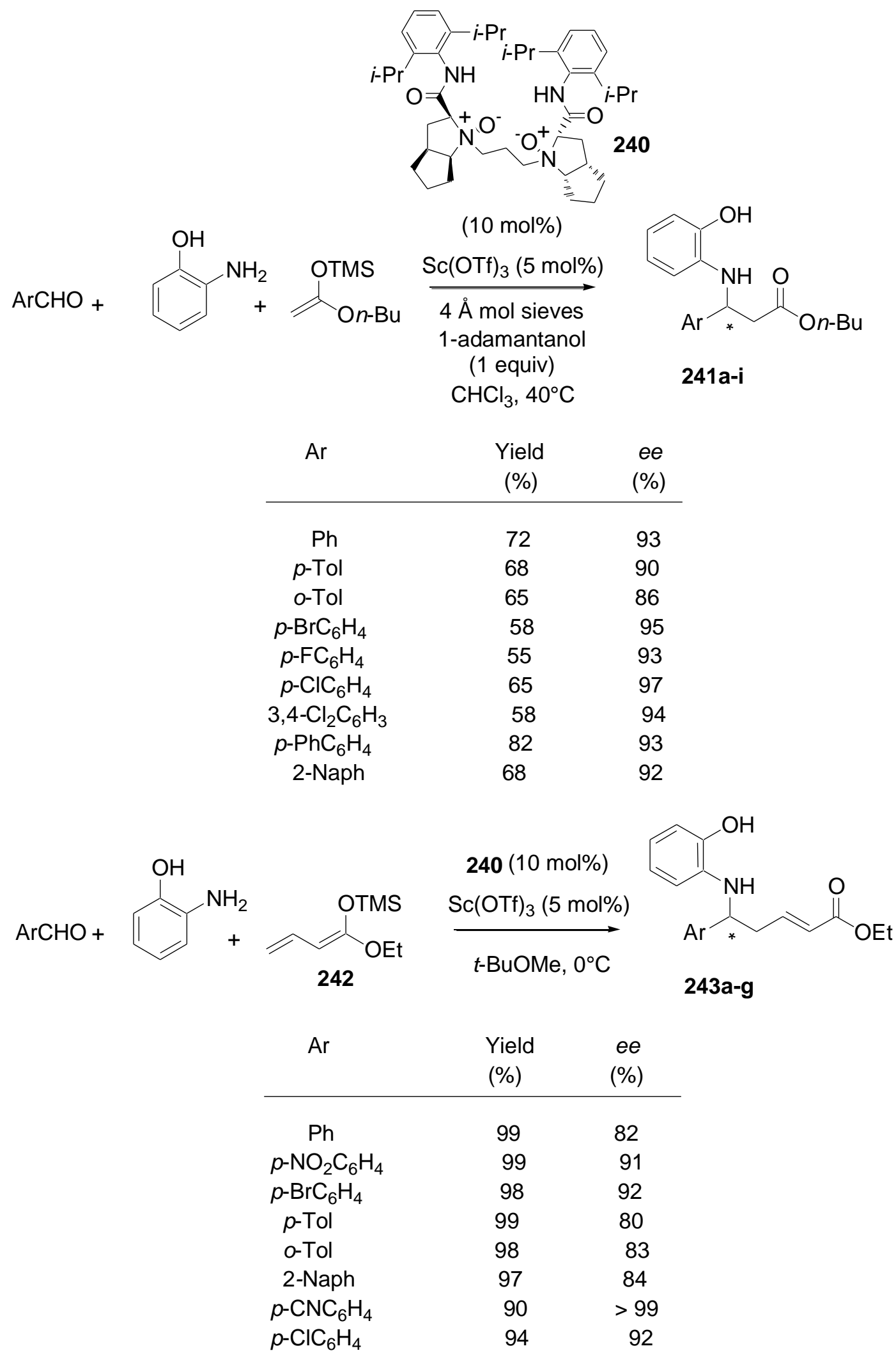

Scheme 60. Sc-catalyzed three-component Mannich-type reactions.

In 2008, Hoveyda et al. described a remarkable protocol for three-component silver(I)-catalyzed enantioselective vinylogous Mannich reactions of in situ generated alkyl-substituted aldimines, including those bearing heteroatom-containing substituents, and readily available siloxyfurans. ${ }^{[144]}$ Particularly high efficiency and exceptional diastereo- and enantioselectivities were achieved through the use of $o$-thiomethyl-p-methoxyaniline-derived aldimines, as shown in Scheme 61. The processes 
were promotted by a combination of AgOAc and as little as $1 \mathrm{~mol} \%$ of easily accessible amino acidbased chiral ligand 244. The corresponding unsaturated $\delta$-lactones $\mathbf{2 4 5 a - h}$ were obtained in 44 to $92 \%$ yield, and in general diastereo- and enantioselectivities of up to $>96 \%$ de and $>98 \%$ ee, respectively. Later, Zanardi et al. have applied similar conditions to achieve corresponding silver-catalyzed diastereo- and enantioselective vinylogous Mannich reactions of pyrrole-based silyl dienolates with in situ generated alkyl-substituted aldimines. ${ }^{[145]}$ The reactions provided the corresponding unsaturated lactams in good to high yields, complete diastereoselectivity in favor of the anti-configured isomer, and high enantioselectivities of up to $96 \% e e$. The utility of the Mannich products was demonstrated in the synthesis of an unprecedented perhydrofuro[3,2-b]pyrrolone product, which is an aza-analogue of naturally occurring (+)-goniofufurone.

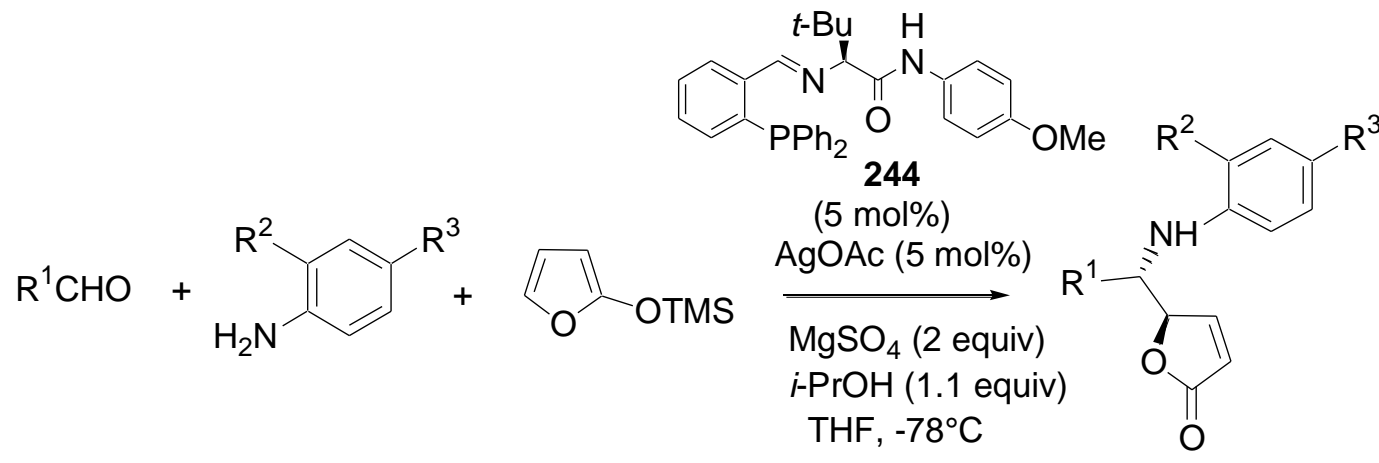

245a-h

\begin{tabular}{cccccc}
$\mathrm{R}^{1}$ & $\mathrm{R}^{2}$ & $\mathrm{R}^{3}$ & $\begin{array}{c}\text { Yield } \\
(\%)\end{array}$ & $\begin{array}{c}\text { de } \\
(\%)\end{array}$ & $\begin{array}{c}\text { ee } \\
(\%)\end{array}$ \\
\hline $\mathrm{Cy}$ & $\mathrm{OMe}$ & $\mathrm{H}$ & 44 & 90 & 88 \\
$\mathrm{Cy}$ & $\mathrm{SMe}$ & $\mathrm{OMe}$ & 90 & $>96$ & $>98$ \\
$\mathrm{Cy}$ & $\mathrm{SMe}$ & $\mathrm{H}$ & 58 & $>96$ & 97 \\
$i-\mathrm{Pr}$ & $\mathrm{SMe}$ & $\mathrm{OMe}$ & 89 & $>96$ & $>98$ \\
$c-\mathrm{Pr}$ & $\mathrm{SMe}$ & $\mathrm{OMe}$ & 88 & $>96$ & $>98$ \\
$i-\mathrm{Bu}$ & $\mathrm{SMe}$ & $\mathrm{OMe}$ & 92 & $>96$ & $>98$ \\
$\mathrm{BnCH}$ & $\mathrm{SMe}$ & $\mathrm{OMe}$ & 79 & $>96$ & $>98$ \\
$n-\mathrm{Hex}$ & $\mathrm{SMe}$ & $\mathrm{OMe}$ & 75 & $>96$ & $>98$
\end{tabular}

Scheme 61. Ag-catalyzed three-component vinylogous Mannich reaction.

The three-component Mannich reaction presents a disavantage in that a moisture-sensitive Lewis acid cannot be used to catalyze the reaction since a stoichiometric amount of water is generated when an imine is formed from an amine and an aldehyde. In 2009, Yanagisawa et al. found that an in situ generated chiral tin bromide alkoxide possessing a binaphthyl structure catalyzed the enantioselective Mannich-type reaction of alkenyl trichloroacetates, ethyl glyoxalate, and aniline derivatives smoothly even in the presence of water or alcohol as well as a polar substituent, such as an amino group or a phenolic hydroxyl group. ${ }^{[146]}$ Indeed, a series of chiral $\beta$-amino ketones were $s y n$-selectively achieved in high yields and enantioselectivities of up to $98 \%$ ee on the basis of this process performed in the presence of a $(S)$-BINOL-derived tin dibromide, possessing a 4-trifluoromethylphenyl group at the 3and 3'-positions, as chiral precatalyst in the presence of sodium ethoxide, sodium iodide, and ethanol. It must be noted that even in situ generated imines possessing a polar amino group gave satisfactory results. In addition, Kobayashi et al. have developed enantioselective Mannich-type reaction of 5hexynal, 2-amino- $m$-cresol and a ketene silyl acetal derived from phenyl propionate by using an in situ 
generated chiral zirconium catalyst of $(S)-6,6^{\prime}-\left(\mathrm{C}_{2} \mathrm{~F}_{5}\right)_{2}$-BINOL. ${ }^{[147]}$ As shown in Scheme 62, the process led to the formation of the corresponding Mannich adduct 246 in 85\% yield, good synstereoselectivity (syn:anti $=91: 9$ ) in combination with excellent enantioselectivity of $96 \%$ ee for the major syn-product. Product $\mathbf{2 4 6}$ was further converted into onchidin, which is a natural cytotoxic, $C_{2^{-}}$ symmetric cyclic decadepsipeptide. In addition, palladium(II)-catalyzed enantioselective threecomponent aminomethylation of $\beta$-ketoesters using formalin and benzylamine trifluoromethanesulfonic acid salt have been developed by Sodeoka et al. ${ }^{[148]}$ In the presence of a chiral palladium complex of biphosphine, the domino reaction afforded the corresponding aminomethylated $\beta$-ketoesters in almost quantitative yields. Among the ligands tested, $(R)$-Segphos gave the best enantioselectivity of $68 \%$ ee. Unfortunately, distinct improvement of the enantiomeric excess was not achieved, although the effects of solvent, reaction temperature, and substituents on the nitrogen atom were examined.

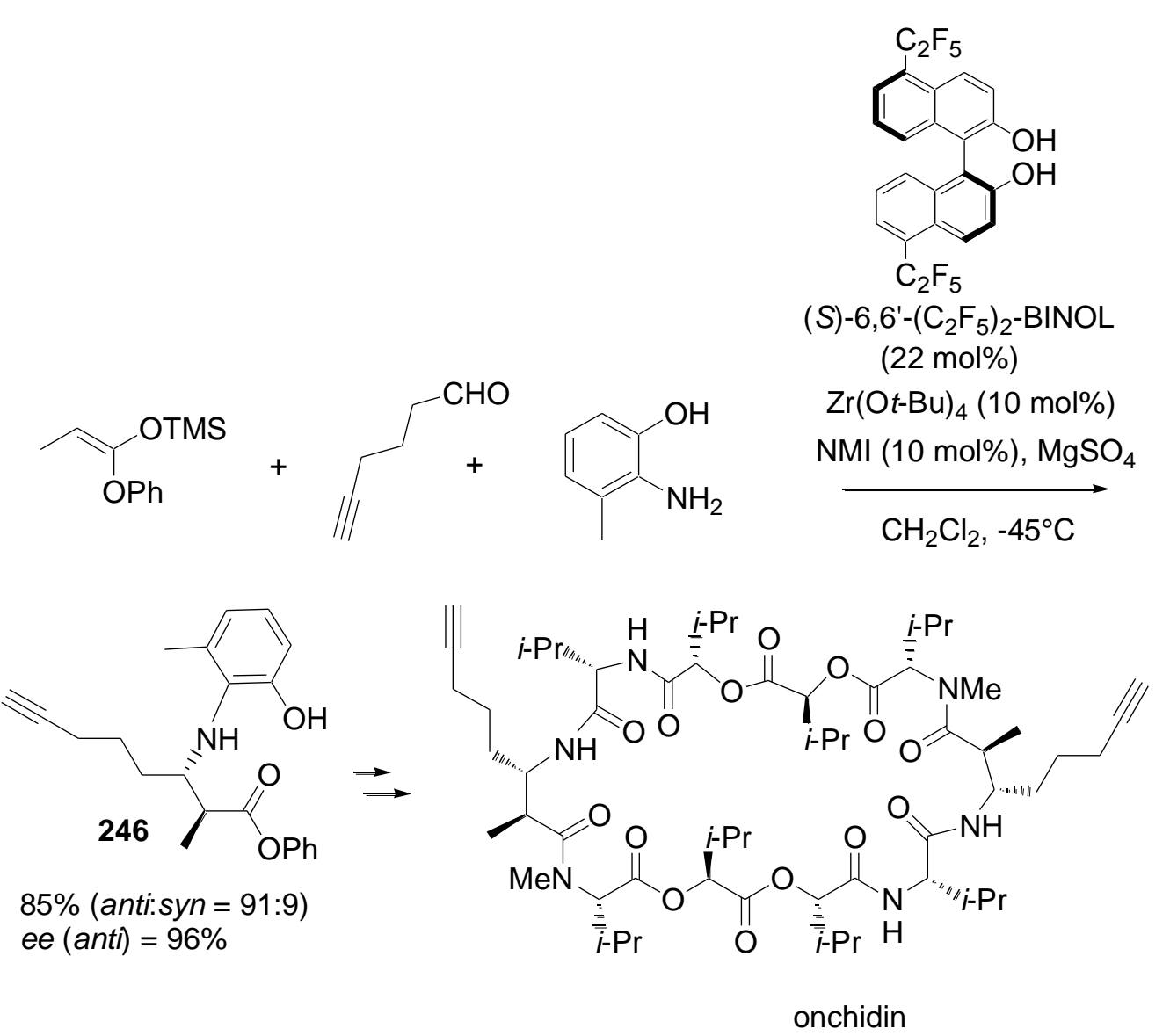

Scheme 62. Zr-catalyzed three-component Mannich-type reaction and synthesis of onchidin.

Finally, a chiral copper(I) complex of (R)-DIFLUORPHOS was used by Shibasaki et al. to induce the first catalytic enantioselective reductive Mannich reaction of ketimines. ${ }^{[149]}$ Indeed, the multicomponent reaction of ketimines, $\alpha, \beta$-unsaturated esters and $(\mathrm{EtO})_{3} \mathrm{SiH}$ as the reducing agent provided the corresponding amines, containing contiguous tetra- and trisubstituted carbons, in good yields, moderate to good diastereoselectivities, and enantioselectivities of up to $91 \% \mathrm{ee}$. It must be noted that this methodology constituted the first entry to the catalytic asymmetric synthesis of $\beta^{2,3,3}$ amino acid derivatives.

\subsection{Multicomponent Reactions initiated by a Pericyclic Reaction}

A number of asymmetric domino reactions initiated by pericyclic reactions have been reported ${ }^{[150]}$ In particular, multicomponent reactions including a pericyclic reaction, such as Diels-Alder-, Knoevenagel-, 1,3-dipolar cycloaddition, and [2+2+2] cycloaddition have been reported. In recent 
years, several examples of enantioselective metal-catalyzed multicomponent reactions initiated by a (hetero)Diels-Alder or a $[2+2+2]$ cycloaddition have been developed. For example, a cobalt(I)catalyzed Diels-Alder reaction of a 1-boron-functionalized 1,3-diene with an alkyne was the first key step in a domino Diels-Alder-allylboration reaction interconnecting three components to provide the corresponding multifunctionalized domino product in good yield (87\%) and moderate enantioselectivity of $71 \% e e e^{[151]}$ The second step of the sequence was the allylation of the aldehyde. The product was regio- and diastereoselectively produced by using a combination of $\mathrm{CoBr}_{2}$ with chiral ligand $(S, S)$-Norphos. Later, Feng et al. reported the synthesis of a range of chiral ring-fused

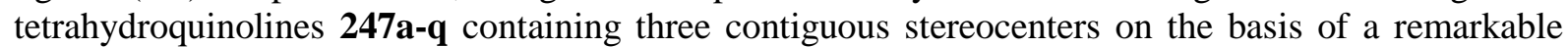
enantioselective three-component inverse electron-demand aza-Diels-Alder reaction catalyzed by a scandium complex of ligand 240. ${ }^{[152]}$ As shown in Scheme 63, the reaction of various aldehydes with substituted $o$-anisidines and cyclopentadiene gave rise to the corresponding tricyclic products $247 \mathbf{a}-\mathbf{q}$ in high yields, and high to excellent diastereo- and enantioselectivities of up to $>98 \%$ de and $>99 \%$ $e e$, respectively. This novel and efficient process opened a novel route to this important class of products which often exhibit potential biological activities. 


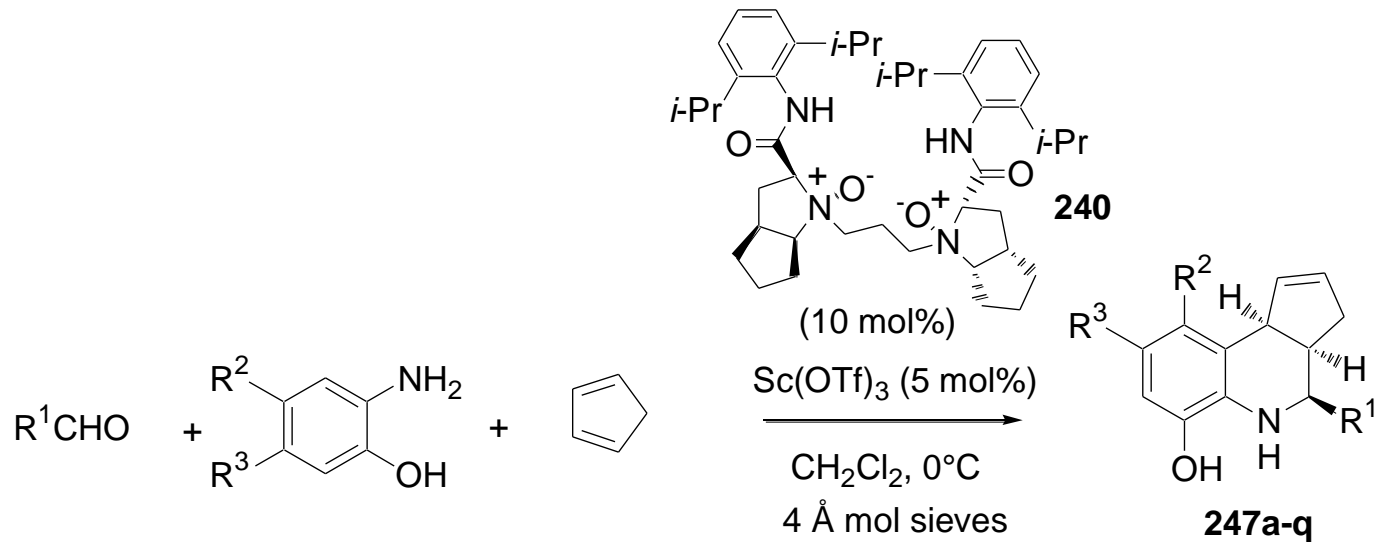

\begin{tabular}{|c|c|c|c|c|}
\hline $\mathrm{R}^{1}$ & $\mathrm{R}^{2}$ & $\mathrm{R}^{3}$ & $\begin{array}{l}\text { Yield } \\
(\%)\end{array}$ & cis:trans \\
\hline
\end{tabular}

\begin{tabular}{|c|c|c|c|c|c|}
\hline $\mathrm{Ph}$ & $\mathrm{H}$ & $\mathrm{H}$ & 90 & $96: 4$ & 97 \\
\hline o-Tol & $\mathrm{H}$ & $\mathrm{H}$ & 62 & $92: 8$ & 92 \\
\hline$m$-Tol & $\mathrm{H}$ & $\mathrm{H}$ & 82 & $95: 5$ & 98 \\
\hline$p$-Tol & $\mathrm{H}$ & $\mathrm{H}$ & 87 & $95: 5$ & 98 \\
\hline$m-\mathrm{ClC}_{6} \mathrm{H}_{4}$ & $\mathrm{H}$ & $\mathrm{H}$ & 93 & $96: 4$ & 93 \\
\hline$p-\mathrm{ClC}_{6} \mathrm{H}_{4}$ & $\mathrm{H}$ & $\mathrm{H}$ & 99 & $95: 5$ & 96 \\
\hline$o, p-\mathrm{Cl}_{2} \mathrm{C}_{6} \mathrm{H}_{3}$ & $\mathrm{H}$ & $\mathrm{H}$ & 95 & $92: 8$ & 94 \\
\hline$m, p-\mathrm{Cl}_{2} \mathrm{C}_{6} \mathrm{H}_{3}$ & $\mathrm{H}$ & $\mathrm{H}$ & 99 & $92: 8$ & 94 \\
\hline$p-\mathrm{CF}_{3} \mathrm{C}_{6} \mathrm{H}_{4}$ & $\mathrm{H}$ & $\mathrm{H}$ & 97 & $96: 4$ & 95 \\
\hline$p-\mathrm{MeOC}_{6} \mathrm{H}_{4}$ & $\mathrm{H}$ & $\mathrm{H}$ & 63 & $90: 10$ & $>99$ \\
\hline$p-\mathrm{PhC}_{6} \mathrm{H}_{4}$ & $\mathrm{H}$ & $\mathrm{H}$ & 72 & $95: 5$ & $>99$ \\
\hline 3-furyl & $\mathrm{H}$ & $\mathrm{H}$ & 82 & $98: 2$ & 95 \\
\hline Cy & $\mathrm{H}$ & $\mathrm{H}$ & 99 & $>99: 1$ & 99 \\
\hline $\mathrm{Et}_{2} \mathrm{CH}$ & $\mathrm{H}$ & $\mathrm{H}$ & 62 & $>95: 5$ & 94 \\
\hline $\mathrm{Ph}$ & $\mathrm{H}$ & $\mathrm{Me}$ & 85 & $96: 4$ & 98 \\
\hline $\mathrm{Ph}$ & $\mathrm{Me}$ & $\mathrm{H}$ & 70 & $92: 8$ & 96 \\
\hline $\mathrm{Ph}$ & $\mathrm{Cl}$ & $\mathrm{H}$ & 96 & $92: 8$ & 90 \\
\hline
\end{tabular}

Scheme 63. Sc-catalyzed three-component inverse electron-demand aza-Diels-Alder reaction.

Transition metal-catalyzed $[2+2+2]$ cycloaddition of unsaturated motifs, such as alkyne and alkene, constitutes the most atom-economical and facile protocol for the construction of a six-membered ring system. ${ }^{[46]}$ In particular, the enantioselective $[2+2+2]$ cycloaddition is a fascinating protocol for the construction of chiral cyclic skeletons. ${ }^{[47 \mathrm{a}-\mathrm{b}]}$ In recent years, this cycloaddition has been included in several enantioselective domino processes, including multicomponent reactions. As an example, Shibata et al. have employed an in situ prepared chiral iridium complex of $(S, S)$-Chiraphos to induce a pseudo-three-component consecutive and enantioselective $[2+2+2]$ cycloaddition of tetraynes with two molecules of protected but-2-yne-1,4-diols to give the corresponding $C_{2}$-symmetrical quateraryl products in moderate to good yields and enantioselectivities of up to $86 \%$ ee ${ }^{[52]}$ In 2011 , Tanaka et al. reported an efficient enantioselective domino intermolecular $[2+2+2]$-intramolecular Diels-Alder reaction occurring between 1,6-diynes and amide-linked 1,5-dienes. ${ }^{[54]}$ The authors have extended the scope of this methodology to the corresponding three-component version of the process. Indeed, the 
reaction of dialkyl acetylenedicarboxylates 248a-b, terminal alkynes 249a-c, and amide-linked 1,5dienes 250a-c, performed in the presence of a cationic rhodium $(\mathrm{I}) /(R)$-BINAP complex, provided the corresponding amides 251a-f in moderate to high yields and excellent enantioselectivities of up to 99\% ee, as shown in Scheme 64. In all cases of substrates studied, the bridged multicyclic products were achieved as single and almost enantiopure regioisomers. In addition, Somfai et al. have described three-component 1,3-dipolar cycloadditions of in situ generated carbonyl ylides to aldimines induced by chiral rhodium-(II) carboxylate catalysts. ${ }^{[153]}$ For example, the reaction of benzylidenebenzylamine, benzaldehyde and ethyl diazoacetate gave rise to the corresponding syn- $\beta$-amino alcohol in low to moderate yield (14-62\%), modest diastereoselectivity (42-88\% de) combined to moderate enantioselectivity of up to $64 \% e e$. In spite of its moderate enantioselectivities, this process allowed interesting building blocks for the synthesis of natural products and other biologically important products that are syn- $\beta$-amino alcohols to be achieved.

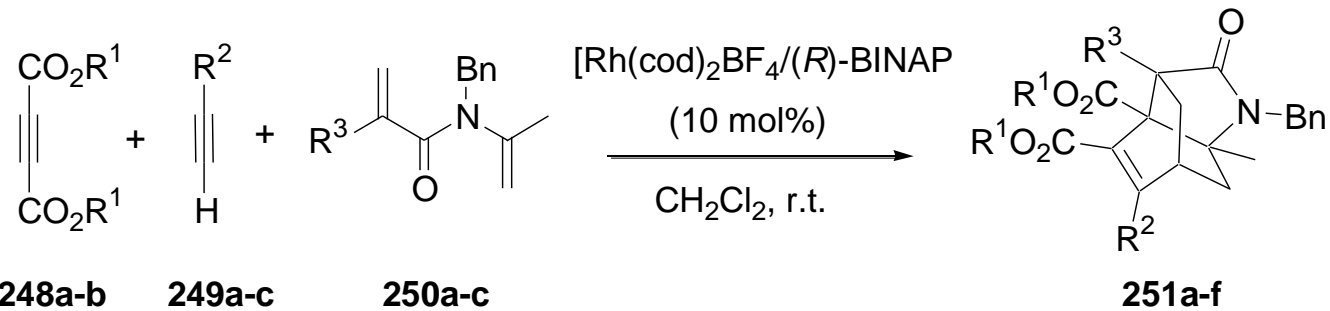

\begin{tabular}{ccccc}
$\mathrm{R}^{1}$ & $\mathrm{R}^{2}$ & $\mathrm{R}^{3}$ & $\begin{array}{c}\text { Yield } \\
(\%)\end{array}$ & $\begin{array}{c}\text { ee } \\
(\%)\end{array}$ \\
\hline $\mathrm{Me}$ & $\mathrm{TMS}$ & $\mathrm{Me}$ & 51 & 99 \\
$\mathrm{Et}$ & $\mathrm{TMS}$ & $\mathrm{Me}$ & 32 & 98 \\
$\mathrm{Me}$ & $\mathrm{Ph}$ & $\mathrm{Me}$ & 40 & 95 \\
$\mathrm{Me}$ & $\mathrm{TMS}$ & $\mathrm{H}$ & 71 & $>99$ \\
$\mathrm{Me}$ & $\left(\mathrm{CH}_{2}\right)_{3} \mathrm{Cl}$ & $\mathrm{Me}$ & 17 & 94 \\
$\mathrm{Me}$ & $\mathrm{TMS}$ & $\mathrm{Ph}$ & 27 & 99
\end{tabular}

Scheme 64. Rh-catalyzed three-component domino intermolecular $[2+2+2]$ cycloaddition-intramolecular Diels-Alder reaction.

\subsection{Multicomponent Reactions based on the Passerini Reaction}

The modern concept of multicomponent reactions is intimately related to the reactions developed with isocyanide reagents. ${ }^{[60]}$ The unique ability of isocyanides to serve as $C$-nucleophiles toward imines and aldehydes, resulting in nitrilium ion electrophiles, enables the four-component Ugi reaction and the three-component Passerini reaction, respectively. ${ }^{[61]}$ Despite the strong relationship between multicomponent reactions and isocyanides, there are still few reactions in which the use of isocyanide reagents leads to chiral compounds, and more particularly those which are induced by chiral catalysts. In 2008, Zhu et al. developed an efficient catalytic enantioselective Passerini three-component reaction, which involved an aldehyde, a carboxylic acid, and an isocyanide with the generation of a stereogenic center to afford an $\alpha$-acyloxyamide. ${ }^{[154]}$ When a chiral $N, N^{\prime}$-bis(3,5-di-tertbutylsalicylidene)-(R,R)-cyclohexane-1,2-diamine was used as the supporting ligand in association with $\mathrm{Et}_{2} \mathrm{AlCl}$, the authors have shown that the reaction was applicable to a wide range of nonchelating aldehydes, carboxylic acids, and isocyanides, allowing a range of $\alpha$-acyloxyamides to be achieved in good yields and high to excellent enantioselectivities of up to $>99 \% e e$. By replacing aliphatic isocyanides with less-reactive aromatic isocyanides, increased selectivity was observed for this process. Furthermore, a variety of carboxylic acids was compatible with the reaction, including 2chloroacetic acid. The presence of chloroacetyl functionality in the Passerini products provided an 
interesting handle for subsequent functionalization reactions. A deacetylated derivative was assigned the $(S)$-configuration, indicating that the isocyanide attacked preferentially on the $R e$-face of the aldehyde. Passerini-type reactions have the general characteristics of the Passerini reaction, but one of the inputs is replaced by a different compound with similar electronic properties. On the basis that the $\mathrm{P} K_{\mathrm{a}}$ of hydrazoic acid was rather similar to carboxylic acids and the azide ion was expected to be a better nucleophile than a carboxylate ion, ${ }^{[155]}$ an asymmetric Passerini-type three-component reaction for the synthesis of 5-(1-hydroxyalkyl)-tetrazoles which used hydrazoic acid instead of the carboxylic acid component was developed by Zhu et al., in 2008. ${ }^{[156]}$ This process constituted the first enantioselective Passerini-type reaction of aldehydes, isocyanides and hydrazoic acid to give the corresponding 5-(1-hydroxyalkyl)tetrazoles 252a-l. This three-component reaction was induced by [(salen)Al(III)Me] complex 253, and was applied to a wide range of linear as well as $\alpha$-branched aliphatic aldehydes and to both aromatic and aliphatic isocyanides, affording the corresponding tetrazoles 252a-l in good to excellent yields and enantioselectivities, as shown in Sheme 65. It must be noted that the three-component Passerini reaction has seldom been used to prepare tetrazoles, which constitute important heterocycles in medicinal chemistry, owing to their increased stability towards metabolic degradation pathways.

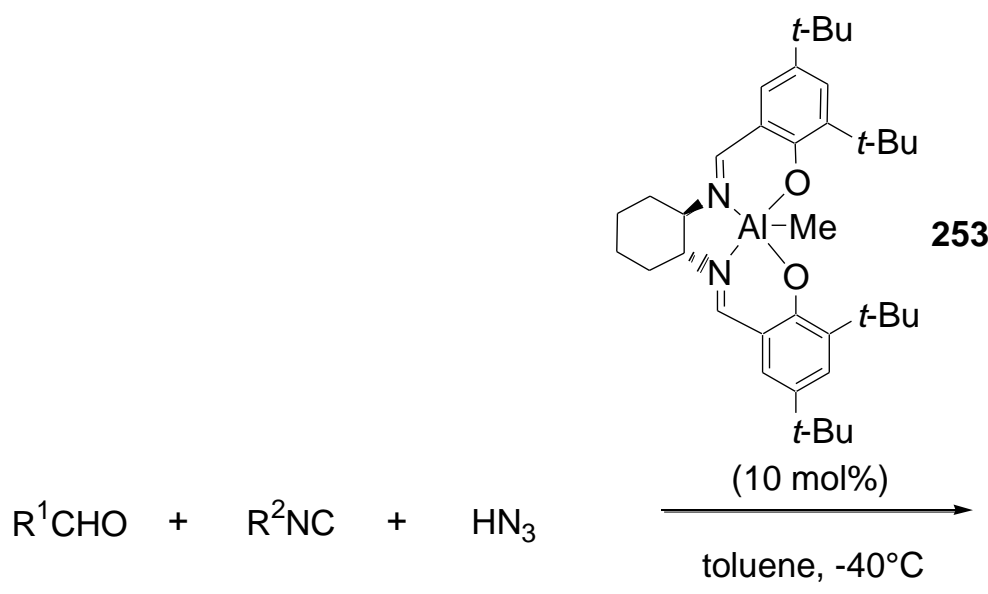<smiles>[R]C(O)c1nnnn1[R]</smiles>

252a-I

\begin{tabular}{|c|c|}
\hline $\mathrm{R}^{1} \quad \mathrm{R}^{2}$ & $\begin{array}{l}\text { Yield } \\
(\%)\end{array}$ \\
\hline
\end{tabular}

\begin{tabular}{cccc}
\hline$i-\mathrm{Pr}$ & $p-\mathrm{MeOC}_{6} \mathrm{H}_{4}$ & 99 & 85 \\
$i-\mathrm{Pr}$ & $\mathrm{Cy}$ & 90 & 95 \\
$\mathrm{Et}$ & $p-\mathrm{MeOC}_{6} \mathrm{H}_{4}$ & 88 & 87 \\
$\mathrm{Cy}$ & $p-\mathrm{MeOC}_{6} \mathrm{H}_{4}$ & 90 & 91 \\
$i-\mathrm{Pr}$ & $\mathrm{Bn}$ & 76 & 92 \\
$\mathrm{Bn}$ & $p-\mathrm{MeOC}_{6} \mathrm{H}_{4}$ & 97 & 64 \\
$n-\mathrm{Hex}$ & $p-\mathrm{MeOC}_{6} \mathrm{H}_{4}$ & 88 & 85 \\
$\mathrm{Cy}$ & $\mathrm{Bn}$ & 91 & 83 \\
$\mathrm{Cy}$ & $\mathrm{Ph}_{\mathrm{Cy}}$ & 68 & 92 \\
$\mathrm{Cy}$ & $p-\mathrm{Tol}$ & 80 & 95 \\
$\mathrm{Cy}$ & $p-\mathrm{NMe}_{2} \mathrm{C}_{6} \mathrm{H}_{4}$ & 95 & 94 \\
$\mathrm{Cy}$ & $2,6-(\mathrm{Me})_{2} \mathrm{C}_{6} \mathrm{H}_{3}$ & 53 & 51
\end{tabular}

Scheme 65. Al-catalyzed three-component Passerini-type reaction. 


\subsection{Multicomponent Reactions initiated by the Friedel-Crafts Reaction}

The asymmetric Friedel-Crafts reaction is one of the most powerful methods to synthesize optically active aromatic compounds and has been included in various enantioselective domino reactions. As a recent example, Arai et al. have reported the enantioselective multicomponent domino Friedel-Crafts-Henry reaction of indoles 254a-b, nitroalkenes, and aldehydes catalyzed by a combination of $\mathrm{Cu}(\mathrm{OTf})_{2}$ with chiral imidazoline-aminophenol ligand $255 .{ }^{[157]}$ The corresponding domino products 256a-g bearing three contiguous stereocenters were obtained in high yields, remarkable enantioselectivities of up to $99 \% e e$, and moderate to good diastereoselectivities of up to $90 \%$ de (Scheme 66). These products could be envisaged readily as key starting materials in the synthesis of hydroxytryptamines.

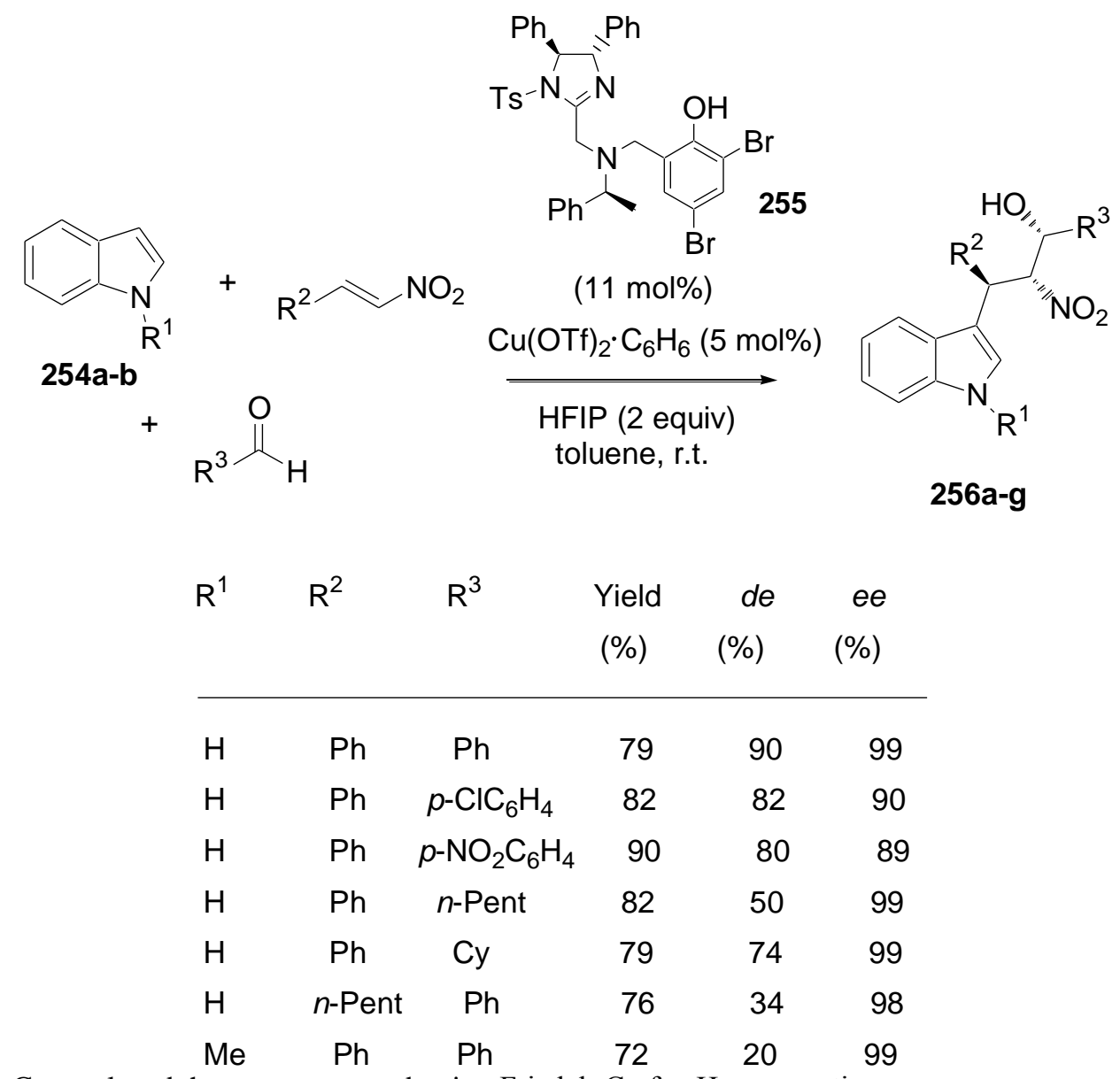

Scheme 66. Cu-catalyzed three-component domino Friedel-Crafts-Henry reaction.

It is well known that one of the most heavily studied families of transition metal catalysts are those based on palladium. Over the past 40 years, many new reactions have been uncovered, and activity in this area has remained high. Among the increasing number of enantioselective multicomponent processes starting with a transition metal-catalyzed reaction, the enantioselective palladium-catalyzed multicomponent transformations have seen an astounding development over the past few years. ${ }^{[19]}$ Indeed, since palladium has the advantage of being compatible with many functional groups, it constitutes an ideal catalyst for multicomponent reactions. ${ }^{[1 \mathrm{~d}, 20]}$ In 2011 , Zhou et al. developed an enantioselective approach to 2,3-disubstituted indolines through consecutive Bronsted acid/palladium complex-promoted domino reactions. ${ }^{[158]}$ Thus, the reaction of 2-substituted indoles 257a-c with aldehydes performed in the presence of a combination of Pd(TFA $)_{2},(R)$-H8-BINAP as the ligand, and $\mathrm{TsOH}$ under hydrogen atmosphere led to the corresponding 2,3-disubstituted indolines 258a-j in good yields and remarkable enantioselectivities of up to $98 \%$ ee, as shown in Scheme 67. The authors assumed that the process began with a Bronsted-acid-promoted Friedel-Crafts reaction of 257a-c and 
aldehydes to give the intermediate vinylogous iminium 259, followed by two asymmetric hydrogenation steps to accomplish this process (Scheme 67).

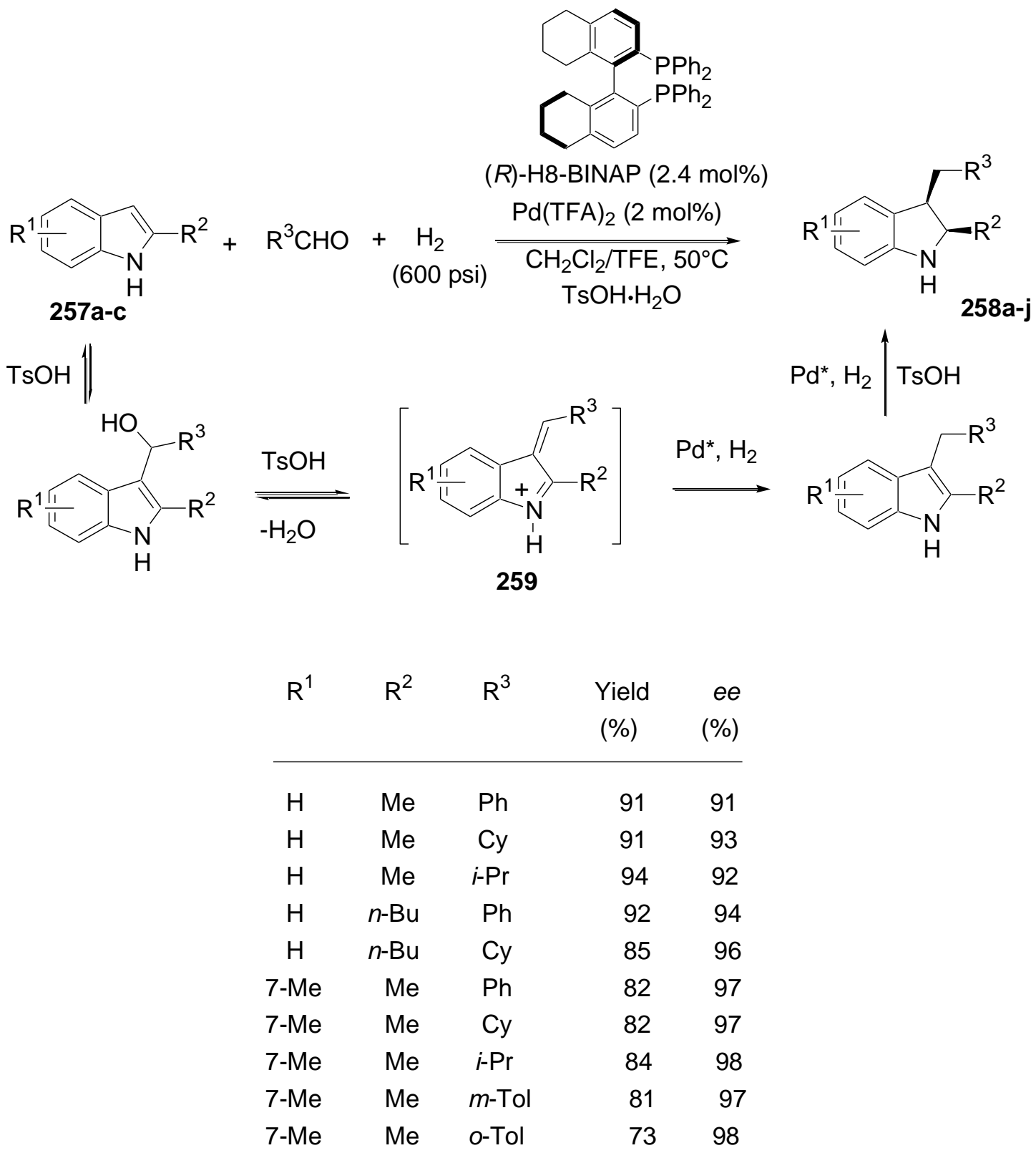

Scheme 67. Pd-catalyzed three-component domino Friedel-Crafts-hydrogenation reaction.

\subsection{Multicomponent Reactions of Alkynes, Aldehydes and Amines}

The copper-catalyzed three-component reaction of terminal alkynes, aldehydes and amines, providing the corresponding chiral propargylamines, has been recently investigated by several groups. In 2006, Knochel et al. employed $\mathrm{CuBr}$ combined with $(R)$-QUINAP as the ligand to induce the reaction with secondary amines, which furnished the corresponding propargylamines 260a-f in both excellent yields and enantioselectivities of up to $98 \%$ ee ${ }^{[159]}$ As shown in Scheme 68, the best results were reached in the case of silylated propargylamines. The applicability of these products in natural product synthesis was successfully demonstrated in the total synthesis of alkaloid $(S)-(+)$-coniine. 


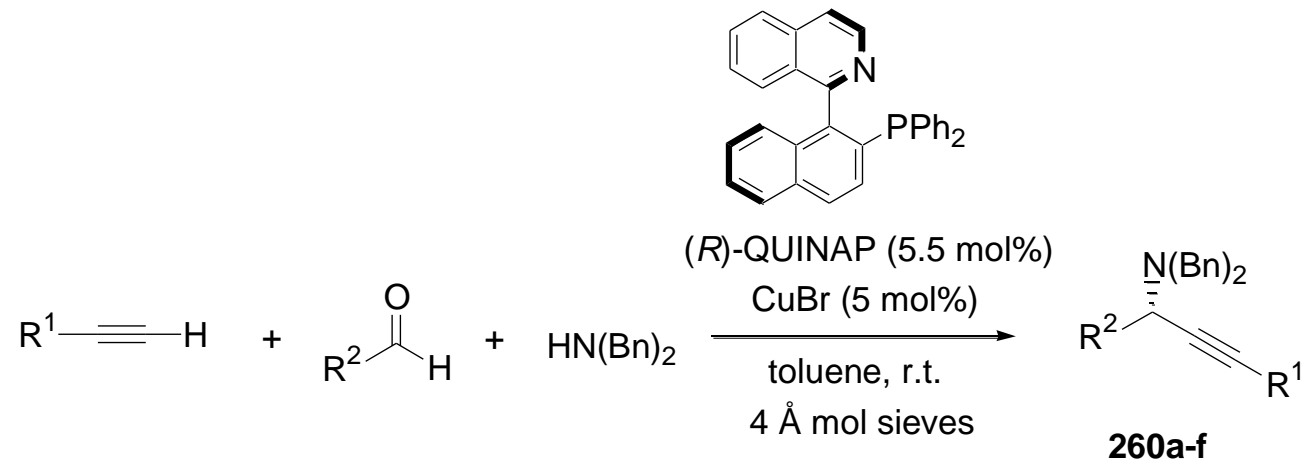

\begin{tabular}{cccc}
$\mathrm{R}^{1}$ & $\mathrm{R}^{2}$ & $\begin{array}{c}\text { Yield } \\
(\%)\end{array}$ & $\begin{array}{c}\text { ee } \\
(\%)\end{array}$ \\
\hline $\mathrm{Ph}$ & $i$-Bu & 98 & 86 \\
TMS & $n-\mathrm{Bu}$ & 82 & 90 \\
TMS & $s-\mathrm{Pent}$ & 95 & 98 \\
TMS & $i$-Pr & 87 & 96 \\
TMS & $c$-Pr & 98 & 92 \\
TMS & $c$-Pent & 98 & 96
\end{tabular}

Scheme 68. Cu-catalyzed three-component reaction of alkynes, aldehydes and secondary amines.

In the same context, Carreira et al. have developed the enantioselective three-component reaction of aldehydes and alkynes with 4-piperidone hydrochloride hydrate, which afforded the corresponding tertiary propargylamines in good yields and enantioselectivities of up to $96 \% e e .^{[160]}$ These results were obtained by using $(R, R)$-PINAP as copper chiral ligand. The use of 4-piperidone as the amine component not only provided access to a useful building block but also highlighted the exquisite chemoselectivity of the process. In the same area, Singh et al. have reported the same type of threecomponent reaction with anilines and catalyzed by a combination of $\mathrm{Cu}(\mathrm{I}) \mathrm{PF}_{6}$ and a chiral $C_{2^{-}}$ symmetric Pybox ligand. ${ }^{[161]}$ This nice process could be applied to a wide variety of aromatic aldehydes, leading to the corresponding aromatic alkynylamines with good to excellent yields (61$99 \%)$ and enantioselectivities $(85-99 \% e e)$. The previously mentioned works deal with threecomponent reactions of aldehydes and amines with aryl- and silyl-substituted alkynes. In 2010, Nakamura et al. extended the scope of this type of three-component reaction to the use of aliphatic terminal alkynes. ${ }^{[162]}$ The reaction of these alkynes with a range of aldehydes and $p$-anisidine afforded, in the presence of a catalytic amount of a combination of $\mathrm{Cu}(\mathrm{OTf})_{2}$ with a closely related chiral $C_{2^{-}}$ symmetric Pybox ligand, the corresponding chiral amines in good yields and remarkable enantioselectivities of up to $98 \%$ ee. It must be noted that Benaglia et al. have also studied the threecomponent reaction of phenylacetylene with amines and aldehydes upon catalysis by copper complexes of chiral bis-imines. ${ }^{[163]}$ The best enantioselectivities of $\leq 75 \%$ ee were obtained by using a chiral bis-imine readily prepared from commercially available binaphthyl diamine. In addition, comparable levels of enantioselectivity $(\leq 74 \%$ ee $)$ were reported by Chan et al. for the threecomponent reaction of ethyl glyoxylate, $p$-anisidine and aliphatic, aromatic alkynes catalyzed by a combination of CuOTf $0.5 \mathrm{C}_{6} \mathrm{H}_{6}$ with another chiral Pybox ligand. ${ }^{[164]}$ Later, Gevorgyan et al. developed an efficient synthesis of chiral 3-aminoindolines the key step of which was the enantioselective copper-catalyzed three-component reaction of piperidine, arylacetylenes and $\mathrm{N}-(2-$ formylphenyl)-4-methylbenzenesulfonamide. ${ }^{[165]}$ This key step was induced by a combination of $\mathrm{CuCl}$ with Trost's $C_{2}$-symmetric biphosphine ligand, providing the corresponding key propargylamines in good yields and moderate to high enantioselectivities (52-93\% ee). These products were subsequently converted into expected chiral indolines through desilylation followed by copper-catalyzed cyclization. Zinc-catalyzed enantioselective three-component reaction of terminal alkynes, aldehydes and $o$-anisidine, which provided the corresponding chiral propargylamines, has been investigated by 
Bolm et al. ${ }^{[166]}$ In this work, a combination of $\mathrm{ZnMe}_{2}$ with a chiral $\beta$-amino alcohol derived from norephedrine was employed to promote the domino reaction, providing propargylamines. The scope of this process could be extended to include alkynes other than phenylacetylene. It must be noted that the use of trimethylsilylethyne and various alkyl-substituted alkynes led to the corresponding products in moderate yields and enantioselectivities, and, moreover, the methodology found a limitation in the impossibility to use electron-poor acetylenes, such as methyl propiolate. On the other hand, a range of amines, stemming from aromatic, heteroaromatic, and aliphatic $\alpha$-branched aldehydes, in combination with $o$-anisidine and phenylacetylene could be prepared in moderate to high yields with enantiomeric excesses ranging from 68 to $97 \% e e$. In the same area, an enantioselective synthesis of $N$-tosyl- $(E)-(2-$ en-3-ynyl)-amines 261a-k has been developed by Xu et al. on the basis of a zinc-mediated addition of two alkynes to $N$-tosylaldimines. ${ }^{[167]}$ As shown in Scheme 69, the three-component reaction allowed a range of chiral $N$-tosylamines to be afforded in high yields and enantioselectivities of up to $99 \% e e$ when BINOL-derived ligand $\mathbf{2 6 2}$ was employed. In order to explain the formation of these products, the authors have proposed the mechanism depicted in Scheme 69, in which alkynylzinc 263 was formed in situ. First, the 1,2-addition of alkynylzinc 263 to $N$-tosylaldimine afforded a $\pi$-complex intermediate 264, which underwent an attack by another alkynylzinc to form a cyclic intermediate $\mathbf{2 6 5}$ under reflux conditions. The carbon-zinc bond could be cleaved by an excess of alkyne to give the intermediate 266. Then, the reaction was quenched with $\mathrm{HCl}$ to give the final product $26 \mathbf{2}$. 


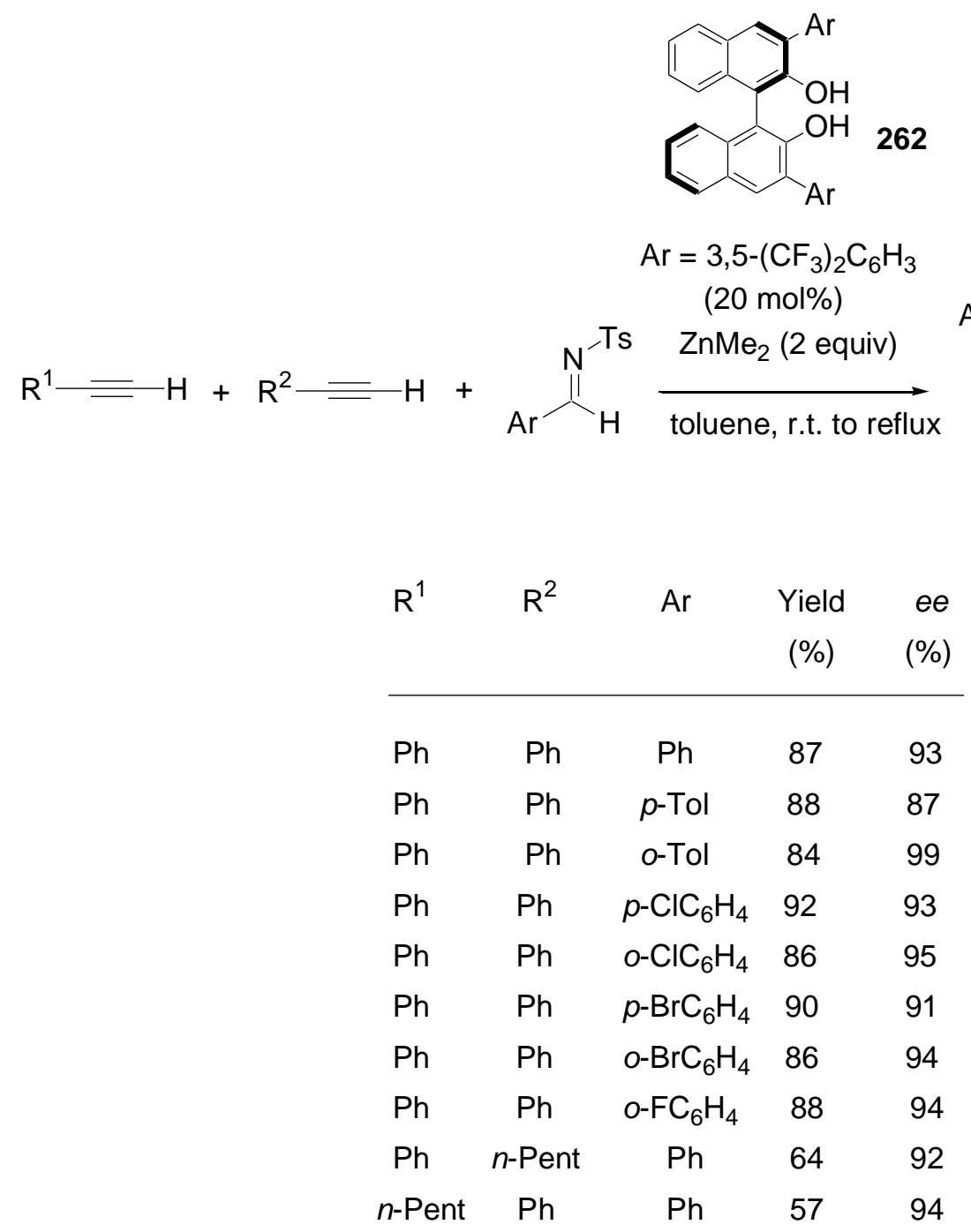

proposed mechanism:
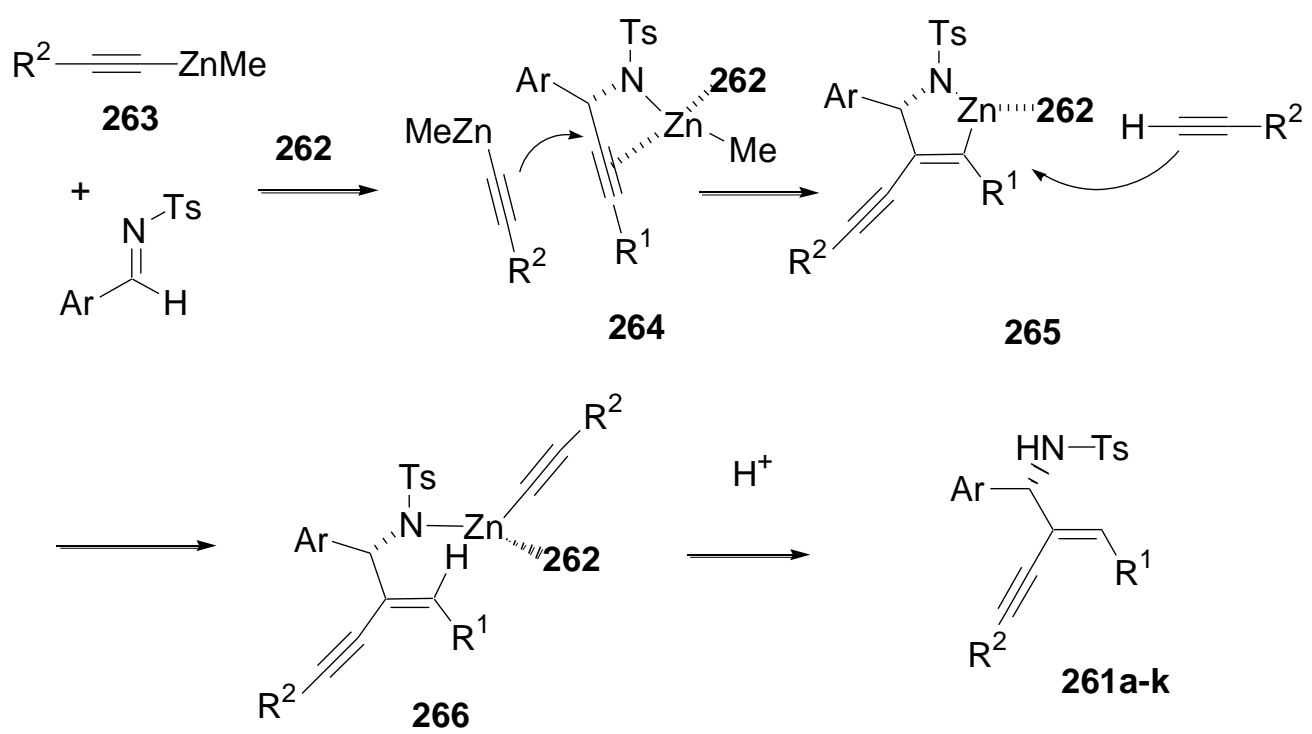

Scheme 69. Zn-catalyzed three-component reaction of $N$-tosylaldimines and alkynes. 


\subsection{Multicomponent Reactions of 1,3-Dienes, Aldehydes and Reducing Agents}

In 2007, Sato et al. developed nickel(0)-catalyzed three-component coupling of 1,3-dienes, aldehydes and triethylsilane as the reducing agent to give regio-, diastereo- and enantioselectively the corresponding $\beta$-triethylsilyloxy $(Z)$-alkenes. ${ }^{[168]}$ On the basis of the screening of various chiral $\mathrm{N}$ heterocyclic carbene precursors, a chiral imidazolium salt having 1-(mesitylphenyl)propyl groups on the nitrogen was selected as the most efficient ligand for nickel to indice chirality in the process, allowing various coupling products to be synthesized in high yields and good to high enantioselectivities of up to $97 \%$ ee. The catalyst was in situ generated from $\mathrm{Ni}(\mathrm{cod})_{2}$, the chiral imidazolium salt ligand, and $\mathrm{Cs}_{2} \mathrm{CO}_{3}$ as a base. Very recently, the same authors have investigated a closely related coupling reaction of 1,3-dienes, with aldehydes using (dimethylphenylsilyl)pinacolborane as the reductant instead of triethylsilylane in the previous work. ${ }^{[169]}$ In this case, chiral phosphoramidite $\mathbf{2 6 7}$ was selected as the most efficient ligand to nickel, providing the corresponding $(E)$-silanes 268a-j to be produced in moderate to high yields and enantioselectivities of up to $97 \%$ ee, as shown in Scheme 70. It must be noted that the coupling of internal 1,3-dienes gave generally lower yields (22-51\%). In each case of substrate studied, a single diastereomer was isolated.

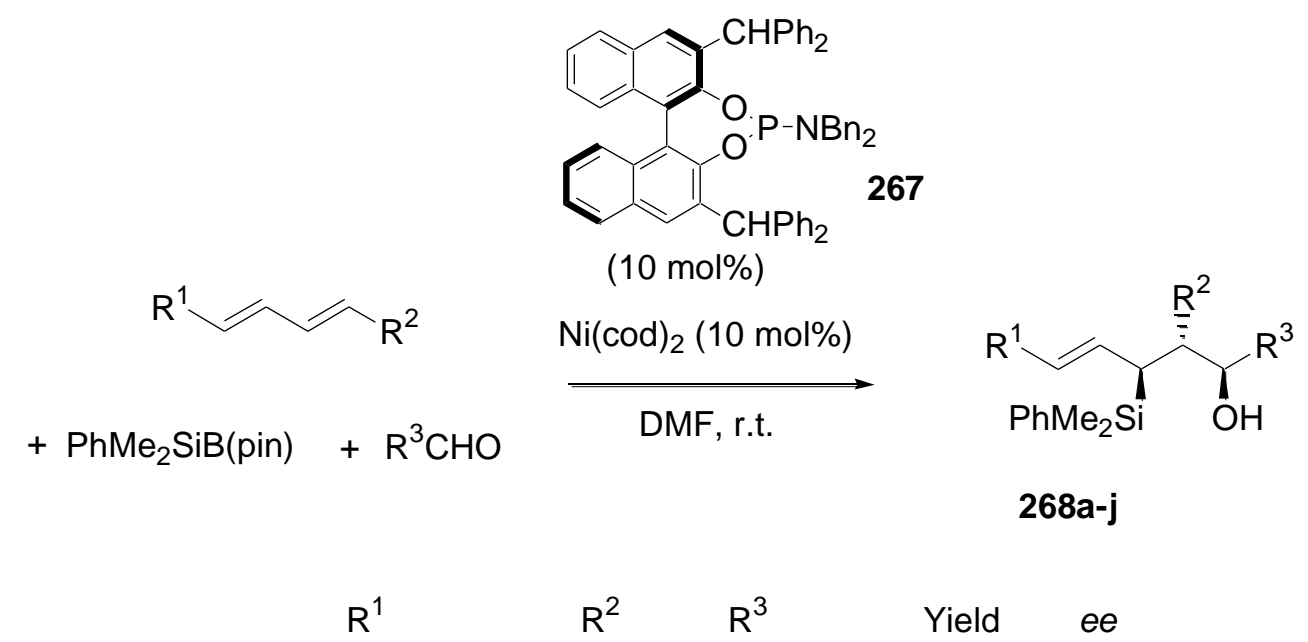

(\%) (\%)

\begin{tabular}{ccccc}
\hline$p-\left(\mathrm{MOMCH}_{2}\right)-\mathrm{C}_{6} \mathrm{H}_{4}$ & $\mathrm{H}$ & $p-\mathrm{Tol}$ & 89 & 96 \\
$p-\left(\mathrm{MOMCH}_{2}\right)-\mathrm{C}_{6} \mathrm{H}_{4}$ & $\mathrm{H}$ & $p-\mathrm{MeO}^{-} \mathrm{C}_{6} \mathrm{H}_{4}$ & 92 & 92 \\
$p-\left(\mathrm{MOMCH}_{2}\right)-\mathrm{C}_{6} \mathrm{H}_{4}$ & $\mathrm{H}$ & $p-\mathrm{CF}_{3}-\mathrm{C}_{6} \mathrm{H}_{4}$ & 29 & 85 \\
$p-\left(\mathrm{MOMCH}_{2}\right)-\mathrm{C}_{6} \mathrm{H}_{4}$ & $\mathrm{H}$ & $2-\mathrm{Naph}$ & 72 & 92 \\
$p-\left(\mathrm{MOMCH}_{2}\right)-\mathrm{C}_{6} \mathrm{H}_{4}$ & $\mathrm{H}$ & $i-\mathrm{Pr}$ & 68 & 96 \\
$p-\left(\mathrm{MOMCH}_{2}\right)-\mathrm{C}_{6} \mathrm{H}_{4}$ & $\mathrm{H}$ & $i-\mathrm{Bu}$ & 56 & 97 \\
$p-\left(\mathrm{MOMCH}_{2}\right)-\mathrm{C}_{6} \mathrm{H}_{4}$ & $\mathrm{H}$ & $\mathrm{Cy}$ & 74 & 94 \\
$\mathrm{PhMe}_{2} \mathrm{Si}$ & $\mathrm{H}$ & $\mathrm{Ph}$ & 80 & 82 \\
$p-\left(\mathrm{MOMCH}_{2}\right)-\mathrm{C}_{6} \mathrm{H}_{4}$ & $\mathrm{Me}$ & $\mathrm{Ph}$ & 22 & 92 \\
$\mathrm{Ph}$ & $\mathrm{Ph}$ & $\mathrm{Ph}$ & 51 & 20
\end{tabular}

Scheme 70. Ni-catalyzed three-component reaction of 1,3-dienes, aldehydes and silylboranes.

In addition, Zhou et al. have developed enantioselective reductive coupling of 1,3-dienes and aldehydes by using $\mathrm{ZnEt}_{2}$ as the reducing agent and nickel complexes of chiral spiro phosphoramidites, such as $\mathbf{2 6 9}$. $^{[170]}$ In this case, the three-component reaction provided the corresponding chiral bishomoallylic alcohols 270a-k in excellent yields and diastereoselectivities 
(anti:syn > 99:1) in almost all the cases of substrates studied, combined with high enantioselectivities of up to $96 \%$ ee, as shown in Scheme 71.

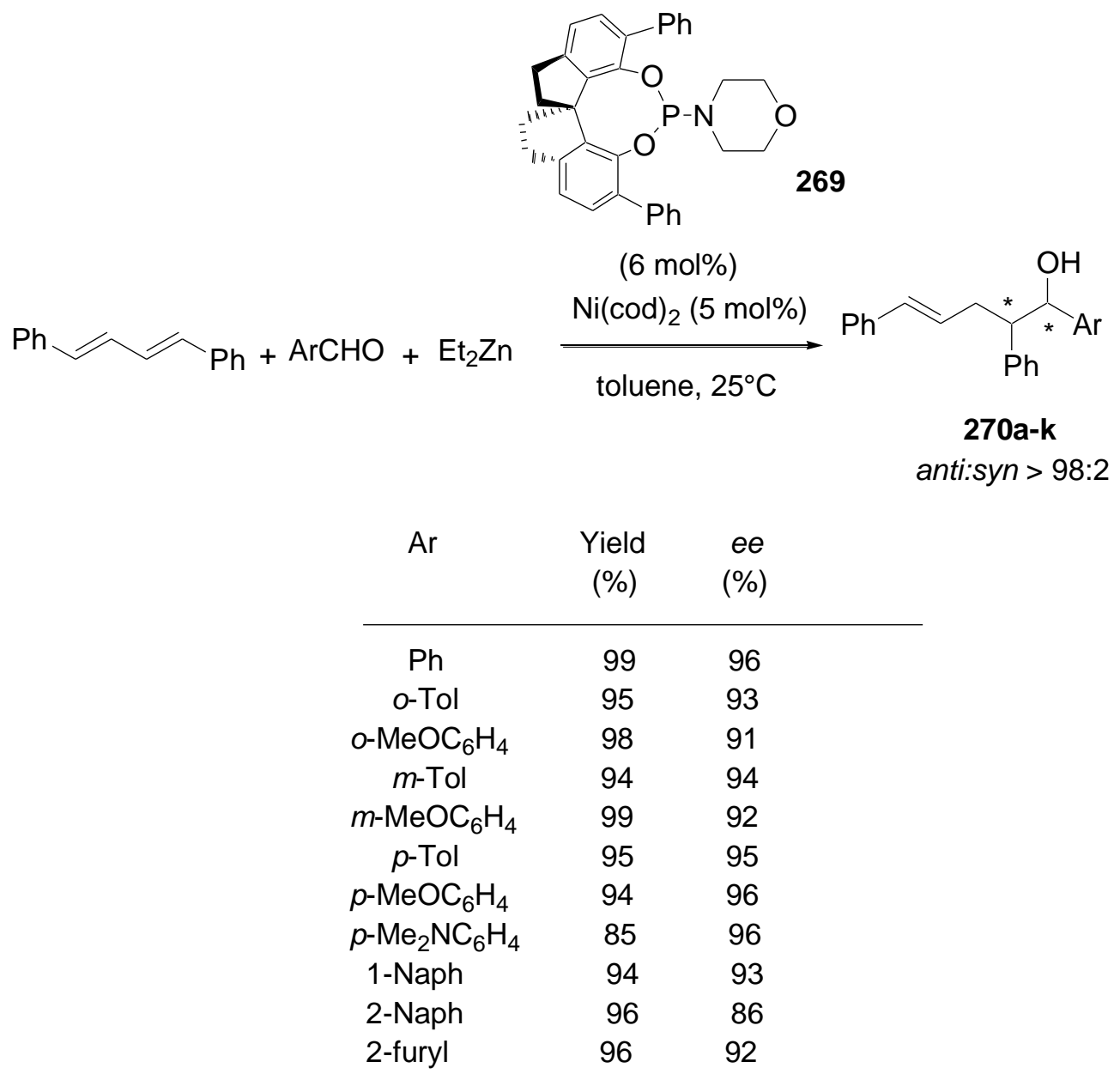

Scheme 71. Ni-catalyzed three-component reaction of 1,3-dienes, aldehydes and $\mathrm{ZnEt}_{2}$.

\subsection{Multicomponent Reductive Amination Reactions of Ketones}

In 2009, chiral (diphosphine) palladium(II) dibromide catalysts were successfully employed by RubioPérez et al. to develop enantioselective domino reductive amination of ketones. ${ }^{[171]}$ As shown in Scheme 73, various chiral amines 271a-g could be synthesized from the corresponding ketones by three-component reaction with anilines under 800 psi of hydrogen pressure with $2.5 \mathrm{~mol} \%$ of catalyst loading. The best results were reached by using $(R)$-BINAP as chiral ligand, which provided good yields and good to excellent enantioselectivities of up to $99 \% \mathrm{ee}$. 


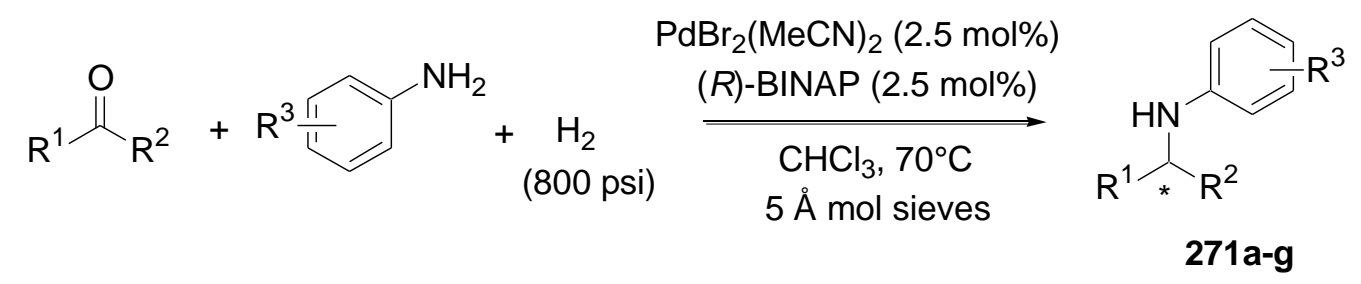

\begin{tabular}{|c|c|c|c|c|}
\hline $\mathrm{R}^{1}$ & $\mathrm{R}^{2}$ & $\mathrm{R}^{3}$ & $\begin{array}{c}\text { Yield } \\
(\%)\end{array}$ & $\begin{array}{r}e e \\
(\%)\end{array}$ \\
\hline
\end{tabular}

$\begin{array}{cclcc}\mathrm{Me} & n-\mathrm{Pent} & m-\mathrm{CF}_{3} & 51 & 95 \\ \mathrm{Et} & n-\mathrm{Bu} & p-\mathrm{Me} & 51 & 95 \\ \mathrm{Et} & \mathrm{Me} & p-\mathrm{Me} & 77 & 99 \\ \mathrm{Et} & \mathrm{Me} & p-\mathrm{Et} & 87 & 92 \\ \mathrm{Et} & \mathrm{Me} & o-\mathrm{CF}_{3} & 76 & 82 \\ i-\mathrm{Bu} & \mathrm{Me} & p-\mathrm{Me} & 73 & 90 \\ t-\mathrm{Bu} & \mathrm{Me} & m-\mathrm{CF}_{3} & 74 & 96\end{array}$

Scheme 72. Pd-catalyzed three-component reductive amination reaction of ketones.

In the same year, Xiao et al. investigated three-component iridium-catalyzed reductive amination of a wide variety of ketones. ${ }^{[172]}$ The reaction of a range of aliphatic ketones with aniline derivatives under hydrogen atmosphere was catalyzed by an iridium complex $\mathbf{2 7 2}$ bearing a chiral phosphate, providing the corresponding chiral amines 273a-h in high yields and enantioselectivities of up to $95 \%$ ee, as shown in Scheme 73. When the authors tried to extend the scope of the reaction to aromatic ketones, they found that no reaction occurred. On the other hand, using a closely related chiral iridium catalyst at a catalyst loading as low as $0.005 \mathrm{~mol} \%$ allowed the process to be achieved, providing the corresponding chiral amines in general excellent yields (91-94\%) and enantioselectivities (88-97\% ee). 


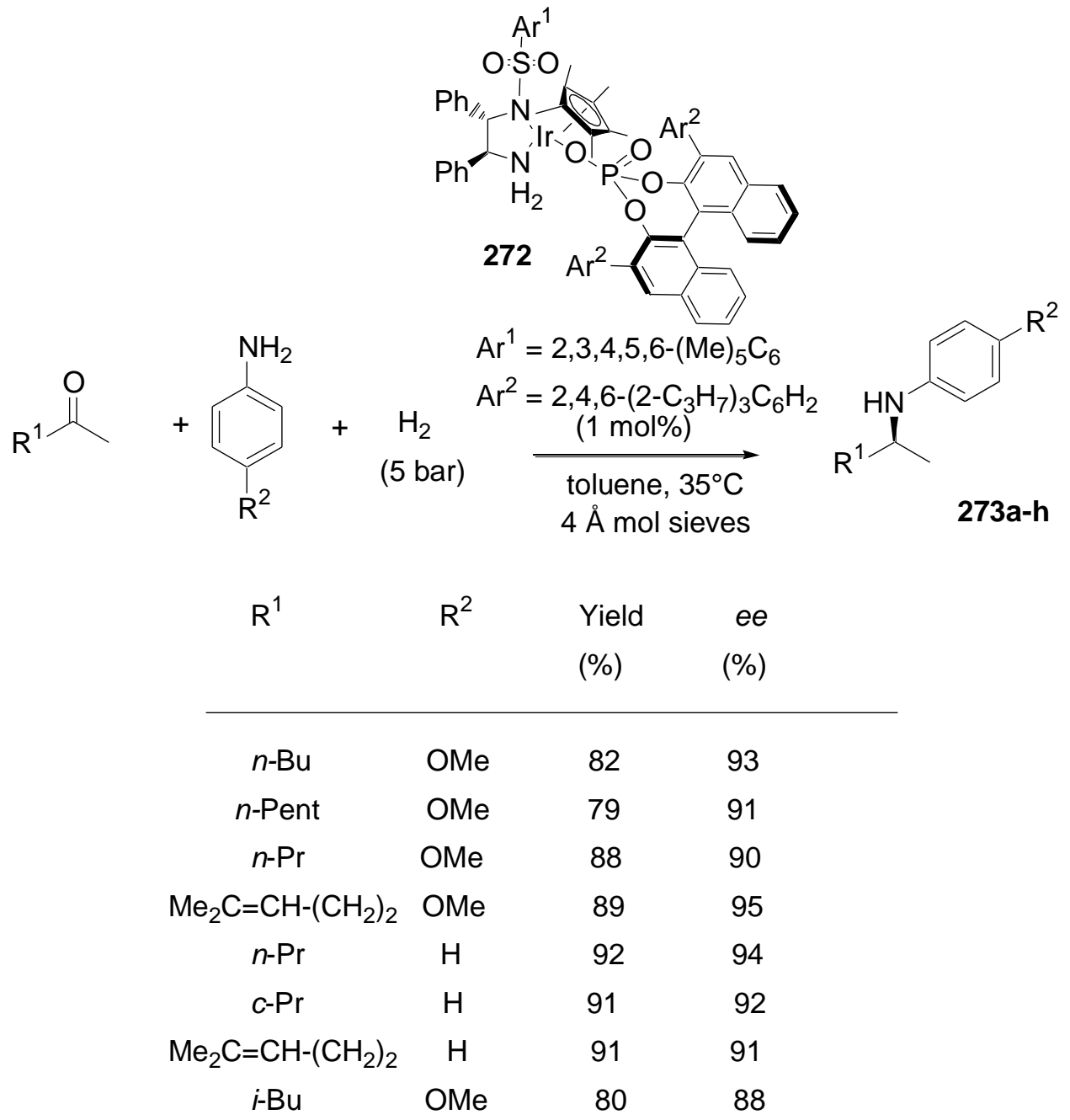

Scheme 73. Ir-catalyzed three-component reductive amination of ketones.

\subsection{Multicomponent Kabachnik-Fields Reactions}

Optically active $\alpha$-aminophosphonates are important synthetic intermediates for the preparation of various natural products. In this context, Feng et al. have reported an enantioselective three-component Kabachnik-Fields reaction induced by catalyst $\mathbf{2 4 0} .{ }^{[173]}$ A series of chiral $\alpha$-amino phosphonates were produced in moderate to good yields (76-96\%) and enantioselectivities of up to $87 \%$ ee through the domino reaction occurring between aldehydes, $o$-aminophenol and diphenyl phosphite. In the same year, Shibata et al. developed direct enantioselective three-component Kabachnik-Fields reaction of aldehydes, $p$-aminophenol and diarylphosphites catalyzed by a chiral zinc(II) complex of $C_{2^{-}}$ symmetric pybim ligand 274. ${ }^{[174]}$ As shown in Scheme 74, a range of $\alpha$-aminophosphonates 275a-h could be achieved in almost quantitative yields in all cases of substrates studied and high enantioselectivities of up to $93 \%$ ee. Although the scandium-catalyzed process described above by Feng et al. employed a lower catalyst loading (5 mol\% instead of $10 \mathrm{~mol} \%)$ and a milder reaction temperature $\left(-20^{\circ} \mathrm{C}\right.$ instead of $\left.-50^{\circ} \mathrm{C}\right)$ to occur in comparison with this zinc-catalyzed process, the later provided both higher yields and enantioselectivities. Moreover, the scope of the zinc-catalyzed process was broader since both aromatic as well as aliphatic aldehydes provided good results. 


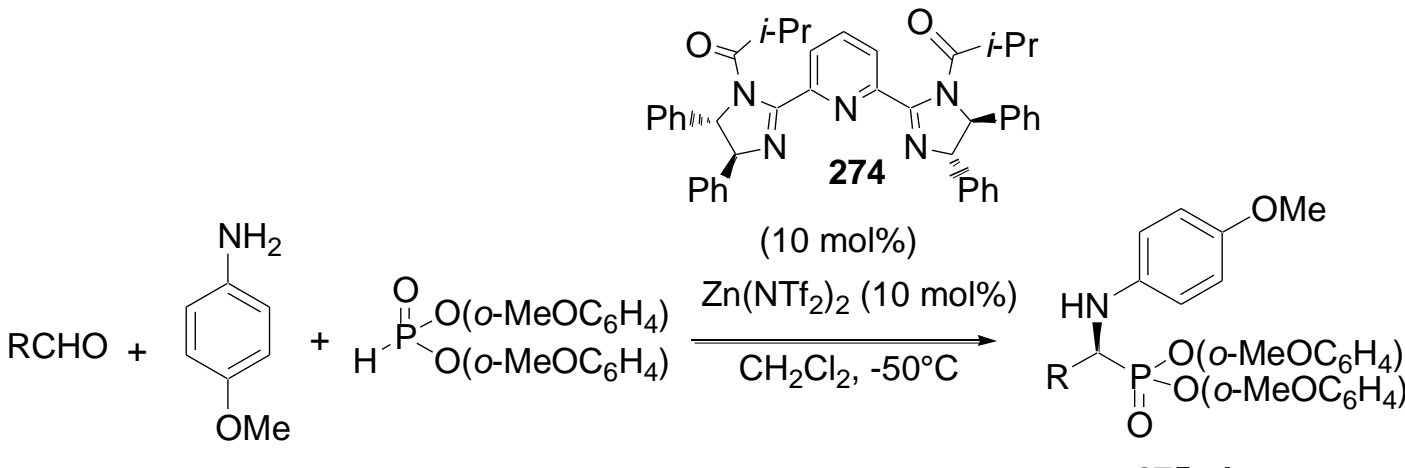

275a-h

\begin{tabular}{ccc}
$\mathrm{R}$ & $\begin{array}{c}\text { Yield } \\
(\%)\end{array}$ & $\begin{array}{c}\text { ee } \\
(\%)\end{array}$ \\
\hline $\mathrm{Ph}$ & 99 & 90 \\
$p$-Tol & 99 & 91 \\
$m-\mathrm{MeOC}_{6} \mathrm{H}_{4}$ & 99 & 90 \\
$p-\mathrm{MeOC}_{6} \mathrm{H}_{4}$ & 86 & 90 \\
$p-\mathrm{HOC}_{6} \mathrm{H}_{4}$ & 99 & 84 \\
$2-\mathrm{Naph}$ & 99 & 82 \\
2 -furyl & 99 & 93 \\
$\mathrm{Cy}$ & 98 & 61
\end{tabular}

Scheme 74. Zn-catalyzed three-component Kabachnik-Fields reaction.

\subsection{Miscellaneous Multicomponent Reactions}

Gold(I) and gold(III) complexes have recently been utilized to catalyze a wide variety of transformations, including three-component reactions. ${ }^{[95 e, ~}{ }^{95 g, 175]}$ As a recent example, Toste et al. have reported an $\mathrm{Au}(\mathrm{I})$-catalyzed three-component reaction of imines, terminal alkynes, and $p$ toluenesulfonylisocyanate to give cyclic carbamimidates. ${ }^{[176]}$ The authors obtained the highest efficiency with enantioselectivities of up to $91 \%$ ee by catalyzing the reaction with a monophosphine gold(I) catalyst $\mathbf{2 7 6}$ bearing a chiral sulfonyl urea as ligand, which was selected among a range of other chiral ligands, including other sulfonyl ureas, carbamates, alkyl/aryl ureas, acyl ureas, amides, and sulfonamides. The process led regioselectively to five-membered carbamimidates $\mathbf{2 7 7 a - i}$ as major products, along with corresponding six-membered carbamimidates 278a-i as minor regioisomers. The authors assumed that the reaction proceeded through alkynylation of aryl-aryl imines generating the corresponding propargylamines $\mathbf{2 7 9}$, which were trapped with $p$-TsNCO to produce acyclic ureas $\mathbf{2 8 0}$. The later were subsequently submitted to 5-exo-dig cyclization to provide final cyclic five-membered carbamimidates $\mathbf{2 7 7} \mathbf{a}-\mathbf{i}$ as major products in moderate to high yields, regio- and enantioselectivities, as shown in Scheme 75. 


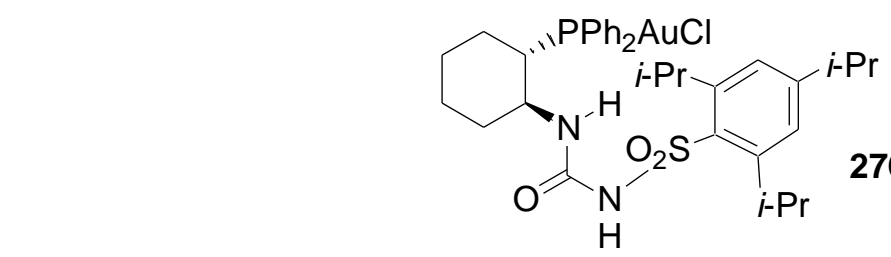

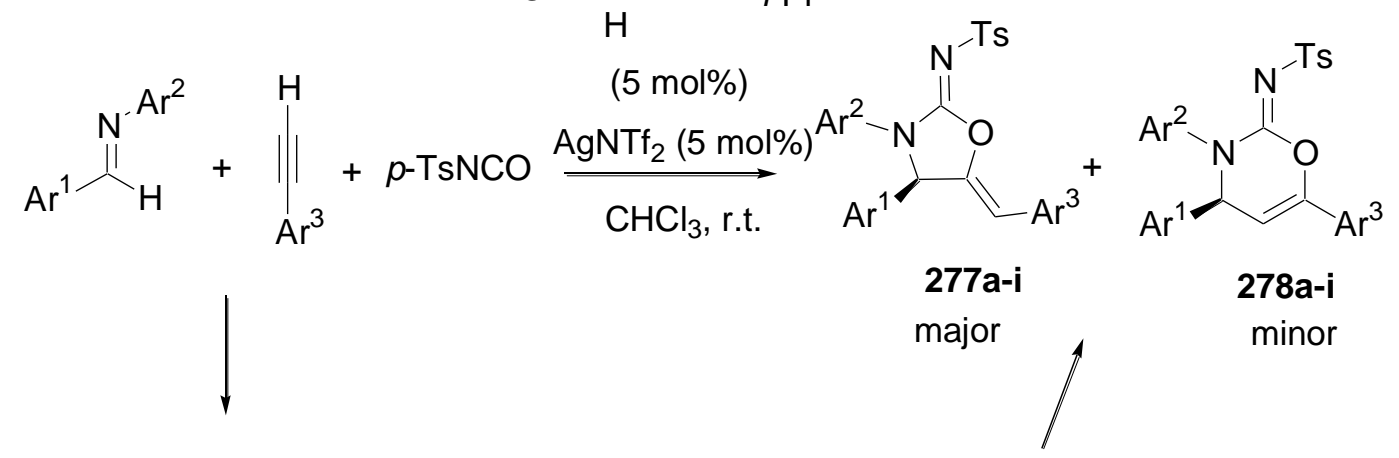<smiles>CC#CC([Al])[Al]</smiles><smiles>CNC(=O)N(Br)C(Br)C#CBr</smiles>

280

\begin{tabular}{|c|c|c|c|c|c|}
\hline $\operatorname{Ar}^{1}$ & $\mathrm{Ar}^{2}$ & $\mathrm{Ar}^{3}$ & $\begin{array}{c}\text { Yield (major) } \\
(\%)\end{array}$ & $\begin{array}{c}e e \text { (major) } \\
(\%)\end{array}$ & $277: 278$ \\
\hline
\end{tabular}

$\begin{array}{ccccccc}\mathrm{Ph} & \mathrm{Ph} & \mathrm{Ph} & 76 & 79 & 8: 1 & \\ p-\mathrm{Tol} & \mathrm{Ph} & \mathrm{Ph} & 76 & 80 & 11: 1 & \\ o-\mathrm{ClC}_{6} \mathrm{H}_{4} & \mathrm{Ph} & \mathrm{Ph} & 61 & 91 & 7: 1 & \\ o-\mathrm{FC}_{6} \mathrm{H}_{4} & \mathrm{Ph} & \mathrm{Ph} & 55 & 86 & 8: 1 & \\ \mathrm{Ph} & 3,5-(\mathrm{Me})_{2} \mathrm{C}_{6} \mathrm{H}_{3} & \mathrm{Ph} & 38 & 91 & 3: 1 & \\ \mathrm{Ph} & p-\mathrm{IC}_{6} \mathrm{H}_{4} & \mathrm{Ph} & 43 & 84 & 3: 1 & \\ \mathrm{Ph} & 3,5-\left(\mathrm{CF}_{3}\right)_{2} \mathrm{C}_{6} \mathrm{H}_{3} & \mathrm{Ph} & 48 & 95 & 5: 1 & \\ \mathrm{Ph} & 2,6-(\mathrm{F})_{2} \mathrm{C}_{6} \mathrm{H}_{3} & \mathrm{Ph} & 48 & 41 & 1.7: 1 & \\ \mathrm{Ph} & \mathrm{Ph} & p-\mathrm{CF}_{3} \mathrm{C}_{6} \mathrm{H}_{4} & 85 & 72 & >20: 1 & \\ \text { Au-catalyzed } & \text { three-component reaction } & \text { of imines, terminal alkynes and } & p- \\ \text { ocyanate. } & & & & & & \end{array}$
toluenesulfonylisocyanate.

On the other hand, the combination of $\mathrm{Rh}(\mathrm{OAc})_{4}$ with a chiral zirconium complex of a Binol derivative was demonstrated by $\mathrm{Hu}$ et al. to catalyze an efficient three-component enantioselective aldol-type reaction of aryl diazoacetates, aldehydes and benzyl alcohol. ${ }^{[177]}$ The authors assumed that the process occurred by trapping a reactive alcoholic oxonium ylide, which was formed in situ from the diazoacetate and benzyl alcohol, with aldehyde activated by zirconium complex to give through an aldol-type addition the final products. This three-component reaction provided a convenient and highly enantioselective route to the construction of an important class of compounds for both organic and medicinal chemistry, which are $\alpha, \beta$-dihydroxy acid derivatives containing two contiguous tetrasubstituted carbon centers. The products were obtained in moderate to good yields (40-82\%) and erythro:threo ratios, combined with high enantioselectivities of up to $98 \%$ ee for the major erythro product. A highly efficient nickel-catalyzed reductive coupling of alkynes and imines using $\mathrm{Et}_{2} \mathrm{Zn}$ as a reductant was achieved by the same authors, affording a range of chiral allylic amines with high yields 
and chemoselectivities. ${ }^{[178]}$ Chiral induction was achieved by employing a nickel catalyst containing a chiral spiro phosphine ligand, which allowed enantioselectivities of up to $97 \%$ ee to be reached. It must be noted that the best results were obtained in the case of aromatic alkynes. In addition, Montgomery et al. have developed asymmetric nickel-catalyzed reductive coupling of aldehydes and alkynes, using triethylsilane as the reductant agent. ${ }^{[179]}$ When the process was catalyzed by nickel complexes of chiral $N$-heterocyclic carbene ligands derived from $C_{2}$-symmetric diamines in the presence of $\mathrm{KO}-t-\mathrm{Bu}$ as a base, it provided the corresponding chiral silyl ethers in moderate to high yields (47-98\%) associated to moderate to good enantioselectivities $(65-85 \%$ ee). In another context, Ryu et al. have developed a highly enantioselective catalytic three-component coupling reaction between an aldehyde, ethyl propiolate, and TMSI to give the corresponding chiral ( $Z$ )- $\beta$-iodo Morita-Baylis-Hillman esters $(R)-281 a-n .{ }^{[180]}$ The process was induced by $(S)$-oxazaborolidinium catalysts 282a-c, providing $(R)$-products in moderate to excellent yields of up to $99 \%$, excellent $Z$ diastereoselectivity along with high enantioselectivities of up to $96 \% e e$, as shown in Scheme 76. Furthermore, the authors have shown that it was possible to prepare the other enantiomers $(S)$-281a-n by performing the reaction upon catalysis with $(R)$-oxazaborolidinium catalysts $282 a-c$. In addition, $(R)-281 a-n$ could be further converted through a single step into corresponding $(Z)$ - $\beta$-branched derivatives with retention of configuration.

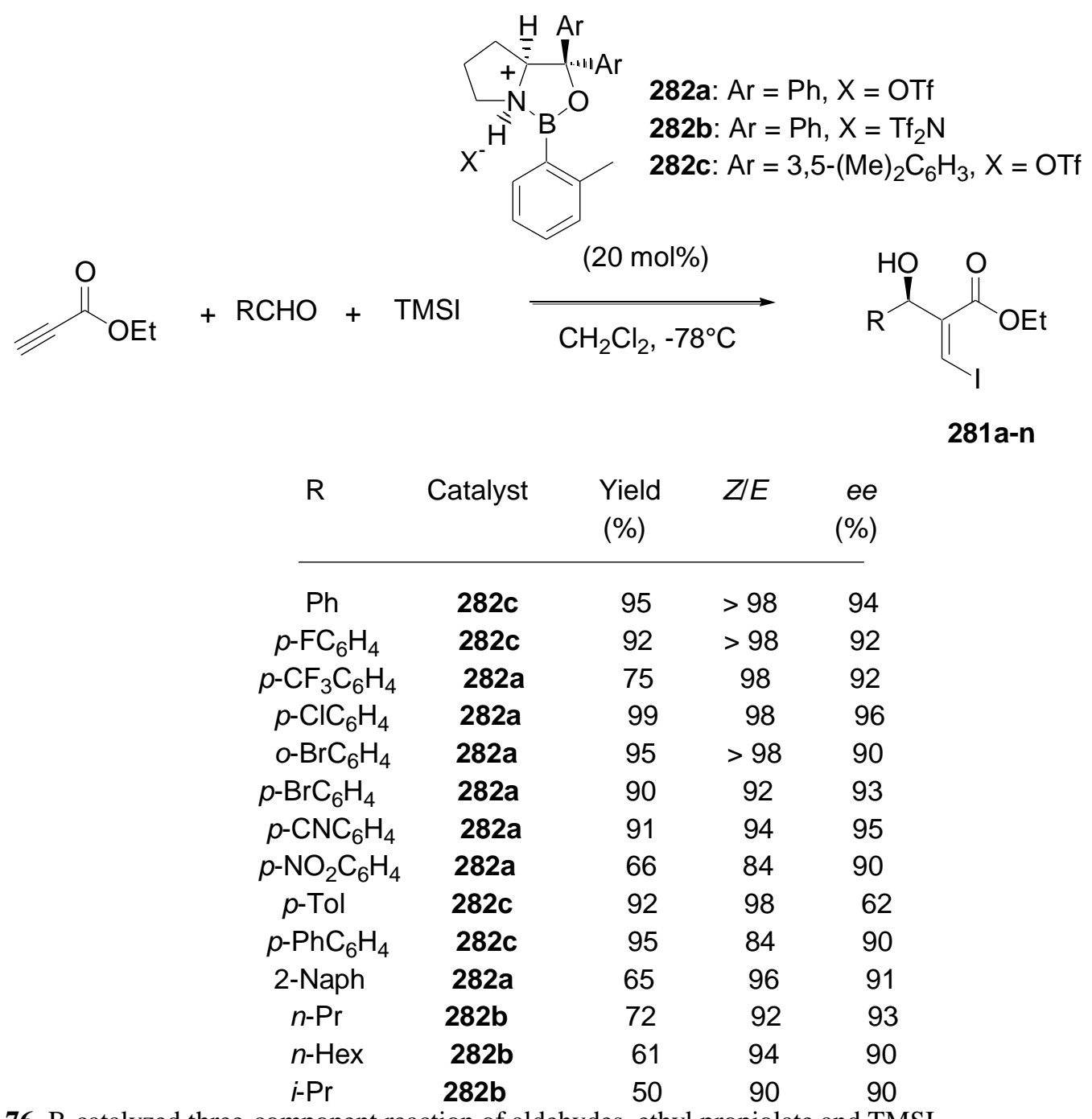

Scheme 76. B-catalyzed three-component reaction of aldehydes, ethyl propiolate and TMSI.

In addition, remarkable levels of regio- and enantioselectivities of up to > 90:10, and 99\% ee, respectively, were reported by Murakami et al. in an intermolecular formal $[2+2+2]$ cycloaddition reaction of two molecules of isocyanates with allenes. ${ }^{[181]}$ The three-component reaction was catalyzed by a combination of $\mathrm{Ni}(\mathrm{cod})_{2}$ with unsymmetrical phosphino-oxazoline chiral ligand $(S, S)-i$-Pr- 
FOXAP. The later has been selected among a range of various chiral ligands, such as $C_{2}$-symmetric biphosphine ligands (S,S)-Chiraphos, (S,S)-Norphos, and (S)-BINAP, which gave lower regioselectivities. This process provided an efficient access to chiral dihydropyrimidine-2,4-diones 283a-m in moderate to good yields, as shown in Scheme 77.

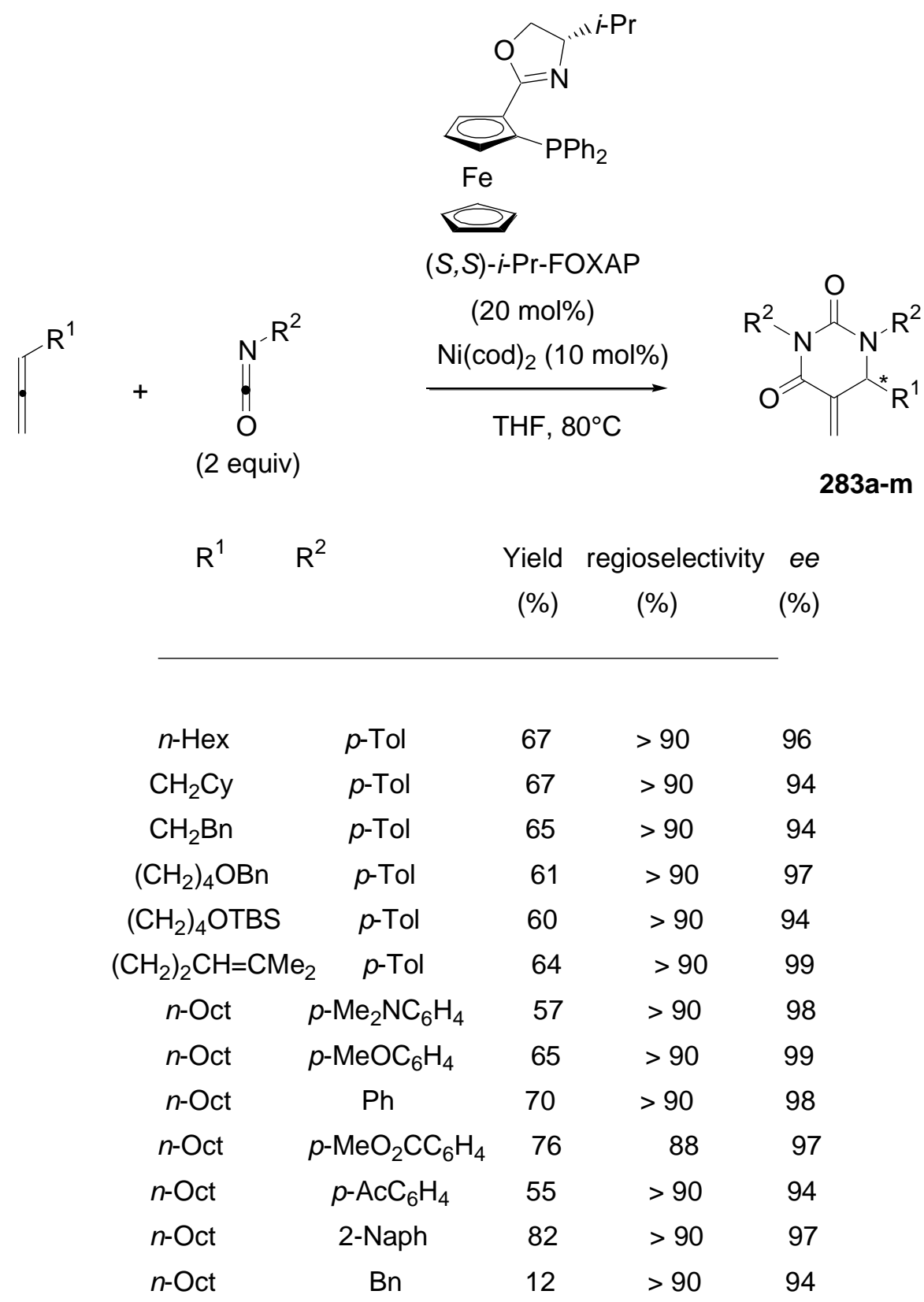

Scheme 77. Ni-catalyzed three-component reaction of isocyanates and allenes.

On the other hand, Zhao et al. have recently developed an enantioselective pseudo-three-component reaction based on double allylations of sodium sulfide. ${ }^{[182]}$ The reaction was catalyzed by a chiral iridium complex, in situ generated from $\left[\operatorname{Ir}(\operatorname{cod}) \mathrm{Cl}_{2}\right.$ and chiral phosphoramidite ligand 284, in the presence of cesium fluoride and water, yielding the corresponding enantiopure chiral $C_{2}$-symmetric bis(1-substituted-allyl)sulfanes $\mathbf{2 8 5} \mathbf{a}-\mathbf{h}$ in good to excellent yields and diastereoselectivities of up to > $98 \%$ de, as shown in Scheme 78. This work constituted the first example in which sodium sulfide was employed as an atom-economical inorganic nucleophile in transition-metal-catalyzed allylation substitutions. It is interesting to note that the double allylation reaction efficiently generated two $\mathrm{C}-\mathrm{S}$ chiral centers in one pot. 


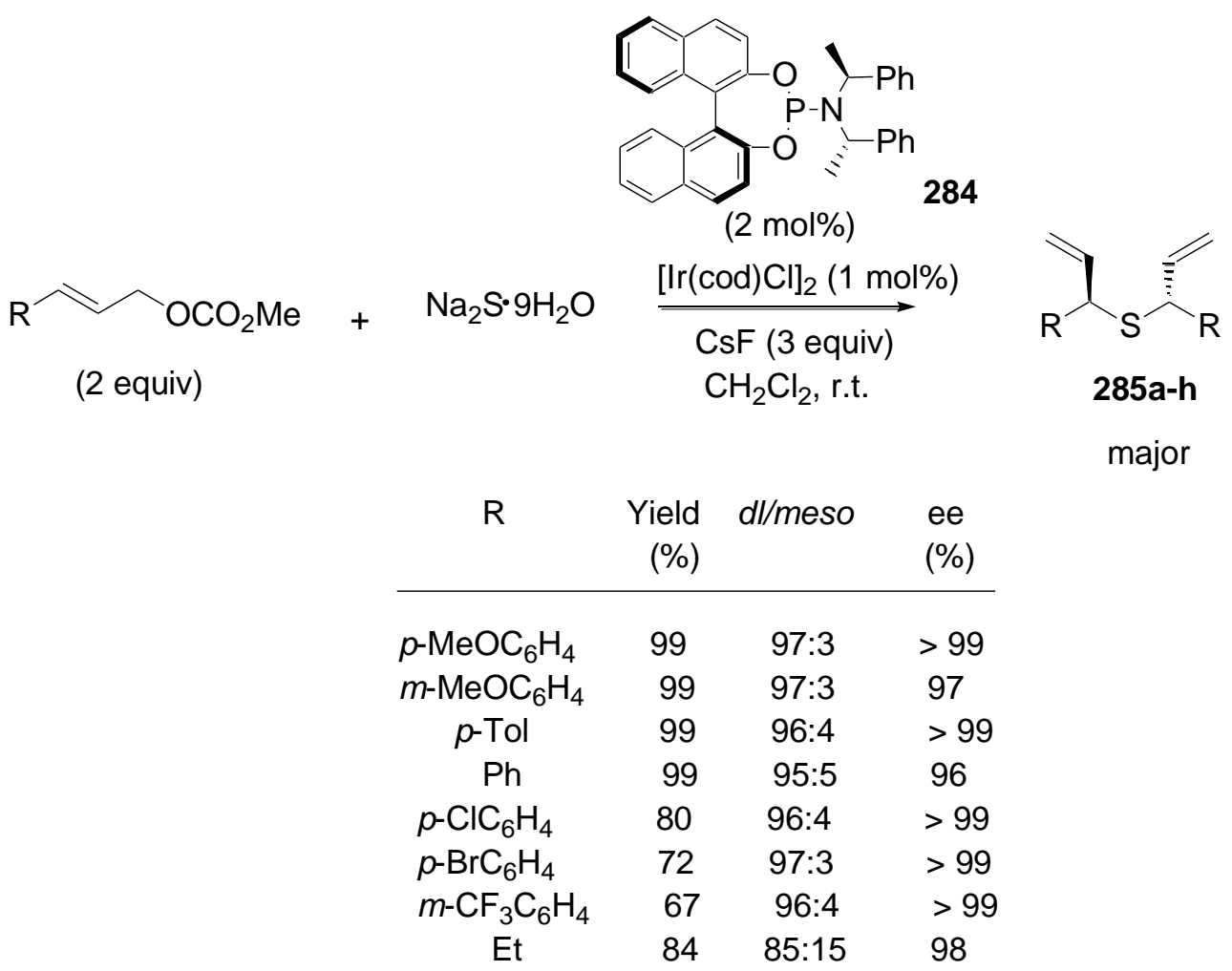

Scheme 78. Ir-catalyzed pseudo-three-component double allylation of sodium sulfide.

Highly functionalized $\delta$-lactones $\mathbf{2 8 6 a - i}$ have been produced by Shibasaki et al. in the presence of a catalytic amount of a combination of $\mathrm{Cu}(\mathrm{OAc})_{2}$ with $(R)$-DIFLUORPHOS through an enantioselective three-component assembly of dialkylzincs, allenic ethyl ester and unactivated ketones $\mathbf{2 8 7 a - f} .{ }^{[183]}$ This process allowed the construction of two $\mathrm{C}-\mathrm{C}$ bonds and one tetrasubstituted chiral center simultaneously. Conjugate addition of alkyl-copper species to an allenic ester produced highly active copper enolate in situ, and the successive asymmetric aldol addition to ketones followed by lactonization afforded the final lactones in high yields and enantioselectivities of up to $98 \% e e$, as shown in Scheme 79. It must be noted that the use of an additive, such as DMSO, HMPA or $\mathrm{Ph}_{2} \mathrm{~S}=\mathrm{O}$, was important for obtaining high yields, with suppression of the undesired $\alpha$-addition pathway. 

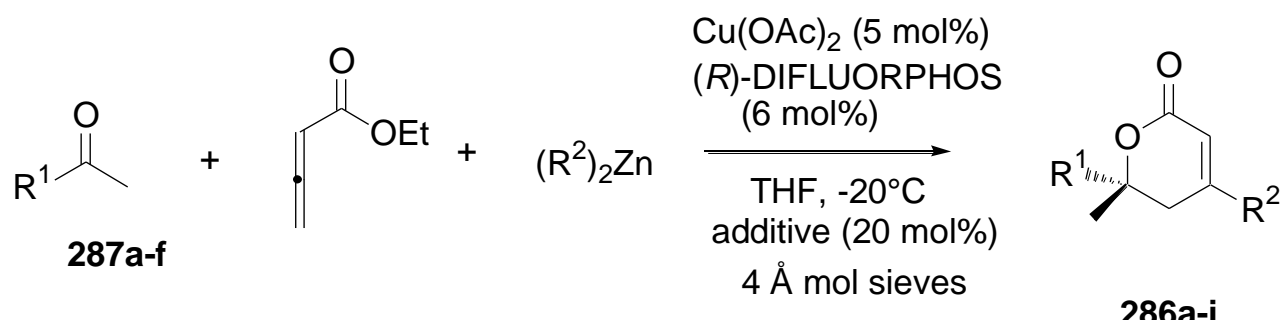

286a-i

\begin{tabular}{llll}
$\mathrm{R}^{1}$ & $\mathrm{R}^{2} \quad$ additive & $\begin{array}{c}\text { Yield } \\
(\%)\end{array}$ & $\begin{array}{r}\text { ee } \\
(\%)\end{array}$ \\
\hline
\end{tabular}

$\begin{array}{ccccc}\mathrm{Ph} & \mathrm{Et} & \mathrm{DMSO} & 92 & 96 \\ p-\mathrm{BrC}_{6} \mathrm{H}_{4} & \mathrm{Et} & \mathrm{HMPA} & 91 & 94 \\ p-\mathrm{MeOC}_{6} \mathrm{H}_{4} & \mathrm{Et} & \text { HMPA } & 73 & 95 \\ \text { cyclohexenyl } & \mathrm{Et} & \text { DMSO } & 79 & 98 \\ i-\mathrm{Bu} & \mathrm{Et} & \mathrm{DMSO} & 76 & 96 \\ \mathrm{Cy} & \mathrm{Et} & \mathrm{DMSO} & 67 & 94 \\ \mathrm{Ph} & \mathrm{Me} & \mathrm{DMSO} & 89 & 94 \\ \mathrm{Cy} & \mathrm{Et} & \mathrm{DMSO} & 67 & 94 \\ \mathrm{Ph} & n-\mathrm{Bu} & \mathrm{Ph}_{2} \mathrm{~S}=\mathrm{O} & 73 & 92\end{array}$

Scheme 79. Cu-catalyzed three-component alkylative aldol reaction.

Feng et al. have demonstrated that chiral $N, N^{\prime}$-dioxide-scandium(III) complexes exhibited an excellent ability for the activation of various electrophiles and showed strong asymmetry-induction capability for many reactions. In this context, these authors have developed modular and tuneable $C_{2^{-}}$ symmetric $N, N^{\prime}$-dioxide ligands, easily synthesized from readily accessible chiral amino acids and amines. These ligands were further applied as scandium ligands to promote the enantioselective direct allylation of aldimines to give the corresponding homoallylic amines 288a-o. ${ }^{[184]}$ Among these ligands, $N, N$ '-dioxide 240 was selected as the most efficient one to perform the three-component reaction of a wide variety of aldimines in situ generated from aldehydes and $o$-anisidine, providing the domino products 288a-o in high yields and remarkable enantioselectivities of up to $97 \%$ ee, as shown in Scheme 80. 


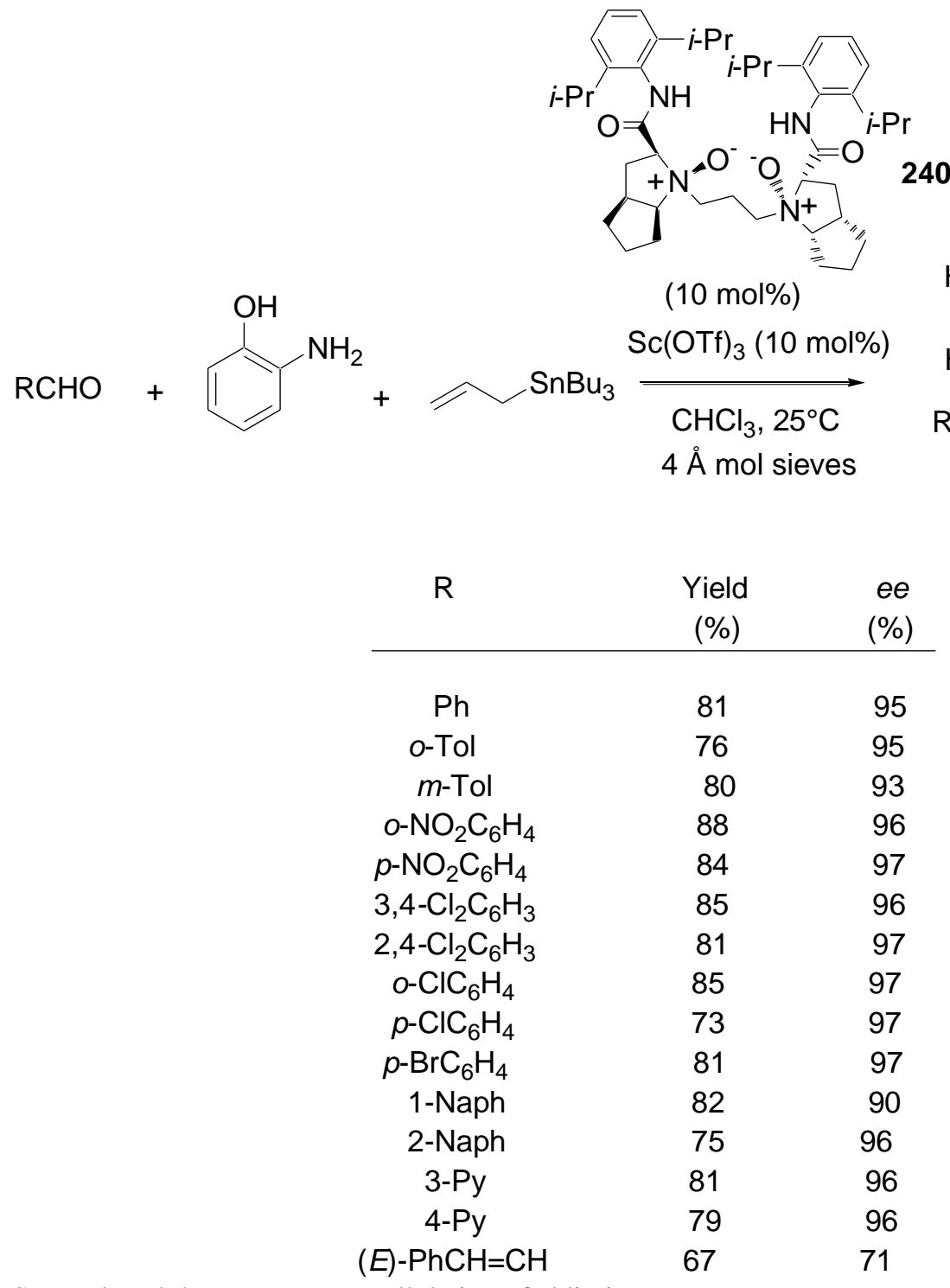

Scheme 80. Sc-catalyzed three-component allylation of aldimines.

In 2011, Wulff et al. described the first multicomponent catalytic asymmetric aziridination reaction, which incorporated a highly simple protocol. ${ }^{[185]}$ This process dealt with a three-component reaction of aldehydes, bis(dimethylanisyl)methyl amine (MEDAM- $\mathrm{NH}_{2}$ ), and ethyl diazo acetate to provide the corresponding chiral aziridine-2-carboxylic esters 289a-h. When promoted by a chiral boroxinate catalyst in situ generated from $\mathrm{B}(\mathrm{OPh})_{3}$ and chiral ligand $(S)$-VAPOL, the reaction afforded products 289a-h with good to high yields, excellent diastereoselectivity of $>96 \%$ de in all cases of substrates studied, and remarkable enantioselectivities ranging from 90 to $98 \% e e$, as shown in Scheme 81. This novel methodology furnished an effective solution to the long-standing problem of imines derived from unbranched aliphatic aldehydes which cannot be purified. 

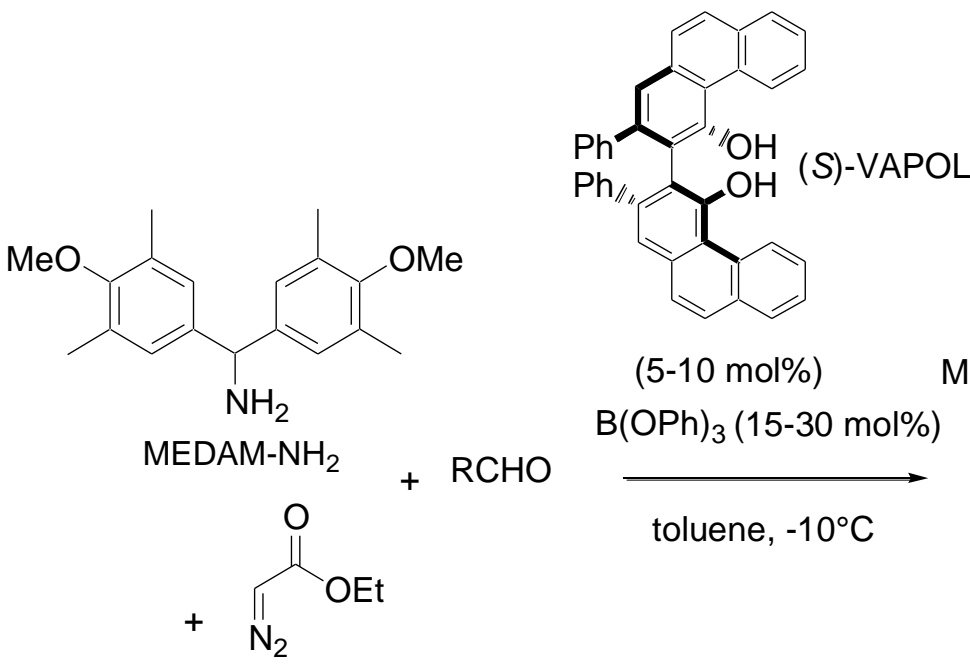

(5-10 mol\%) $\mathrm{B}(\mathrm{OPh})_{3}(15-30 \mathrm{~mol} \%)$ toluene, $-10^{\circ} \mathrm{C}$<smiles>[R]C1C(C(=O)OCC)N1C(c1cc(C)c(OC)c(C)c1)c1cc(C)c(OC)c(C)c1</smiles>

de $>96 \%$

$\mathrm{R} \quad$ Yield ee

$(\%) \quad(\%)$

$\begin{array}{ccc}\mathrm{Me}\left(\mathrm{CH}_{2}\right)_{14} & 80 & 96 \\ \mathrm{TBSO}\left(\mathrm{CH}_{2}\right)_{7} & 80 & 98 \\ \mathrm{EtO}_{2} \mathrm{C}\left(\mathrm{CH}_{2}\right)_{3} & 82 & 97 \\ \mathrm{Bn}\left(\mathrm{CH}_{2}\right)_{2} & 55 & 93 \\ \mathrm{BnCH}{ }_{2} & 96 & 97 \\ \mathrm{Bn} & 94 & 98 \\ \mathrm{Cy} & 95 & 90 \\ t-\mathrm{Bu} & 95 & 92\end{array}$

Scheme 81. B-catalyzed three-component aziridination of aldehydes.

In 2007, Tietze et al. reported a new palladium-catalyzed three-component domino Wacker-carbonylation reaction, allowing the synthesis of a wide range of chiral chromans and benzodioxins to be achieved. ${ }^{[186]}$ The combination of a CO insertion with an enantioselective Wacker process was described for the first time. Indeed, a series of chiral chromans 290a-g were produced through the three-component reaction of unsaturated phenols with alcohols under CO-atmosphere in moderate to good yields and high enantioselectivities of up to $99 \%$ ee, as shown in Scheme 82. The scope of the methodology was extended to monoallyl ethers, providing under same conditions the corresponding 2,3-dihydrobenzo[1,4]dioxins 290h-k in high yields and general excellent enantioselectivities ranging from 95 to $99 \%$ ee (Scheme 82). These processes were catalyzed by palladium(II)trifluoroacetate as palladium source, $p$-benzoquinone as reoxidant, and $(S, S)$-Bn-BOXAX as chiral ligand, under a $\mathrm{CO}$-atmosphere as a source of $\mathrm{CO}$ at ambient pressure. Later, the same authors employed a more economical methodology employing the same catalyst albeit used in lower catalyst loadings, such as $12 \mathrm{~mol} \%$ instead of $40 \mathrm{~mol} \%$ of $(S, S)$-Bn-BOXAX, combined with $3 \mathrm{~mol} \%$ instead of $10 \mathrm{~mol} \%$ of palladium(II)trifluoroacetate. Moreover, the reaction was performed in methanol at room temperature instead of dichloromethane at $60^{\circ} \mathrm{C}$. In these conditions, alkenyl phenol 117 provided the corresponding ester 291 in $80 \%$ yield and $96 \%$ ee. This domino product could be subsequently converted into natural product 4-dehydroxydiversonol. ${ }^{\text {[1a] }}$ 


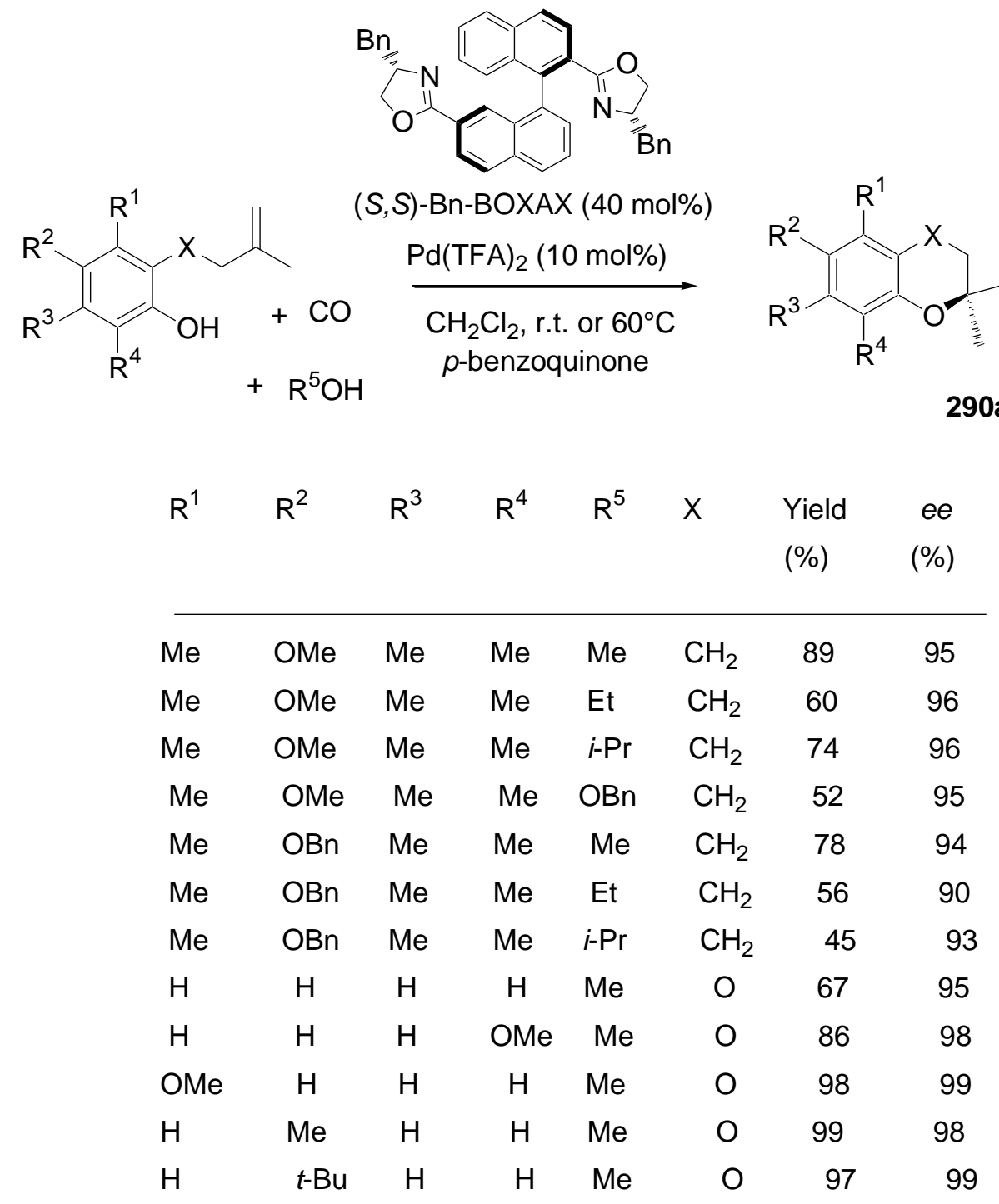
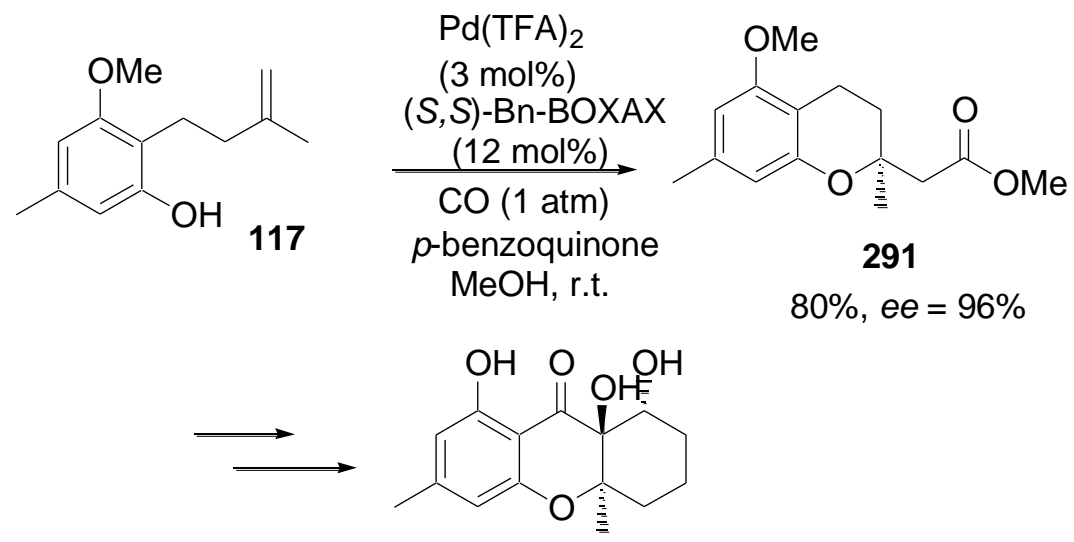

4-dehydroxydiversonol

Scheme 82. Pd-catalyzed three-component Wacker-carbonylation reactions.

Lanthanides have also been employed to catalyze enantioselective domino reactions. As a recent example, Mlynarski et al. have developed ytterbium complex-catalyzed direct asymmetric domino aldol-Tishchenko reaction of two molecules of aromatic aldehydes with aliphatic and aromatic ketones. ${ }^{[187]}$ This three-component reaction was promoted by a combination of ytterbium triflate and 
(1R,2S)-1-phenyl-2-(1-pyrrolidynyl)-1-propanol derived from ephedrine. It afforded the corresponding domino products, which were subsequently converted into corresponding 1,3-diols through saponification, since the assigned 1,2-anti-1,3-anti stereochemistry of the domino products could be readily supported by NMR spectroscopic analysis of separately derived diols. The yields and enantioselectivities in 1,3-diols were moderate to good $(25-92 \%$ yield, $53-86 \% e e)$, while anti diastereocontrol was high in all cases of substrates studied. This methodology offerred a simple yet powerful way to prepare enantiomerically enriched anti-1,3-diols with high diastereocontrol from unmodified substrates. It must be noted that there are a few examples of enantioselective $\mathrm{C}-\mathrm{C}$ bond formation leading to quaternary centers which involve free radical intermediates. In this context, Cobb et al. have developed a novel asymmetric domino addition-trapping radical reaction, establishing a carbon chiral quaternary center. ${ }^{[188]}$ The multicomponent reaction occurred between an $\alpha, \beta$-unsaturedamide, allyltributylstannane, and an alkyl iodide in the presence of a combination of $\mathrm{Yb}(\mathrm{OTf})_{3}$ and a chiral pybox ligand as catalyst system. Moderate to good yields associated to low to moderate enantioselectivities $(15-73 \%$ ee $)$ were obtained for the corresponding $\alpha$-allyl amides bearing a quaternary stereogenic center in $\alpha$-position. A good enantioselectivity of $73 \%$ ee could be reached in only one case of substrate arisen from the use of tert-butyl iodide. In addition, a rare example of dualmetal enantiocatalysis was reported by $\mathrm{Hu}$ et al., in $2010 .{ }^{[189]}$ These authors have shown that the cooperative catalysis of $\left[\mathrm{Rh}(\mathrm{OAc})_{4}\right]_{2}$ with a chiral zinc complex of $(S)$ - $t$-Bu-box ligand 292 applied to the three-component reaction of diazo compounds with $\mathrm{H}_{2} \mathrm{O}$ and $\alpha, \beta$-unsaturated 2-acyl imidazoles 293a-i afforded the corresponding $\gamma$-hydroxyketones 294a-j which beared a stereogenic quaternary carbon center. As shown in Scheme 83, these highly functionalized products were achieved in good yields and high diastereo- and enantioselectivities of up to $98 \%$ de and $99 \%$ ee, respectively. The authors have proposed that rhodium catalyst promoted the formation of an oxonium ylide generated in situ from the aryl diazoacetate and water, which was further trapped by $\alpha, \beta$-unsaturated 2-acyl imidazole 293 activated by zinc catalyst through a Michael-type addition to give the final product. Electronic variations on the aromatic substituents of diazoacetates as well as imidazoles were tolerated in this process. The products were readily converted into the corresponding $\gamma$-hydroxy carboxylic acid derivatives, which constitute key intermediates in the construction of natural products and pharmaceuticals. 


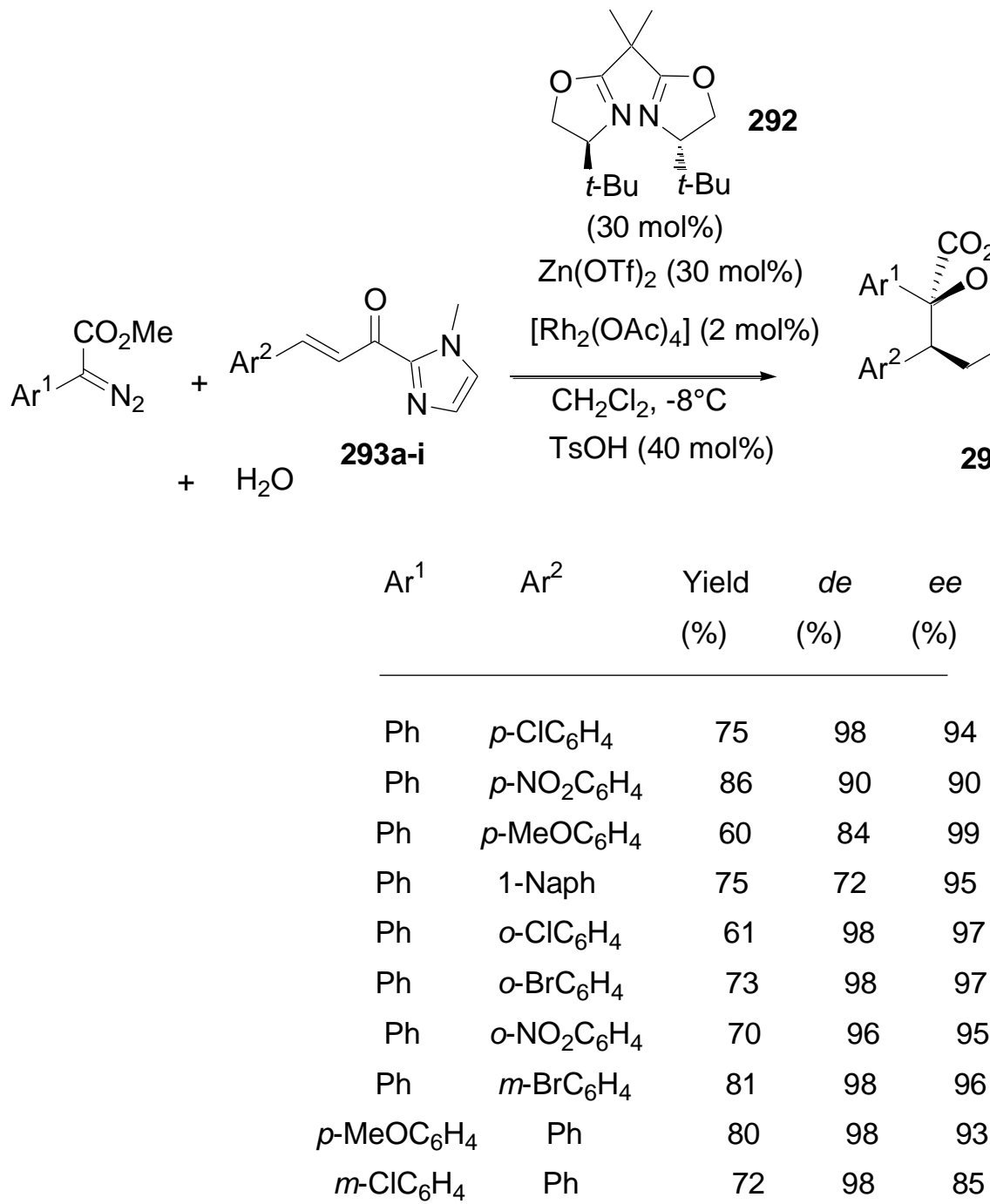

Scheme 83. Rh- and Zn-catalyzed three-component reaction of diazo compounds, $\alpha, \beta$-unsaturated 2-acyl imidazoles and $\mathrm{H}_{2} \mathrm{O}$.

The Reformatsky reaction is the well-recognized carbon-carbon bond-forming reaction of $\alpha$-halo esters with aldehydes or ketones in the presence of $\mathrm{Zn}$ metal to give $\beta$-hydroxy esters. Recently, a rhodium- and nickel-catalyzed Reformatsky reaction in which dialkylzinc (methyl or ethyl), acting as the $\mathrm{Zn}$ source, reacted smoothly with carbonyl compounds and imines. Taking advantage of $(1 S, 2 R)$ $N$-methylephedrine as a cheap and recoverable chiral ligand, Cozzi et al. have discovered the first homogeneous enantioselective nickel-catalyzed imino Reformatsky reaction. ${ }^{[190]}$ The process was a three-component reaction occurring between aromatic aldehydes, $\alpha$-bromo esters and $o$-anisidine, in which $\mathrm{ZnMe}_{2}$ played multiple roles as dehydrating agent for the formation of the imine, reductant of $\mathrm{Ni}(\mathrm{II})$ salt to $\mathrm{Ni}(0)$, and coordinating metal. In this context, a range of chiral $\beta$-amino esters could be synthesized in moderate to good yields (40-67\%) and enantioselectivities of up to $92 \%$ ee on the basis of this domino reaction. In 2010, Dias et al. reported a small but remarkable study on a silvercatalyzed enantioselective three-component reaction of glycine methyl ester hydrochloride $\mathbf{2 9 5}$ with $\mathrm{N}$-methylmaleimide 296, and benzaldehyde, which afforded, through domino carbonyl-ylide formation-1,3-dipolar cycloaddition reaction, the corresponding endo adduct $\mathbf{2 9 7}$ in $88 \%$ yield, and both almost complete diastereo-, and enantioselectivities, as shown in Scheme 84. ${ }^{[78]}$ The process was performed in toluene in the presence of a catalytic amount of TEA, and employed a $5 \mathrm{~mol} \%$ of an equimolecular mixture of $(S)$-BINAP and $\mathrm{AgSbF}_{6}$ as catalyst system. Furthermore, this methodology could be extended to the three-component reaction of glycine methyl ester hydrochloride $\mathbf{2 9 5}$, aldehyde 298, and sulfone 299, which afforded the corresponding endo product $\mathbf{3 0 0}$. Once again, impressive results were obtained, since this product was formed in $86 \%$ yield, complete 
diastereoselectivity, combined with enantioselectivity of $98 \%$ ee, as shown in Scheme 84. The selection of the substrates resulted from a domino two-component study involving preformed imines, reported in the same work. The counterion of $\mathrm{Ag}(\mathrm{I})$ played an important role in this sensitive reaction. Indeed, it was found that the reactions proceeded smoothly in the presence of the weakly coordinating $\mathrm{SbF}_{6}{ }^{-}$counterion, providing high yields and enantioselectivities, whereas no conversion was observed with $\mathrm{ClO}_{4}{ }^{-}$was used as the counterion. In another context, the Pauson-Khand reaction is a formal $[2+2+1]$ cycloaddition in which an alkyne, an alkene, and CO furnish a cyclopentenone derivative. ${ }^{[191]}$ A recent example of multicomponent asymmetric version of this reaction was described by Verdaguer et al. with the first asymmetric intermolecular cobalt-catalyzed Pauson-Khand reaction, in 2007. ${ }^{[192]} \mathrm{In}$ this work, the use of camphor-derived chiral ligands provided low to high yields (12-98\%) and modest enantioselectivities of $\leq 40 \%$ ee.
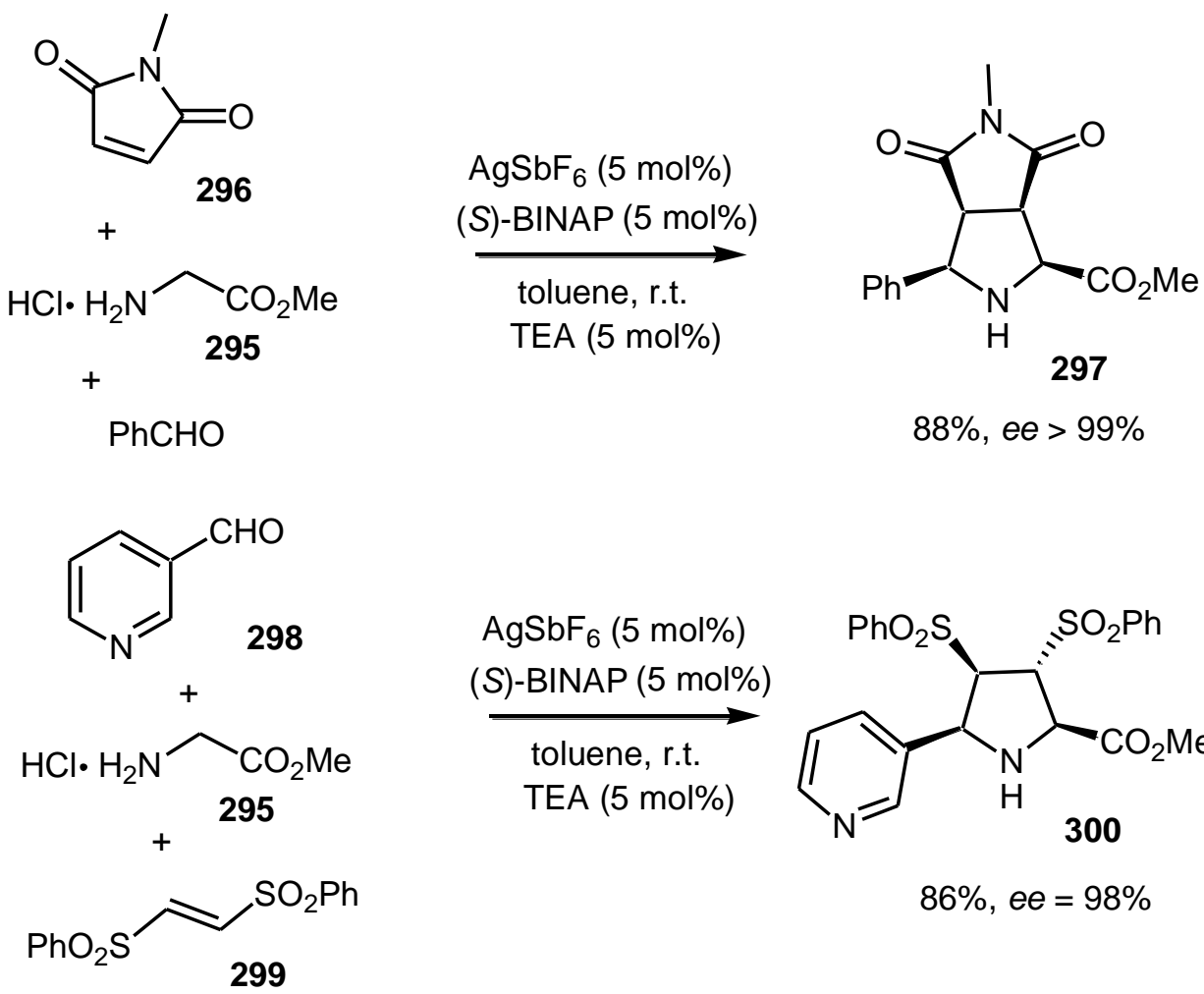

Scheme 84. Ag-catalyzed three-component domino carbonyl-ylide formation-1,3-dipolar cycloaddition reactions.

\section{Conclusions}

This review illustrates how much asymmetric organometallic catalysis has contributed to the development of enantioselective domino and multicomponent reactions. It updates the major progress in the field of enantioselective one-, two-, and multicomponent domino reactions promoted by chiral metal catalysts, covering the literature since the beginning of 2006. It well illustrates the power of these elegant one-pot processes of two or more bond-forming reactions, evolving under identical conditions in which the subsequent transformation takes place at the functionalities obtained in the former transformation, following the same principles that are found in biosynthesis from the nature. These fascinating reactions have rapidly become one of the most current fields in organic chemistry. During the last 6 years, an explosive number of novel powerful asymmetric domino and multicomponent processes have been developed on the basis of asymmetric metal catalysis, which is fast becoming fundamental in many manufacturing processes. In particular, a number of novel enantioselective domino reactions have been promoted by chiral rhodium and gold catalysts. In some cases, up to eight stereogenic centers could be generated in excellent stereoselectivities. The wide variety of these novel highly efficient domino processes well reflects that of metals employed to induce them. Indeed, an increasing number of different metals such as magnesium, scandium, 
titanium, ruthenium, cobalt, rhodium, iridium, nickel, palladium, platinum, copper, silver, gold, zinc, aluminum, as well as tin have been found effective catalysts. The economical interest in combinations of asymmetric metal catalytic processes with the concept of domino and multicomponent reactions is obvious, and has allowed reaching easily high molecular complexity with often excellent levels of stereocontrol with simple operational one-pot procedures, and advantages of savings in solvent, time, energy, and costs by avoiding costly protecting groups and time-consuming purification procedures after each step. Undoubtedly, the future direction in this field is to continue expanding the scope of enantioselective domino and multicomponent reactions through the combination of different types of reactions, the employment of novel chiral catalysts, and apply these powerful strategies to the synthesis of biologically interesting molecules including natural products, and that of novel chiral ligands, and functional materials.

\section{References}

[1] a) L. F. Tietze, I. Hiriyakkanavar, H. P. Bell, Chem. Rev. 2004, 104, 3453-3516; b) E. Negishi, Handbook of Organopalladium Chemistry for Organic Synthesis, John Wiley \& Sons, Inc., Hoboken NJ, 2002, 2, 1689-1705; c) M. Beller, C. Bolm, Transition Metals for Organic Synthesis, Wiley-VCH, Weinheim, 1998, Vol. 1 and Vol. 2; d) G. Poli, G. Giambastiani, A. Heumann, Tetrahedron 2000, 56, 5959-5989; e) A. de Meijere, P. von Zezschwitz, H. Nüske, B. Stulgies, J. Organomet. Chem. 2002, 653, 129-140.

[2] a) L. F. Tietze, U. Beifuss, Angew. Chem., Int. Ed. 1993, 32, 131-163; b) L. F. Tietze, Chem. Rev. 1996, 96, 115-136; c) L. F. Tietze, G. Brasche, K. Gericke, Domino Reactions in Organic Synthesis, Wiley-VCH, Weinheim, 2006.

[3] K. C. Nicolaou, D. J. Edmonds, P. G. Bulger, Angew. Chem., Int. Ed. 2006, 45, 7134-7186.

[4] S. E. Denmark, A. Thorarensen, Chem. Rev. 1996, 96, 137-165.

[5] C. J. Chapman, C. G. Frost, Synthesis 2007, 1-21.

[6] D. E. Fogg, E. N. dos Santos, Coord. Chem. Rev. 2004, 248, 2365-2379.

[7] a) L. F. Tietze, A. Modi, Med. Res. Rev. 2000, 20, 304-322; b) Multicomponent Reactions (Eds.: J. Zhu, H. Bienaymé), Wiley-VCH, Weinheim, 2005; c) D. J. Ramon, M. Yus, Angew. Chem., Int. Ed. 2005, 44, 1602-1634; d) Synthesis of Heterocycles via Multicomponent Reactions (Eds.: R. V. A. Orru, E. Ruijter), Topics in Heterocyclic Chemistry, Vols. I and II, Springer, Berlin, 2010.

[8] a) C. Grondal, M. Jeanty, D. Enders, Nature Chemistry 2010, 2, 167-178; b) K. C. Nicolaou, J. S. Chen, Chem. Soc. Rev. 2009, 38, 2993-3009; c) B. B. Touré, D. G. Hall, Chem. Rev. 2009, 109, 4439-4486; d) M. Colombo, I. Peretto, Drug Discovery Today 2008, 13, 677-684; e) C. Hulme, V. Gore, Curr. Med. Chem. 2003, 10, 51-80; f) A. Padwa, S. K. Bur, Tetrahedron 2007, 63, 5341-5378.

[9] a) Chem. Soc. Rev. 38(11), 2009, Special Issue on Rapid formation of molecular complexity in organic synthesis; b) Y. Coquerel, T. Boddaert, M. Presset, D. Mailhol, J. Rodriguez, in: Ideas in Chemistry and Molecular Sciences, Advances in Synthetic Chemistry, (Ed.: B. Pignataro), Wiley-VCH, Weinheim, 2010, Vol. 1, ch. 9, p. 187.

[10] a) G. H. Posner, Chem. Rev. 1986, 86, 831-844; T.-L. Ho, in: Tandem Organic Reactions; Wiley, New York; 1992; b) H. Waldmann, Nachr. Chem. Tech. Lab. 1992, 40, 1133-1140; c) K. Fukumoto, Synth. Org. Chem. Jpn. 1994, 52, 2-18; d) R. A. Bunce, Tetrahedron 1995, 51, 13103-13159; e) P. J. Parsons, C. S. Penkett, A. J. Shell, Chem. Rev. 1996, 96, 195-206; f) P. C. F. Balaure, P. I. A. Filip, Rev. Roum. Chim. 2002, 46(8), 809-833; g) E. Capdevila, J. Rayo, F. Carrion, I. Jové, J. I. Borrell, J. Teixido, Afinidad 2003, 506, 317-337; h) L. F. Tietze, N. Rackelmann, Pure Appl. Chem. 2004, 76, 1967-1983; i) P. I. Dalko, L. Moisan, Angew. Chem., Int. Ed. 2004, 43, 5138-5175; j) H. Pellissier, Tetrahedron 2006, 62, 2143-2173; k) H. Pellissier, Tetrahedron, 2006, 62, 1619-1665; 1) D. Enders, C. Grondal, M. R. M. Hüttl, Angew. Chem., Int. Ed. 2007, 46, 1570-1581; m) G. Guillena, D. J. Ramon, M. Yus, Tetrahedron: Asymmetry 2007, 18, 693-700; n) D. M. D’Souza, T. J. J. Müller, Chem. Soc. Rev. 2007, 36, 1095-1108; o) A.-N. Alba, X. Companyo, M. Viciano, R. Rios, Curr. Org. Chem. 2009, 13, 1432-1474; p) J. E. Biggs-Houck, A. Younai, J. T. Shaw, Curr. Opin. Chem. Biol. 2010, 14, 371-382; q) M. Ruiz, P. Lopez-Alvarado, G. Giorgi, J. C. Menéndez, Chem. Soc. Rev. 2011, 40, 3445-3454; r) L. Albrecht, H. Jiang, K. A. Jorgensen, Angew. Chem., Int. Ed. 2011, 50, 8492-8509; s) H. Pellissier, Adv. Synth. Catal. 2012, 354, 237-294; t) C. De Graaff, E. Ruijter, R. V. A. Orru, Chem. Soc. Rev. 2012, 41, 3969-4009.

[11] Comprehensive Asymmetric Catalysis (Eds.: E. N. Jacobsen, A. Pfaltz, H. Yamamoto), Springer, Berlin, 1999.

[12] a) E. Knoevenagel, Chem. Ber. 1896, 29, 172-174; b) U. Eder, G. Sauer, R. Wiechert, Angew. Chem., Int. Ed. Engl. 1971, 10, 496-497; c) Z. G. Hajos, D. R. Parrish, J. Org. Chem. 1974, 39, 1615-1621; d) K. A. Ahrendt, C. J. Borths, D. W. C. MacMillan, J. Am. Chem. Soc. 2000, 122, 4243-4244; e) B. List, R. A. Lerner, 
C. F. Barbas, J. Am. Chem. Soc. 2000, 122, 2395-2396; f) B. List, Chem. Commun. 2006, 819-824; g) A. Erkkilä, I. Majander, P. M. Pihko, Chem. Rev. 2007, 107, 5416-5470; h) S. Mukherjee, J. W. Yang, S. Hoffmann, B. List, Chem. Rev. 2007, 107, 5471-5569; i) X. Yu, W. Wang, Org. Biomol. Chem. 2008, 6, 20372046; j) C. Palomo, A. Mielgo, Angew. Chem., Int. Ed. 2006, 45, 7876-7880.

[13] a) P. I. Dalko, L. Moisan, Angew. Chem., Int. Ed. 2001, 40, 3726-3748; b) A. Berkessel, H. Gröger, in: Asymmetric Organocatalysis-From Biomimetic Concepts to Powerful Methods for Asymmetric Synthesis; Wiley-VCH, Weinheim, 2005; c) J. Seayad, B. List, Org. Biomol. Chem. 2005, 3, 719-724; d) M. S. Taylor, E. N. Jacobsen, Angew. Chem., Int. Ed. 2006, 45, 1520-1543; e) P. I. Dalko, in: Enantioselective Organocatalysis; Wiley-VCH, Weinheim, 2007; f) P. I. Dalko, Chimia 2007, 61, 213-218; g) H. Pellissier, Tetrahedron 2007, 63, 9267-9331; h) A. G. Doyle, E. N. Jacobsen, Chem. Rev. 2007, 107, 5713-5743; i) M. G. Gaunt, C. C. C. Johansson, A. McNally, N. C. Vo, Drug Discovery Today 2007, 2, 8-27; j) Chem. Rev., 2007, 107(12), 5413-5883, Special Issue on Organocatalysis (Ed.: B. List); k) D. W. C. MacMillan, Nature 2008, 455, 304-308; 1) X. Yu, W. Wang, Chem. Asian. J. 2008, 3, 516-532; m) A. Dondoni, A. Massi, A., Angew. Chem., Int. Ed. 2008, 47, 4638-4660; n) P. Melchiorre, M. Marigo, A. Carlone, G. Bartoli, Angew. Chem., Int. Ed. 2008, 47, 6138-6171; o) F. Peng, Z. Shao, J. Mol. Catal. A 2008, 285, 1-13; p) C. F. Barbas, Angew. Chem., Int. Ed. 2008, 47, 42-47; q) C. Palomo, M. Oiarbide, R. Lopez, Chem. Soc. Rev. 2009, 38, 632-653; r) S. Bertelsen, K. A. Jorgensen, Chem. Soc. Rev. 2009, 38, 2178-2189; s) L.-W. Xu, J. Luo, Y. Lu, Chem. Commun. 2009, 1807-1821; t) M. Bella, T. Gasperi, Synthesis 2009, 1583-1614; u) L. Gong in: Special Topic: Asymmetric Organocatalysis, in: Chin. Sci. Bull. 2010, 55, 1729-1731; v) B. List in: Asymmetric Organocatalysis, in: Top. Curr. Chem. 2010, 291; w) H. Pellissier, in: Recent Developments in Asymmetric Organocatalysis, Royal Society of Chemistry, Cambridge, 2010; x) Enantioselective Organocatalyzed Reactions, Vols. I and II, (Ed.: R. Mahrwald), 2011, Springer, Berlin.

[14] a) R. M. de Figueiredo, M. Christmann, Eur. J. Org. Chem. 2007, 2575-2600; b) E. Marquès-Lopez, R. P. Herrera, M. Christmann, Nat. Prod. Rep. 2010, 27, 1138-1167.

[15] a) R. Noyori, in: Asymmetric Catalysts in Organic Synthesis, Wiley, New-York, 1994; b) Comprehensive Asymmetric Catalysis, (Eds.: E. N. Jacobsen, A. Pfaltz, H. Yamamoto), Springer, Berlin, 1999; c) Catalytic Asymmetric Synthesis, $2^{\text {nd }}$ ed. (Ed.: I. Ojima), Wiley-VCH, New-York, 2000; d) Transition Metals for Organic Synthesis, $2^{\text {nd }}$ ed. (Eds.: M. Beller, C. Bolm), Wiley-VCH, Weinheim, 2004; e) D. J. Ramon, M. Yus, Chem. Rev. 2006, 106, 2126-2208.

[16] T. Komnenos, Justus Liebigs Ann. Chem. 1883, 218, 145-169.

[17] a) P. Perlmutter, in: Conjugate Addition Reactions in Organic Synthesis, Pergamon Press, Oxford, 1992; b) N. Krause, A. Hoffmann-Roder, Synthesis 2001, 171-196; c) M. P. Sibi, S. Manyem, Tetrahedron 2000, 56, 8033-8061; d) M. Kanai, M. Shibasaki, in: Catalytic Asymmetric Synthesis, $2^{\text {nd }}$ ed., Wiley, New York, 2000, p. 569.

[18] M. Kitamura, T. Miki, K. Nakano, R. Noyori, Tetrahedron Lett. 1996, 37, 5141-5144.

[19] T. Vlaar, E. Ruijter, R. V. A. Orru, Adv. Synth. Catal. 2011, 353, 809-841.

[20] a) I. Nakamura, Y. Yamamoto, Chem. Rev. 2004, 104, 2127-2198; b) G. Zeni, R. Larock, Chem. Rev. 2004, 104, 2285-2310; c) J.-C. Wasilke, S. J. Obrey, R. T. Baker, G. C. Bazan, Chem. Rev. 2005, 105, 1001-1020; d) S. Cacchi, G. Fabrizi, Chem. Rev. 2005, 105, 2873-2920.

[21] T. Nishikata, Synlett 2007, 3055-3057.

[22] X. Yu, X. Lu, Org. Lett. 2009, 11, 4366-4369.

[23] F. Zhou, M. Yang, X. Lu, Org. Lett. 2009, 11, 1405-1408.

[24] X. Yu, X. Lu, Adv. Synth. Catal. 2011, 353, 2805-2813.

[25] G. Liu, X. Lu, Adv. Synth. Catal. 2007, 349, 2247-2252.

[26] K. Li, A. Alexakis, Chem. Eur. J. 2007, 13, 3765-3771.

[27] T. Den Hartog, A. Rudolph, B. Macia, A. J. Minnaard, B. L. Feringa, J. Am. Chem. Soc. 2010, 132, 14349-14351.

[28] a) D. Bonne, Y. Coquerel, T. Constancieux, J. Rodriguez, Tetrahedron: Asymmetry 2010, 21, 1085-1109; b) C. Simon, T. Constancieux, J. Rodriguez, Eur. J. Org. Chem. 2004, 4957-4980.

[29] Z. Dong, X. Liu, J. Feng, M. Wang, L. Li, X. Feng, Eur. J. Org. Chem. 2011, 137-142.

[30] T. Arai, N. Yokoyama, A. Mishiro, H. Sato, Angew. Chem., Int. Ed. 2010, 49, 7895-7898.

[31] Modern Aldol Reactions, (Ed.: R. Mahrwald), 2004, Wiley-VCH, Weinheim.

[32] T. Yoshino, H. Morimoto, G. Lu, S. Matsunaga, M. Shibasaki, J. Am. Chem. Soc. 2009, 131, 17082-17083.

[33] S. Wang, M.-X. Wang, D.-X. Wang, J. Zhu, Eur. J. Org. Chem. 2007, 4076-4080.

[34] A. Yanagisawa, N. Kushihara, K. Yoshida, Org. Lett. 2011, 13, 1576-1578.

[35] S. Gosiewska, S. Martinez Herreras, M. Lutz, A. L. Spek, R. W. A. Havenith, G. P. M. van Klink, G. van Koten, R. J. M. Klein Gebbink, Organometallics 2008, 27, 2549-2559.

[36] a) J. M. Lee, Y. Na, H. Han, S. Chang, Chem. Soc. Rev. 2004, 33, 302-312; b) D. H. Paull, C. J. Abraham, M. T. Scerba, E. Alden-Danforth, T. Lectka, Acc. Chem. Res. 2008, 41, 655-663; c) Z. Shao, H. Zhang, Chem. 
Soc. Rev. 2009, 38, 2745-2755; d) M. Rueping, R. M. Koenigs, I. Atodiresei, Chem. Eur. J. 2010, 16, 9350-9365; e) C. Zhong, X. Shi, Eur. J. Org. Chem. 2010, 2999-3025; f) J. Zhou, Chem. Asian J. 2010, 5, $422-434$.

[37] H. Young Kim, K. Oh, Org. Lett. 2011, 13, 1306-1309.

[38] a) P. Chiu, Synthesis 2004, 2210-2215; b) H. Nishiyama, T. Shiomi, Top. Curr. Chem. 2007, 279, $105-137$.

[39] a) D. Zhao, K. Oisaki, M. Kanai, M. Shibasaki, Tetrahedron Lett. 2006, 47, 1403-1407; b) D. Zhao, K. Oisaki, M. Kanai, M. Shibasaki, J. Am. Chem. Soc. 2006, 126, 14440-14441.

[40] B. H. Lipshutz, B. Amorelli, J. B. Unger, J. Am. Chem. Soc. 2008, 130, 14378-14379.

[41] J. Deschamp, O. Riant, Org. Lett. 2009, 11, 1217-1220.

[42] O. Chuzel, J. Deschamp, C. Chauster, O. Riant, Org. Lett. 2006, 8, 5943-5946.

[43] J. Deschamp, O. Chuzel, J. Hannedouche, O. Riant, Angew. Chem., Int. Ed. 2006, 45, 1292-1297.

[44] a) C. Bee, S. B. Han, A. Hassan, H. Iida, M. J. Krische, J. Am. Chem. Soc. 2008, 130, 2746-2747; b) S. B. Han, A. Hassan, M. J. Krische, Synthesis 2008, 2669-2679.

[45] M. Kita, H. Oki, K. Ogata, S.-i. Fukuzawa, Synlett 2009, 1299-1302.

[46] a) Y. Yamamoto, Curr. Org. Chem. 2005, 9, 503-509; b) S. Kotha, E. Brahmachary, K. Lahiri, Eur. J. Org. Chem. 2005, 4741-4761; c) P. R. Chopade, J. Louie, Adv. Synth. Catal. 2006, 348, 2307-2327; d) Y. Shibata, K. Tanaka, Synthesis 2012, 323-350.

[47] a) T. Shibata, K. Tsuchikama, Org. Biomol. Chem. 2008, 1317-1323; b) K. Tanaka, Chem. Asian J. 2009, 4, 508-518.

[48] K. Tanaka, T. Osaka, K. Noguchi, M. Hirano, Org. Lett. 2007, 9, 1307-1310.

[49] G. Nishida, N. Suzuki, K. Noguchi, K. Tanaka, Org. Lett. 2006, 8, 3489-3492.

[50] A. Wada, K. Noguchi, M. Hirano, K. Tanaka, Org. Lett. 2007, 9, 1295-1298.

[51] T. Shibata, T. Chiba, H. Hirashima, Y. Ueno, K. Endo, Angew. Chem., Int. Ed. 2009, 48, 8066-8069.

[52] T. Shibata, S. Yoshida, Y. Arai, M. Otsuka, K. Endo, Tetrahedron 2008, 64, 821-830.

[53] T. Shibata, T. Chiba, H. Hirashima, Y. Ueno, K. Endo, Heteroatom Chem. 2011, 22, 363-370.

[54] M. Kobayashi, T. Suda, K. Noguchi, K. Tanaka, Angew. Chem., Int. Ed. 2011, 50, 1664-1667.

[55] W. Oppolzer, J.-M. Gaudin, Helv. Chim. Acta 1987, 70, 1477-1481.

[56] Y. Uozumi, A. Tanahashi, T. Hayashi, J. Org. Chem. 1993, 58, 6826-6832.

[57] B. M. Trost, G. Dong, Chem. Eur. J. 2009, 15, 6910-6919.

[58] a) H. He, W.-B. Liu, L.-X. Dai, S.-L. You, Angew. Chem., Int. Ed. 2010, 49, 1496-1499; b) K.-Y. Ye, H. He, W.-B. Liu, L.-X. Dai, G. Helmchen, S.-L. You, J. Am. Chem. Soc. 2011, 133, 19006-19014.

[59] J. Schütte, S. Ye, H.-G. Schmalz, Synlett 2011, 2725-2729.

[60] A. Doemling, I. Ugi, Angew. Chem., Int. Ed. 2000, 39, 3168-3210.

[61] A. Doemling, Chem. Rev. 2006, 106, 17-89.

[62] S.-X. Wang, M.-X. Wang, D.-X. Wang, J. Zhu, Org. Lett. 2007, 9, 3615-3618.

[63] T. Yue, M.-X. Wang, D.-X. Wang, G. Masson, J. Zhu, J. Org. Chem. 2009, 74, 8396-8399.

[64] H. Mihara, Y. Xu, N. E. Shepherd, S. Matsunaga, M. Shibasaki, J. Am. Chem. Soc. 2009, 131, 8384-8385.

[65] a) M. P. Doyle, D. C. Forbes, Chem. Rev. 1998, 98, 911-935; b) K. V. Gothelf, K. A. Jorgensen, Chem. Rev. 1998, 98, 863-909; c) A. Padwa, M. D. Weingarten, Chem. Rev. 1996, 96, 223-269; d) S. Karlsson, H.-E. Högberg, Org. Prep. Proc. Int. 2001, 33, 103-172; e) I. N. N. Namboothiri, A. Hassner, Top. Curr. Chem. 2001, 216, 1-49; f) S. Kanemasa, Synlett 2002, 1371-1387; g) K. V. Gothelf, Synthesis 2002, 211-247; h) G. Broggini, G. Molteni, A. Terraneo, G. Zecchi, Heterocycles 2003, 59, 823-858; i) I. Coldham, R. Hufton, Chem. Rev. 2005, 105, 2765-2809; j) H. Pellissier, Tetrahedron 2007, 63, 3235-3285; k) S. Kanemasa, Heterocycles 2010, 82, 87-200.

[66] A. Padwa, Acc. Chem. Res. 1991, 24, 22-28.

[67] a) A. Padwa, S. F. Hornbuckle, Chem. Rev. 1991, 91, 263-309; b) A. Padwa, Helv. Chim. Acta 2005, 88, 1357-1374; c) A. Padwa, J. Organomet. Chem. 2005, 690, 5533-5540; d) A. Padwa, Chem. Soc. Rev. 2009, 38, 3072-3081.

[68] D. M. Hodgson, P. A. Stupple, C. Johnstone, Tetrahedron Lett. 1997, 38, 6471-6472.

[69] a) H. Tsutsui, N. Shimada, T. Abe, M. Anada, M. Nakajima, S. Nakamura, H. Nambu, S. Hashimoto, Adv. Synth. Catal. 2007, 349, 521-526; b) Y. Kurosaki, N. Shimada, M. Anada, H. Nambu, S. Hashimoto, Bull. Korean Chem. Soc. 2010, 31, 694-696.

[70] N. Shimada, M. Anada, S. Nakamura, H. Nambu, H. Tsutsui, S. Hashimoto, Org. Lett. 2008, 10, 36033606.

[71] N. Shimada, T. Hanari, Y. Kurosaki, K. Takeda, M. Anada, H. Nambu, M. Shiro, S. Hashimoto, J. Org. Chem. 2010, 75, 6039-6042.

[72] N. Shimada, T. Hanari, Y. Kurosaki, M. Anada, H. Nambu, S. Hashimoto, Tetrahedron Lett. 2010, 51, $6572-6575$.

[73] N. Shimada, T. Oohara, J. Krishnamurthi, H. Nambu, S. Hashimoto, Org. Lett. 2011, 13, 6284-6287. 
[74] H. Nambu, M. Hikime, J. Krishnamurthi, M. Kamiya, N. Shimada, S. Hashimoto, Tetrahedron Lett. 2009, 50, 3675-3678.

[75] D. M. Hodgson, R. Glen, A. J. Redgrave, Tetrahedron: Asymmetry 2009, 20, 754-757.

[76] H. Suga, T. Suzuki, K. Inoue, A. Kakehi, Tetrahedron 2006, 62, 9218-9225.

[77] a) H. Suga, D. Hishimoto, S. Higuchi, M. Ohtsuka, T. Arikawa, T. Tsuchida, A. Kakehi, T. Baba, Org. Lett. 2007, 9, 4359-4362; b) H. Suga, S. Higuchi, M. Ohtsuka, D. Ishimoto, T. Airkawa, Y. Hashimoto, S. Misawa, T. Tsuchida, A. Kakehi, T. Baba, Tetrahedron 2010, 66, 3070-3089.

[78] M. Martin-Rodriguez, C. Najera, J. M. Sansano, P. R. R. Costa, E. C. de Lima, Dias, A. G., Synlett 2010, 962-966.

[79] a) R. F. Heck, J. Am. Chem. Soc. 1968, 90, 5518-5526; b) T. Mizoroki, Bull. Chem. Soc. Jpn. 1971, 44, 581-581; c) R. F. Heck, J. P. Nolley, J. Org. Chem. 1972, 37, 2320-2322; d) R. F. Heck, Org. React. 1982, 27 , 345-390; e) A. de Meijere, F. E. Meyer, Angew. Chem., Int. Ed. Engl. 1994, 33, 2379-2411; f) M. Shibasaki, C. D. J. Boden, A. Kojima, Tetrahedron 1997, 53, 7371-7395; g) P. J. Guiry, A. Hennessy, J. Cahill, Top. Catal. 1997, 4, 311-326; h) I. P. Beletskaya, A. V. Cheprakov, Chem. Rev. 2000, 100, 3009-3066; i) C. Amatore, A. Jutard, Acc. Chem. Res. 2000, 33, 314-321; j) A. B. Dounay, L. E. Overman, Chem. Rev. 2003, 103, 2945-2964; k) M. Shibasaki, E. M. Vogl, T. Ohshima, Adv. Synth. Catal. 2004, 346, 1533-1552; 1) A. G. Coyne, M. O. Fitzpatrick, P. J. Guiry in: The Mizoroki-Heck Reaction, (Ed.: M. Oestreich), Wiley, Chichester, 2009; m) D. Mc Cartney, P. J. Guiry, Chem. Soc. Rev. 2011, 40, 5122-5150.

[80] a) S. Bräse, A. de Meijere, in: Metal-Catalyzed Cross Coupling Reactions, (Eds.: A. de Meijere, F. Diederich), Wiley-VCH, Weinheim, 2004; b) A. B. Dounay, L. E. Overman, in: The Mizoroki-Heck Reaction, (Ed.: M. Oestreich), Wiley, Chichester, 2009.

[81] a) O. Reiser, M. Weber, A. de Meijere, Angew. Chem., Int. Ed. Engl. 1989, 59, 74-79; b) K. Albrecht, O. Reiser, M. Weber, A. de Meijere, Angew. Chem., Int. Ed. Engl. 1989, 28, 1037-1038; c) S. P. Watson, G. R. Knox, N. M. Heron, Tetrahedron Lett. 1994, 35, 9763-9766; d) R. Grigg, P. Kennewell, A. Teasdale, V. Sridharan, Tetrahedron Lett. 1993, 34, 153-156; e) R. Grigg, V. Sridharan, Tetrahedron Lett. 1992, 33, 79657968; f) F. E. Meyer, K. H. Ang, A. G. Steinig, A. de Meijere, Synlett 1994, 191-193; g) G. D. Harris, R. J. Herr, S. M. Weinreb, J. Org. Chem. 1993, 58, 5452-5464.

[82] N. E. Carpenter, D. J. Kucera, L. E. Overman, J. Org. Chem. 1989, 54, 5846-5848.

[83] S. P. Maddaford, N. G. Andersen, W. A. Cristofoli, B. A. Keay, J. Am. Chem. Soc. 1996, 118, 1076610773.

[84] R. Crigg, V. Sridharan, J. Organomet. Chem. 1999, 576, 65-87.

[85] A. Pinto, Y. Jia, L. Neuville, J. Zhu, Chem. Eur. J. 2007, 13, 961-967.

[86] a) J. M. Hopkins, E. Gorobets, B. M. M. Wheatley, M. Parvez, B. A. Keay, Synlett 2006, 3120-3124; b) D. A. Rankic, D. Lucciola, B. A. Keay, Tetrahedron Lett. 2010, 51, 5724-5727.

[87] D. Lucciola, B. A. Keay, Synlett 2011, 1618-1622.

[88] a) J. Reinhard, Angew. Chem., Int. Ed. 2009, 48, 9034-9037; b) R. I. McDonald, G. Liu, S. S. Stahl, Chem. Rev. 2011, 111, 2981-3019.

[89] L. F. Tietze, K. M. Sommer, J. Zinngrebe, F. Stecker, Angew. Chem., Int. Ed. 2005, 44, 257-259.

[90] a) L. F. Tietze, F. Stecker, J. Zinngrebe, K. M. Sommer, Chem. Eur. J. 2006, 12, 8770-8776; b) L. F. Tietze, T. Kinzel, Pure Appl. Chem. 2007, 79, 629-650.

[91] a) L. F. Tietze, D. A. Spiegl, F. Stecker, J. Major, C. Raith, C. Große, Chem. Eur. J. 2008, 14, 8956-8963; b) L. F. Tietze, A. Düfert, Pure Appl. Chem. 2010, 82, 1375-1392.

[92] G. B. Bajracharya, M. A. Arai, P. S. Koranne, T. Suzuki, S. Takizawa, H. Sasai, Bull. Chem. Soc. Jpn. 2009, 82, 285-302.

[93] K.-T. Yip, M. Yang, K.-L. Law, N.-Y. Zhu, D. Yang, J. Am. Chem. Soc. 2006, 128, 3130-3131.

[94] W. He, K.-T. Yip, N.-Y. Zhu, D. Yang, Org. Lett. 2009, 11, 5626-5628.

[95] a) B. M. Trost, M. J. Krische, Synlett 1998, 1-16; b) C. Aubert, O. Buisine, M. Malacria, Chem. Rev. 2002, 102, 813-834; c) I. J. S. Fairlamb, Angew. Chem., Int. Ed. 2004, 43, 1048-1052; d) C. Nevado, A. M. Echavarren, Synthesis 2005, 167-182; e) L. Zhang, J. Sun, S. A. Kozmin, Adv. Synth. Catal. 2006, 348, 2271-2296; f) V. Michelet, P. Y. Toullec, J.-P. Genêt, Angew. Chem., Int. Ed. 2008, 47, 4268-4315; g) E. Jimenez-Nunez, E. Echavarren, Chem. Rev. 2008, 108, 3326-3350; h) P. Belmont, E. Parker, Eur. J. Org. Chem. 2009, 6075-6089.

[96] a) G. C. Lloyd-Jones, Org. Biomol. Chem. 2003, 1, 215-236; b) A. R. Chianese, S. J. Lee, M. R. Gagné, Angew. Chem., Int. Ed. 2007, 46, 4042-4046; c) A. Fürstner, P. W. Davies, Angew. Chem., Int. Ed. 2007, 46, 3410-3449; d) A. S. K. Hashmi, Chem. Rev. 2007, 107, 3180-3211; e) S. I. Lee, N. Chatani, Chem. Commun. 2009, 371-384; f) P. Y. Toullec, V. Michelet, Top. Curr. Chem. 2011, 302, 31-80.

[97] a) N. Bongers, N. Krause, Angew. Chem., Int. Ed. 2008, 47, 2178-2181; b) R. A. Widenhoefer, Chem. Eur. J. 2008, 14, 5382-5391; c) S. Sengupta, X. Shi, ChemCatChem 2010, 2, 609-619; d) A. Pradal, P. Y. Toullec, V. Michelet, Synthesis 2011, 1501-1514. 
[98] a) C.-M. Chao, E. Genin, P. Y. Toullec, J.-P. Genêt, V. Michelet, J. Organomet. Chem. 2009, 694, 538-545; b) C.-M. Chao, M. R. Vitale, P. Y. Toullec, J.-P. Genêt, V. Michelet, Chem. Eur. J. 2009, 15, $1319-1323$.

[99] a) A. Fürstner, L. Morency, Angew. Chem., Int. Ed.2008, 47, 5030-5033; b) A. S. K. Hashmi, Angew. Chem., Int. Ed. 2008, 47, 6754-6756.

[100] a) G. Stork, A. W. Burgstahler, J. Am. Chem. Soc. 1955, 77, 5068-5077; b) A. Eschenmoser, L. Ruzicka, O. Jeger, D. Arigoni, Helv. Chim. Acta 1955, 38, 1890-1904; c) A. Eschenmoser, D. Arigoni, Helv. Chim. Acta 2005, 88, 3011-3025.

[101] A. Pradal, C.-M. Chao, M. R. Vitale, P. Y. Toullec, V. Michelet, Tetrahedron 2011, 67, 4371-4377.

[102] V. Michelet, L. Charruault, S. Gladiali, J.-P. Genêt, Pure Appl. Chem. 2006, 78, 397-407.

[103] P. Y. Toullec, C.-M. Chao, Q. Chen, S. Gladiali, J.-P. Genêt, V. Michelet, Adv. Synth. Catal. 2008, 350, 2401-2408.

[104] A. Grossmann, D. Enders, Angew. Chem., Int. Ed. 2011, 50, 2-14.

[105] Y. Matsumoto, K. B. Selim, H. Nakanishi, K.-i. Yamada, Y. Yamamoto, K. Tomioka, Tetrahedron Lett. 2010, 51, 404-406.

[106] A. Martinez, P. Garcia-Garcia, M. A. Fernandez-Rodriguez, F. Rodriguez, R. Sanz, Angew. Chem., Int. Ed. 2010, 49, 4633-4637.

[107] S. Handa, L. M. Slaughter, Angew. Chem., Int. Ed. 2012, 51, 2912-2915.

[108] F. Liu, D. Qian, L. Li, X. Zhao, J. Zhang, Angew. Chem., Int. Ed. 2010, 49, 6669-6672.

[109] G. Zhou, F. Liu, J. Zhang, Chem. Eur. J. 2011, 17, 3101-3104.

[110] S. G. Sethofer, T. Mayer, F. D. Toste, J. Am. Chem. Soc. 2010, 132, 8276-8277.

[111] A. M. Jadhav, S. Bhunia, H.-Y. Liao, R.-S. Liu, J. Am. Chem. Soc. 2011, 133, 1769-1771.

[112] B. J. Anderson, M. A. Guino-o, D. S. Glueck, J. A. Golen, A. G. DiPasquale, L. M. Liable-Sands, A. L. Reingold, Org. Lett. 2008, 10, 4425-4428.

[113] C. A. Mullen, A. N. Campbell, M. R. Gagné, Angew. Chem., Int. Ed. 2008, 47, 6011-6014.

[114] S. Hajra, S. Bar, Chem. Commun. 2011, 3981-3982.

[115] V. Rauniyar, Z. J. Wang, H. E. Burks, F. D. Toste, J. Am. Chem. Soc. 2011, 133, 8486-8489.

[116] a) P. Renaud, M. Gerster, Angew. Chem., Int. Ed. Ed. 1998, 37, 2562-2579; b) M. P. Sibi, N. A. Porter,

Acc. Chem. Res. 1999, 32, 163-171; c) G. Bar, A. F. Parsons, Chem. Soc. Rev. 2003, 32, 251-263; d) M. P. Sibi, S. Manyem, J. Zimmerman, Chem. Rev. 2003, 103, 3263-3296.

[117] H. Miyabe, R. Asada, A. Toyoda, Y. Takemoto, Angew. Chem., Int. Ed. 2006, 45, 5863-5866.

[118] a) H. Miyaka, A. Toyoda, Y. Takemoto, Synlett 2007, 1885-1888; b) H. Miyabe, Y. Takemoto, Chem. Eur. J. 2007, 13, 7280-7286.

[119] D. Yang, B.-F. Zheng, Q. Gao, S. Gu, N.-Y. Zhu, Angew. Chem., Int. Ed. 2006, 45, 255-258.

[120] G. A. Cutting, N. E. Stainforth, M. P. John, G. Kociok-Köhn, M. C. Willis, J. Am. Chem. Soc. 2007, 129, $10632-10633$.

[121] S. Son, G. C. Fu, J. Am. Chem. Soc. 2007, 129, 1046-1047.

[122] a) L. V. R. Bonaga, M. E. Krafft, Tetrahedron 2004, 60, 9795-9833; b) K. H. Park, Y. K. Chung, Synlett 2005, 545-559; c) S. E. Gibson, N. Mainolfi, Angew. Chem., Int. Ed. 2005, 44, 3022-3037; d) T. Shibata, Adv. Synth. Catal. 2006, 348, 2328-2336.

[123] a) H. W. Lee, A. S. C. Chan, F. Y. Kwong, Chem. Commun. 2007, 2633-2635; b) H. W. Lee, L. N. Lee, A. S. C. Chan, F. Y. Kwong, Eur. J. Org. Chem. 2008, 3403-3406.

[124] a) K. Kanao, Y. Miyake, Y. Nishibayashi, Organometallics 2010, 29, 2126-2131; b) Y. Nishibayashi, Synthesis 2012, 489-503.

[125] O. Bondarev, C. Bruneau, Tetrahedron: Asymmetry 2010, 21, 1350-1354.

[126] A. T. Londregan, D. Bernhardson, J. Bradow, T. M. Makowski, G. Storer, J. Warmus, C. Wooten, X. Yang, Tetrahedron: Asymmetry 2010, 21, 2072-2075.

[127] M. Weber, S. Jautze, W. Frey, R. Peters, J. Am. Chem. Soc. 2010, 132, 12222-12225.

[128] X. Fu, J. Feng, Z. Dong, L. Lin, X. Liu, X. Feng, Eur. J. Org. Chem. 2011, 5233-5236.

[129] S. H. Lecker, N. H. Nguyen, K. P. C. Vollhardt, J. Am. Chem. Soc. 1986, 108, 856-858.

[130] W. Cao, X. Liu, W. Wang, L. Lin, X. Feng, Org. Lett. 2011, 13, 600-603.

[131] B. T. Parr, Z. Li, H. M. L. Davies, Chem. Sci. 2011, 2, 2378-2382.

[132] A. Boyer, M. Lautens, Angew. Chem., Int. Ed. 2011, 50, 7346-7349.

[133] a) I. Ugi, R. Meyr, U. Fetzer, C. Steinbrückner, Angew. Chem. 1959, 71, 386-388; b) R. V. A. Orru, M. de Greef, Synthesis 2003, 1471-1499; c) E. Ruijter, R. Scheffelaar, R. V. A. Orru, Angew. Chem. Int. Ed. 2011, 50, 6234-6246.

[134] J. C. Gonzales-Gomez, F. Foubelo, M. Yus, Tetrahedron Lett. 2008, 49, 2343-2347.

[135] S. Guo, Y. Xie, X. Hu, C. Xia, H. Huang, Angew. Chem., Int. Ed. 2010, 49, 2728-2731.

[136] I.-H. Chen, L. Yin, W. Itano, M. Kanai, M. Shibasaki, J. Am. Chem. Soc. 2009, 131, 11664-11665. 
[137] S. Guo, Y. Xie, X. Hu, H. Huang, Org. Lett. 2011, 13, 5596-5599.

[138] a) J. Boruwa, N. Gogoi, P. P. Saikia, N. C. Barua, Tetrahedron: Asymmetry 2006, 17, 3315-3326; b) C. Palomo, M. Oiarbide, A. Laso, Eur. J. Org. Chem. 2007, 2561-2574; c) E. Marquès-Lopez, P. Merino, T. Tejero, R. P. Herrera, Eur. J. Org. Chem. 2009, 2401-2420; d) Y. Alvarez-Casao, E. Marques-Lopez, R. P. Herrera, Symmetry 2011, 3, 220-245.

[139] D. Shi, Y. Xie, H. Zhou, C. Xia, H. Huang, Angew. Chem., Int. Ed. 2012, 51, 1248-1251.

[140] C. Mannich, W. Krosche, Arch. Pharm. 1912, 250, 647-667.

[141] a) M. Arend, B. Westermann, N. Risch, Angew. Chem., Int. Ed. 1998, 37, 1044-1070; b) A. Cordova, Acc. Chem. Res. 2004, 37, 102-112; c) J. M. M. Verkade, L. J. C. Van Hemert, P. J. L. M. Quaedflieg, F. P. J. T. Rutjes, Chem. Soc. Rev. 2008, 37, 29-41; d) R. Gomez Arrayas, J. C. Carretero, Chem. Soc. Rev. 2009, 38, 1940-1948.

[142] S. Chen, Z. Hou, Y. Zhu, J. Wang, L. Lin, X. Liu, X. Feng, Chem. Eur. J. 2009, 15, 5884-5887.

[143] Q. Zhang, Y. Hui, X. Zhou, L. Lin, X. Liu, X. Feng, Adv. Synth. Catal. 2010, 352, 976-980.

[144] H. Mandai, K. Mandai, M. L. Snapper, H. Hoveyda, J. Am. Chem. Soc. 2008, 130, 17961-17969.

[145] B. Ranieri, C. Curti, L. Battistini, A. Sartori, L. Pinna, G. Casiraghi, F. Zanardi, J. Org. Chem. 2011, 76, 10291-10298.

[146] A. Izumiseki, K. Yoshida, A. Yanagisawa, Org. Lett. 2009, 11, 5310-5313.

[147] S. Kobayashi, J. Kobayashi, R. Yazaki, M. Ueno, Chem. Asian J. 2007, 2, 135-144.

[148] Y. Hamashima, N. Sasamoto, N. Umebayashi, M. Sodeoka, Chem. Asian J. 2008, 3, 1443-1455.

[149] Y. Du, L.-W. Xu, Y. Shimizu, K. Oisaki, M. Kanai, M. Shibasaki, J. Am. Chem. Soc. 2008, 130, $16146-16147$.

[150] J. Poulin, C. M. Grisé-Bard, L. Barriault, Chem. Soc. Rev. 2009, 38, 3092-3101.

[151] G. Hilt, W. Hess, K. Harms, Org. Lett. 2006, 8, 3287-3290.

[152] M. Xie, X. Chen, Y. Zhu, B. Gao, L. Lin, X. Liu, X. Feng, Angew. Chem., Int. Ed. 2010, 49, 3799-3802.

[153] S. Torssell, P. Somfai, Adv. Synth. Catal. 2006, 348, 2421-2430.

[154] S.-X. Wang, M.-X. Wang, D.-X. Wang, J. Zhu, Angew. Chem., Int. Ed. 2008, 47, 388-391.

[155] J. M. McManus, R. M. Herbst, J. Org. Chem. 1959, 24, 1643-1649.

[156] T. Yue, M.-X. Wang, D.-X. Wang, J. Zhu, Angew. Chem., Int. Ed. 2008, 47, 9454-9457.

[157] a) T. Arai, N. Yokoyama, Angew. Chem., Int. Ed. 2008, 47, 4989-4992; b) T. Arai, M. Wasai, N. Yokoyama, J. Org. Chem. 2011, 76, 2909-2912.

[158] Y. Duan, M.-W. Chen, Z.-S. Ye, D.-S. Wang, Q.-A. Chen, Y.-G. Zhou, Chem. Eur. J. 2011, 17, 7193-7197.

[159] N. Gommermann, P. Knochel, Chem. Eur. J. 2006, 12, 4380-4392.

[160] P. Aschwanden, C. R. J. Stephenson, E. M. Carreira, Org. Lett. 2006, 8, 2437-2440.

[161] A. Bisai, V. K. Singh, Org. Lett. 2006, 8, 2405-2408.

[162] S. Nakamura, M. Ohara, Y. Nakamura, N. Shibata, T. Toru, Chem. Eur. J. 2010, 16, 2360-2362.

[163] F. Colombo, M. Benaglia, S. Orlandi, F. Usuelli, J. Mol. Catal. A 2006, 260, 128-134.

[164] Z. Shao, X. Pu, X. Li, B. Fan, A. S. C. Chan, Tetrahedron: Asymmetry 2009, 20, 225-229.

[165] D. Chernyak, N. Chernyak, V. Gevorgyan, Adv. Synth. Catal. 2010, 352, 961-966.

[166] L. Zani, T. Eichhorn, C. Bolm, Chem. Eur. J. 2007, 13, 2587-2600.

[167] C. Yin, X.-Q. Hu, X.-P. Hui, P.-F. Xu, Adv. Synth. Catal. 2009, 351, 1512-1516.

[168] Y. Sato, Y. Hinata, R. Seki, Y. Oonishi, N. Saito, Org. Lett. 2007, 9, 5597-5599.

[169] N. Saito, A. Kobayashi, Y. Sato, Angew. Chem., Int. Ed. 2012, 51, 1228-1231.

[170] Y. Yang, S.-F. Zhu, H.-F. Duan, C.-Y. Zhou, L.-X. Wang, Q.-L. Zhou, J. Am. Chem. Soc. 2007, 129, 2248-2249.

[171] L. Rubio-Pérez, F. J. Pérez-Flores, P. Sharma, L. Velasco, A. Cabrera, Org. Lett. 2009, 11, 265-268.

[172] C. Li, B. Villa-Marcos, J. Xiao, J. Am. Chem. Soc. 2009, 131, 6967-6969.

[173] X. Zhou, D. Shang, Q. Zhang, L. Lin, X. Liu, X. Feng, Org. Lett. 2009, 11, 1401-1404.

[174] M. Ohara, S. Nakamura, N. Shibata, Adv. Synth. Catal. 2011, 353, 3285-3289.

[175] a) M. Bandini, Chem. Soc. Rev. 2011, 40, 1358-1367; b) A. Fürstner, Chem. Soc. Rev. 2009, 38, 3208-3221; c) Z. Li, C. Brouwer, C. He, Chem. Rev. 2008, 108, 3239-3265; d) A. Arcadi, Chem. Rev. 2008, 108, 3266-3325; e) D. J. Gorin, B. D. Sherry, F. D. Toste, Chem. Rev. 2008, 108, 3351-3378; f) A. S. K. Hashmi, M. Rudolph, Chem. Soc. Rev. 2008, 37, 1766-1775; g) H. C. Shen, Tetrahedron 2008, 64, 3885-3903; h) R. Skouta, C.-J. Li, Tetrahedron 2008, 64, 4917-4938.

[176] M. J. Campbell, F. D. Toste, Chem. Sci. 2011, 2, 1369-1378.

[177] X. Zhang, H. Huang, X. Guo, X. Guan, L. Yang, W. Hu, Angew. Chem., Int. Ed. 2008, 47, 6647-6649.

[178] C.-Y. Zhou, S.-F. Zhu, L.-X. Wang, Q.-L. Zhou, J. Am. Chem. Soc. 2010, 132, 10955-10957.

[179] M. R. Chaulagain, G. J. Sormunen, J. Montgomery, J. Am. Chem. Soc. 2007, 129, 9568-9569.

[180] B. K. Senapati, G.-S. Hwang, S. Lee, D. H. Ryu, Angew. Chem., Int. Ed. 2009, 48, 4398-4401. 
[181] T. Miura, M. Morimoto, M. Murakami, J. Am. Chem. Soc. 2010, 132, 15836-15838.

[182] S. Zheng, W. Huang, N. Gao, R. Cui, M. Zhang, X. Zhao, Chem. Commun. 2011, 6969-6971.

[183] K. Oisaki, D. Zhao, M. Kanai, M. Shibasaki, J. Am. Chem. Soc. 2007, 129, 7439-7443.

[184] X. Li, X. Liu, Y. Fu, L. Wang, L. Zhou, X. Feng, Chem. Eur. J. 2008, 14, 4796-4798.

[185] A. K. Gupta, M. Mukherjee, W. D. Wulff, Org. Lett. 2011, 13, 5866-5869.

[186] L. F. Tietze, J. Zinngrebe, D. A. Spiegl, F. Stecker, Heterocycles 2007, 74, 473-489.

[187] J. Mlynarski, B. Rakiel, M. Stodulski, A. Suszcynska, J. Frelek, Chem. Eur. J. 2006, 12, 8158-8167.

[188] S. Rajikumar, K. Shankland, G. D. Brown, A. J. A. Cobb, Synlett 2006, 689-692.

[189] X.-Y. Guan, L.-P. Yang, W. Hu, Angew. Chem., Int. Ed. 2010, 49, 2190-2192.

[190] P. G. Cozzi, E. Rivalta, Pure Appl. Chem. 2006, 78, 287-291.

[191] a) S. E. Gibson, A. Stevenazzi, Angew. Chem., Int. Ed. 2003, 42, 1800-1810; b) J. Blanco-Urgoiti, L. Anorbe, L. Pérez-Serrano, G. Dominguez, J. Pérez-Castells, Chem. Soc. Rev. 2004, 33, 32-42.

[192] A. Lledo, J. Solà, X. Verdaguer, A. Riera, M. A. Maestro, Adv. Synth. Catal. 2007, 349, 2121-2128. 